Florida International University FIU Digital Commons

FIU Electronic Theses and Dissertations

University Graduate School

$1-11-2013$

\title{
A Model for Continuous Measurement of Drilled Shaft Diameter During Construction
}

Masood Hajali

Florida International University, mhaja002@fiu.edu

DOI: $10.25148 /$ etd.FI13042905

Follow this and additional works at: https:// digitalcommons.fiu.edu/etd

Part of the Civil Engineering Commons, Construction Engineering and Management Commons, Geotechnical Engineering Commons, and the Structural Engineering Commons

\section{Recommended Citation}

Hajali, Masood, "A Model for Continuous Measurement of Drilled Shaft Diameter During Construction" (2013). FIU Electronic Theses and Dissertations. 881.

https://digitalcommons.fiu.edu/etd/881

This work is brought to you for free and open access by the University Graduate School at FIU Digital Commons. It has been accepted for inclusion in FIU Electronic Theses and Dissertations by an authorized administrator of FIU Digital Commons. For more information, please contact dcc@fiu.edu. 


\section{FLORIDA INTERNATIONAL UNIVERSITY}

Miami, Florida

\section{A MODEL FOR CONTINUOUS MEASUREMENT OF DRILLED SHAFT DIAMETER DURING CONSTRUCTION}

A dissertation submitted in partial fulfillment of the

requirements for the degree of

DOCTOR OF PHILOSOPHY

in

CIVIL ENGINEERING

by

Masood Hajali

2013 
To: Dean Amir Mirmiran

College of Engineering and Computing

This dissertation, written by Masood Hajali, and entitled A Model for Continuous Measurement of Drilled Shaft Diameter During Construction, having been approved in respect to style and intellectual content, is referred to you for judgment.

We have read this dissertation and recommend that it be approved.

Ton-Lo Wang

Hesham Ali

Nakin Suksawang

\begin{tabular}{r} 
Nakin Suksawang \\
\hline Yimin Zhu \\
Caesar Abi Shdid, Major Professor
\end{tabular}

Date of Defense: January 11, 2013

The Dissertation of Masood Hajali is approved.

Dean Amir Mirmiran College of Engineering and Computing

Dean Lakshmi N. Reddi
University Graduate School

Florida International University, 2013 
(C) Copyright 2013 by Masood Hajali

All rights reserved. 


\section{DEDICATION}

I dedicate this dissertation to my lovely parents, brother (Saeed) and sister (Sahar) who did not see me much during my Ph.D. program. Without their love, support, and patience, this dream would not have come true.

$$
\begin{aligned}
& \text { اين يايان نامه را به يُر، مادر، برادر (سعيد) و خواهر (سحر) دوست داشتنيم تقديم مىكنم كه در طول دوران } \\
& \text { دكتر ا نتو انستم در كنارشون باثم .بدون عشق، حمايت، و صبر آنها اين رويا دست نيافتنى بود. }
\end{aligned}
$$




\section{ACKNOWLEDGMENTS}

I owe my deepest gratitude to my advisor, Dr. Caesar Abi Shdid, for his invaluable guidance and support throughout my Ph.D. studies. He has by far been the most influential and inspiring teacher and advisor I have had the privilege of working with. Indeed he has been the predominant source of the academic and professional expertise I have acquired throughout my Ph.D. I am also grateful to Dr. Ton-Lo Wang, Dr. Hesham Ali, Dr. Nakin Suksawang, and Dr. Yimin Zhu for serving on my advisory committee.

I also want to acknowledge Edgar Polo, Pedram Zohrevand, Brandon Mintz, Amir Sotoodeh, Arash Nejadpak and all personnel and students at the Titan America Structures and Construction Testing Laboratory of the Florida International University for their assistance during the experimental program of this research.

I am also thankful to the Florida International University Graduate School for

providing me with Doctoral Evidence Acquisition (DEA) and Dissertation Year Fellowship (DYF) to complete my doctoral work. 


\title{
ABSTRACT OF THE DISSERTATION \\ A MODEL FOR CONTINUOUS MEASUREMENT OF DRILLED SHAFT \\ DIAMETER DURING CONSTRUCTION
}

\author{
by
}

Masood Hajali

Florida International University, 2012

Miami, Florida

\section{Professor Caesar Abi Shdid, Major Professor}

Non-Destructive Testing (NDT) of deep foundations has become an integral part of the industry's standard manufacturing processes. It is not unusual for the evaluation of the integrity of the concrete to include the measurement of ultrasonic wave speeds. Numerous methods have been proposed that use the propagation speed of ultrasonic waves to check the integrity of concrete for drilled shaft foundations. All such methods evaluate the integrity of the concrete inside the cage and between the access tubes. The integrity of the concrete outside the cage remains to be considered to determine the location of the border between the concrete and the soil in order to obtain the diameter of the drilled shaft. It is also economic to devise a methodology to obtain the diameter of the drilled shaft using the Cross-Hole Sonic Logging system (CSL). Performing such a methodology using the CSL and following the CSL tests is performed and used to check the integrity of the inside concrete, thus allowing the determination of the drilled shaft diameter without having to set up another NDT device.

This proposed new method is based on the installation of galvanized tubes outside the shaft across from each inside tube, and performing the CSL test between the inside 
and outside tubes. From the performed experimental work a model is developed to evaluate the relationship between the thickness of concrete and the ultrasonic wave properties using signal processing. The experimental results show that there is a direct correlation between concrete thicknesses outside the cage and maximum amplitude of the received signal obtained from frequency domain data. This study demonstrates how this new method to measuring the diameter of drilled shafts during construction using a NDT method overcomes the limitations of currently-used methods.

In the other part of study, a new method is proposed to visualize and quantify the extent and location of the defects. It is based on a color change in the frequency amplitude of the signal recorded by the receiver probe in the location of defects and it is called Frequency Tomography Analysis (FTA). Time-domain data is transferred to frequency-domain data of the signals propagated between tubes using Fast Fourier Transform (FFT). Then, distribution of the FTA will be evaluated. This method is employed after CSL has determined the high probability of an anomaly in a given area and is applied to improve location accuracy and to further characterize the feature. The technique has a very good resolution and clarifies the exact depth location of any void or defect through the length of the drilled shaft for the voids inside the cage.

The last part of study also evaluates the effect of voids inside and outside the reinforcement cage and corrosion in the longitudinal bars on the strength and axial load capacity of drilled shafts. The objective is to quantify the extent of loss in axial strength and stiffness of drilled shafts due to presence of different types of symmetric voids and corrosion throughout their lengths. 


\section{TABLE OF CONTENTS}

CHAPTER

PAGE

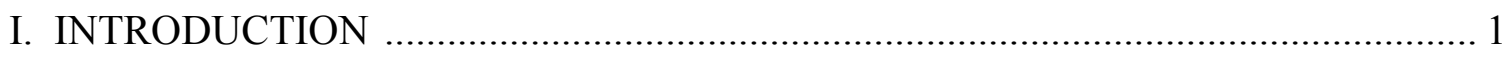

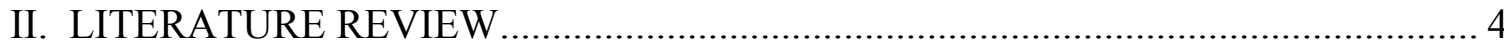

Nondestructive Tests History ……………………….................................... 4

Shaft Head Impact Tests .......................................................................... 6

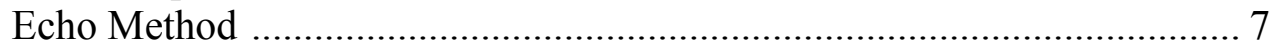

Sonic Echo Technique …………………………………………....... 8

Impulse Response Technique ............................................................. 10

Impulse Log Technique …………………………………………..... 10

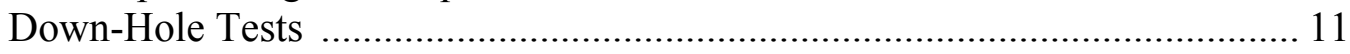

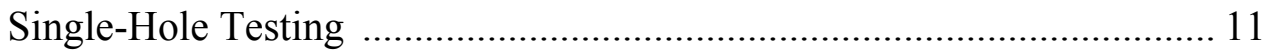

Cross-Hole Testing ………………………………………………... 12

Cross-Hole Analyzer .................................................................. 17

Data Acquisition Signal .............................................................. 18

First Arrival Time ..................................................................... 18

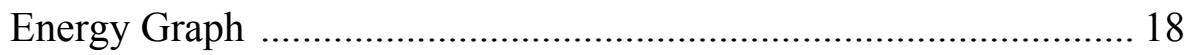

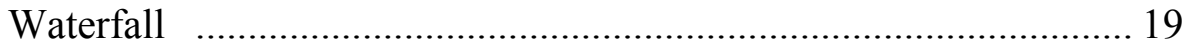

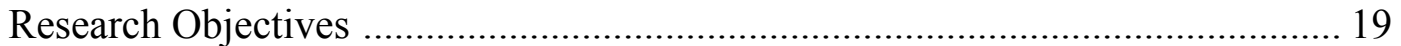

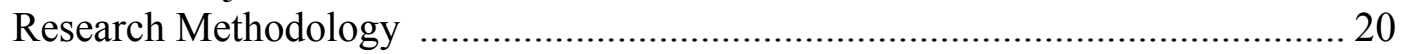

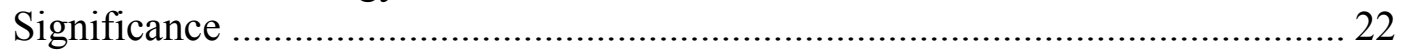

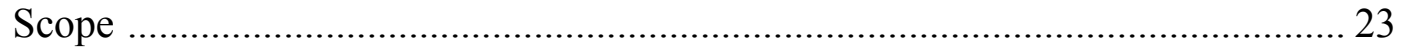

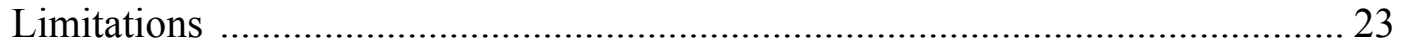

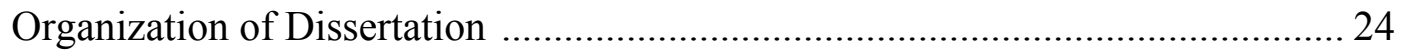

III. CONTINUOUS MEASUREMENT OF DRILLED SHAFT DIAMETER DURING

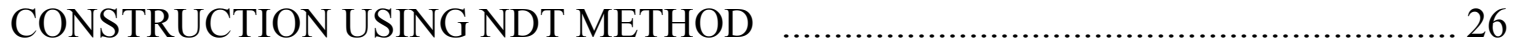

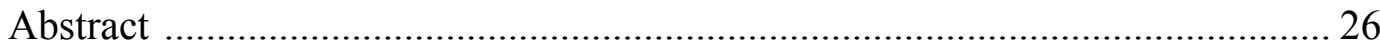

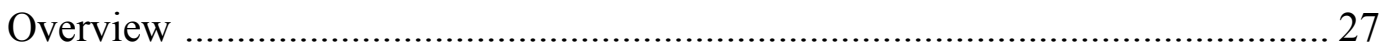

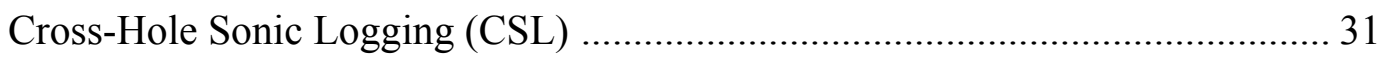

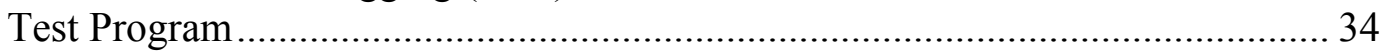

Materials and Test Samples ..................................................................... 34

Test Procedure ................................................................................ 38

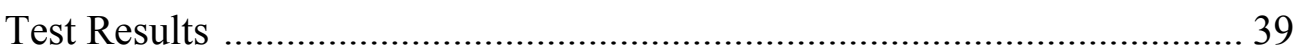

Signal Processing on the CSL Test Results ........................................................ 41

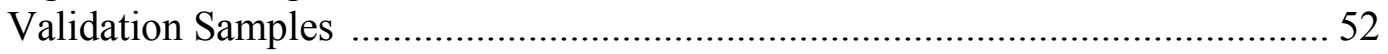

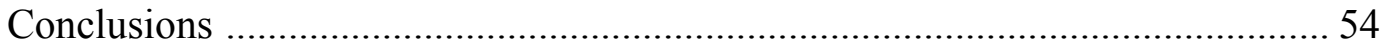

IV. CSL AND FREQUENCY TOMOGRAPHY ANALYSIS OF DRILLED SHAFT BRIDGE FOUNDATIONS TO DETECT THE DEFECTS LOCATIONS .......................56

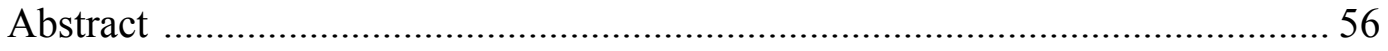

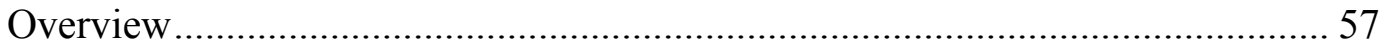




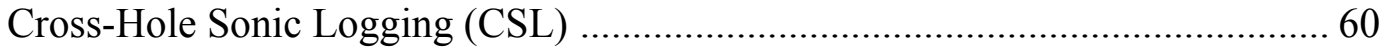

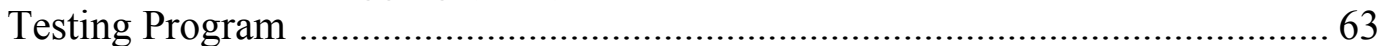

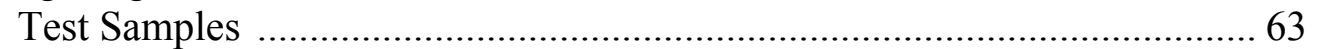

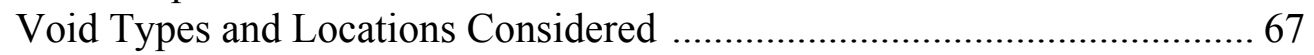

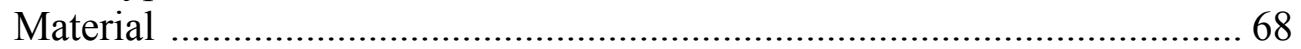

Test Procedure .................................................................................. 70

Signal Processing on the CSL Test Results ................................................... 71

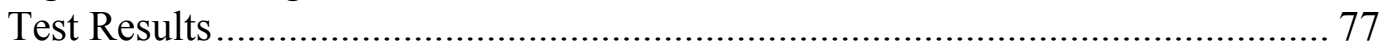

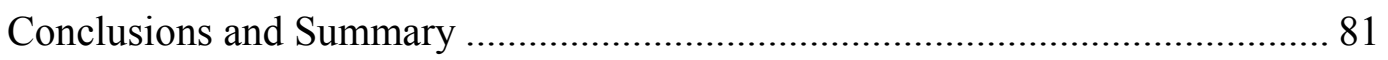

V. BEHAVIOR OF AXIALY LOADED SHAFT FOUNDATIONS WITH SYMMETRIC VOIDS OUTSIDE AND INSIDE THE CAGING …......................... 83

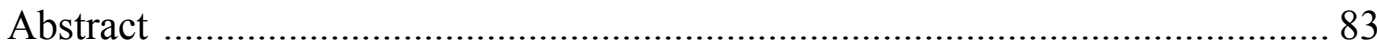

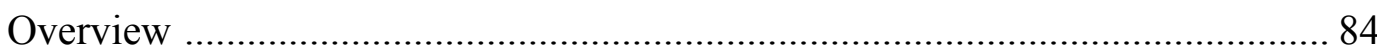

Testing Program ............................................................................................ 87

Void Shapes and Locations Considered .................................................... 87

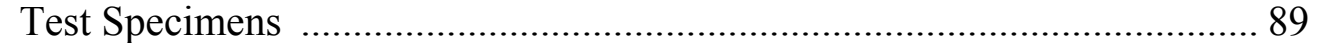

Materials Properties ............................................................................. 92

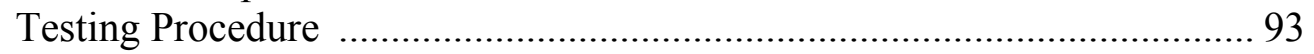

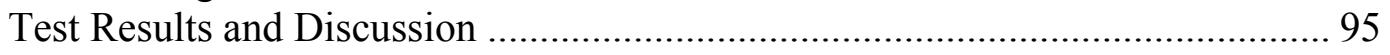

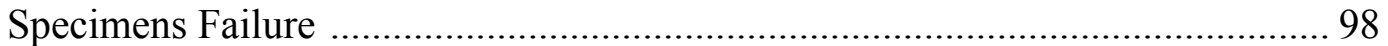

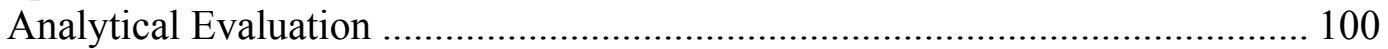

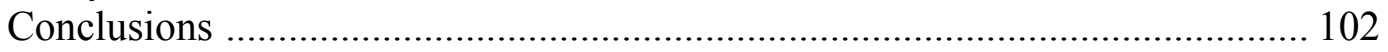

VI. EVALUATION OF DRILLED SHAFT STRUCTURAL CAPACITY REDUCTION DUE TO CORROSION IN LONGITUDINAL BARS ............................................... 104

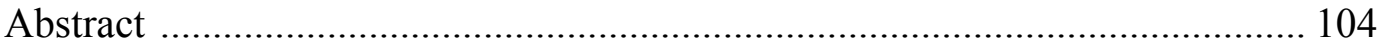

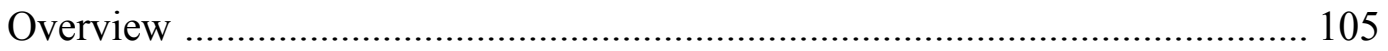

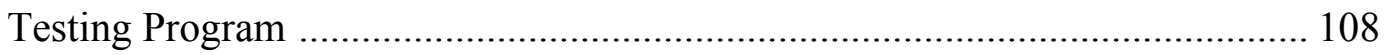

Void Shapes and Location Considered …............................................ 108

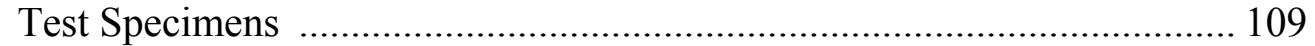

Material Properties .......................................................................... 113

Testing Procedures ......................................................................... 114

Test Results and Discussion ...................................................................... 116

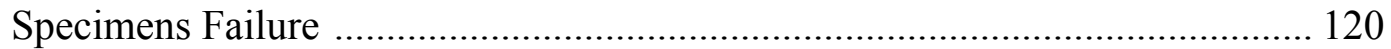

Axial Load Capacity Reduction Over Time Due to Corrosion ........................ 122

Conclusions and Recommendations .......................................................... 125

VII. CONTRIBUTION OF THE SIDE RESISTANCE AND TIP RESISTANCE ON THE TOTAL AXIAL LOAD CAPACITY OF DRILLED SHAFT FOUNDATIONS. 128

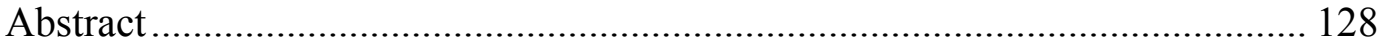

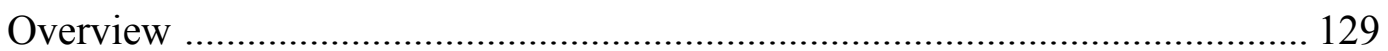

Drilled Shaft Resistance ............................................................................ 129

Estimation of Drilled Shaft Resistance in Cohesive Soils .............................. 130

Side Resistance ............................................................................... 130 


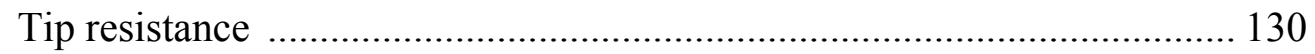

Estimation of Drilled Shaft Resistance in Cohesion-less Soils ......................... 131

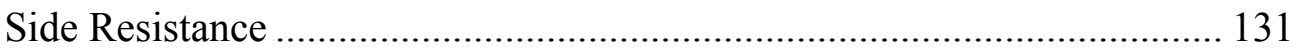

Tip resistance ………..................................................................... 131

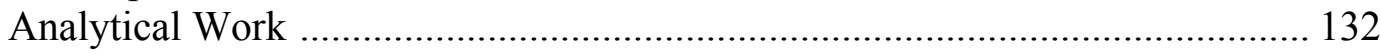

Finite Element Model ............................................................................ 135

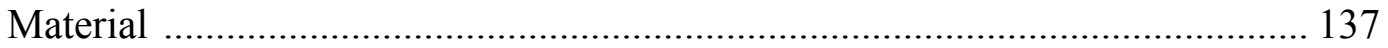

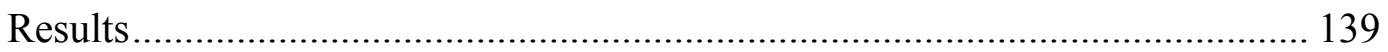

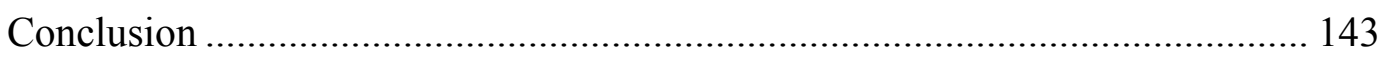

VIII. SUMMARY AND CONCLUSIONS ............................................................ 145

NDT Assessment to Obtain the Shape of the Drilled Shaft Foundations ............... 146

NDT Assessment to Detect the Defect Location of Drilled Shaft Foundations ..... 146

Structural Capacity Reduction due to Anomalies in Shaft Foundations.................. 147

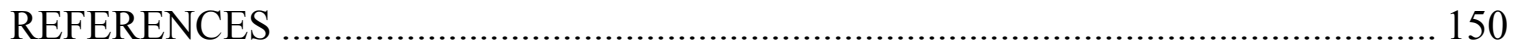

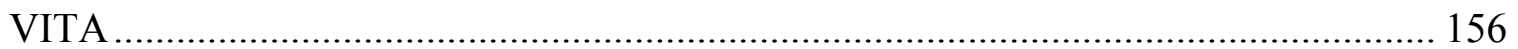




\section{LIST OF TABLES}

TABLE

PAGE

1. Range of P-wave Velocity in Various Soils and Rocks ......................................... 33

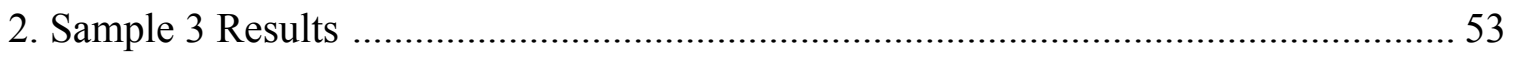

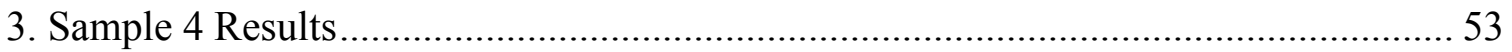

4. Characteristics of Tested Drilled Shaft Specimens with Built Voids ........................ 68

5. Characteristics of Tested Drilled Shaft Specimens ................................................ 90

6. Maximum Axial Load Capacity for Shafts with Different Types of Voids .............. 98

7. Experimental vs. Analytical Axial Loads for the Drilled Shaft Specimens ........... 101

8. Specifications of Tested Drilled Shaft Specimens for Corrosion ........................... 111

9. Axial Load Capacity Reduction with Time in Drilled Shaft Foundations ................ 125

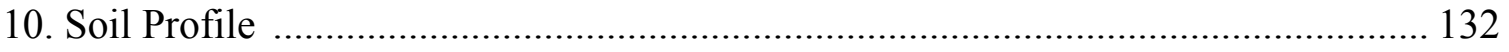

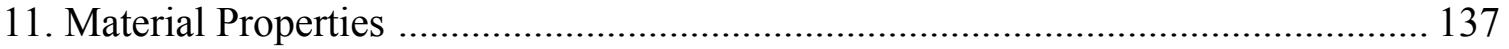

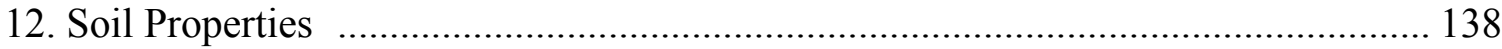




\section{LIST OF FIGURES}

FIGURE

PAGE

Figure 2.1 The Ultrasonic system for integrity testing ........................................ 16

Figure 2.2 Data Acquisition Signal, Energy/AT Graph, Waterfall Diagram................... 17

Figure 3.1 Actual and Theoretical Concrete Volume versus Depth Plot........................ 30

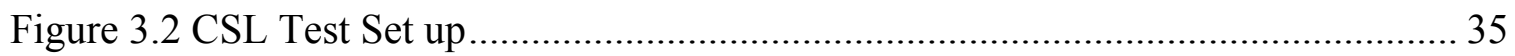

Figure 3.3 Drilled Shaft Sample Size ….............................................................. 35

Figure 3.4 (a) Installing the Outside Galvanized Tubes, (b) Installing the Sona-tube ..... 36

Figure 3.5 (a) Concrete Placement inside the Sona-tube, (b) Taking out the Sona-tube

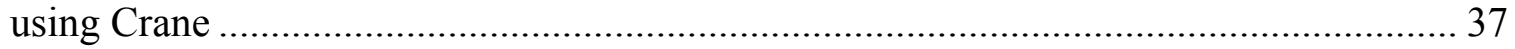

Figure 3.6 CSL Test on the Drilled Shaft Samples.................................................... 38

Figure 3.7 CSL Tubes Arrangement - Top View .................................................... 39

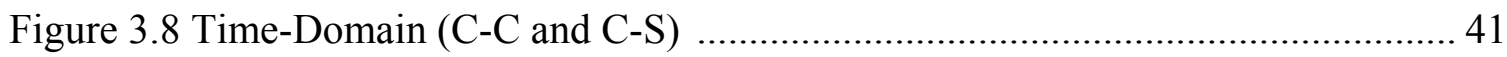

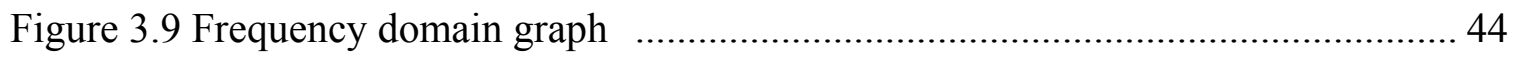

Figure 3.10 De-noised and Fitted Frequency Domain curve (4-5 and 1-4).................... 44

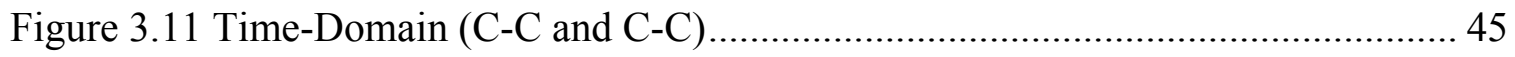

Figure 3.12 De-noised and Fitted Frequency Domain curve (4-5 and 4-6)................... 45

Figure 3.13 De-noised and Fitted Frequency Domain curve (2-5 and 3-6)................... 46

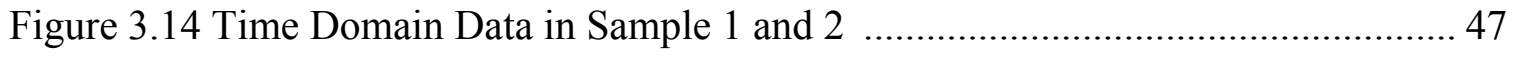

Figure 3.15 Frequency Domain Data in Sample 1 and 2 ........................................... 47

Figure 3.16 Amplitude of Signal versus Frequency .............................................. 48

Figure 3.17 Concrete Thickness versus Maximum Amplitude of Signal for Sample 1 ... 49

Figure 3.18 Concrete Thickness with Maximum Amplitude of Signal for Sample 2 ..... 49

Figure 3.19 Variation of Concrete Thickness with Maximum Amplitude of Signal....... 50 
Figure 3.20 Trend-line Fitted Curve on Concrete Thickness versus Maximum Amplitude

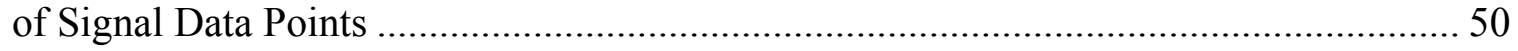

Figure 3.21 CSL Test between an Inside Tube and Outside Tube nal ............................ 52

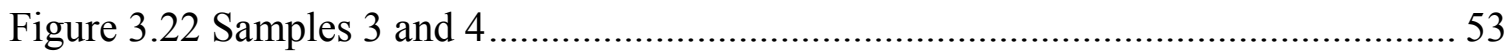

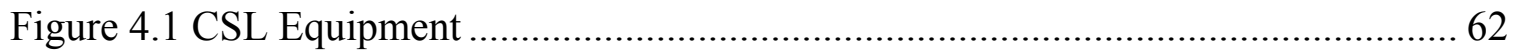

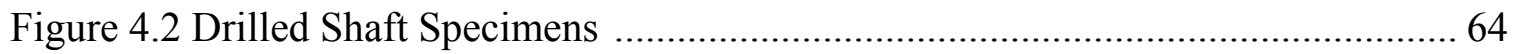

Figure 4.3 CSL Tubes Arrangement - Top View …………………………………...... 64

Figure 4.4 (a) Installing the Outside Galvanized Tubes, (b) Installing the Sona-tube ..... 65

Figure 4.5 (a) Concrete Placement inside the Sona-tube, (b) Taking out the Sona-tube

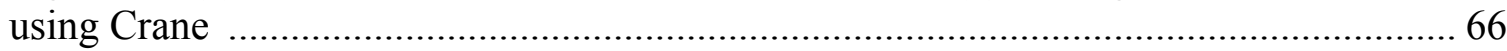

Figure 4.6 Constructed Voids inside the Caging Through the Length of the Shaft

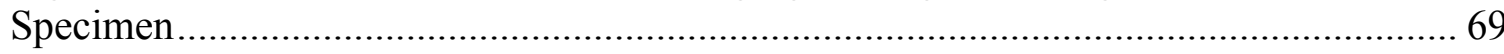

Figure 4.7 CSL Test on the Drilled Shaft Samples....................................................... 71

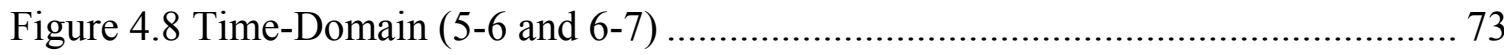

Figure 4.9 De-noised and Fitted Frequency Domain curve (5-6 and 6-7)....................... 73

Figure 4.10 Frequency Domain Graph Through the Shaft Length.................................... 76

Figure 4.11 Time Domain Tomography (Specimen 1)................................................. 79

Figure 4.12 Frequency Domain Tomography (Specimen 1) ............................................ 79

Figure 4.13 Time Domain Tomography (Specimen 2)................................................ 80

Figure 4.14 Frequency Domain Tomography (Specimen 2) .......................................... 80

Figure 5.1 Typical Void Anomalies in a Drilled Shaft [8] .............................................. 86

Figure 5.2 Shape of the Voids Considered in the Experimental Program ........................ 88

Figure 5.3 Drilled Shaft Profile with Void at the Middle ................................................ 88

Figure 5.4 (a) Steel Cage of Specimen, (b) Sonatube with Void Tybe B, 10\% .............. 91

Figure 5.5 Specimens Formwork Before Concrete Placement ......................................... 91

Figure 5.6 Stress-Strain Curves of Steel Rebar .............................................................. 93 
Figure 5.7 Hydraulic Actuator Machine Used for the Tests at FIU's TASCT Laboratory

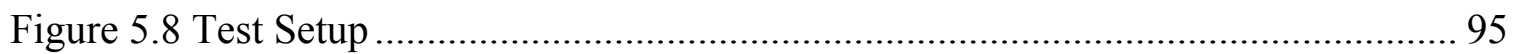

Figure 5.9 Axial Load versus Vertical Displacement for Specimens 1-4 (void Type A). 96

Figure 5.10 Axial Load versus Vertical Displacement for Specimens 5-8 (void Type B)96

Figure 5.11 Axial Load versus Vertical Displacement for Specimens 9-12 (void Type C) 97

Figure 5.12 Failure in Shaft Specimens after Testing................................................... 100

Figure 5.13 Axial Load versus Vertical Displacement for Specimens 14 and 15 (Intact

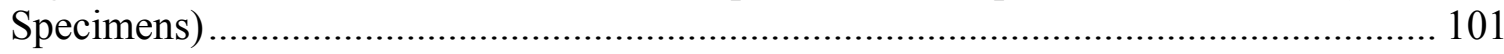

Figure 6.1 Shape of the Voids Considered in the Experimental Program ...................... 109

Figure 6.2 Drilled Shaft Profile with Void at the Middle ............................................... 109

Figure 6.3 (a) Steel Cage of Specimen, (b) Sonatube Cut with 20\% Void Area............ 112

Figure 6.4 Specimens Ready for Testing ............................................................... 113

Figure 6.5 Stress-Strain Curves of Steel Rebar ........................................................ 114

Figure 6.6 Hydraulic Actuator Machine Used for the Tests at FIU's TASCT Laboratory 116

Figure 6.7 Axial Load versus Vertical Displacement for Specimens 1 and 6 ................ 117

Figure 6.8 Axial Load versus Vertical Displacement for Specimens 1-5 (Corrosion) .. 118

Figure 6.9 Axial Load Capacity vs. Corrosion Percentage in Longitudinal Rebars ...... 119

Figure 6.10 Axial Load versus Vertical Displacement for Specimens 6 and 7 ............. 120

Figure 6.11 Failure in Shaft Specimens after Testing .................................................. 121

Figure 6.12 Summary of Electrochemical Test cell Data at 50\% and 100\% Saturation 123

Figure 6.13 Longitudinal Bar Section with Corroded Thickness x .............................. 124

Figure 7.1 Side Resistance vs. Depth for Different Drilled Shaft Diameters .................. 133

Figure 7.2 Tip Resistance vs. Depth for Different Drilled Shaft Diameters................... 133 
Figure 7.3 Total Axial Resistance vs. Depth for Different Drilled Shaft Diameters...... 134

Figure 7.4 Side Resistance Percentage vs. Depth for Different Drilled Shaft Diameters

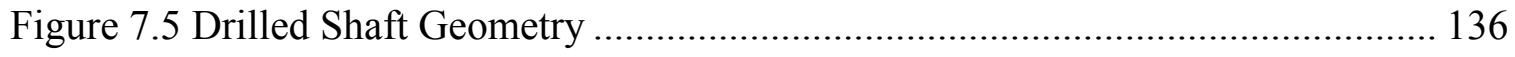

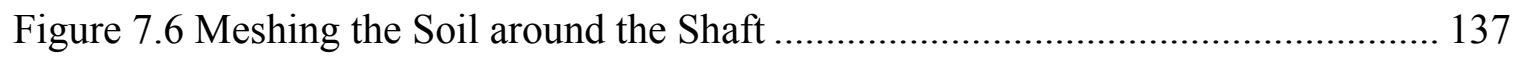

Figure 7.7 Z-component of Displacement in Drilled Shaft Nodes (Un-confined Model)

Figure 7.8 Z-component of Displacement in Longitudinal and Stirrups (Un-confined

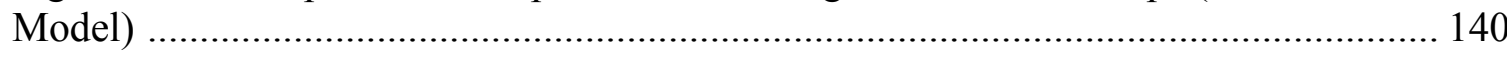

Figure 7.9 Load-displacement in drilled Shaft (Un-confined Model) .......................... 141

Figure 7.10 Load-displacement in Soil (Un-confined Model).................................... 142

Figure 7.11 Load-displacement Analytical in Comparison to Finite Element .............. 143 


\section{INTRODUCTION}

Drilled shaft foundations are the most versatile types of foundations, and have been used increasingly as a foundation for different structures in Florida. Drilled shafts are often used in many retrofit projects with certain ground conditions such as soft soil, limestone, loose sand, water saturated sand, and soils with boulders. This foundation system is typically used for projects in which large concentrated loads and lateral resistance are major factors, such as bridges and other large structures. During the past decade, there has been a large amount of research on drilled shaft foundations, with most relating to the axial load-carrying capacity of the drilled shafts. These foundations usually carry very high design loads; that is why they need to be built with a high level of quality assurance and control applied to each in-place constructed deep foundation element.

Part of the axial load carrying capacity of the drilled shafts is resisted by the soil below the tip, which is the end-bearing capacity of the shaft. The other part is resisted by the side friction developed along the shaft or skin friction capacity, which can be affected by the shape of the drilled shaft after construction. Therefore, accurate measurement of the drilled shaft diameter along its entire length after construction is crucial in determining its actual axial load carrying capacity. Currently, to determine the diameter of drilled shafts as concrete is being placed, the inspector must make a concrete volume versus depth plot. The objectives of this plot are to verify that enough concrete is placed into the shaft and that "actual concrete" volume is consistent with the theoretical volume. The actual concrete volume is the accumulative volume of concrete necessary to fill the drilled shaft to its design elevation. The theoretical concrete volume is the accumulative 
volume of concrete that would fill a cylindrical shape with dimensions that of the drilled shaft under consideration.

By comparing actual to theoretical concrete volumes, the inspector can get a feel for what is happening below the ground surface. Substantial differences between theoretical and actual concrete volumes will reveal anomalies in the as-built shaft, as will be demonstrated in later examples. To plot a concrete volume versus depth, first plot the theoretical cumulative concrete volume line. As each load is placed in the shaft, determine the accumulated volume and the elevation at the top of the concrete level and plot that point for each load. Each line segment represents a concrete volume placed in the shaft from each truck. These points form a plot of actual concrete placed relative to the theoretical line. One important characteristic of the concrete versus volume plot is the slope of each segment. The desired segment slope must be relatively parallel to the slope of the theoretical volume line. Where slope of segment is not parallel, this may lead to some undesirable characteristics of the concreted shaft and may adversely impact its design capacity.

This method of measurement, that uses discrete points to determine the diameter of the drilled shaft, only gives an average of the diameter between any two points of measurement because of the fatting and necking that maybe taking place during the filling process. This method therefore falls short of a continuous accurate measurement of the drilled shaft diameter, and a more accurate method is needed.

Also, some surface NDT methods (shaft head impact tests) have been used for realizing the shaft shape profile using the surface reflection techniques such as Impulse Echo, Impulse Response, and Impedance Logging. Shaft head impact tests (Sonic Echo 
and Sonic Mobility), where the response to an impact on the head of the shaft is measured by a transducer coupled to that shaft head.

The shaft head impact tests (Sonic Echo Technique, Impulse Response Technique, and Impedance Log Technique) just can produce a probable shaft shape profile with depth because they do not have access to entire length of the drilled shaft. The resultant computed shape by surface NDT methods is symmetrical about the shaft axis and this indicates that they are not accurate methods. This research proposes to develop a new method of determining an accurate measurement of the diameters of drilled shafts during construction using down hole nondestructive tests such as CrossHole Sonic Logging testing and also evaluation of drilled shafts quality control and quality assurance. 


\section{LITERATURE REVIEW}

\section{Non-destructive Tests History}

The use of drilled shafts as foundations for bridges and other structures has greatly increased in recent years due to the advent of routine non-destructive evaluation (NDE) methods. The availability of the NDE methods has given engineers and contractors the false impression that any defects that may have been produced during construction due to problems in concreting, drilling, casing, slurry and rebar cage placement can be identified and repaired before the bridge is opened to traffic.

NDT of deep foundations is a complex topic covering a number of different techniques designed to gain information about the integrity and quality of the material that makes up a deep foundation. Typical foundation materials are concrete, timber, steel and rock. Deep foundations vary in size and shape, may be constructed of a combination of materials and may be built by a combination of several different techniques. Each combination of size, shape, material, and construction method creates a unique set of circumstances that includes the risk of a variety of defects specific to those circumstances. Those same circumstances will determine the accessibility of the foundation for inspection during construction and for NDT examination after construction.

The variations in possible defect types, foundation access and construction material have led to the development of several different NDT methods over the last 30 years. Each method has been designed for a specific purpose and a defined range of 
circumstances, and therefore has a specific and unique set of capabilities that determine its applicability to a particular project.

By the mid-1950s, it was well-established that the propagation velocity of a stress wave through concrete was a function of the modulus and density of the material, and researchers had begun to look at ways of using stress waves to assess the quality and integrity of deep foundation shafts.

Current equipment for NDT of foundations is based on either PCs or hand-held computers, and in some cases data can be transmitted via modem or cellular telephone from the construction site to the engineer's office in a matter of minutes after completion of testing. Although high-strain dynamic pile testing was developed initially to determine bearing capacity or hammer efficiency, it was quickly realized that evaluation of driving stresses and identification of shaft damage also provided valuable information. The lowstrain Impulse-Echo (or Sonic-Echo) test was developed in the 1960s. One of the leading researchers to explore the capabilities and limitations of the Impulse- Echo method was Jean Paquet. The earliest versions of the Impulse-Echo test used a hammer impact to generate a stress wave, and an oscillograph, or UV recorder, to record the response of a geophone or an accelerometer attached to the top of the shaft. As the Impulse-Echo test was evolving, other visionaries in the United States also saw the potential for NDT of drilled shafts.

The introduction of digital computers has revolutionized the field, and the Impulse-Response method is now widely accepted throughout the world for the assessment of drilled shafts, locating voids beneath pavement slabs and behind tunnel 
linings and assessing concrete quality in structures ranging from parking decks to chimneys and storage silos.

The stories of the Cross-Hole Sonic Log (CSL) and Parallel-Seismic methods are similar. These methods were also developed by the CEBTP in the late 1960s (Paquet, 1969; Paquet and Briard, 1976) but were hampered by the technology of the time. The first use of the CSL method in the Americas was by the Hertlein in 1986. Drilled shafts were constructed in the Spokane River for the repair of the flood-damaged powerhouse at the Upstream Dam Hydroelectric Project in Spokane, Washington. The construction conditions were extremely difficult because the river was still in flood, and so the owner decided that it would be a good time to try CSL to verify the quality of the foundations.

Two main families of non-destructive tests related to deep foundations are:

a) Shaft head impact tests (Sonic Echo and Sonic Mobility), where the Iresponse to an impact on the head of the shaft is measured by a transducer coupled to that shaft head.

b) Cross-hole or down-hole tests (Sonic Logging, Gamma-Gamma Logging and Parallel Seismic) where pre-placed tubes in or adjacent to the shaft act as guides for sensors.

\section{Shaft Head Impact Tests}

Shaft head impact tests are type of NDT tests for deep foundation. In these kinds of tests the transmitter and receiver of the waves are installed at top surface of the shaft and they do not have access to entire length of the drilled shaft. Some surface NDT methods (shaft head impact tests) have been used for realizing the shaft shape profile using the surface reflection techniques such as Impulse Echo, Impulse Response, and 
Impedance Logging. The echo method and vibration tests are two preliminary concepts of the shaft head impact tests.

\section{Echo Method}

The 'echo method' started in 1968 with the publication of Jean Paquet's paper on nondestructive testing of shafts in the French National Building and Civil Engineering Annals (English translation by Xiang Yee (Yee, 1991)). The test equipment used at that time was limited to analog technology and data storage was a dream for the future. This first paper dealt with the application of electric transmission line theory to the onedimensional problem of compression stress bar-waves transmitted from the shaft head down the shaft.

Paquet explored the limitations of the method, particularly with respect to excitation frequency bandwidth. Bar-wave analysis in both time-domains and frequencydomains was discussed. Paquet laid down the fundamental theories for stress-wave transmission down shafts, including changes in shaft and soil dynamic impedance and damping of stress waves by shaft material and surrounding soil. However, he considered the Sonic-Echo principle to be simple. He compared the method to ultrasound techniques used for metal testing, stressing the difference that metal ultrasonic testing uses a stream of waves containing tens of periods of sinusoids with well-defined frequencies, with great lateral dimensions of the emitter in relation to the emitted wavelength and a consequent directional effect. This method encounters several difficulties when applied to shafts:

a) A significant damping of higher frequencies in concrete shafts caused by the unhomogenous nature of the concrete. 
b) Wave propagation damping caused by the lateral soil.

c) Difficulty in coupling a directional emitter to the shaft head.

He explored the limitations of the method, particularly with respect to excitation frequency bandwidth. Bar-wave analysis in both time-domains and frequency-domains was discussed. The test equipment used at that time was limited to analog technology, with shaft head excitation by swept-frequency vibrators mounted on the head of the foundation shaft.

\section{Sonic Echo Technique}

Sonic-echo test or impact-echo test is used to evaluate the integrity of drilled shafts. When a stress wave generated by hand-held hammer at the shaft head penetrates along the shaft and meets different media like defects and embedded ground, it is reflected to the shaft head and received by the accelerometer or velocity transducer. The test is also called the low strain test because a small hammer induces a low strain on the shaft head upon impact. Hearne, Stokoe and Reese (1981) introduced test procedures and their equipment arrangements consisting of accelerometers on the shaft head as well as embedded geophones bonded to rebar cages.

The Sonic-Echo test is performed by striking the shaft head with a light hammer and measuring the response of the shaft with a sensor (accelerometer or geophone velocity transducer) coupled to the shaft head. The hammer blow generates a compressive stress wave which is channeled down the shaft as a 'bar-wave'. The latter is partly reflected back towards the shaft head by any change in impedance within the shaft. These impedance changes can be as a result of changes in shaft section, concrete density 
or shaft-soil properties. The stress wave is transmitted through the shaft at a velocity, $\mathrm{v}_{\mathrm{b}}$, and the time lapse, $t$, between the hammer impulse and the arrival of the reflected waves at the shaft head from shaft tip is a measure of the distance traveled by the stress wave, such that:

$t=\frac{2 L}{v_{b}}$

where $L$ represents the distance to the reflecting surface (shaft tip in this case) and $v_{b}$ is the bar-wave velocity of propagation through the shaft material.

The material in the shaft head must be prepared such that no delamination or micro cracking is present, to ensure a clean transmission of the stress wave down the shaft. The sensor is coupled to the shaft head, usually with a grease or gel, and the shaft is struck with the hammer at or near the shaft axis. Normally, a hammer weighing less than $1 \mathrm{~kg}$ with a plastic impact tip is used. Heavier hammers have sometimes been found to give better results for large shafts greater than $1 \mathrm{~m}$ in diameter. The test is repeated several (at least three) times in order to obtain representative samples by averaging of these individual results. The more hammer blows recorded, then the greater the reduction in the effects of random signals (noise) from other site activities or system noise. As the effects of this extraneous noise are reduced, so the repeatable parts of the signal are enhanced. As a general rule, background noise can be reduced by a factor of $\sqrt{n}$, where $n$ is the number of superimposed signals from tests on the same shaft. 


\section{Impulse Response Technique}

Impulse response, a nondestructive surface reflection technique, offers a way to assess the quality and integrity of deep foundations. While the impulse response test is a straightforward method to implement, interpretation of the data is often difficult. The response of a shaft will be affected by construction conditions, accessibility and quality of the concrete, as well as by gross defects in geometry. As a result, test responses seldom resemble the ideal theoretical response. The difficulty is increased when the accessibility of the shaft is limited by the presence of a shaft cap or other structures.

Consider the case of a perfect free cylindrical shaft of length $\mathrm{L}$ resting on the surface of an elastic foundation. If a constant maximum force $\mathrm{F}_{0}$ is applied at the head of the shaft and the maximum shaft head velocity $\mathrm{V}_{0}$ is measured at varying frequencies, it is observed that resonant responses are spaced at equal intervals along the frequency spectrum:

$$
\Delta f=\frac{v_{c}}{2 L}
$$

where $\mathrm{v}_{\mathrm{c}}$ is the velocity of the wave propagation along the shaft.

\section{Impedance Log Technique}

The main idea of this method is to introduce a transient stress wave into the drilled shaft and then utilize the reflected signals to obtain the impedance profile of the shaft. The impedance profile can then be used to recover the cross-sectional profile or material property along the length of the shaft. Any anomaly, which results in changes in impedance, would be detected by this method. For the IR method, the impact force and 
the particle velocity response must be both measured versus time on the impacted surface. These two time histories are then transformed to the frequency domain using the Fast Fourier Transform (FFT).

In the last decade, a relatively new method for evaluating the integrity of shafts, the Impedance Log (IL) method was proposed and briefly described by Paquet. The reported main capability of this method is to recover the changes of the cross-sectional area of the shaft by obtaining its impedance as a function of the distance from the shaft head. In other words, the method provides the geometric profile of the shaft and its variation with depth. This is indeed the major purpose that a nondestructive testing technique for shafts is intended to achieve.

\section{Down-hole Tests}

The Down-hole Test is a method which determines the quality of the concrete by analyzing direct compressional and shear waves between two boreholes which have been lower down in entire length of the drilled shaft.

\section{Single-hole testing}

Single-hole ultrasonic testing is a variation on the conventional cross-hole method. It is extremely useful under the following conditions:

1) if cross hole testing was planned, but some tubes were accidentally damaged, and only one is available for testing

2) in shafts without tubes where core drilling was performed

3) in hollow driven piles 
4) in small diameter shafts where there it is impractical to install multiple shafts and the sonic test is inapplicable

In this method, both probes are lowered into the same tube, one above the other. As long as the probes are closely spaced, the first arrival will belong to the wave passing in the water filling the tube. At a larger spacing, the wave traveling through the surrounding concrete will arrive earlier, due to the higher wave speed. Thus, both FAT and energy provide information about the quality of the concrete around the hole. The single-hole ultrasonic method can find defects as thin as $3 \mathrm{~cm}$ if they surround the tube, or defects $10 \mathrm{~cm}$ thick at a distance of $7 \mathrm{~cm}$ from the tube. A word of caution: is impossible to apply the method in steel tubes, since they intend to refract the waves towards the horizon. In fact, the FAT recorded in steel tubes will represent the propagation in the water filling the tube.

\section{Cross-hole Sonic Logging}

Cross-Hole Sonic Logging system (CSL) is a common type of NDT, which is currently used to check the integrity of placed drilled shafts based on propagation of ultrasonic waves between two or more access tubes inside the reinforcing cage. CSL is a NDT method which involves ultrasonic signal transmission through the shaft between two parallel water filled access tubes. The access tubes are often tied to the rebar cage and cast permanently into the shaft. The total number of access tubes typically depends on the diameter of the shaft. A transmitter probe and a receiver probe are lowered to the bottom of the shaft in separate access tubes. Measurements of the signal transmission are 
collected approximately every $5 \mathrm{~cm}$ as the probes are raised to the top of the shaft. The cables attached to the probes are pulled through calibrated encoder wheels which can accurately determine the depth of the probe during testing.

CSL is the most reliable technique for assessing the integrity of in-place constructed deep foundation elements such as drilled shafts. The CSL method is used to measure the speed of ultrasonic waves between water-filled access tubes. A number of access tubes (PVC or steel galvanized) are installed inside the reinforcing cage prior to concrete placement as guides for sensors. A transmitter and receiver sensor are lowered down to the bottom of adjacent tubes and placed such that they are in the same horizontal plane. The transit time of an ultrasonic pulse through the material between the tubes is measured as the probes are raised until they reach to the top of the drilled shaft. Since the distance between the two tubes is known, the velocity of the ultrasonic wave which travels from source to receiver can be evaluated by the following relationship:

$$
C=\frac{L}{t}
$$

$\mathrm{L}$ is the distance between the tubes and $\mathrm{t}$ is the arrival time. In homogeneous, good quality concrete, the sound wave speed is around $3,800 \mathrm{~m} / \mathrm{s}(12,000$ to $13,000 \mathrm{ft} / \mathrm{s})$ and is related to the modulus of elasticity, E, unit weight, $\gamma$, and gravitational acceleration, g, as follows:

$$
C=\sqrt{\frac{E^{*} g}{\gamma}}
$$

The velocity of the ultrasonic wave determines the presence of the defect due to voids or soil intrusions. If for any reason the condition of the concrete is changed, the 
wave speed will be reduced relative to that of the sound concrete value. The integrity of the concrete outside the cage needs to be considered to determine the location of the border between the concrete and the soil in order to get the diameter of the drilled shaft. It is also economic to find a methodology to get the diameter of the drilled shaft using CSL, since it can be performed after the CSL tests to check the integrity of the inside concrete, and without having to set up and use another NDT device.

Cross hole ultrasonic testing technique is now well-known and has been standardized in several countries. Still, there is scant data regarding its performance in terms of flaw detectability. Sarhan et al. (2002) quoted a number of sources relating to this question, and concluded that flaws occupying up to $15 \%$ of the shaft's cross section could remain undetected.

The ultrasonic integrity test is of the intrusive type, which means it is usually performed in pre-installed access tubes. In rare cases the test may also be carried out in drilled holes. Access tubes are usually made of steel, although plastic tubes are quite common in the US. Whatever the material, tubes are expensive, and the engineer is expected to specify the minimum number of tubes that will give him an adequate chance to discover all important flaws. Li et al. (2005) made an attempt to correlate the number of tubes installed in a shaft with detection probability of flaws. Modern ultrasonic equipment can without difficulty cover a distance of at least four meters between emitter and receiver, but the usefulness of such a large spacing is doubtful. The rule provided by ASTM limits the maximum tube spacing along the perimeter to less than $1 \mathrm{~m}$. A finite element analysis has been carried out shows that a flaw halfway between two tubes is 
detectable only if its size is at least $40 \%$ of the tube spacing. Thus the ASTM rule ensures detection of flaws in the order of $400 \mathrm{~mm}$.

To detect an inferior material inclusion of dimension $\mathrm{d}$, it should be much larger than the wavelength (Santamarina et al. 2001). The emitter frequency specified by the various Standards varies between $20 \mathrm{kHz}$ and $100 \mathrm{kHz}$. If, as mentioned above, it can be aimed at the $400 \mathrm{~mm}$ detection threshold, then the lower-end emitter frequencies allowed by the standards are acceptable. The higher end frequency, on the other hand, produces wavelengths approaching the size of individual aggregates and causing high attenuation. From our experience, frequencies in the order of 50 to $60 \mathrm{kHz}$ combine long range with good resolving power.

An ultrasonic testing consists of the following components (Figure 2.1):

a) A pair of probes (emitter and receiver): Each of these is equipped with a ceramic piezoelectric element and the applicable electronics. The frequency of the system is determined by the properties of the elements, with the usual range being 40 to $100 \mathrm{kHz}$. This conforms to wavelengths in the order of 40 to $100 \mathrm{~mm}$.

b) A depth encoder(s): that produces a predetermined number of pulses per revolution. Pulse generator and signal processor.

c) A computer that handles the following functions:

Identification of the shaft and the profile, input of the control parameter for the specific measurement, monitoring the depth from the encoder output, controlling the pulse rate of the emitter, saving the output, and processing the data and displaying the results. 


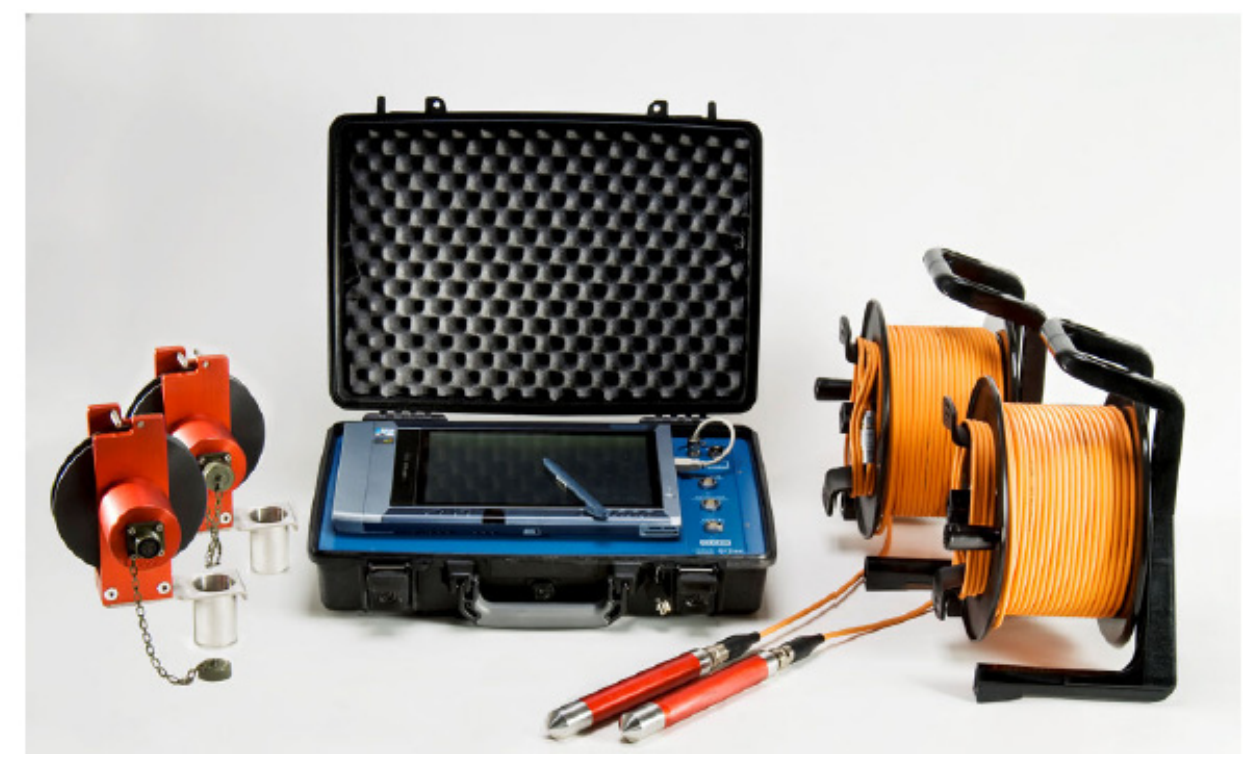

Figure 2.1. The Ultrasonic system for integrity testing

Before to start testing a shaft, the access tubes have to be checked for free access and filled with water to obtain good acoustic coupling. Two pulleys are then inserted into the tubes, at least one of which is equipped with a depth meter. The probes (emitter and receiver) are then inserted over the pulleys and lowered into the tubes. After reaching the bottom of the tubes, the operator must first ascertain that they are at the same level. Probes may be found at different levels because of poor tube workmanship or because one or both tubes is blocked by debris. The probes are then pulled simultaneously upwards with smooth motion until they reach the pulleys. During this time the emitter produces a continuous series of pulses, sending waves in all directions. The vertical distance between successive pulses is determined by the operator, with $50 \mathrm{~mm}$. being a good typical figure.

For each profile in the shaft the following items are important to be plotted:

a) First arrival time(FAT) of each pulse versus depth

b) Relative energy versus depth 


\section{Cross-Hole Analyzer}

After performing the CSL test between two access tubes, the Cross-Hole Analyzer (CHA) software can be used to analyze the results. CHA evaluates the quality of the concrete of deep foundations by the CSL method. The CHA detects arrival time by locating the peak value of a signal, then by using a relative percentage of that peak as a threshold for locating the leading edge. This value can be monitored visually by the horizontal blue dotted line on the signal trace graph. The data acquisition signal, AT/energy plot, and sonic map or waterfall diagram are displayed in the CHA software as shown in Figure 2.2.
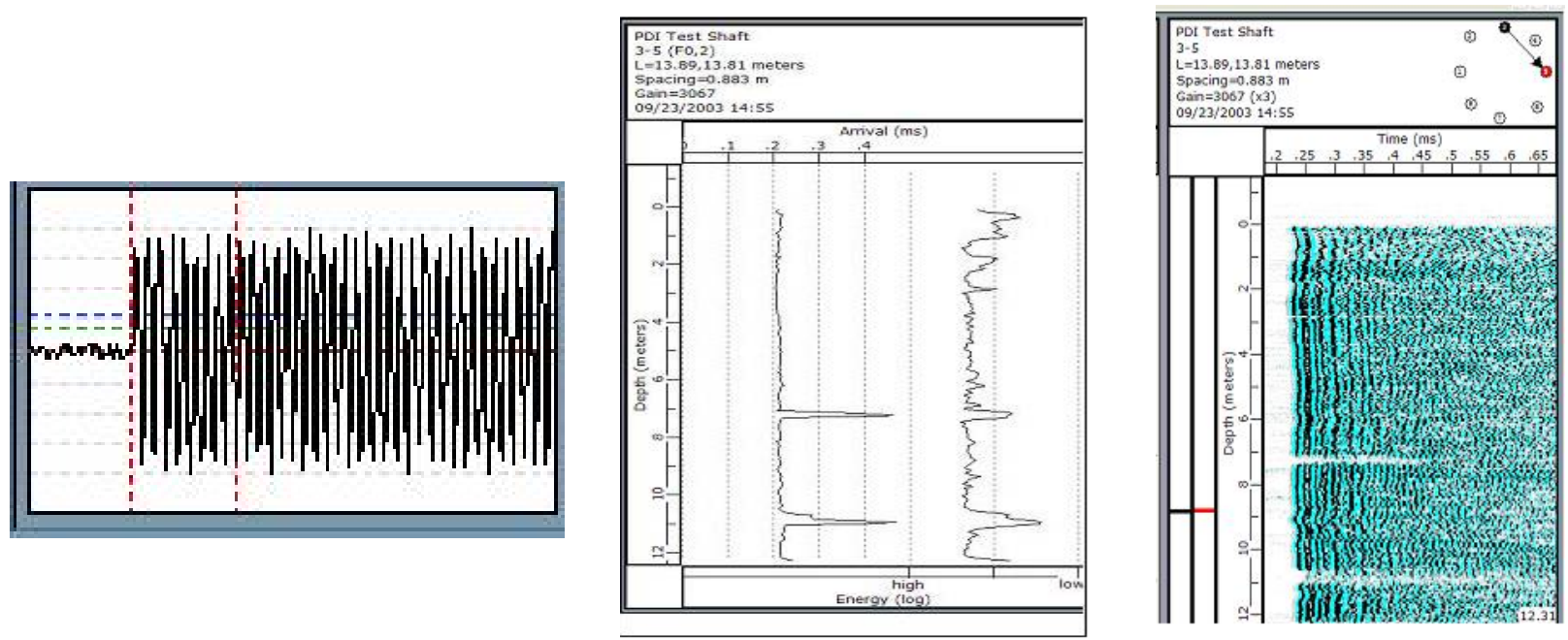

Figure 2.2. Data Acquisition Signal, Energy/AT Graph, Waterfall Diagram 


\section{Data Acquisition Signal}

The data acquisition signal graph includes 250 data points, sampled at $500 \mathrm{kHz}$. The graph represents data points versus strength of the received signal by the receiver probe (represents data points versus strength of the received signal).

\section{First Arrival Time}

The first item is the shape of the FAT vs. depth plot. As long as FAT is more or less constant, it indicates that there is no change in concrete quality between the tubes along the shaft. A local increase of the arrival time is considered as an anomaly that may be the result of an obstacle (or flaw) on the straight path between the probes at the corresponding depth. The ultrasonic waves will either travel through this flaw at a reduced velocity or bypass it, with a respective increase in travel time. Experimental work (Stain \& Williams 1991) indicated that lower-strength concrete has little effect on either transmission time or signal attenuation. On the other hand, segregated concrete, bentonite polluted concrete and pockets of pure bentonite slurry do strongly affect the signal.

\section{Energy Graph}

Energy is the other useful parameter which it can be obtained from the ultrasonic test. It is true that in uniform concrete the both energy and FAT depend on the distance traveled, but still it pays to study them separately. The main reason for this is that, unlike FAT, which can assume many values, energy is practically invariant. If the waves pass through an inclusion, both parameters should be affected. A local increase in FAT without a corresponding decrease in energy may mean that the wrong FAT picking method has 
been used. If, on the other hand a decrease of the measured energy without an increase in FAT is notified, it usually is a result of a constriction of the travel path and the defect is located out of the straight line connecting the probes. There are two different plots in the Energy/AT graph; the left one could be arrival time or wave speed and the right one is energy plot. The energy plot is based on the following equation:

Energy $=[$ received signal strength $($ volts $)] *$ arrival time (millisecond) $]$

\section{Waterfall diagram}

The waterfall diagram is a three dimensional display of acquired data. The vertical axis is the depth of the shaft, the horizontal axis is time (total width is 500 micro-seconds), the third dimension represents signal strength detected by the receiver and is distinguished by color (white for zero volts, black for -10 volts, and green for +10 volts).

\section{Research Objectives}

The main objectives of this research project are:

1) Developing a new method to measure the diameter of drilled shafts during construction using a nondestructive testing method that overcomes the limitations of the currently-used method. This proposed new method promises to produce more accurate results due to one's ability to conduct it continuously throughout the depth of the drilled shaft during its construction.

2) A new method of determining an accurate location of the voids in drilled shafts after performing CSL test between inside tubes that overcomes the limitations and inaccuracies of currently used methods was developed using application of signal 
processing on the CSL test results. This method is based on a color change in the frequency amplitude of the signal recorded by receiver probe in the location of defects and it is called Frequency Tomography Analysis (FTA).

3) Evaluating the effect of voids inside and outside the reinforcement cage on the strength and axial load capacity of drilled shafts. Also, quantifying the extent of loss in axial strength and stiffness of drilled shafts due to presence of three different types of symmetric voids throughout their lengths; also, to evaluate the potential for buckling of longitudinal bars within the various types of voids.

4) Investigating the effect of rebar corrosion on the axial load carrying capacity of drilled shaft foundations with symmetric voids. And quantifying the extent of loss in axial strength of drilled shafts due to presence of different corrosion percentages in the longitudinal bars. The results of the experimental program were used to investigate the drilled shafts' capacity reduction rate over a period of 40 years in Miami soil conditions due to such corrosion in the longitudinal bars.

5) A three-dimensional finite element model of the entire drilled shaft system subjected to axial load will be completed using ANSYS.

\section{Research Methodology}

To complete the mentioned objectives, thirty two (32) large-scale drilled shaft samples were built and tested at the Florida International University's (FIU) Titan America Structures and Construction Testing (TASCT) laboratory. Five (5) drilled shaft samples were built to assess the applicability of NDT for continuous measurement of drilled shaft diameter (objective 1). The method is based on the installation of galvanized 
tubes outside the shaft in front of each inside tube, and performing CSL test between the inside and outside tubes. From experimental work a model is developed to evaluate the relationship between thickness ${ }^{1}$ of concrete and ultrasonic wave properties using signal processing. Experimental results show that there is a correlation between concrete thicknesses outside the cage and maximum amplitude of the received signal obtained from frequency domain data.

Two (2) drilled shaft samples were built to develop a new method of determining an accurate location of the voids in drilled shafts after performing CSL test (objective 2). It is based on a color change in the frequency amplitude of the signal recorded by the receiver probe in the location of defects and it is called Frequency Tomography Analysis (FTA). Time-domain data is transferred to frequency-domain data of the signals propagated between tubes using Fast Fourier Transform (FFT). Then, distribution of the FTA will be evaluated. This method is employed after CSL has determined the high probability of an anomaly in a given area and is applied to improve location accuracy and to further characterize the feature.

Fifteen (15) large-scale drilled shaft samples were built and tested using a hydraulic actuator to evaluate the effect of symmetric voids on the axial load capacity reduction of drilled shaft foundations (objective 3). Different anomaly types were considered in the form of symmetric voids with different cross sectional areas ranging from 10 percent to 40 percent of the gross cross sectional area of the shaft model based on the common void percentages in real-life drilled shafts. The shaft specimens were

\footnotetext{
${ }^{1}$ Concrete thickness is the distance between outside edge of the Sona-tube to the border of the concrete and soil.
} 
constructed with three different types of built-in symmetric voids in an attempt to study the effect of voids outside and inside the caging on the axial load capacity of drilled shafts.

Seven (7) scaled drilled shaft samples were tested in the lab to study their structural behavior with respect to corrosion in longitudinal bars. Based on the Miami soil conditions, the corrosion rate in the reinforcing bars and the drilled shafts axial load capacity reduction rate will then be calculated for a 40 -year life span. Tests were also performed to determine the crack pattern and failure behavior (field observation) of the drilled shafts under axial loading.

Three (3) drilled shaft samples were built to evaluate the effect of the type of the Cross-Hole Sonic Logging (CSL) tube on the axial load capacity in drilled shaft foundations. One sample considered without tube, one sample with PVC tubes and one sample with galvanized tube.

\section{Significance}

The significance of this work lies in the development of a new method that can be used by engineers to inspect the true size of drilled shaft foundation while detecting with a high level of precision the location of defects. Having such capabilities will enable engineers to provide a level of quality assurance never seen before in deep foundation construction. Such advancement will ensure that the most important part of a structure, its underground foundations, are constructed properly and according to the specified dimensions; thus allowing them to safely carry their intended loads. 
The new technique developed in this research promises to improve the quality and efficiency of CSL testing for engineers, enabling them to visualize and quantify the extent and exact location of drilled shaft defects.

\section{Scope}

The scope of this study centers around developing a new model of evaluating drilled shafts to better estimate their structural load capacity.

This is achieved by an innovative approach that uses signal processing on the commonly used CSL test in order to determine the exact size and location of voids inside the drilled shaft. This is complemented with an experimentally developed model that correlates the location and size of voids to the structural capacity of the shaft.

The scope of this study also included examining of the factors that affect the structural capacity of drilled shafts, including steel corrosion and shaft diameter. The study used an experimental approach to develop a model that relates corrosion to structural capacity reduction rate during any period of time.

\section{Limitations}

1. Water level, liquefaction impact, and slurry effect were not considered in the seconddegree polynomial relationship that was developed between concrete thicknesses and the maximum amplitude of the signal. Also, the model was developed to obtain the diameter of a drilled shaft located in limestone strata. Probably, this model will change for other type of soil since the P-wave velocity and time arrival is different in

different types of soil and rock and depends on the density of the soil. Future work 
can develop the model with the same idea to obtain the curve for various types of soils.

2. FTA method is used to visualize and quantify the extent and exact location of drilled shaft defects. The size and shape of the voids located outside the caging cannot be recognized using FTA technique since this method was used for the CSL test data between the inside tubes.

3. The drilled shaft samples built to evaluate the effect of different sizes and shapes of voids and corrosion on the axial load capacity reduction of drilled shaft foundations were tested without including any surrounding soil.

4. The corrosion rate in the reinforcing bars and the drilled shafts axial load capacity reduction rate were calculated for a 40-year life span based on the Miami soil conditions. For different soil media the structural capacity reduction rate will change and it depends on the properties of the soil such as moisture content, organic content, level of compaction and grain size, $\mathrm{pH}$, chloride concentration, and resistivity of the soil.

\section{Organization of Dissertation}

This dissertation consists of seven chapters. Except for this first chapter of introduction and the last chapter (Chapter 7), which includes conclusions of the present study and recommendations for the future research, the other chapters (2-6) represent papers from this study published, in press, or in review. Chapter 2 demonstrates a new method of determining an accurate measurement of the diameters of drilled shafts during construction using down hole nondestructive tests such as Cross-Hole Sonic Logging 
testing and also evaluation of drilled shafts quality control and quality assurance. Chapter 3 proposes a new method to detect the exact location of the defects after performing CSL test. To test this method, two drilled shaft samples with prefabricated voids were built at FIU's TASCT laboratory. Samples were tested seven days after concrete placement using CSL and the CHA results were evaluated using signal processing. An improved standard method is proposed that considers not only the traditional arrival time changes but also the signal strength and frequency amplitude of the signal reduction to improve the location accuracy. Chapter 4 presents an experimental work to evaluate the effect of various types of voids on the axial load capacity of the shaft as a function of different percentages of the cross-sectional area. Tests were performed to determine the effects of shape, size and length of voids on the shafts' axial load capacity; and to evaluate the crack pattern and stress concentration near the voids, or the fracture behavior (field observation) of the drilled shaft under axial loading. Chapter 5 includes an experimental study to evaluate the effect of rebar corrosion on the axial load carrying capacity of drilled shaft foundations with symmetric voids. Using the experimental results and based on the Miami soil properties, the corrosion rate in the reinforcing bars and the drilled shafts axial load capacity reduction rate will then be calculated for a 40-year life span in Miami soil condition. Chapter 6 presents a threedimensional finite element modeling of a drilled shaft subjected to axial load using ANSYS12. The top displacement and settlement of the drilled shaft are verified with analytical results. 


\title{
III. CONTINUOUS MEASUREMENT OF DRILLED SHAFT DIAMETER DURING CONSTRUCTION USING NDT METHOD
}

\author{
Masood Hajali and Caesar Abishdid
}

\begin{abstract}
Non-Destructive Testing (NDT) of deep foundations has become an integral part of the industry's standard manufacturing processes. It is not unusual for the evaluation of the integrity of the concrete to include the measurement of ultrasonic wave speeds. Numerous methods have been proposed that use the propagation speed of ultrasonic waves to check the integrity of concrete for drilled shaft foundations. All such methods evaluate the integrity of the concrete inside the cage and between the access tubes. The integrity of the concrete outside the cage remains to be considered to determine the location of the border between the concrete and the soil in order to obtain the diameter of the drilled shaft. It is also economic to devise a methodology to obtain the diameter of the drilled shaft using the Cross-Hole Sonic Logging system (CSL). Performing this methodology using the CSL and after the CSL tests has been performed which is used to check the integrity of the inside concrete will allow the determination of the drilled shaft diameter without having to set up another NDT device. A set of tests are performed at the FIU's Titan America Structures and Construction Laboratory (TASCL) to assess the applicability of NDT for continuous measurement of drilled shaft diameter. This proposed new method is based on the installation of galvanized tubes outside the shaft in front of each inside tube, and performing CSL test between the inside and outside tubes. From experimental work a model is developed to evaluate the relationship between
\end{abstract}


thickness $^{2}$ of concrete and ultrasonic wave properties using signal processing. Experimental results show that there is a correlation between concrete thicknesses outside the cage and maximum amplitude of the received signal obtained from frequency domain data. This paper demonstrates how this new method to measure the diameter of drilled shafts during construction using a NDT method overcomes the limitations of currentlyused methods.

Keywords: Drilled Shaft Diameter, Non-Destructive Testing, Cross-Hole Sonic Logging, Integrity, Concrete Thickness, Signal Processing, Maximum Amplitude of Signal.

\section{Overview}

Drilled shaft foundations are the most versatile type of foundations, and have been used increasingly for different structures in localities with high water tables. Drilled shafts are often used in many retrofit projects with certain ground conditions such as soft soil, limestone, loose sand, water saturated sand, and soils with boulders. This foundation system is typically used for projects in which large concentrated loads and lateral resistance are major factors, such as bridges and other large structures. During the past decade, there has been a large amount of research on drilled shaft foundations, with most relating to the axial load-carrying capacity of the drilled shafts. These foundations usually carry very high design loads; that is why they need to be built with a high level of quality assurance and control applied to each in-place constructed deep foundation element. Part of the axial load carrying capacity of the drilled shafts is resisted by the soil

\footnotetext{
${ }^{2}$ Concrete thickness is the distance between outside edge of the Sona-tube to the border of the concrete and soil.
} 
below the tip, which is the end-bearing capacity of the shaft. The other part is resisted by the side friction developed along the shaft or skin friction capacity, which can be affected by the shape of the drilled shaft after construction. Therefore, accurate measurement of the drilled shaft diameter along its entire length after construction is crucial in determining its actual axial load carrying capacity.

Surface NDT methods are a type of NDT tests for evaluating the integrity of concrete in deep foundations. In these kinds of tests, the transmitter and receiver of the waves are installed at the top surface of the shaft and do not have access to entire length of the drilled shaft for realizing the shaft shape profile. Jean Paquet (1968) introduced the echo method on nondestructive testing of drilled shafts. Sonic-echo test or impact-echo test was used to evaluate the integrity of drilled shafts. When a stress wave generated by a hand-held hammer at the shaft head penetrates along the shaft and meets different media like defects and embedded ground, it is reflected to the shaft head and received by the accelerometer or velocity transducer. The test is also called the low strain test because a small hammer induces a low strain on the shaft head upon impact. Hearne, Stokoe and Reese (1981) introduced test procedures and their equipment arrangements consisting of accelerometers on the shaft head as well as embedded geophones bonded to rebar cages.

The impulse response method is another surface NDT method that relies on the identification of compressive wave reflections. This method was developed by Higgs and Robertson (1979) in France to evaluate shaft integrity.

The Sonic Echo (SE) method is a low strain integrity test conducted from the surface. Test equipment include an impulse hammer. The impulse hammer has a built-in load cell 
that can measure the force and duration of the impact. The test involves hitting the foundation top with the hammer to generate wave energy that travels down the foundation. The wave reflects off irregularities or the bottom of the foundation and travels up the foundation to the foundation top. The receiver measures the vibration response of the foundation for each impact. The signal analyzer or PC processes displays the hammer and receiver outputs. Foundation integrity is evaluated by identifying and analyzing the arrival times, direction, and amplitude of reflections measured by the receiver in time. The receiver output is usually integrated and exponentially amplified with time (Koten and Middendorp, 1981) to enhance weak reflections. Digital filtering with a low-pass filter of about $2,000 \mathrm{~Hz}$ is usually applied to eliminate high frequency noise. In some cases, where reflections are difficult to identify, an impedance imaging procedure is used to obtain a 2-D image of the shaft (Paquet, 1991).

Paquet and Briard (1976) showed that for bored piles or drilled shafts the best approach was to analyze the vibration response in the frequency-domain, particularly if defects in the top few meters were to be detected. At that point, a divergence occurred between the frequency-domain approach developed in France and applied in the UK predominantly to drilled shaft construction (Davis and Robertson, 1975, 1976) and the time-domain approach adopted in Holland and the Scandinavian countries, where precast driven piles were the norm and time domain analysis was adequate for shafts with constant cross-section (Reiding et al., 1984; VanWeele et al., 1987).

Another common method currently used to determine the diameter of drilled shafts as concrete is being placed involves an inspector making a concrete volume versus depth plot as shown in Figure 3.1. The objective of this plot is to verify that the actual 
diameter of the drilled shaft is consistent with the theoretical diameter. The actual concrete volume is the accumulative volume of concrete necessary to fill the drilled shaft to its design depth. The theoretical concrete volume is the accumulative volume of concrete that would fill a cylindrical shape with dimensions that of the design. By comparing actual to theoretical concrete volumes, the Inspector can get a feel for what is happening below the ground surface.

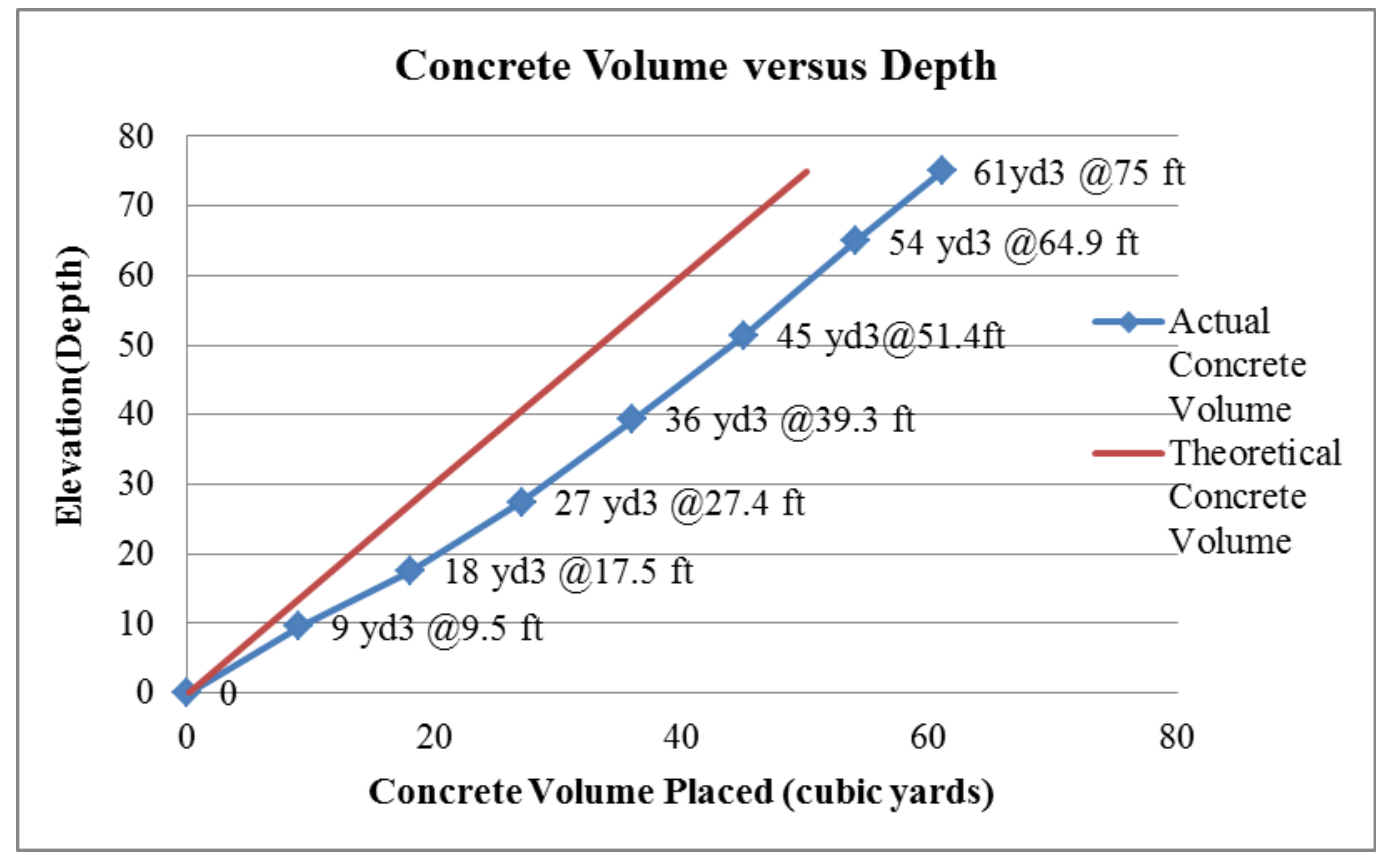

Figure 3.1: Actual and Theoretical Concrete Volume versus Depth Plot

This method of measurement, that uses discrete points to determine the diameter of the drilled shaft, only gives an average of the diameter between any two points of measurement because of the fattening and necking that maybe taking place during the filling process between two points of measurement. This method therefore falls short of a continuous accurate measurement of the drilled shaft diameter, and a more accurate method is needed. Also, surface NDT methods which are used for realizing the shaft 
shape profile can only produce a probable shaft shape profile with depth because they do not have access to the entire length of the drilled shaft. The resultant computed shape by surface NDT methods is symmetrical about the shaft axis and this indicates that they are not accurate methods. This paper demonstrates a new method of determining an accurate measurement of the diameters of drilled shafts during construction using down hole nondestructive tests such as Cross-Hole Sonic Logging testing and also evaluation of drilled shafts quality control and quality assurance.

\section{Cross-Hole Sonic Logging (CSL)}

The first use of the CSL method in the Americas was by Hertlein in 1986. This method was discussed by Baker (1993) and O'Neill (1999). CSL is a common type of NDT, which is currently used to check the integrity of placed drilled shafts based on propagation of ultrasonic waves between two or more access tubes inside the reinforcing cage. CSL is the most reliable technique for assessing the integrity of in-place constructed deep foundation elements such as drilled shafts. Sarhan et al. (2002) quoted a number of sources that flaws occupying up to $15 \%$ of the drilled shaft's cross section could remain undetected. CSL establishes the homogeneity and integrity of concrete, such as voids or soil intrusions. The CSL method is used to measure the speed of ultrasonic waves between water-filled access tubes. A number of access tubes (PVC or steel galvanized) are installed inside the reinforcing cage prior to concrete placement as guides for sensors. To carry out the test, the probes with $215 \mathrm{~mm}$ length and $25 \mathrm{~mm}$ in diameter are lowered down to the toe of the tubes. The transit time of an ultrasonic compressional wave (p-wave) signal from a signal source in one access tube to a receiver 
in another access tube is continuously measured from the bottom to the top of the shaft (Figure 3.1). The frequency of the signal that travels between tubes is about $40 \mathrm{KHz}$. The first arrival time can be used to determine the ultrasonic pulse velocity $(C)$, if the distance between tubes is measured.

The velocity of $\mathrm{P}$ waves in a medium is related to the dynamic modulus of material, $E$, density of material, $\rho$, and Poisson's ratio, $\mu$, as follows:

$$
C=\sqrt{\frac{E}{\rho} \cdot \frac{(1-\mu)}{(1-2 \mu) \cdot(1+\mu)}}
$$

In homogeneous, good quality concrete, the ultrasonic wave speed is around 12,000 to $13,000 \mathrm{ft} / \mathrm{s}$, in water is $4,800 \mathrm{ft} / \mathrm{s}$, and in air is $1,100 \mathrm{ft} / \mathrm{s}$. Normal density of concrete is about $150 \mathrm{lb} / \mathrm{ft}^{3}\left(2,400 \mathrm{~kg} / \mathrm{m}^{3}\right)$. The dynamic modulus of concrete varies from 4,060 to $5,800 \mathrm{ksi}(28$ to $40 \mathrm{GPa}$ ) and the Poisson's ratio of concrete is between 0.1 to 0.2. The range of the P-wave velocity is different in different types of soil and rock as shown in Table 1 [1]. Koerner et al. [2] utilized spectrum analysis to determine the predominant frequency $(f)$ of sound waves in soil in the range of $0-40 \mathrm{kHz}$. The predominant frequency band of sound waves in unconfined compression and triaxial tests was $250 \mathrm{~Hz}$ to $8 \mathrm{kHz}$. Soil consists of particles with different sizes and shapes which forms a skeleton whose voids are filled with water and air. Hence, the compressional wave with $40 \mathrm{kHz}$ attenuates inside soil and cannot travel. Using other probes to send lower frequency can help to solve the problem inside porous material. Frequency of waves used in this study is around $10 \mathrm{kHz}$ due to attenuation of compressional waves in soils with actual frequency of CSL. 
The velocity of the ultrasonic wave determines the presence of the defect due to voids or soil intrusions. If for any reason the condition of the concrete is changed, the wave speed will be reduced relative to that of the sound concrete value. After performing the CSL test between two access tubes, the Cross-Hole Analyzer (CHA) software can be used to analyze the results. CHA evaluates the quality of the concrete of deep foundations by the CSL method. The CHA detects arrival time by locating the peak value of a signal, then by using a relative percentage of that peak as a threshold for locating the leading edge. This value can be monitored visually by the horizontal blue dotted line on the signal trace graph. The data acquisition signal graph includes 250 data points, sampled at $500 \mathrm{KHz}$. The graph represents data points versus strength of the received signal by the receiver probe. The strength of the signal range is between -10 to +10 volts and center is zero. The energy can be also calculated and curved base on:

Energy $=[$ received signal strength $($ volts $)] *[$ arrival time (millisecond) $]$

\begin{tabular}{llc}
\hline & \multicolumn{2}{c}{ P-wave velocity } \\
\cline { 2 - 3 } Type of soil or rock & $\mathrm{m} / \mathrm{sec}$ & $\mathrm{ft} / \mathrm{sec}$ \\
\hline Soil & & \\
sand, dry silt & $200-1000$ & $650-3300$ \\
Alluvium & $500-2000$ & $1650-6600$ \\
Compacted clays, clayey gravel, and dense clayey & & \\
sand & $1000-2500$ & $3300-8200$ \\
Loess & $250-750$ & $800-2450$ \\
Rock & & \\
Slate and shale & $2500-5000$ & $8200-16400$ \\
Sandstone & $1500-5000$ & $4900-16400$ \\
Granite & $4000-6000$ & $13100-19700$ \\
Sound limestone & $5000-10000$ & $16400-32800$ \\
\hline
\end{tabular}

Table1. Range of P-wave Velocity in Various Soils and Rocks 
When a soil is saturated below the water level, the wave velocity may change. Pwaves can travel with a velocity of about 5,000 ft/ses through water. For dry, loose soils, the velocity may be well below $5,000 \mathrm{ft} / \mathrm{sec}$. However, in a saturated condition, the waves will travel through water that is present in void spaces with a velocity of about 5,000 $\mathrm{ft} / \mathrm{sec}$. If the presence of groundwater has not been detected, the P-wave velocity may be erroneously interpreted to indicate a stronger material such as limestone than is actually present in situ.

\section{Test Program}

\section{Materials and Test Samples}

The test specimens used in this study to perform the CSL through the length of the shaft are designed to simulate a drilled shaft foundation. Five drilled shaft samples were built at FIU's TASCL (see Figure 3.2). The diameter of each drilled shaft specimen was 20 inches, with a length of 4 feet. The formwork had a length of 60 inches, a width of 48 inches, and a height of 48 inches as shown in Figure 3.3. A sona-tube with a diameter of 20 inches and a length of 5 feet was used as a casing around the drilled shaft. The shaft was longitudinally reinforced with fifteen (15) No. 6 steel bars that were equally spaced around the perimeter. This amount of steel corresponds to 2.12 percent of the gross cross-sectional area of the shaft. The spirals consist of No. 4 bars spaced along the axis of the shafts at 4 inch. 


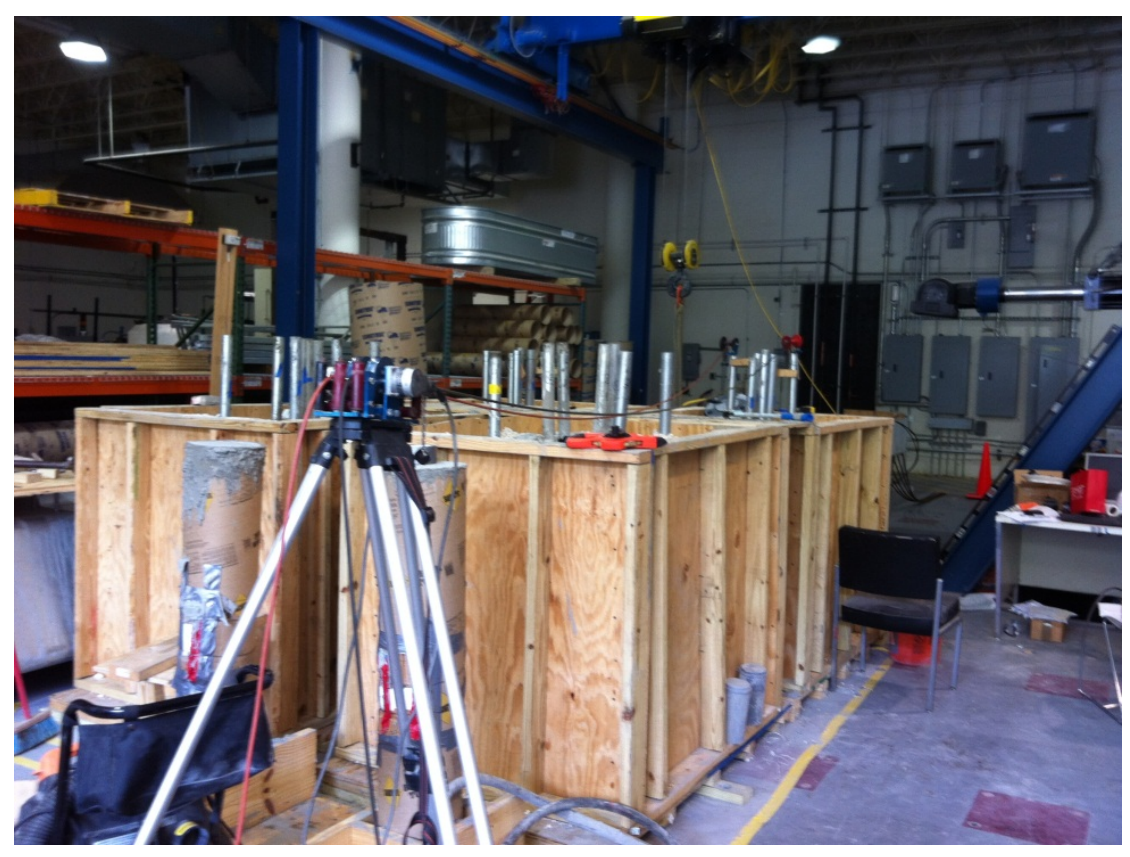

Figure 3.2. CSL Test Set up

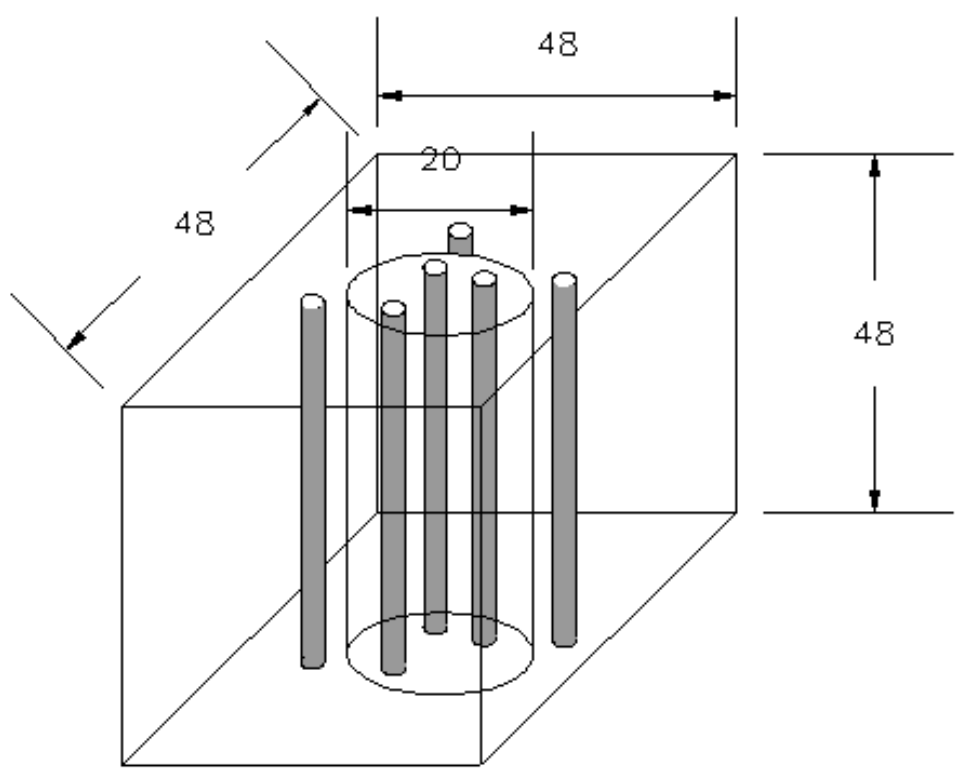

Figure 3.3: Drilled Shaft Sample Size

The number of access tubes required in order to conduct the cross-hole sonic logging tests is very important. For each specimen, three access tubes were installed 
inside the cage. Each tube is fixed at the end and at two points throughout the length of the shaft (Figure 3.4). First, a preliminary sample was built to find out a proper parameter that can be related to the thickness of concrete outside the cage. The preliminary sample has three inside tube with 4, 5, and 7 inches distances from the edge of the shaft. Second, two samples (samples 1 and 2) were built to develop the model for various concrete thicknesses from 2 inches to 7 inches. Sample 1 covers concrete thicknesses of 4, 5, and 6 inches and sample 2 covers concrete thicknesses of 2, 3, and 7 inches. Third, two samples (sample 3 and 4) were built to validate the model. Sample 3 has four inside galvanized tubes with $3.5,4.5,5.5$, and 6.5 inches distances from the edge of the drilled shaft. Sample 4 has four inside galvanized tubes with 3, 4, 5, and 6 inches distances from the edge. Samples 3 and 4 were tested two weeks after concrete placement to validate the model provided from samples 1 and 2 .

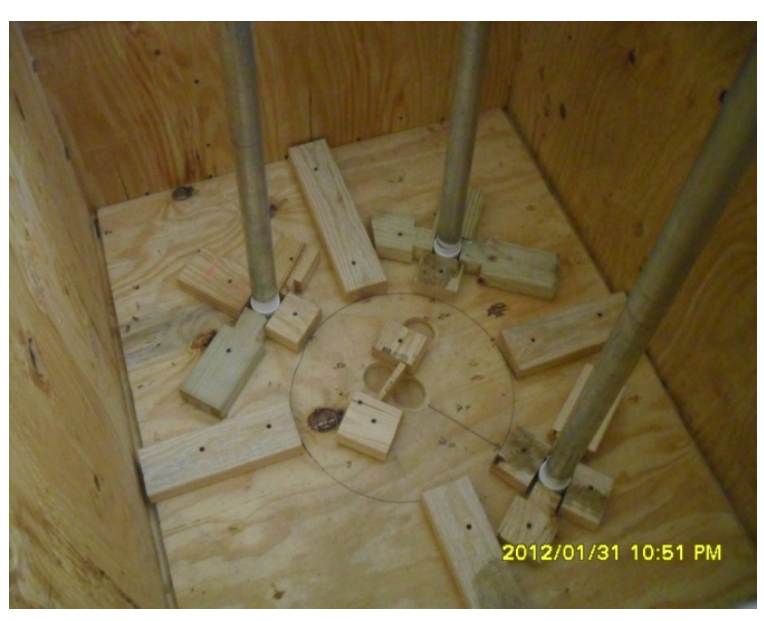

(a)

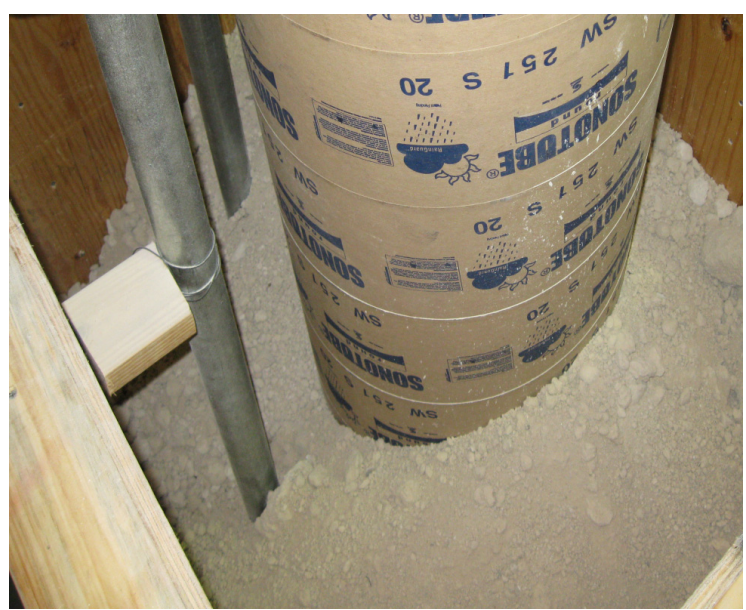

(b)

Figure 3.4. (a) Installing the Outside Galvanized Tubes, (b) Installing the Sona-tube 
For each sample, eight cubic yards of dry limestone with a unit weight of $80 \mathrm{lb} / \mathrm{ft}^{3}$ were used for the soil outside the sona-tube. While pouring limestone inside the framework, the soil is compacted in three lifts. Concrete with 7,000 psi compressive strength was placed inside the sona-tube (Figure 3.5a). The sona-tube was then removed using an overhead crane (Figure 3.5b). The concrete was then vibrated inside the drilled shaft to have a drilled shaft with different diameter through the length. Vibration will cause the concrete to penetrate inside the soil and create a perfect bond between the soil and concrete. The galvanized tubes were aligned to have the same distance of 3 inches from the edge while the concrete is fresh.

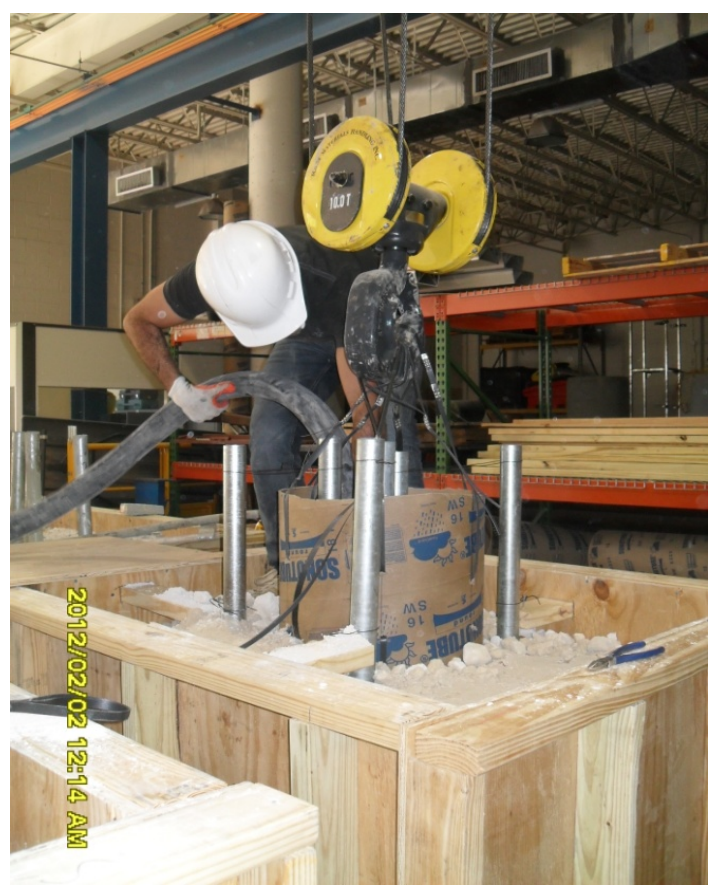

(a)

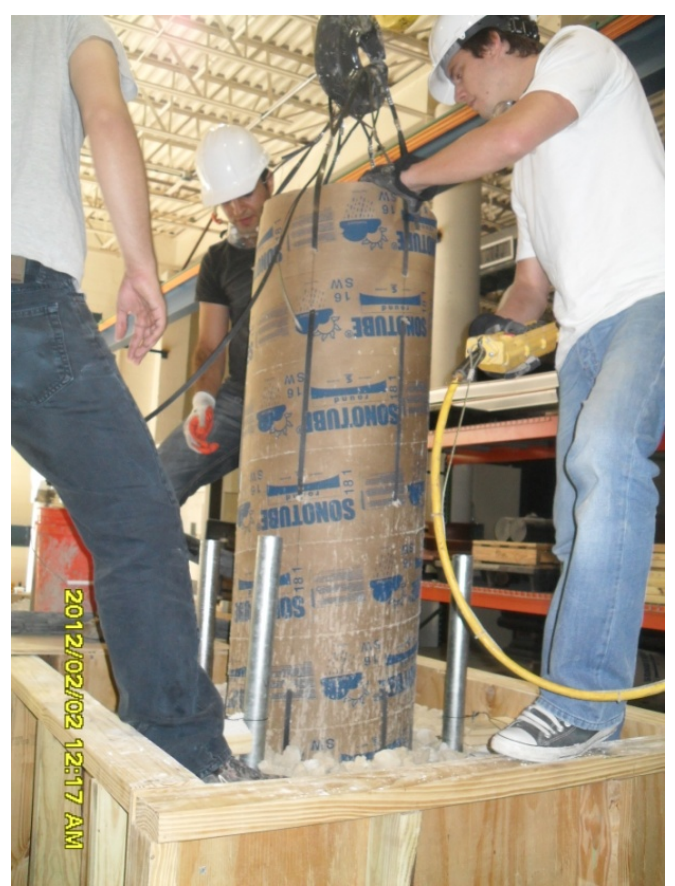

(b)

Figure 3.5: (a) Concrete Placement inside the Sona-tube, (b) Taking out the Sona-tube using Crane 


\section{Test Procedure}

The procedure to get the diameter of the drilled shaft is to perform the CSL test between an inside and an outside tube, and apply a signal processing on the results to analyze the data from the CHA software. Five drilled shaft sample were tested (Figure 3.6a). One preliminary sample was tested; two samples were tested to develop the concrete thickness versus amplitude of the signal model, and two samples were used as validation models. Before testing a shaft, the access tubes were checked for free access and filled with water to obtain good acoustic coupling. Two probes connected to pulleys are then inserted into the tubes, at least one of which is equipped with a depth meter (Figure 3.6b). The emitter and receiver probes are then lowered into the tubes. After reaching the bottom of the tubes, the probes are then pulled simultaneously upwards with smooth motion until they reach the top. During this time the emitter produces a continuous series of pulses, sending waves in all directions. For each profile in the shaft, the following items are plotted: (a) first arrival time (FAT) of each pulse versus depth and (b) relative energy versus depth.

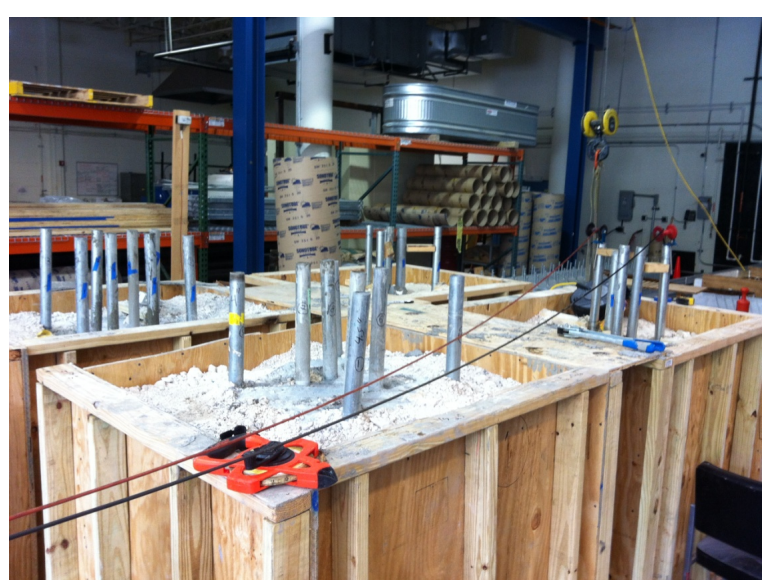

(a)

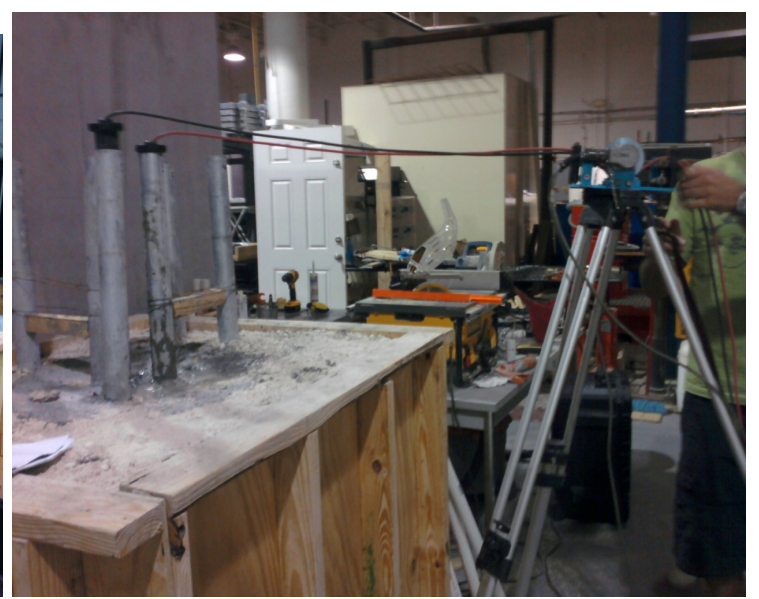

(b)

Figure 3.6: CSL Test on the Drilled Shaft Samples 
Three CSL tests were performed between the tubes inside the concrete (tubes 4-5, 4-6, and 5-6) and three CSL tests between inside and outside tubes (tubes 1-4, 2-5, and 36) in the preliminary sample one week after concrete placement. Figure $3.7 \mathrm{a}$ shows the CSL tube arrangements for the preliminary sample and samples 1 and 2 with three inside tubes and three outside tubes. Figure $3.7 \mathrm{~b}$ shows the validation samples with four inside tubes and four outside tubes.

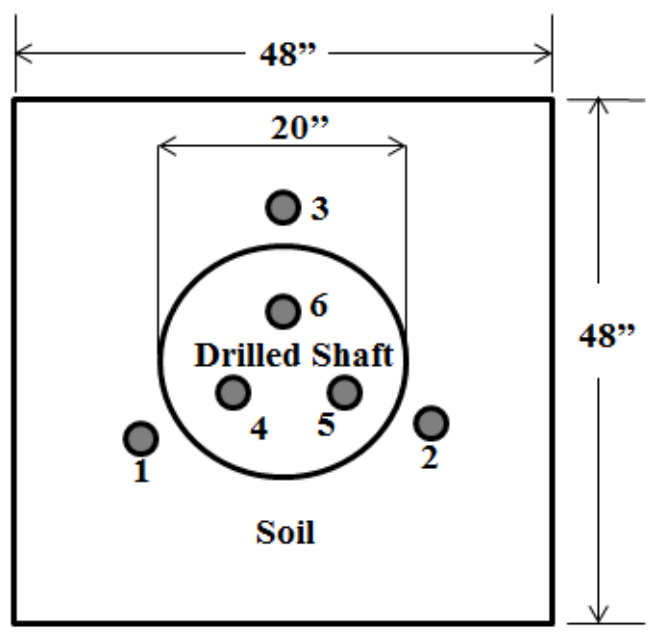

(a) Preliminary Sample and Samples 1 and 2

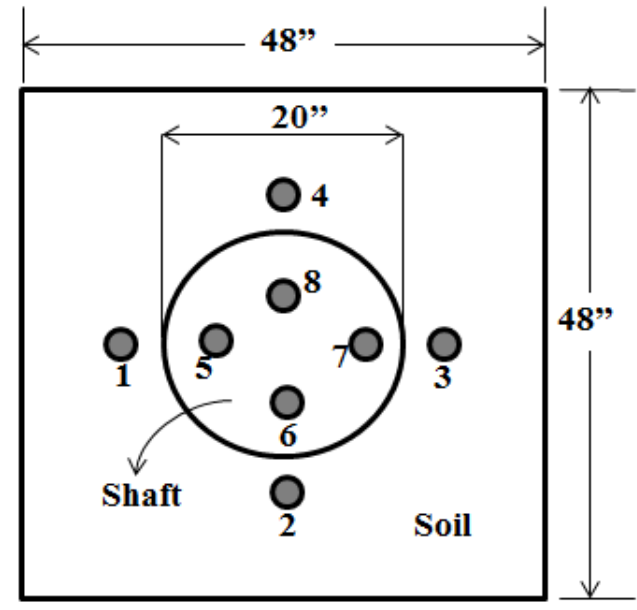

(b) Samples 3 and 4

Figure 3.7: CSL Tubes Arrangement - Top View

\section{Test Results}

The first output is the shape of the FAT versus depth plot. As long as FAT is more or less constant, it indicates that there is no change in concrete quality between the tubes along the shaft. A local increase of the arrival time is considered as an anomaly that may be the result of an obstacle (or flaw) on the straight path between the probes at the corresponding depth. The ultrasonic waves will either travel through this flaw at a reduced velocity or bypass it, with a respective increase in travel time. Experimental 
work (Stain and Williams 1991) indicated that lower-strength concrete has little effect on either transmission time or signal attenuation.

Energy is the second useful output obtained from the ultrasonic test. It is true that in uniform concrete, both energy and FAT depend on the distance traveled, but still it pays to study them separately. The main reason for this is that, unlike FAT which can assume many values, energy is practically invariant. If the waves pass through an inclusion, both parameters should be affected. A local increase in FAT without a corresponding decrease in energy may mean that the wrong FAT picking method has been used. If, on the other hand there is a decrease of the measured energy without an increase in FAT is noticed, it usually is a result of a constriction of the travel path and the defect is located out of the straight line connecting the probes.

Time domain data can easily be obtained from the data acquisition signal. The horizontal axis in the data acquisition signal is the data point, and it should be divided by the frequency to determine time as in the following equation:

$t=n \cdot T=\frac{n}{f}$

where $t$ is the time, $n$ is data points, $f$ is frequency, and $T$ is the period. The most important part of the CHA software is the data acquisition signal graph, which is based on the time domain data. Figure 3.8 is the time domain for two separate CSL tests on the preliminary drilled shaft sample at the height of 31.5 inches. One test is between two tubes in concrete $(\mathrm{C}-\mathrm{C})$ and the other test is between one tube in concrete and one tube in soil (C-S). Since, limestone material is not as dense as concrete, it can be seen that FAT for $\mathrm{C}-\mathrm{S}$ test is much higher than that in the $\mathrm{C}-\mathrm{C}$ test; this is because the ultrasonic wave 
travel time is much higher. From the results of the preliminary test, a proper parameter that can be correlated to the concrete thickness outside the cage can be found. Drawing different parameters versus concrete thicknesses such as FAT, energy, velocity, strength of signal, and amplitude of signal shows that maximum amplitude of the signal has the best correlation with concrete thickness. Maximum amplitude of signal is obtainable from the frequency domain data. Therefore, time domain data has to be converted to the frequency domain data to calculate the maximum amplitude of the signal.

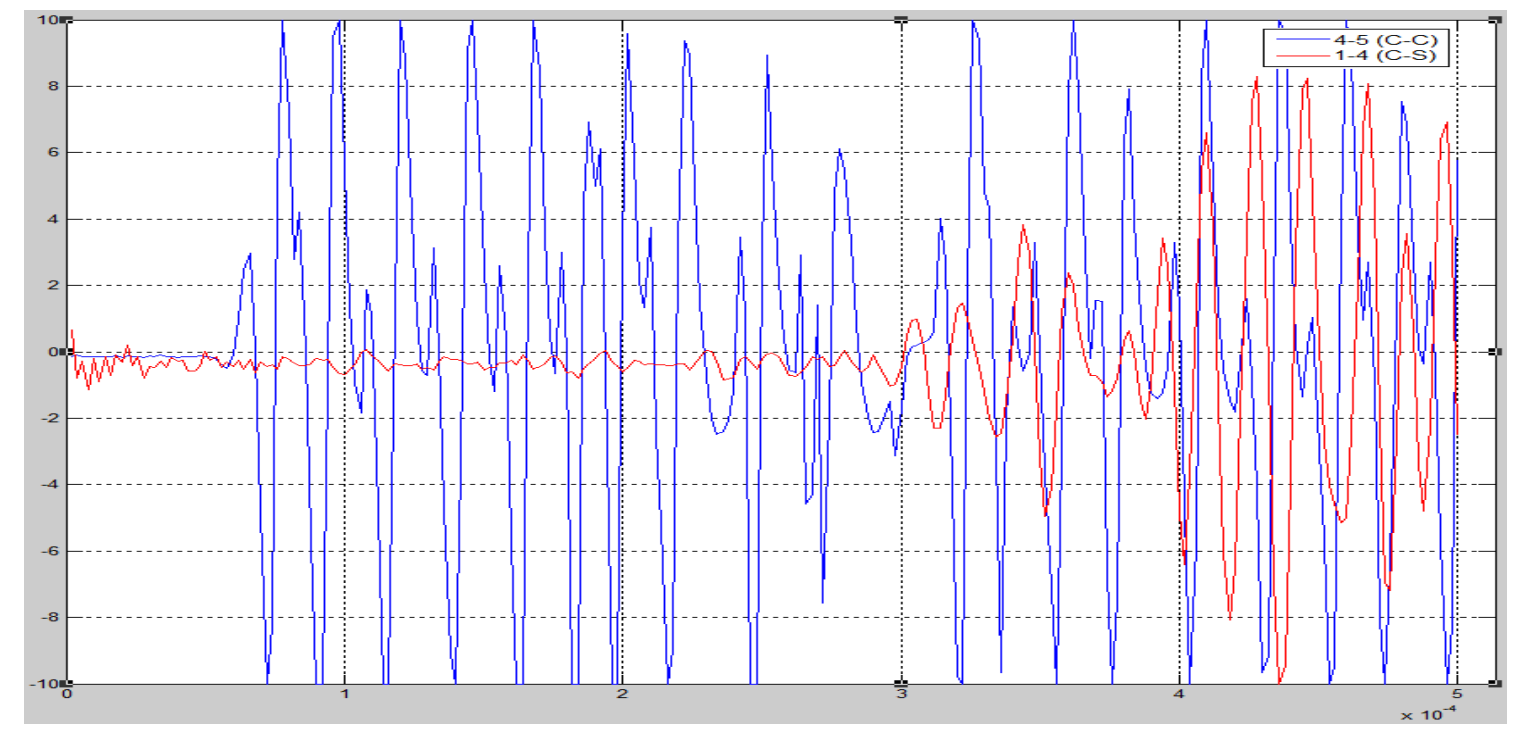

Figure 3.8: Time-Domain (C-C and C-S)

\section{Signal Processing On the CSL Test Results}

Without a frequency domain, one is not able to realize the maximum strength or amplitude of the signal received by the receiver probe. This indicates that the time domain data has to be converted to frequency domain data in order to obtain the frequency versus amplitude plot. Fast Fourier Transform (FFT) will be used in a Matlab 
program to perform this signal processing. Discrete Fourier Transform (DFT) is a specific kind of discrete transform, used in Fourier analysis. It transforms one function into another, which is called the frequency domain. DFT is widely used in signal processing to analyze the frequencies, because it takes a discrete signal in the time domain and transforms that signal into its discrete frequency domain representation. The DFT transforms time-based data into frequency-based data. The DFT of a vector $x$ of length $n$ is another vector $y$ of length $n$ :

$y_{p+1}=\sum_{j=0}^{n-1} \omega^{j p} x_{j+1}$

where $\omega$ is a complex $n^{\text {th }}$ root of unity and is defined by:

$\omega=e^{-2 \pi i / n}$

FFT is an efficient algorithm to compute the DFT and its inverse with a significant speed increase. The functions $\mathrm{Y}=\mathrm{FFT}(\mathrm{x})$ implement the transform using following equation:

$X(k)=\sum_{j=1}^{n} x(j) \omega_{n}^{(j-1)(k-1)}$

where $\omega$ is an $n^{\text {th }}$ root of unity.

$\omega_{n}=e^{-2 \pi i / n}$

It is difficult to identify the frequency components by looking at the original signal. Converting it to the frequency domain, the discrete Fourier transform of the noisy signal $y$ is found by taking the fast Fourier transform (FFT). The FFT utilizes some algorithms to do the same thing as the DTF, but in much less time. The following process was carried out using Matlab to obtain the maximum amplitude of the received signal from the data acquisition in CHA. 
1) Change the data acquisition signal to time domain data, 2) Transform the timedomain data to frequency-domain data using FFT, 3) De-noise the frequency-domain data, 4) Obtain the polynomial tenth degree curve fitting from the de-noised data using a Polyfit process in Matlab, and 5) Get the maximum amplitude of the signal recorded at the receiver probe.

Six CSL tests were performed in the preliminary sample. Three C-C tests were performed between tubes 4-5, 4-6, and 5-6 and three C-S tests between tubes 1-4, 2-5, and 3-6. Figure 3.9 shows the frequency domain graph for those two tests, which is obtained from time domain using FFT in the preliminary sample. Figure 3.10 shows the frequency domain curve after de-noising and fitting with polynomial tenth degree. Figure 3.8 also shows that the maximum amplitude of the signal is $7.2 \times 10^{-4}$ for $\mathrm{C}-\mathrm{C}$ test and is $2.8 \times 10^{-4}$ for C-S test with concrete thickness of 7 inches. Figure 3.11 compares the time domain for two C-C tests, and it can be seen that both tests have exactly the same FAT; Figure 3.12 shows that they almost have the same maximum amplitude of signal. Figure 3.13 compare two C-S tests and it shows that for test $2-5$ with concrete thickness of 5 inches, the maximum amplitude of the signal is about $8 \times 10^{-5}$, and for test 3-6 with concrete thickness of 4 inches, it is $6.5 \times 10^{-5}$. All these results from the preliminary sample show that the concrete thickness can be correlated to the maximum amplitude of the signal. More drilled shaft samples need to be tested in order to further develop this relationship. All results show that the maximum amplitude of signal occurs at $500 \mathrm{kHz}$. This is because the data acquisition signal graph includes 250 data points, sampled at 500 $\mathrm{KHz}$ in the CHA software results. 


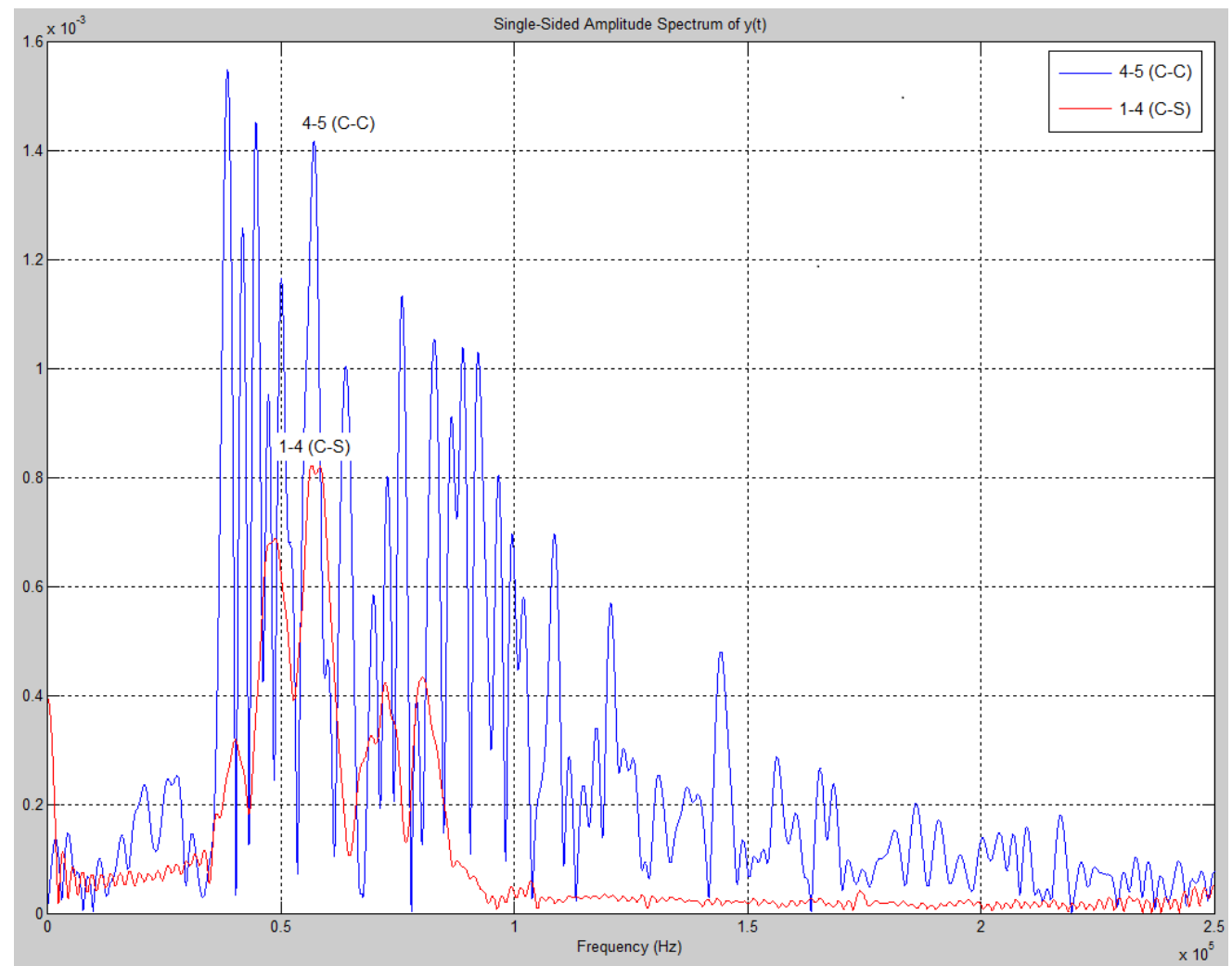

Figure 3.9: Frequency domain graph

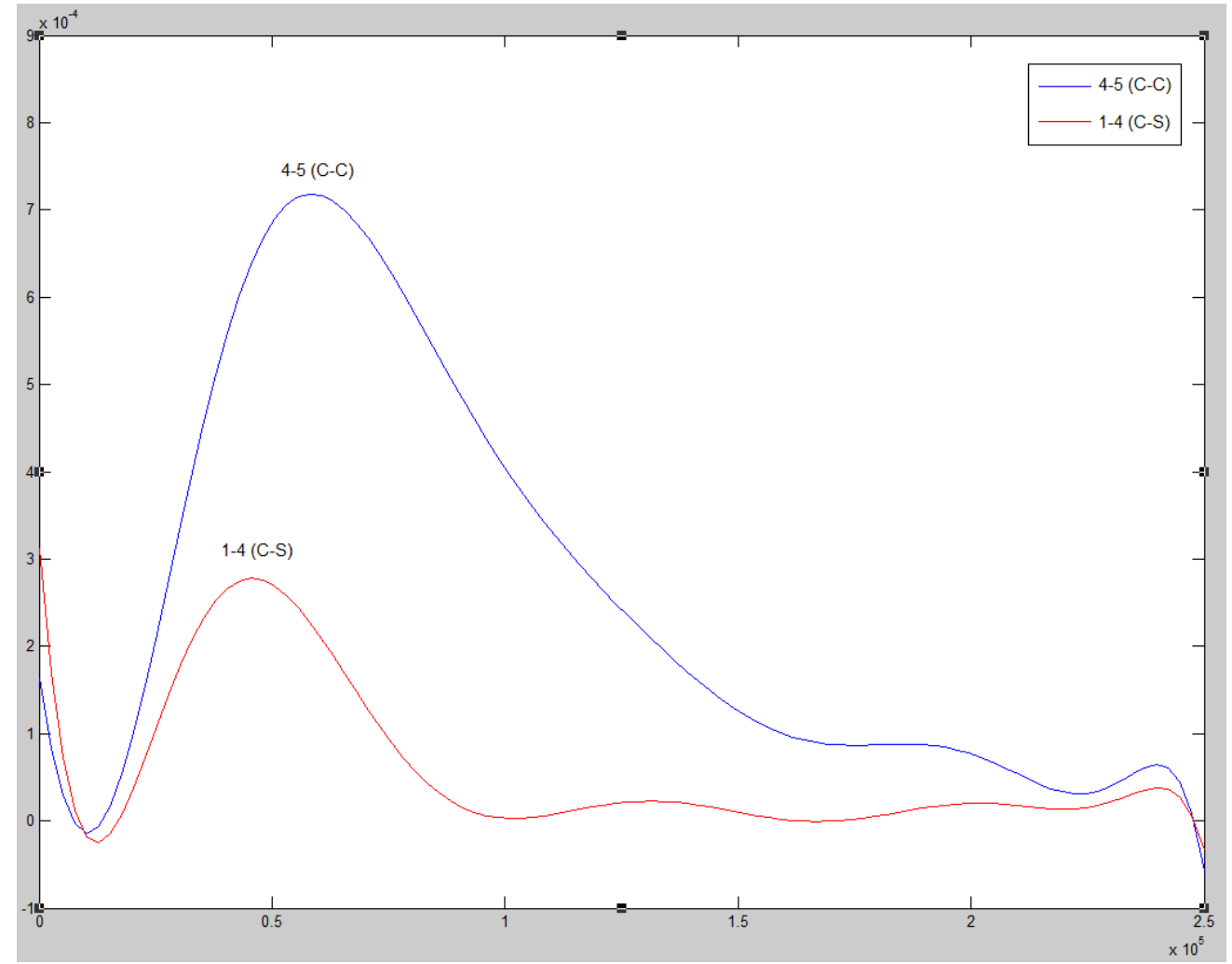

Figure 3.10: De-noised and Fitted Frequency Domain curve (4-5 and 1-4) 


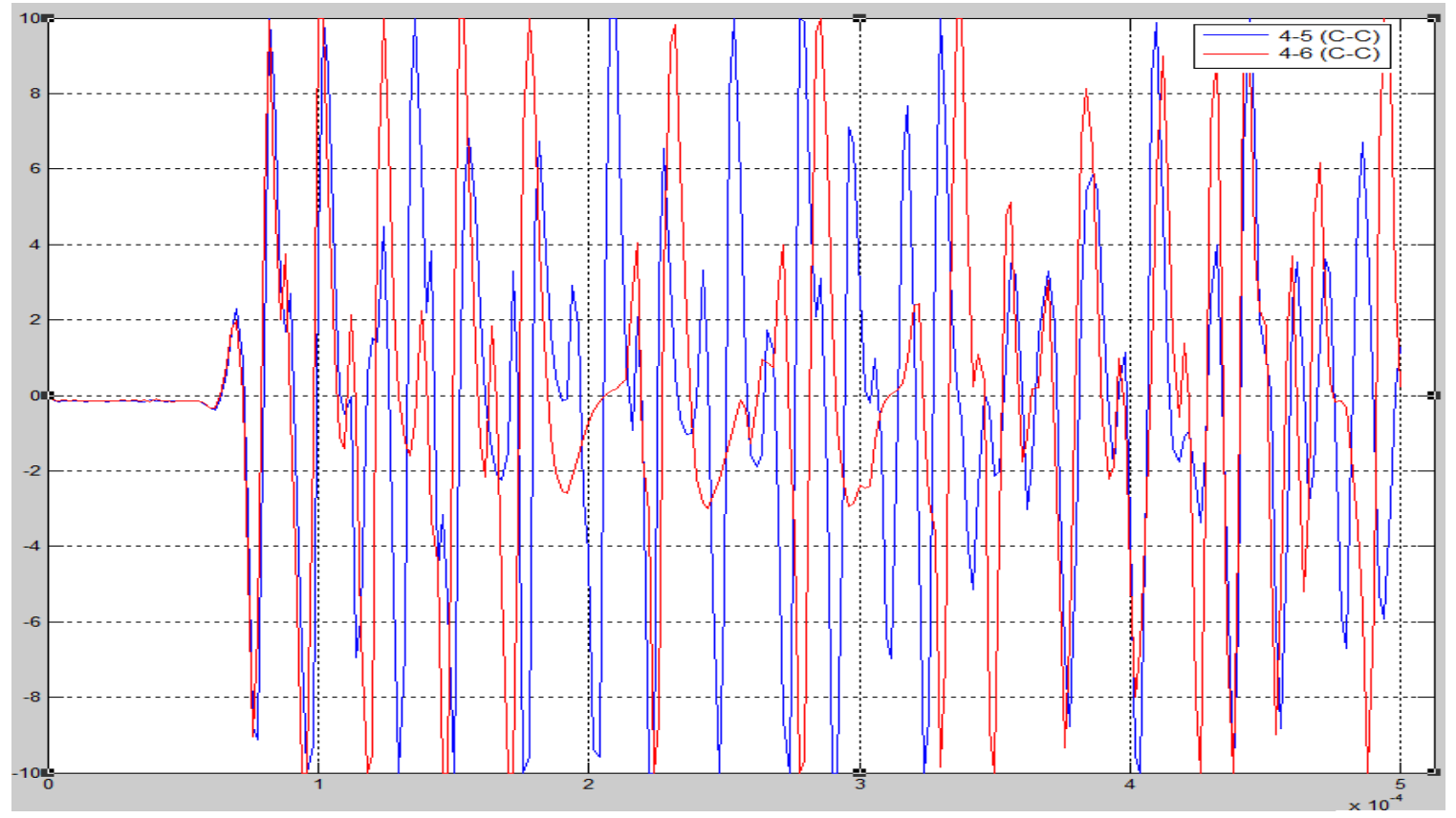

Figure 3.11: Time-Domain (C-C and C-C)

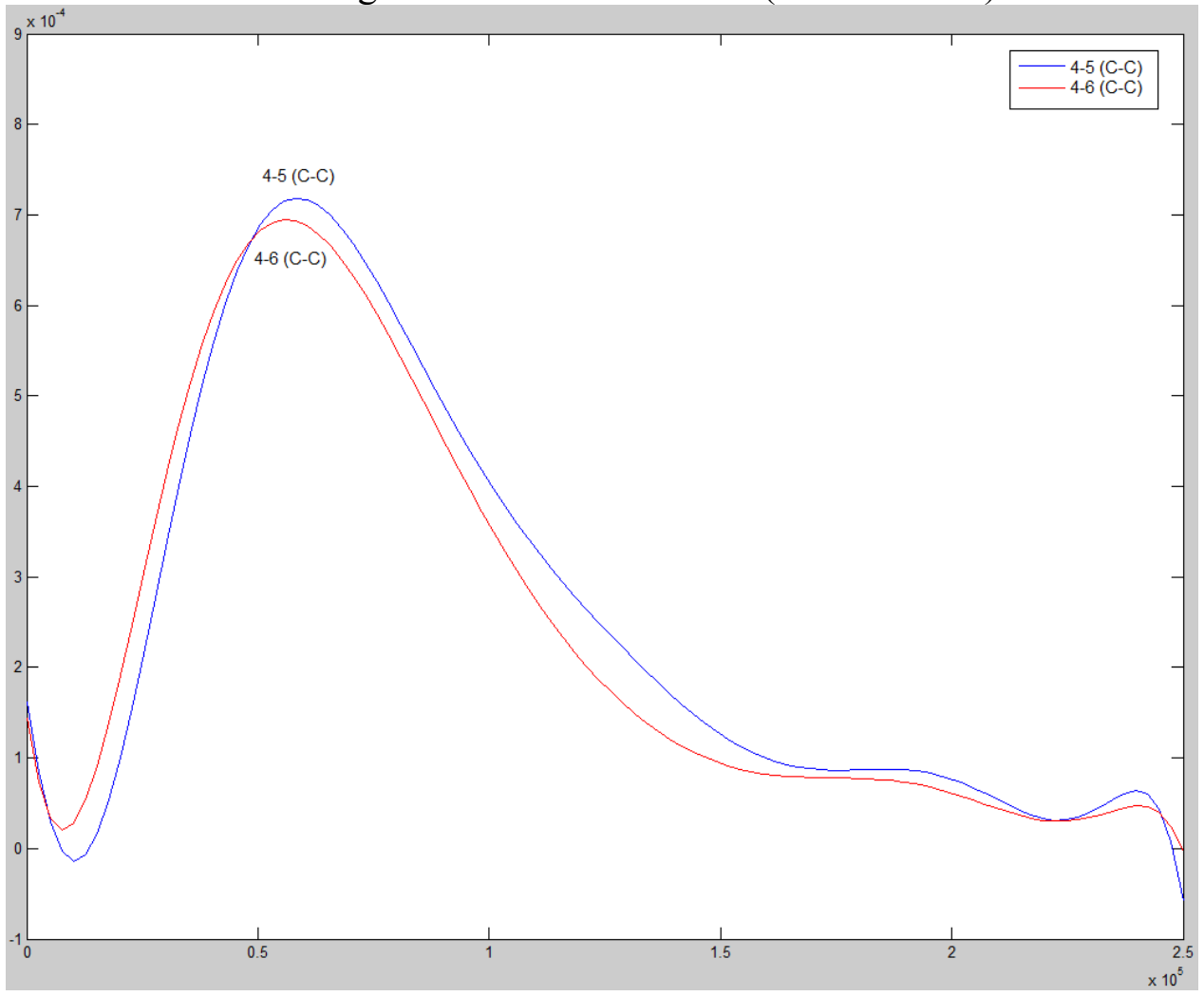

Figure 3.12: De-noised and Fitted Frequency Domain curve (4-5 and 4-6) 


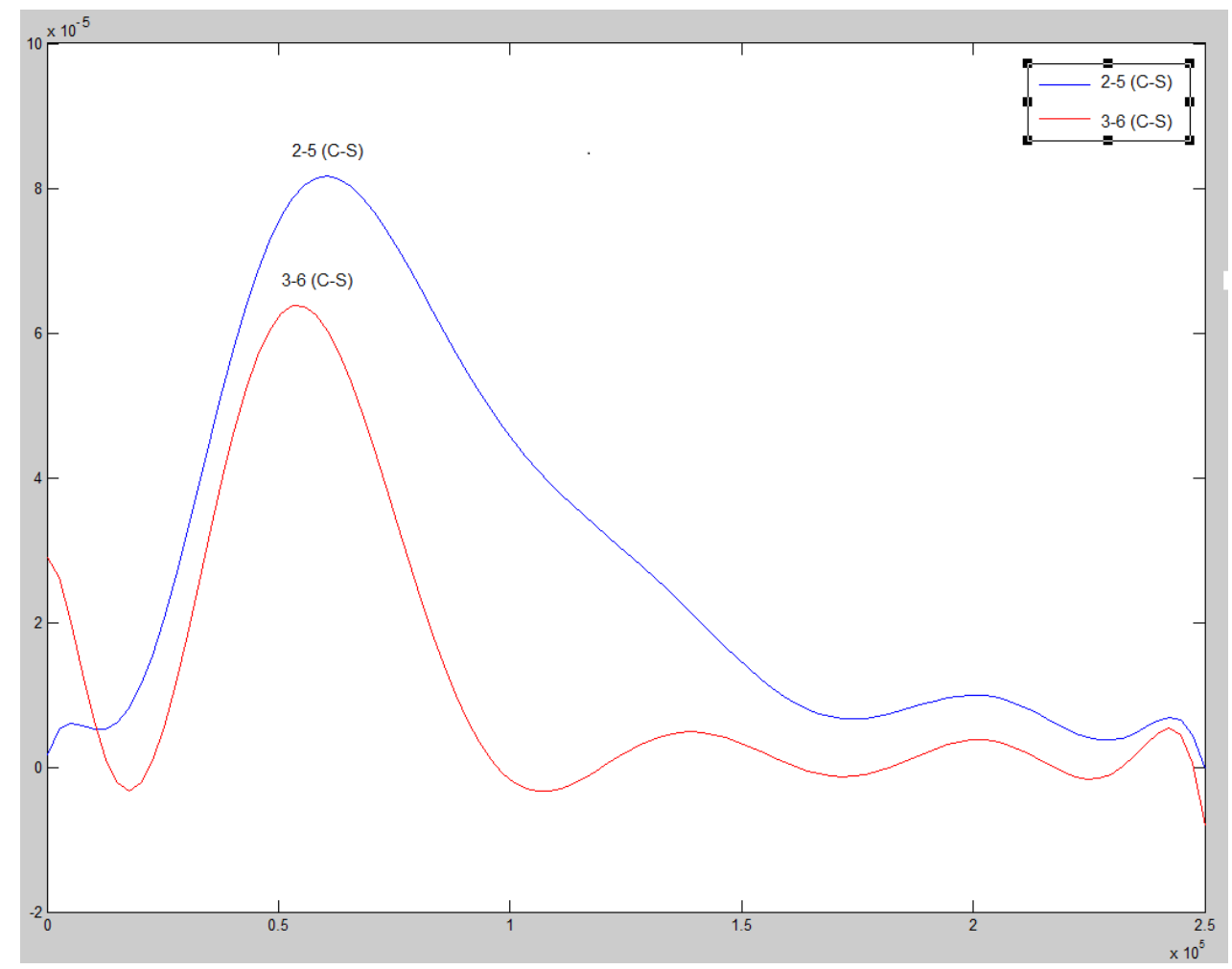

Figure 3.13: De-noised and Fitted Frequency Domain curve (2-5 and 3-6)

Samples 1 and 2 were built in an effort to obtain more data points for the concrete thickness versus the maximum amplitude of signal. Figure 3.14 shows the time domain for six tests that were performed on samples 1 and 2 at the depth of 3 feet from top of the shaft. Sample 1 has three inside galvanized tubes at 4, 5, and 6 inches away from the edge of the drilled shaft, and sample 2 has three inside galvanized tubes at 2, 3, and 7 inches away from the edge of the drilled shaft. For both samples 1 and 2, three tubes were installed outside the drilled shaft and inside soil at 3 inches away from the edge of the shaft, as shown in Figures 3.2 and 3.4. Both samples were tested one week after concrete placement in order to provide the concrete thickness versus maximum amplitude of signal 
curve. Figure 3.15 shows the frequency domain data and Figure 3.16 shows the de-noised and fitted curve for concrete thicknesses from 2 inches to 7 inches.

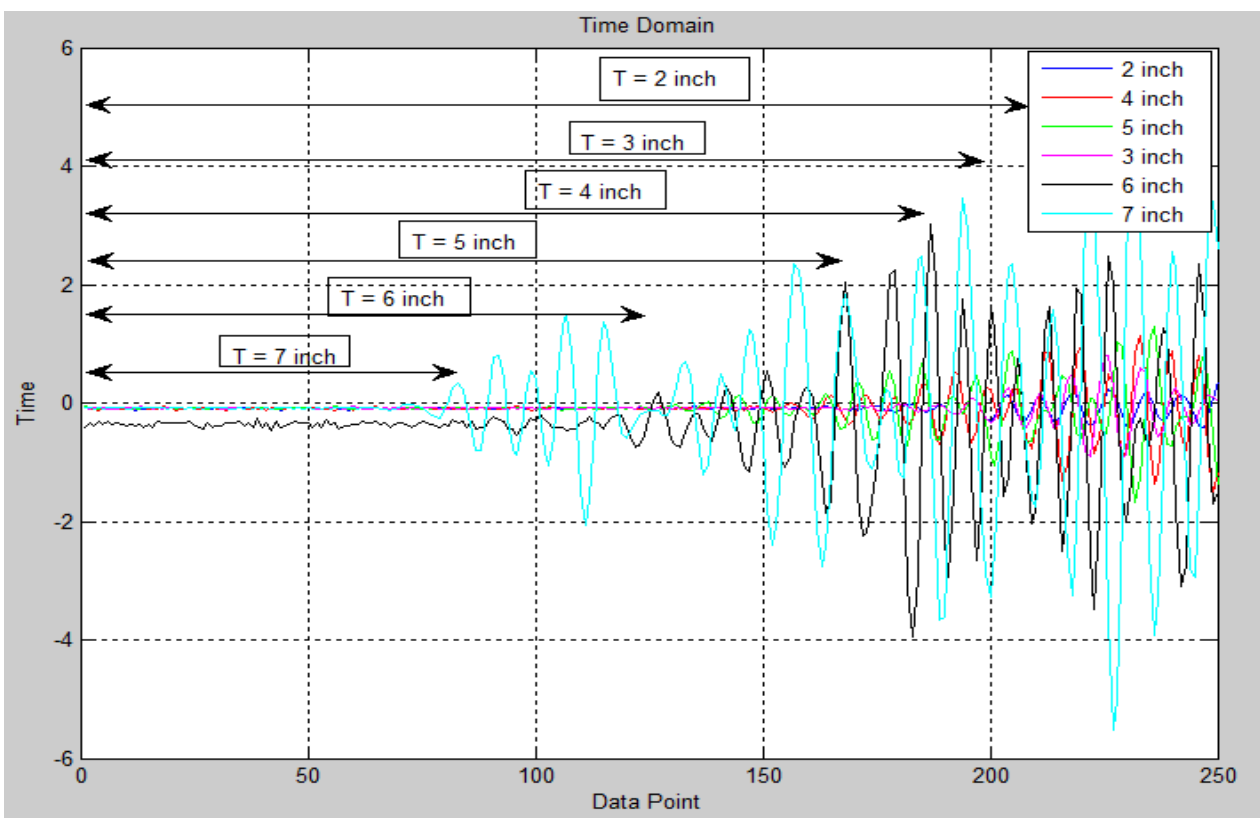

Figure 3.14: Time Domain Data in Sample 1 and 2

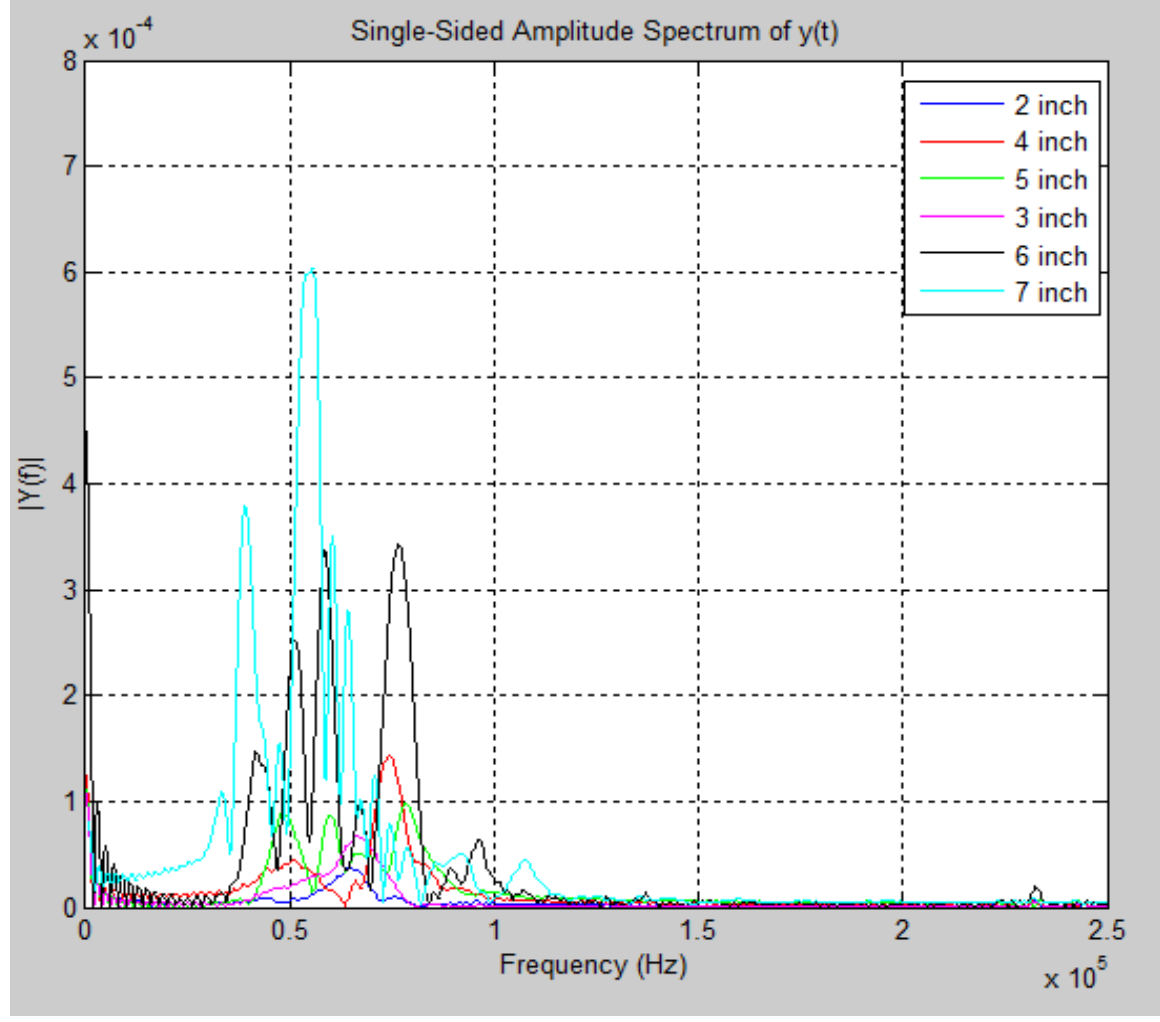

Figure 3.15: Frequency Domain Data in Sample 1 and 2 


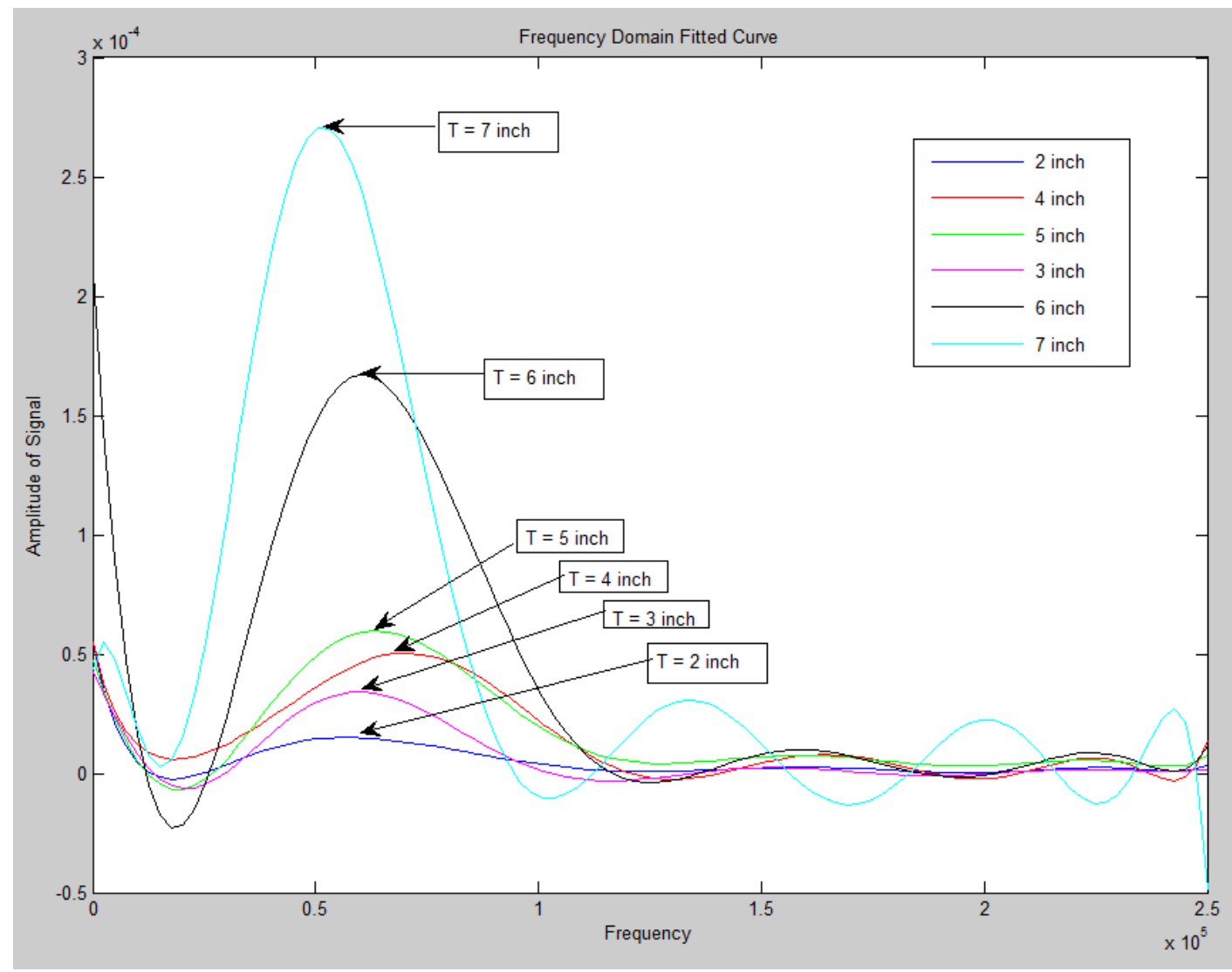

Figure 3.16: Amplitude of Signal versus Frequency

After 28 days when the samples are dry and strong enough, they can be opened so that the actual thickness of concrete can be measured at different depths. The length of each drilled shaft sample is 48 inches, and there are six inside tubes in both samples. There are three inside tubes in sample 1 and three inside tubes in sample 2, which add up to 6 different concrete thicknesses. Two hundred eighty eight $(6 \times 48=288)$ data points can be derived from the results of the signal processing at each inch of drilled shaft depth. An empirical curve can then be drawn for the maximum amplitude of signal versus concrete thickness. Figure 3.17 shows the maximum amplitude of the signal for concrete thicknesses of 2, 3, and 7 inches in sample 1, and Figure 3.18 shows the maximum amplitude of the signal for concrete thicknesses of 4, 5, and 6 inches in sample 2. 


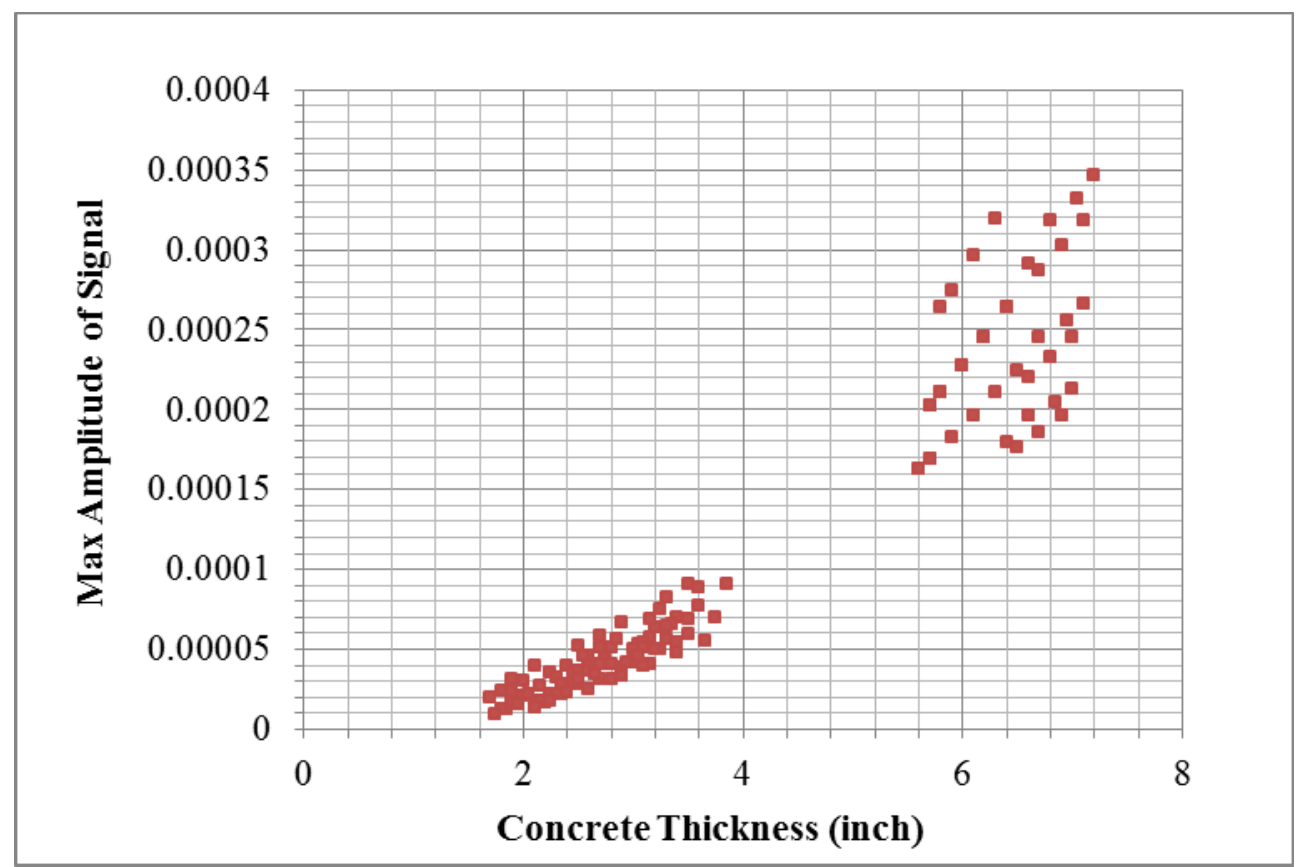

Figure 3.17: Concrete Thickness versus Maximum Amplitude of Signal for Sample 1

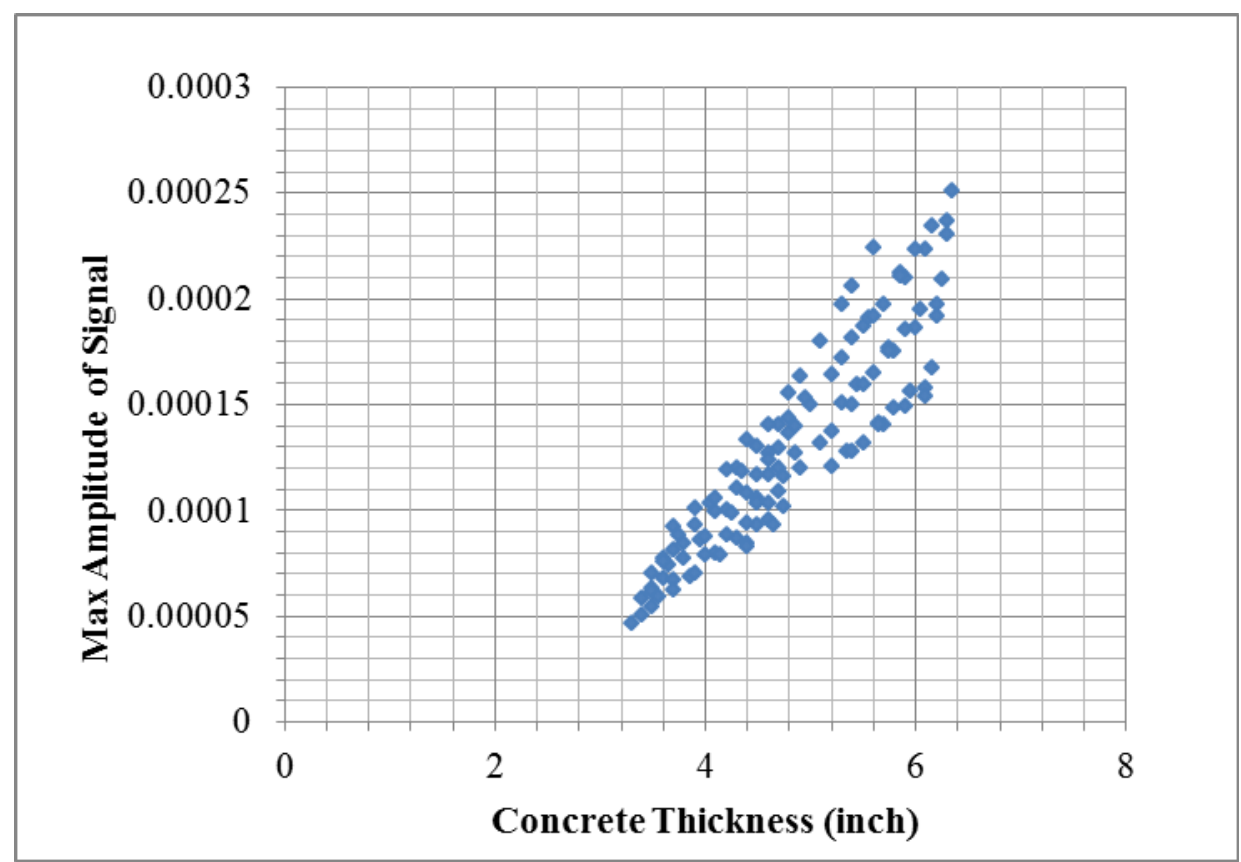

Figure 3.18: Concrete Thickness with Maximum Amplitude of Signal for Sample 2

Figures 3.17 and 3.18 can be superimposed as shown in Figure 3.19 to show the variation of amplitude of the signal for concrete thicknesses from 2 inches to 7 inches. Figure 3.19 
shows that with increase in concrete thickness, the error in the thickness increases. Also, a second degree polynomial relationship can be obtained as shown in Figure 3.20.

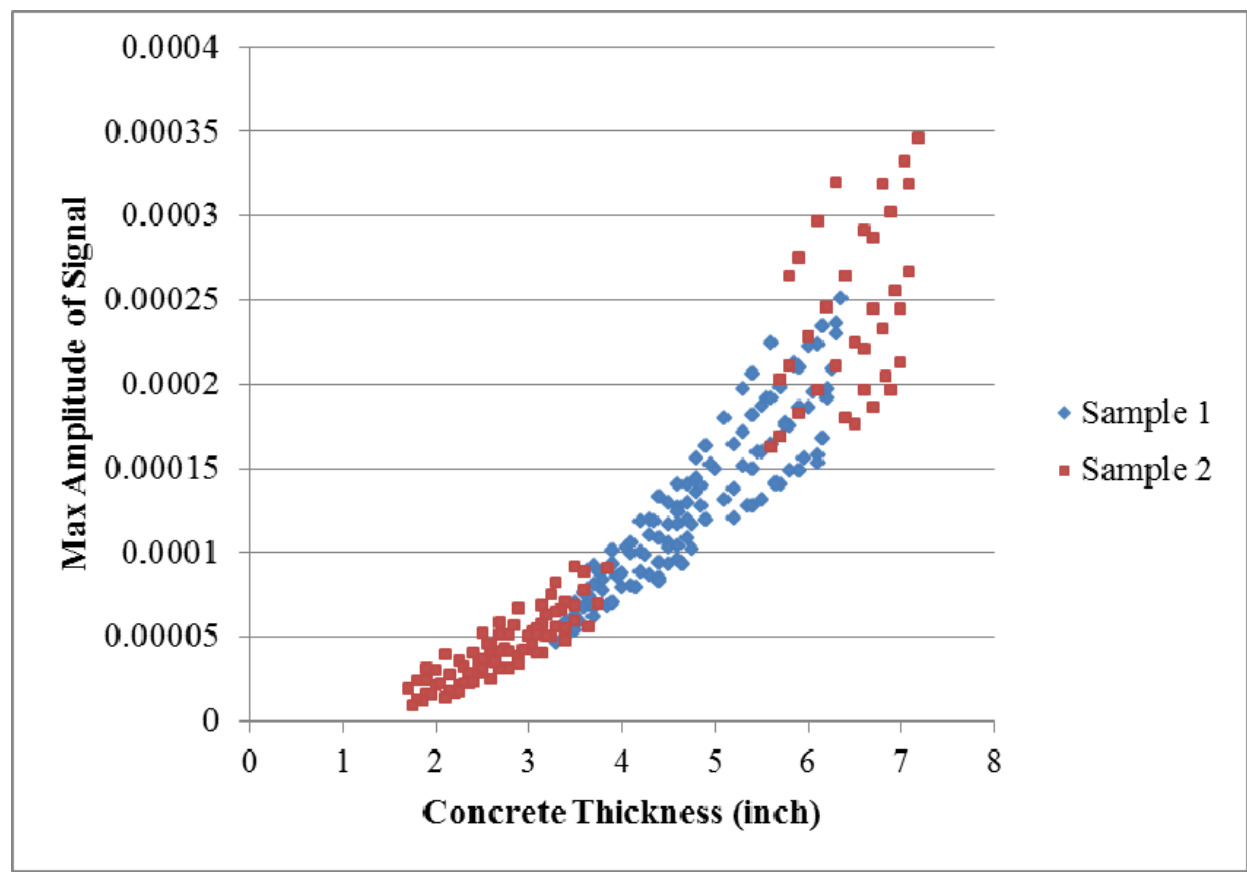

Figure 3.19: Variation of Concrete Thickness with Maximum Amplitude of Signal

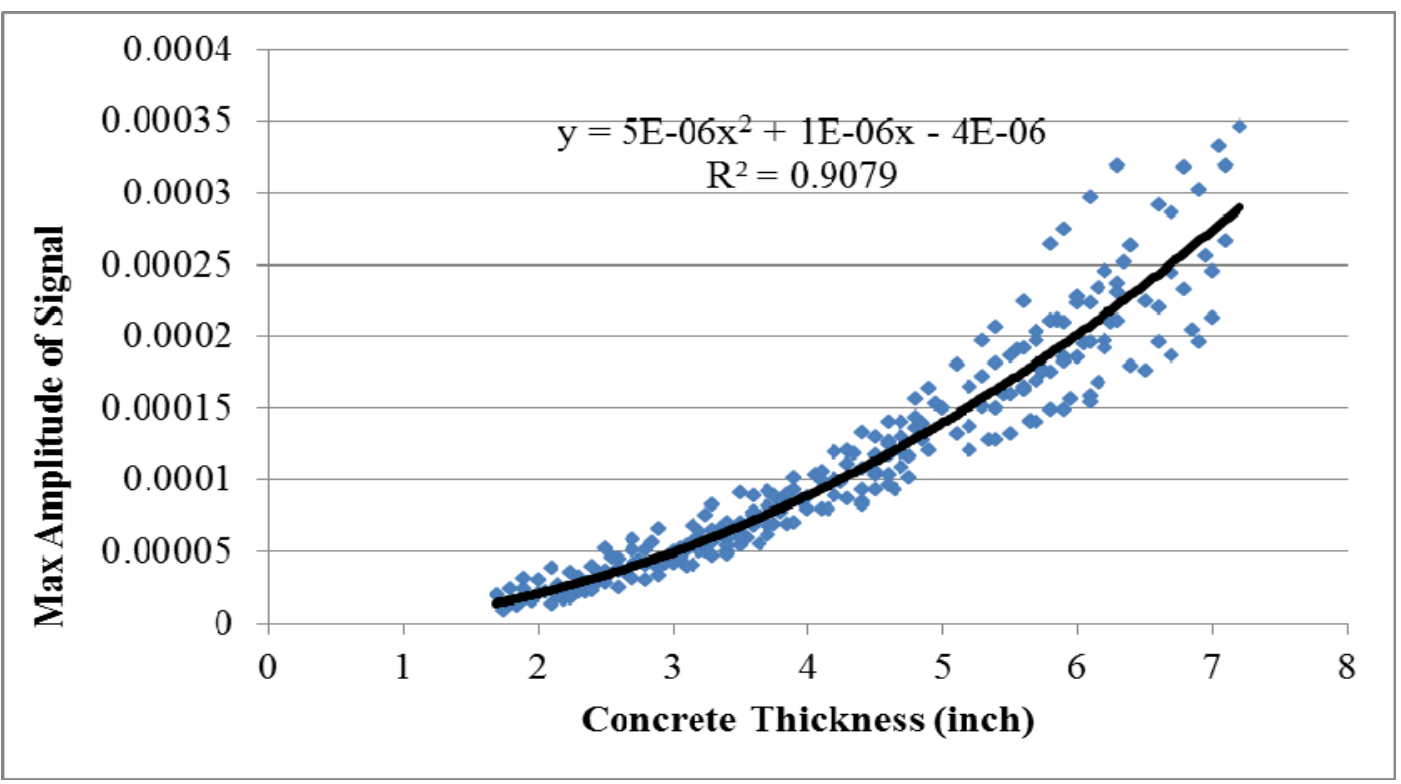

Figure 3.20: Trend-line Fitted Curve on Concrete Thickness versus Maximum Amplitude of Signal Data Points 
Using 288 data points, the following empirical relationship can be derived for estimating the thickness of concrete outside the cage in drilled shaft foundation based on the maximum amplitude of the signal in that height.

$$
T=\frac{1}{10}\left(-1+\sqrt{81+2 \times 10^{7} A}\right)
$$

where $A$ is maximum amplitude of the signal and $T$ is thickness of concrete as shown in Figure 3.20. When the maximum amplitude of signal is known from the CSL test results at each depth, the thickness of concrete in each side of the cage can then be calculated from Equation (11). The diameter of the drilled shaft $(D)$ is then calculated using Equation (12) as shown in Figure 3.21.

$$
D=T_{1}+T_{2}+S+d
$$

$T_{1}$ and $T_{2}$ are the concrete thicknesses outside the cage as shown in Figure 3.21, $S$ is the center to center distance between the CSL tubes, and $d$ is diameter of CSL tube. The recommended access tubes are nominal 1.5 to 2.0 inches $(38$ to $50 \mathrm{~mm}$ ) inside diameter. In this study galvanized tube with 2 inch inside diameter was used. 


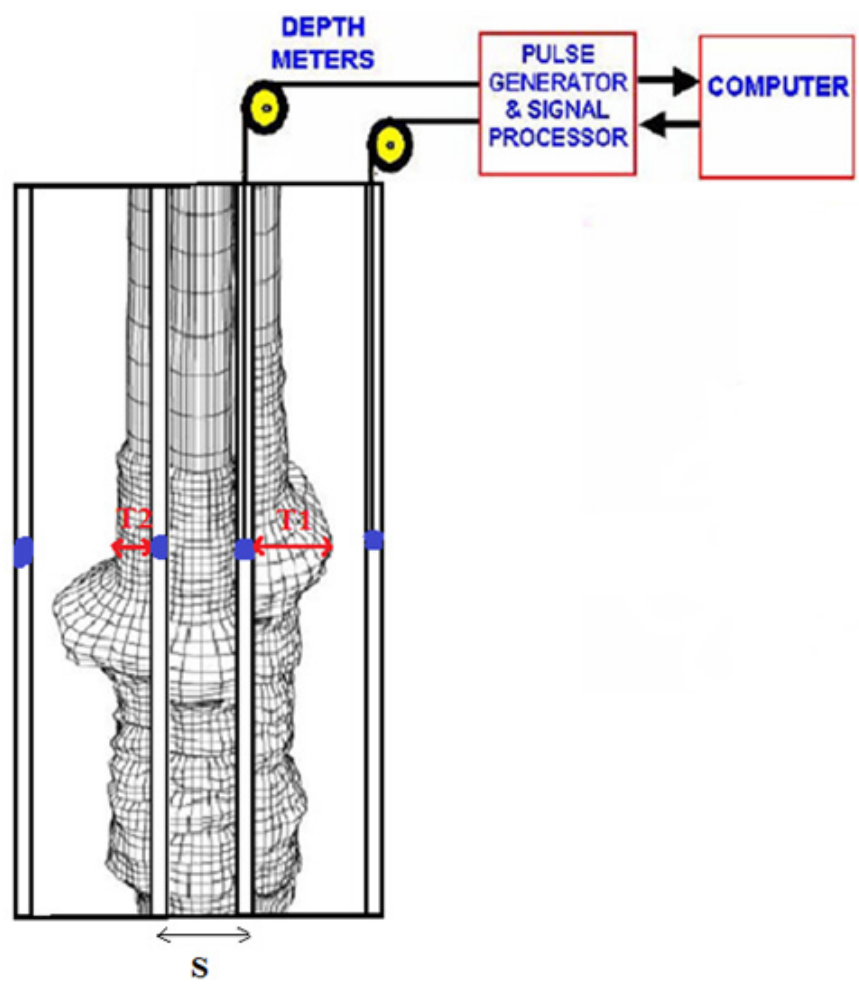

Figure 3.21: CSL Test between an Inside Tube and Outside Tube

\section{Validation Samples}

The last two drilled shaft samples (samples 3 and 4) were built to validate the model that was developed to find the concrete thickness. Sample 3 has four inside galvanized tubes at $3.5,4.5,5.5$, and 6.5 inches away from the edge of the drilled shaft as shown in Figure 3.5b. Sample 4 has four inside galvanized tubes at 3, 4, 5, and 6 inches away from the edge of the drilled shaft. It has also four outside tubes with 3 inches away from the edge of the drilled shaft inside the soil. Same dry limestone soil is used in samples 3 and 4 . Four CSL tests were carried out between tubes 1-5, 2-6, 3-7, and 4-8 two weeks after concrete placement. Table 2 shows the results that were found in sample 3 over a depth of 3 feet. After four weeks, the validation samples were opened and the actual diameters 
of the shafts were measured and compared with the diameters calculated from Equations (11) and (12).

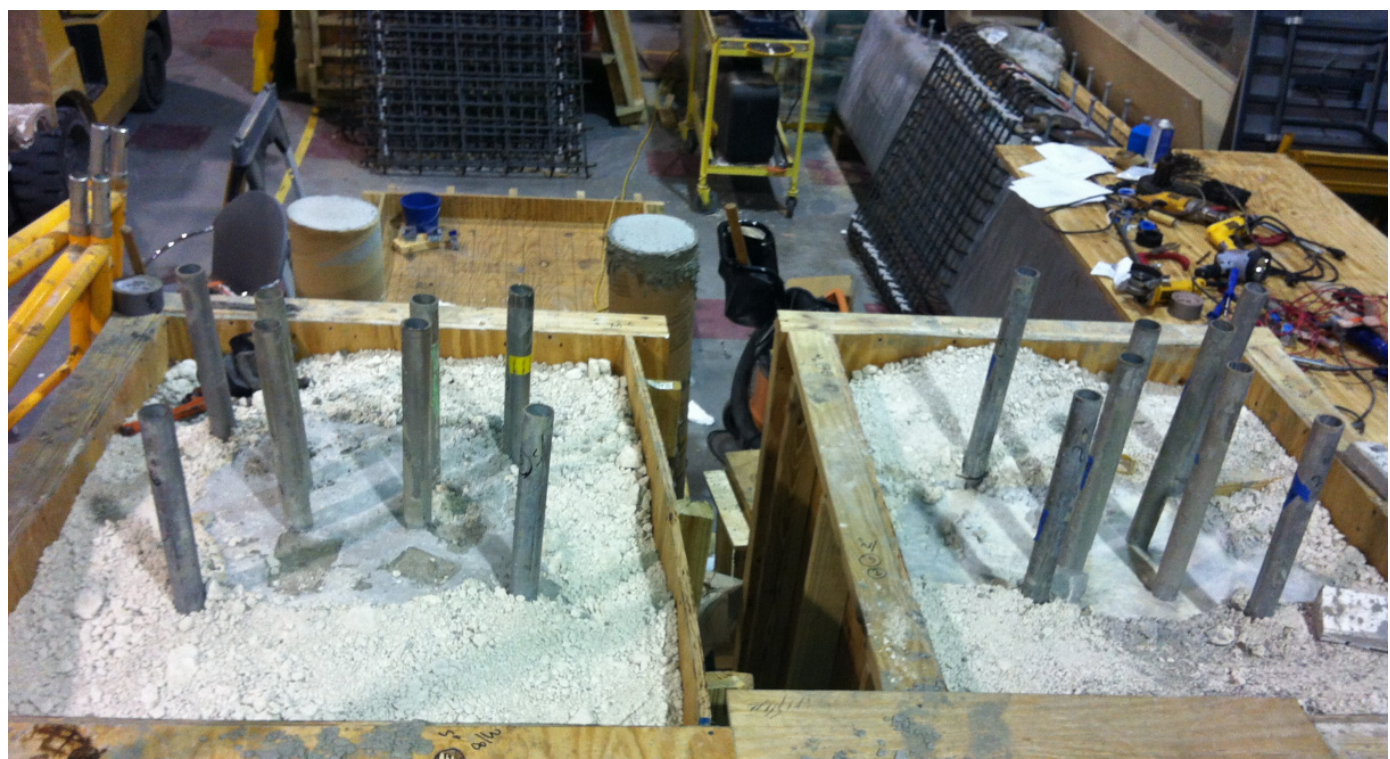

Figure 3.22: Samples 3 and 4

\begin{tabular}{|c|c|c|c|c|c|c|}
\hline Tests & FAT & Energy & $\begin{array}{c}\text { Max } \\
\text { (millisec) }\end{array}$ & $\begin{array}{c}\text { Actual } \\
\text { Thickness } \\
\text { (millisec*volts) }\end{array}$ & $\begin{array}{c}\text { Thickness using } \\
\text { Equation (11) } \\
\text { (inch) }\end{array}$ & Error \\
\hline $1 \_5$ & 0.293 & $3.37 \mathrm{E}-04$ & 0.0000689 & 3.5 & 3.719685851 & 6.276739 \\
\hline $2 \_6$ & 0.311 & $3.31 \mathrm{E}-04$ & 0.00007823 & 4.5 & 3.956599561 & 12.07557 \\
\hline $3 \_7$ & 0.393 & $1.95 \mathrm{E}-04$ & 0.000185 & 5.5 & 6.048983656 & 9.981521 \\
\hline $4 \_8$ & 0.453 & $2.24 \mathrm{E}-04$ & 0.000244 & 6.5 & 6.943436661 & 6.822102 \\
\hline
\end{tabular}

Table 2: Sample 3 Results

\begin{tabular}{|c|c|c|c|c|c|c|}
\hline Tests & $\begin{array}{c}\text { FAT } \\
\text { (millisec) }\end{array}$ & $\begin{array}{c}\text { Energy } \\
\text { (millisec*volts) }\end{array}$ & $\begin{array}{c}\text { Max } \\
\text { Amplitude }\end{array}$ & $\begin{array}{c}\text { Actual } \\
\text { Thickness } \\
\text { (inch) }\end{array}$ & $\begin{array}{c}\text { Thickness using } \\
\text { Equation (11) } \\
\text { inch }\end{array}$ & $\begin{array}{c}\text { Error } \\
\%\end{array}$ \\
\hline $1 \_5$ & 0.157 & $2.61 \mathrm{E}-04$ & 0.0000581 & 3 & 3.426754882 & 14.22516 \\
\hline $2 \_6$ & 0.253 & $1.67 \mathrm{E}-04$ & 0.0000751 & 4 & 3.878693253 & 3.032669 \\
\hline $3 \_7$ & 0.363 & $1.95 \mathrm{E}-04$ & 0.0001552 & 5 & 5.542694392 & 10.85389 \\
\hline $4 \_8$ & 0.427 & $2.07 \mathrm{E}-04$ & 0.0001888 & 6 & 6.110475022 & 1.84125 \\
\hline
\end{tabular}

Table 3: Sample 4 Results 


\section{Conclusion}

1. A new method of determining an accurate measurement of the diameters of drilled shafts during construction that overcomes the limitations and inaccuracies of currently used methods was developed using down-hole nondestructive testing.

2. In order to obtain the exact diameter of the drilled shaft, the location of the border between the concrete and the soil had to be determined through the evaluation of the integrity of the concrete outside the cage. The methodology that was developed to obtain the diameter of the drilled shaft is economic, since it does not require the setup and use of another NDT device, but rather builds upon the CSL tests used to check the integrity of the inside concrete.

3. A second-degree polynomial relationship between concrete thicknesses and the maximum amplitude of the signal was derived with an average percent error of 8.5. Also, variation of concrete thickness with the maximum amplitude of the signal curve showed that with increasing thickness of concrete the error increases.

4. The maximum amplitude of the signal for various concrete thicknesses occurred at the same frequency of the data acquisition signal graph in CHA sampled at $500 \mathrm{KHz}$.

5. The FFT could not precisely locate the interface between the soil and the concrete. The FFT results showed a significant variation in the magnitude of the signal amplitude from concrete thickness of 5 inches to 6 and 7 inches.

6. While more preparation is required to install outside tubes for CSL testing offered in this study, it is reasonable to perform testing on all production shafts. CSL provides more ability to quantify a defect in the shaft and allows for accurate determination of 
shaft quality inside and outside the cage to have better estimation of its actual load carrying capacity. 


\title{
IV. CSL AND FREQUENCY TOMOGRAPHY ANALYSIS OF DRILLED SHAFT BRIDGE FOUNDATIONS TO DETECT THE DEFECTS LOCATIONS
}

\author{
Masood Hajali and Caesar Abishdid
}

\begin{abstract}
Cross-hole Sonic Logging (CSL) has become the standard method used to evaluate the integrity of bridge drilled shaft foundations based on travelling of ultrasonic waves between probes in parallel tubes. Many previous studies have relied on the arrival time and wave speed to detect the defects of drilled shaft foundation, such as in cross-hole tomography. In this study, a processing method for three component wide-band CSL data is presented. It is based on a color change in the frequency amplitude of the signal recorded by the receiver probe in the location of defects, and it is called Frequency Tomography Analysis (FTA). Time-domain data is transferred to frequency-domain data of the signals propagated between the tubes using Fast Fourier Transform (FFT). The distribution of the FTA was later evaluated. This method is employed after a CSL test has determined the high probability of an anomaly in a given area and is applied to improve the location accuracy and to further characterize the features of the defect. Two drilled shaft samples were built in FIU's Titan America Structures and Construction Testing (TASCT) laboratory. Some cubic foam pieces are inserted throughout the length inside the cage before concrete placement to replicate defects. FTA is then utilized after the CSL tests to detect the location of the defects. The technique has a very good resolution and clarifies the exact depth location of any void or defect through the length of the drilled shaft for the voids inside the cage.
\end{abstract}


Keywords: Drilled Shaft, Cross-hole Sonic Logging (CSL), Frequency Tomography Analysis (FTA), Integrity, Time-domain, Frequency-domain, Fast Fourier Transform (FFT), Defects.

\section{Overview}

The development of drilled shafts, more or less independently, in various parts of the world led to different terminologies (O'Neil and Reese, 1999) [1].There are various methods to construct the shafts, wet method is the regular method where shafts are cast under wet conditions using slurry to keep the hole open during drilling and casting of the concrete. Sometimes casing is installed to make the drilling process easier and keep the hole open during the drilling process. In many cases, casing is used in the top part of the shaft length. The casing maybe left in place, but is usually temporary and is removed after the concrete placement due to its high cost. During this construction process of the drilled shaft, different types of anomalies such as necking, soft-bottom gap at the base, voids or soil intrusions, poor quality concrete, and dry chunks of concrete can occur. Such anomalies are due to concrete being sometimes dry, water penetration into the borehole, collapse in soft strata, falling of boring spoils from the surface, tightly-spaced rebars, or dry chunks of concrete.

Drilled shaft foundations usually carry large loads because of their larger diameters and long lengths. For this reason, they need to be built with a high level of quality assurance and control applied to each in-place constructed deep foundation 
element. A single drilled shaft can be used instead of group of piles to support the same total load. Hence, the integrity of the drilled shaft can affect its overall performance. Integrity testing using Nondestructive Test (NDT) methods in deep foundations is checking the structural condition of the foundations. Several methods are available to perform this testing. CSL has become a common and reliable method among the most usual methods of NDT testing. ASTM D6760 [2] provides a complete guidance for the CSL test procedure.

The first use of the CSL method in the Americas was by the Hertlein in 1986. This method was discussed in detail by Baker (1993) [3] and O'Neill (1999). CSL is a common type of NDT, which is currently used to check the integrity of placed drilled shafts based on propagation of ultrasonic waves between two or more access tubes inside the reinforcing cage. CSL is the most reliable technique for assessing the integrity of inplace constructed deep foundation elements such as drilled shafts. Sarhan et al. (2003) [4] quoted a number of sources citing that flaws occupying up to $15 \%$ of the drilled shaft's cross section could remain undetected. Camp et al. (2007) [5] found that, out of 441 drilled shafts tested on multiple projects in South Carolina, approximately $75 \%$ of the projects had at least one shaft containing an anomaly, and 33\% of all shafts tested contained at least one anomaly.

Crosshole Sonic Logging Tomography (CSLT) method [6] is a velocity imaging method for anomaly zones. CSL data can be collected by initially offsetting either the source or the receiver and then pulling the two probes together as to maintain a constant non-zero angle between them. In the CSLT method, data is collected by running a zerooffset log in combination with several positive offset (receiver is shallower) and negative 
offset (source is shallower) logs. This procedure is repeated for all possible access tube combinations to form a three-dimensional tomography dataset. CSLT needs specialized analyses software for true 3-D imaging.

Several variations of the CSL test have been developed using the same instrumentation as the CSL. These tests are typically employed after CSL has determined the high probability of an anomaly in a given area, and are applied to improve location accuracy and to further characterize the feature. One of the most popular of these tests is Cross-hole Tomography (CT). A CT test is performed by leaving the receiver in a fixed position and raising the hydrophone while the hydrophone is producing sonic pulses. As in the CSL test, the arrival times from the hydrophone to the receiver are recorded. This procedure produces ray-paths that allows for three dimensional modeling of the suspect shaft. The anomalous zone is the slow-velocity area which lies in between 31 and 33 feet below the top of the concrete near tube one. Note that the center of the shaft is sound (Olson, 2003).

Olson and Hollena [7] (2002) illustrated the use of Crosshole Tomographic (CT) velocity imaging of concrete defects in drilled shafts. They used CT method for color velocity tomograms of defects in actual bridge shafts. They showed the ability of CT to provide 2-D and 3-D velocity images of a potential defect provides excellent data on the shape and severity of CSL anomalies. CT is an analytical technique which is increasingly used in hydrological and geological studies. Some applications of CT have been reported by Tronicke (2002) in hydrological and Fullagar [8] (2000) in mining application.

Haramy (2006) [9] presented a comprehensive study on the performance monitoring of concrete mix during its hydration process, CSL detection of anomaly locations, 
tomographic imaging of the anomaly, and the effects of anomalies on drilled shaft capacity. When anomalies occur, the NDE methods can assist in detecting their locations and sizes. The anomaly near the top of a drilled shaft will significantly affect the structural capacity of drilled shafts [10].

Anomalies throughout the length can significantly reduce the axial load capacity of the drilled shaft, and their effect becomes severe after the installation and can lead to the unsatisfactory performance of the drilled shafts. That is why they need to be detected accurately in order to consider their influence on the drilled shaft's axial load carrying capacity. The purpose of this study is to present a new method to detecting the exact location of defects after performing the CSL test. To accomplish this objective, two drilled shaft samples with pre-inserted voids were built at FIU's TASCT laboratory. The samples were tested seven days after concrete placement using CSL, and the CHA results were evaluated using signal processing. An improved standard method is proposed that considers not only the traditional arrival time changes, but also the signal strength and frequency amplitude of the signal reduction in order to improve the location accuracy.

\section{Cross-hole Sonic Logging (CSL)}

Cross-hole Sonic Logging (CSL) CSL is the most widely accepted and used integrity testing method for drilled shaft foundations. CSL establishes the homogeneity and integrity of concrete, such as voids or soil intrusions by recording the time and computing the velocity of signals from an emitter to a receiver probe (Lew et al., 2002) [11]. The CSL method is used to measure the speed of ultrasonic waves between water-filled 
access tubes. A number of access tubes (PVC or steel galvanized) are installed inside the reinforcing cage prior to concrete placement as guides for the sensors. To carry out the test, the probes with 8.5 inch $(215 \mathrm{~mm})$ length and 1 inch $(25 \mathrm{~mm})$ in diameter are lowered down to the toe of the tubes. The transit time of an ultrasonic compressional wave (p-wave) signal from a signal source in one access tube to a receiver in another access tube is measured from the bottom to the top of the shaft (Figure 4.1). Ultrasonic transmitter and receiver probes are capable of producing records at a minimum frequency of 40,000 Hz with good signal amplitude and energy through good quality concrete. The probes shall be less than 1.1 inches $(28 \mathrm{~mm})$ in diameter and shall freely descend through the full depth of properly installed access tubes in the drilled shafts. The first arrival time can be used to determine the ultrasonic pulse velocity $(C)$ if the distance between tubes is measured.

The velocity of $\mathrm{P}$ waves in a medium is related to the dynamic modulus of material, $E$, density of material, $\rho$, and Poisson's ratio, $\mu$, as follows:

$$
C=\sqrt{\frac{E}{\rho} \cdot \frac{(1-\mu)}{(1-2 \mu) \cdot(1+\mu)}}
$$

In homogeneous, good quality concrete, the ultrasonic wave speed is around 12000 to $13000 \mathrm{ft} / \mathrm{s}(3658$ to $3962 \mathrm{~m} / \mathrm{s})$, in water is $4800 \mathrm{ft} / \mathrm{s}(1463 \mathrm{~m} / \mathrm{s})$, and in air is $1100 \mathrm{ft} / \mathrm{s}(335 \mathrm{~m} / \mathrm{s})$. Normal density of concrete would be about $150 \mathrm{lb} / \mathrm{ft}^{3}\left(2400 \mathrm{~kg} / \mathrm{m}^{3}\right)$. The dynamic modulus of concrete varies from 4060 to $5800 \mathrm{ksi}$ (28 to $40 \mathrm{GPa}$ ), and the Poisson's ratio of concrete is between 0.1 to 0.2 .

Any change in the velocity of the ultrasonic wave signifies the presence of a defect due to voids or soil intrusions. If for any reason the condition of the concrete 
varies, the wave speed will be reduced relative to that of the sound concrete value. After performing the CSL test between two access tubes, the Cross-Hole Analyzer (CHA) software can be used to analyze the results. CHA evaluates the quality of the concrete of deep foundations by the CSL method. The CHA detects the arrival time by locating the peak value of the signal, then by using a relative percentage of that peak as a threshold for locating the leading edge. This value can be monitored visually by the horizontal blue dotted line on the signal trace graph. The data acquisition signal graph includes 250 data points, sampled at $500 \mathrm{KHz}$. The graph represents data points versus strength of the received signal by the receiver probe. The strength or amplitude of the signal range is between -10 to +10 volts. The energy can be also calculated and plotted base on:

Energy $=[$ received signal strength (volts) $] *$ arrival time (millisecond) $]$

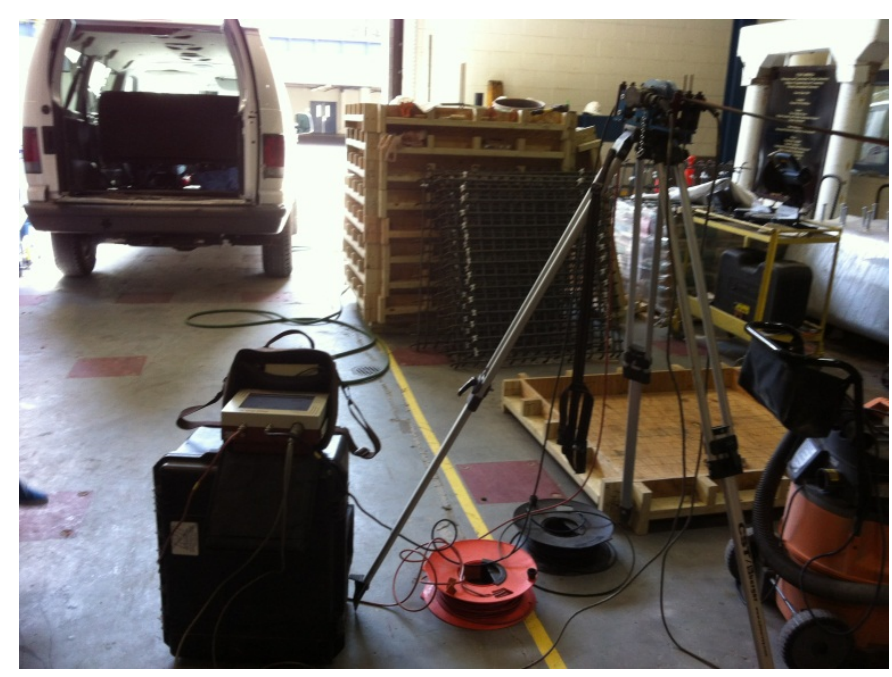

Figure 4.1. CSL Equipment 


\section{Testing Program}

Two drilled shaft specimens were tested at FIU's TASCT laboratory using the CSL equipment. Each specimen has four galvanized tubes outside the shaft and four tubes inside the shaft. Therefore, six CSL tests were carried out between the tubes inside the shaft and four CSL tests between the tubes inside and outside the shaft. The length and diameter of the shafts, stirrup spacing, size of the formwork around the shaft, number of the CSL tubes, and steel reinforcement amount were kept constant in both specimens.

\section{Test Specimens}

The specimens used in this study to perform the CSL test throughout the length of the shaft are designed to simulate a drilled shaft foundation. Two drilled shaft specimens were built at FIU's TASCT laboratory (Figure 4.2). The diameter of each drilled shaft specimen was 20 inches $(50.8 \mathrm{~cm})$, with a length of 4 feet $(122 \mathrm{~cm})$. The formwork had a length of 48 inches $(122 \mathrm{~cm})$, a width of 48 inches $(122 \mathrm{~cm})$, and a height of 48 inches $(122 \mathrm{~cm})$ as shown in Figure 4.2. A sona-tube with a diameter of 20 inches $(50.8 \mathrm{~cm})$ and a length of 4 feet was used as a casing around the drilled shaft. The shaft was longitudinally reinforced with six (6) No. 10 steel bars that were equally spaced around the perimeter. This amount of steel corresponds to 1.06 percent of the gross crosssectional area of the shaft. The real drilled shafts should be longitudinally reinforced with an amount of steel that is around 2.2 percent of the gross cross-sectional area of the shaft. But in this study, the amount of longitudinal bars will have no effect on the nondestructive tests results. The longitudinal bars were Grade 60 with the nominal yield 
strength of $60 \mathrm{ksi}(414 \mathrm{MPa})$. The horizontal ties used were size No. 4, and were spaced along the axis of the shaft at 4 inches O.C. A total of twelve (12) No. 4 ties were used throughout each shaft specimen. The clear cover provided on the ties was 1 inch (Figure 4.3). The CSL tubes that are installed inside and outside the cage were galvanized with 2 inches inside diameter.
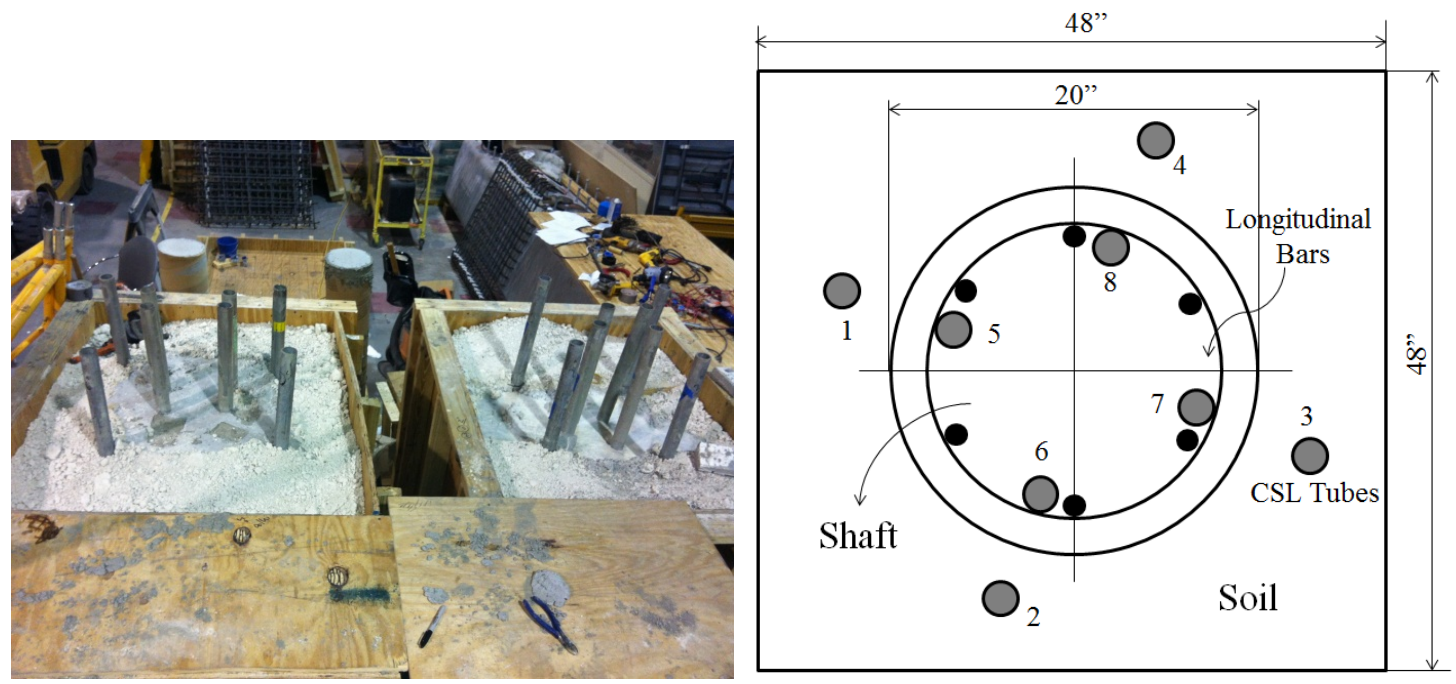

Figure 4.2: Drilled Shaft Specimens

Figure 4.3: CSL Tubes Arrangement - Top View

The number of access tubes required in order to conduct the CSL tests is very important. The specimens have four access galvanized tubes inside the cage and four tubes outside the cage. Each galvanized tube is fixed at the end and at two points throughout the length of the shaft (Figure 4.4). For all the specimens, the outside galvanized tubes were installed 3 inches away from edge of the shaft. The specimens were tested one week after concrete placement to allow for proper curing. 


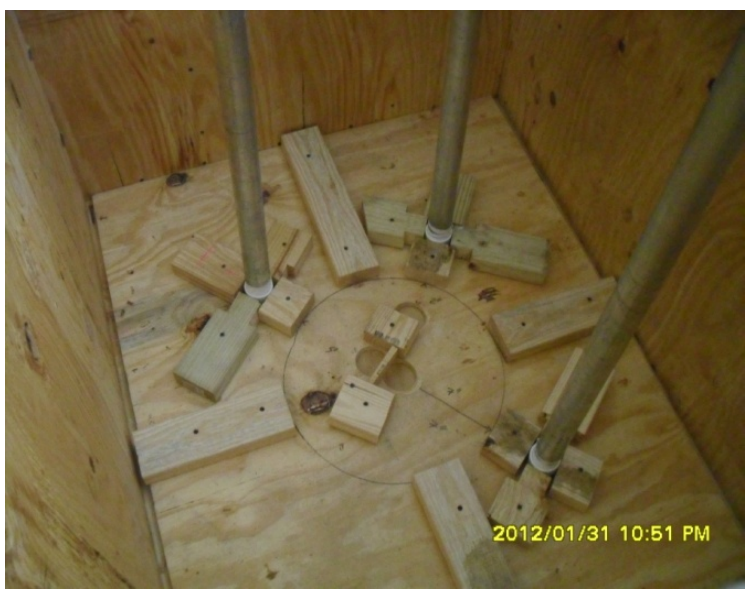

(a)

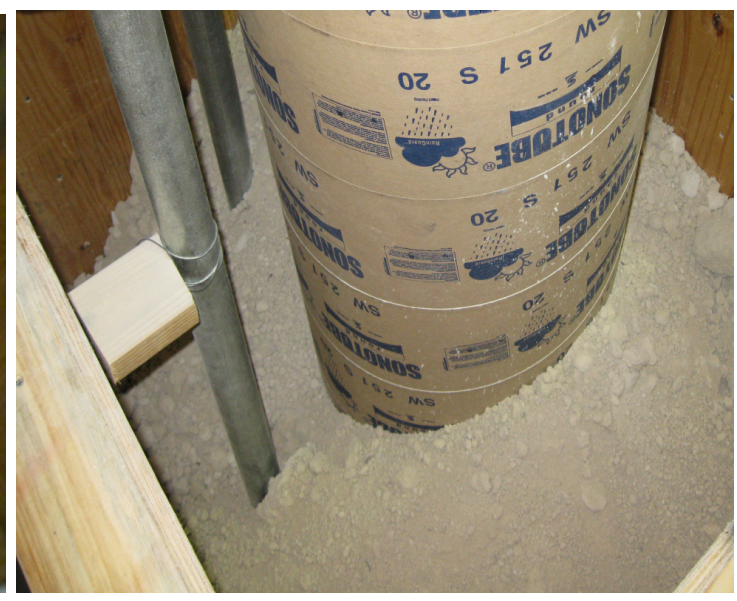

(b)

Figure 4.4. (a) Installing the Outside Galvanized Tubes, (b) Installing the Sona-tube For each specimen, eight cubic yards of dry limestone with a unit weight of $80 \mathrm{lb} / \mathrm{ft}^{3}$ were used to simulate the soil outside the shaft. While pouring limestone inside the forms, the soil was compacted in three lifts. Concrete with 5,000 psi ultimate compressive strength was placed inside the sona-tube (Figure 4.5a). The sona-tube was then removed using an overhead crane (Figure 4.5b). 


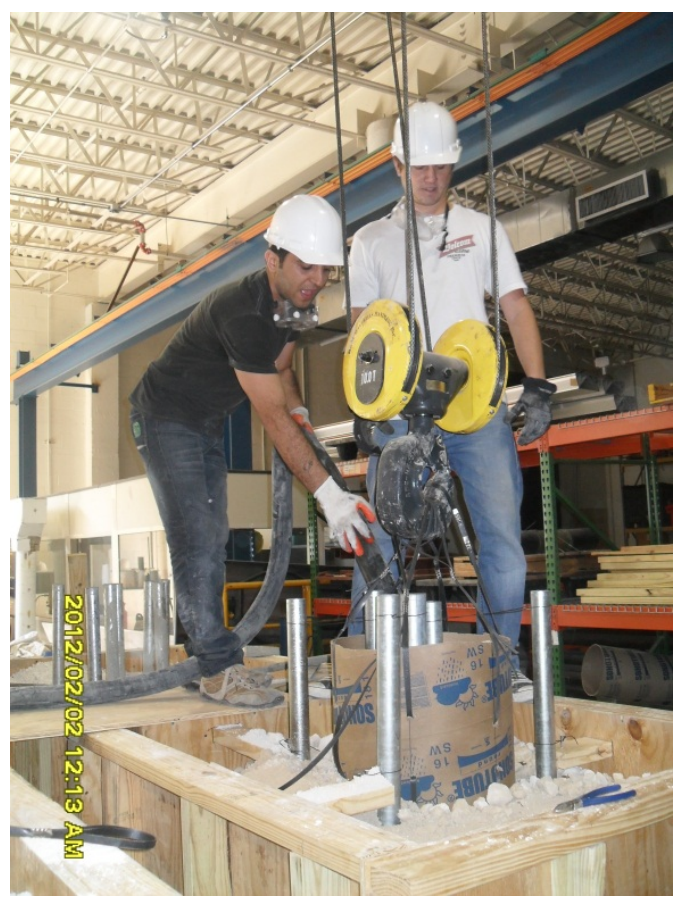

(b)

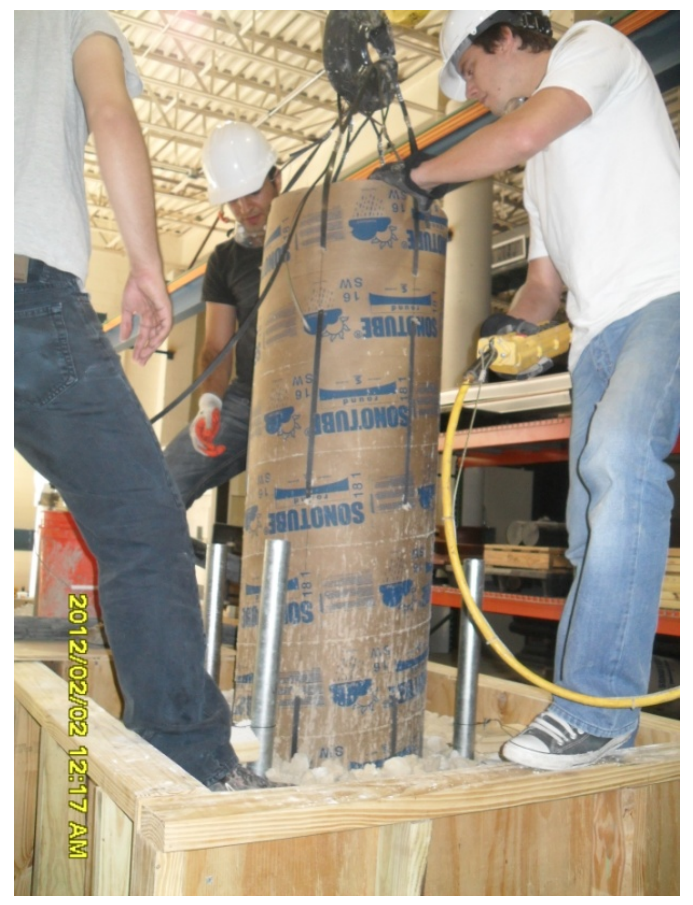

(b)

Figure 4.5: (a) Concrete Placement inside the Sona-tube, (b) Removing the Sona-tube using Crane

Prior to positioning the steel cage inside the sonatube, eight 1-inch plastic spacers were installed throughout the length of the cage to keep the cage at the center of sonatube and insuring the 1 inch concrete cover. A wood formwork was built and placed at the bottom of the sonatube to ensure that the steel cage was aligned properly and to secure the fluid concrete during casting. Concrete was pumped vertically inside the Sonatubes for both specimens to ensure uniformity. Concrete placement was continued in a single operation to the top of the shaft. The concrete mix for the drilled shaft specimens was designed in such a manner so as to be workable and could flow easily through the rebar cage by gravity to the bottom of the shaft without the need for vibration. Concrete was 
not vibrated after casting to simulate actual conditions where concrete in drilled shafts is not consolidated.

\section{Void Types and Locations Considered}

Iskander, et al. (2003) [12] studied drilled shafts constructed with built in defects located in various areas within the shaft. He concluded that defects included voids and soil inclusions occupying $5-45 \%$ of the cross section. He also concluded that down hole methods such as CSL and cross hole tomography are generally able to identify defects exceeding $10 \%$ of the cross sectional area. The built voids that were placed in the shaft specimens are occupying almost $20 \%$ of gross cross sectional area of the shaft specimen based on the common voids percentage in real drilled shafts.

One type of voids was considered which was installed inside the caging of the two specimens. For the first specimen the prefabricated voids were inserted at the top and the bottom of the shaft, and for the second specimen the void was inserted in the middle of the shaft. Foam pieces were used to replicate the voids inside the cage and were secured at the center of the steel cage before casting. Steel wire was used to tie the foam pieces to the reinforcement bars and keep the foam at the center of the cage.

Table 4 shows the characteristics of the tested shaft specimens with built-in voids inside the cage. Void type, void percentage and their locations, and the number of CSL tubes are listed in this table for both specimens. In Specimen 1, one void has a length of 7 inch $(17.8 \mathrm{~cm})$ and is located between depths of 5 inches and 12 inches $(12.7 \mathrm{~cm}$ to 30.5 $\mathrm{m})$ from the surface. The second void is 7 inch $(17.8 \mathrm{~cm})$ in length and is located at the 
bottom of the shaft between the depths of 36 inches and 43 inches $(91 \mathrm{~cm}$ to $109 \mathrm{~cm}$ ), as shown in Figure 4.6(a). In specimen 2, void has length of 7 inch $(17.8 \mathrm{~cm})$ and is located at the middle of the shaft specimen between depths of 24 inch to 31 inch $(61 \mathrm{~cm}$ to 79 $\mathrm{cm}$ ) from the surface. In Specimen 2, the void is inside the caging (Figure 4.6b). All the voids have the same cross sectional shape occupying $20 \%$ of gross cross sectional area of the drilled shaft.

Table 4: Characteristics of Tested Drilled Shaft Specimens with Built Voids

\begin{tabular}{|c|c|c|c|c|c|}
\hline $\begin{array}{c}\text { Specime } \\
\text { n No. }\end{array}$ & $\begin{array}{c}\text { Number of } \\
\text { Inside Tubes }\end{array}$ & $\begin{array}{c}\text { Void Length } \\
\text { (inch) }\end{array}$ & $\begin{array}{c}\text { Void } \\
\text { Percentage }\end{array}$ & Void Type & Void Location \\
\hline 1 & 4 & 7 & $20 \%$ & inside & $\begin{array}{c}\text { Top and Bottom } \\
\text { of the Shaft }\end{array}$ \\
\hline 2 & 4 & 7 & $20 \%$ & inside & $\begin{array}{c}\text { Middle of the } \\
\text { Shaft }\end{array}$ \\
\hline
\end{tabular}

\section{Materials}

The concrete used in this study was normal weight concrete $\left(150 \mathrm{lbs} / \mathrm{ft}^{3}\right.$ or 23.565 $\left.\mathrm{kN} / \mathrm{m}^{3}\right)$. Standard concrete cylinder samples with 4-inch $(10.16 \mathrm{~cm})$ diameters and 8-inch (20.32 cm) lengths were tested using the Concrete Compression Machine in the laboratory at FIU. The average measured axial compressive strength for three standard cylinders was $62,832 \mathrm{lbs}(280 \mathrm{KN})$ at 28 days. Therefore, the cured concrete cylinders had a compressive strength at 28 days equal to $5000 \mathrm{psi}$ ( $34.5 \mathrm{MPa}$ ). The concrete slump was measured to be 4 inches $(10.16 \mathrm{~cm})$ at the time of casting, and the maximum coarse aggregate size (rounded river gravel) was 0.5 inch $(1.27 \mathrm{~cm})$. Fine aggregate was based on ASTM C33 natural sand with a fineness modulus of 3.0. The cement was type I 
Portland cement and comprised about 24 percent of the weight of the mix. The water to cement ratio varied between 0.4 and 0.42 , depending on the moisture content of the aggregate. A No. 4 bar was tested using a Universal Tensile Testing Machine in the laboratory at FIU. The tensile test loading ratio used was $100 \mathrm{lbs} / \mathrm{sec}(445 \mathrm{~N} / \mathrm{sec})$. The longitudinal steel and lateral ties in all the tested specimens were Grade 60, with yield strength of $60 \mathrm{ksi}(414 \mathrm{MPa})$. The actual yield strength was more than the nominal value (65 ksi, $448 \mathrm{MPa})$, and the modulus of elasticity was $29 \times 10^{6} \mathrm{ksi}\left(2 \times 10^{8} \mathrm{MPa}\right)$.

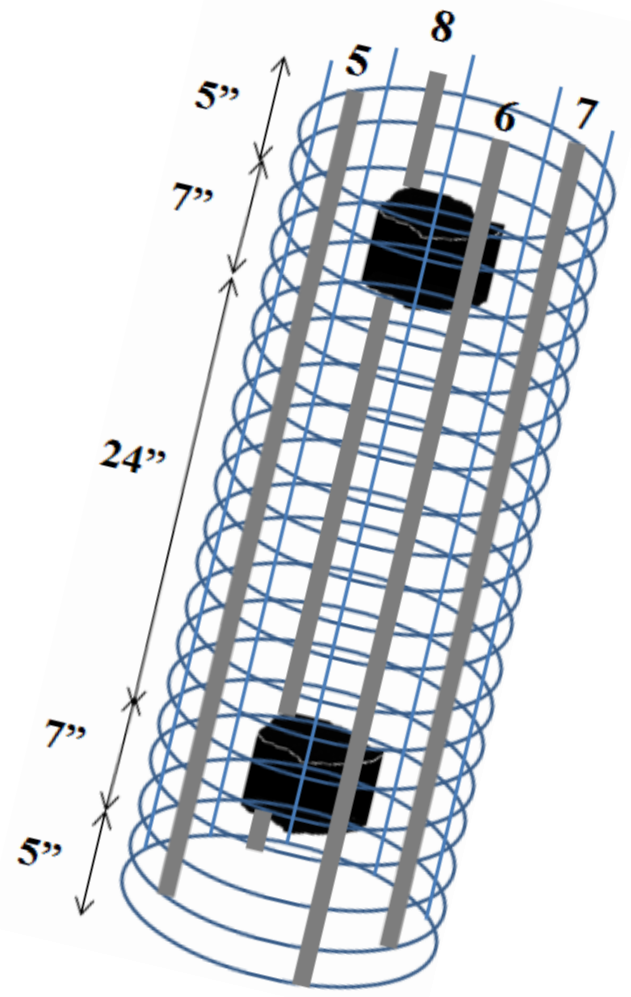

(a) Specimen 1

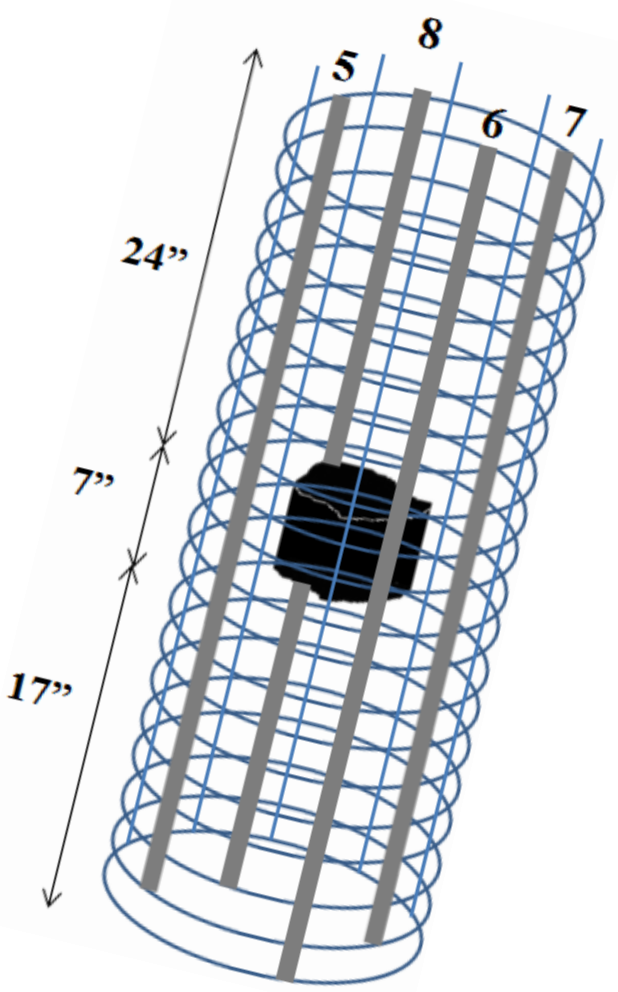

(b) Specimen 2

Figure 4.6: Constructed Voids inside the Caging Through the Length of the Shaft Specimen 


\section{Test Procedure}

The procedure to detect the voids and defects inside the drilled shaft is to perform the CSL test between inside tubes and apply a signal processing on the results to analyze the data from the CHA software. Before testing a shaft, the access tubes were checked for free access and filled with water to obtain good acoustic coupling. The tubes were fit with a watertight shoe on the bottom and a removable cap on the top. The tubes were secured to the interior of the reinforcement cage at regular intervals. Two probes connected to pulleys were then inserted into the tubes, one of which equipped with a depth meter (Figures $4.7 \mathrm{a}$ and $4.7 \mathrm{~b}$ ). The emitter and receiver probes were then lowered into the tubes. After reaching the bottom of the tubes, the probes were then pulled simultaneously upwards with smooth motion until they reached the top. During this time the emitter produced a continuous series of pulses, sending waves in all directions. For each profile, the First Arrival Time (FAT) and data acquisition signal of each pulse was plotted every two inches.

In Specimens 1 and 2, six CSL tests were performed between the tubes inside the concrete (Tubes 5-6, 5-7, 5-8, 6-7, 6-8 and 7-8) in order to detect the voids inside the caging one week after concrete placement. Also, four CSL tests were performed between inside and outside tubes (Tubes 1-5, 2-6, 3-7, and 4-8).

The CSL test may be performed any time after concrete placement when the concrete has obtained sufficient strength, which is almost $66 \%$ of the ultimate concrete strength. Because the concrete strength and quality generally increase as the concrete cures, longer wait times are usually desirable; particularly if minimum pulse wave speeds are specified, or to reduce result variability between drilled shafts, or even as a function of depth in a 
single drilled shaft. However, if PVC tubes are used for wet cast shafts, long wait times increase the tube de-bonding which is detrimental to the test. Production drilled shaft installation and subsequent construction influence the dates of CSL testing. The drilled shaft shall be tested no sooner than three calendar days after placement of all concrete in any drilled shaft, but within ten days after placement and prior to loading for test drilled shafts, or within forty five days after placement on production drilled shafts.

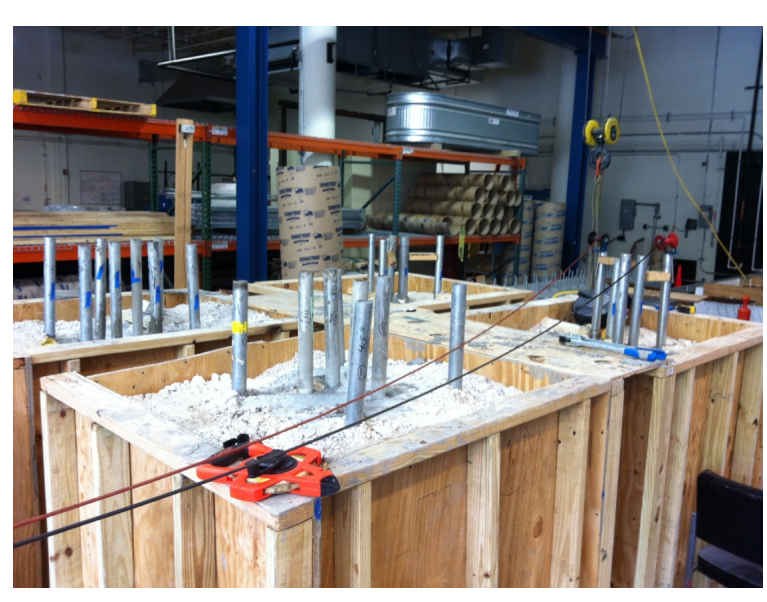

(b)

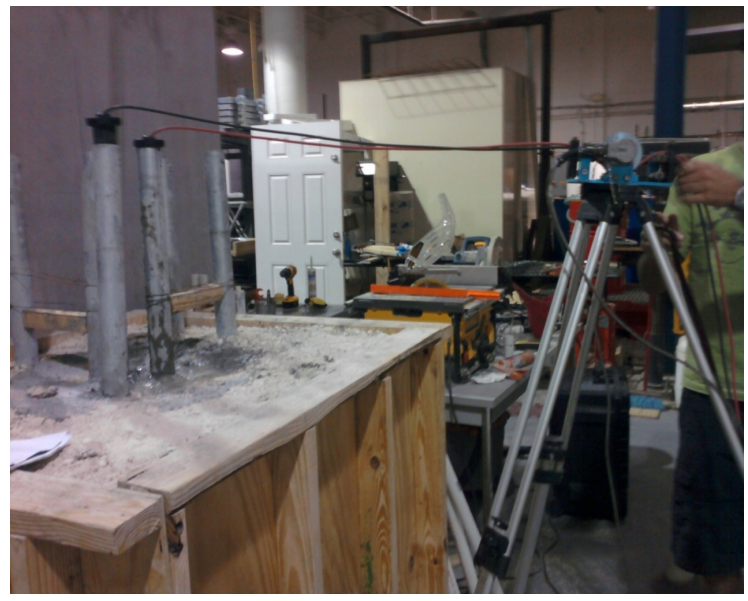

(b)

Figure 4.7: CSL Test on the Drilled Shaft Samples

\section{Signal Processing On the CSL Test Results}

After performing the CSL test, CHA can be used to record the data acquisition signal graph which included 250 data points at each height. Time domain data can easily be obtained from the data acquisition signal. The horizontal axis in the data acquisition signal is the data point, and it should be divided by the frequency to determine time as in the following equation: 
$t=n \cdot T=\frac{n}{f}$

where $t$ is the time, $n$ is data points, $f$ is frequency, and $T$ is the period. The most important part of the CHA software is the data acquisition signal graph, which is based on the time domain data. Figure 4.8 is the data acquisition signal for two separate CSL tests on the drilled shaft specimen at the height of 31.5 inches. Both tests are between two tubes in concrete $(\mathrm{C}-\mathrm{C})$. Figure 4.8 compares the time domain for two $\mathrm{C}-\mathrm{C}$ tests, and it can be seen that both tests have exactly the same FAT. Figure 4.9 shows the frequency domain curve for the same tests after de-noising and fitting with a tenth degree polynomial. It shows that they have approximately the same maximum amplitude for the signal. It shows that the maximum amplitude of the signal is around $7.0 \times 10^{-4}$ when both tubes are placed in concrete. Since, limestone material is not as dense as concrete, it can be said that FAT for concrete-soil test is much higher than that in the concrete-concrete test; this is because the ultrasonic wave travel time is much longer. 


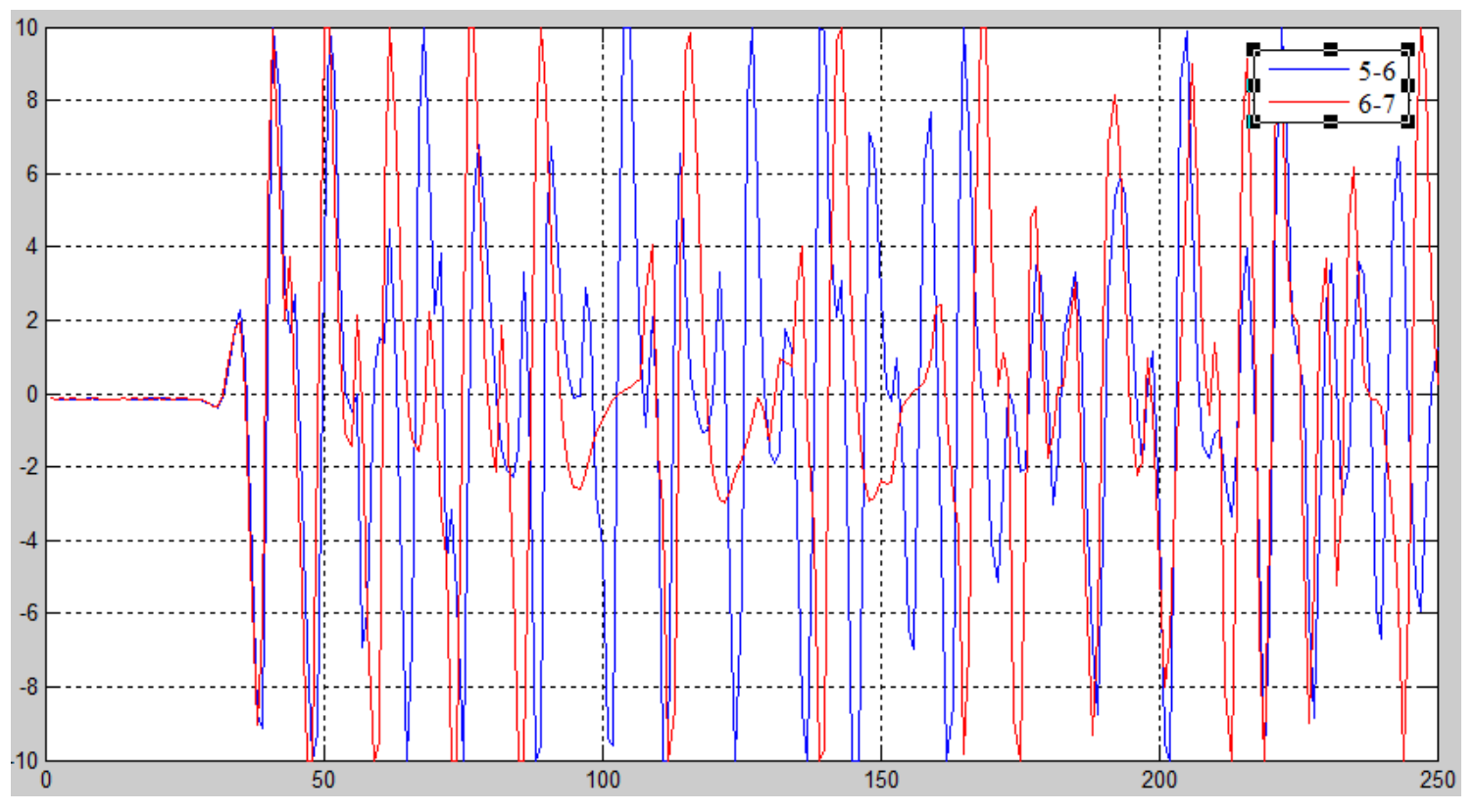

Figure 4.8: Time-Domain (5-6 and 6-7)

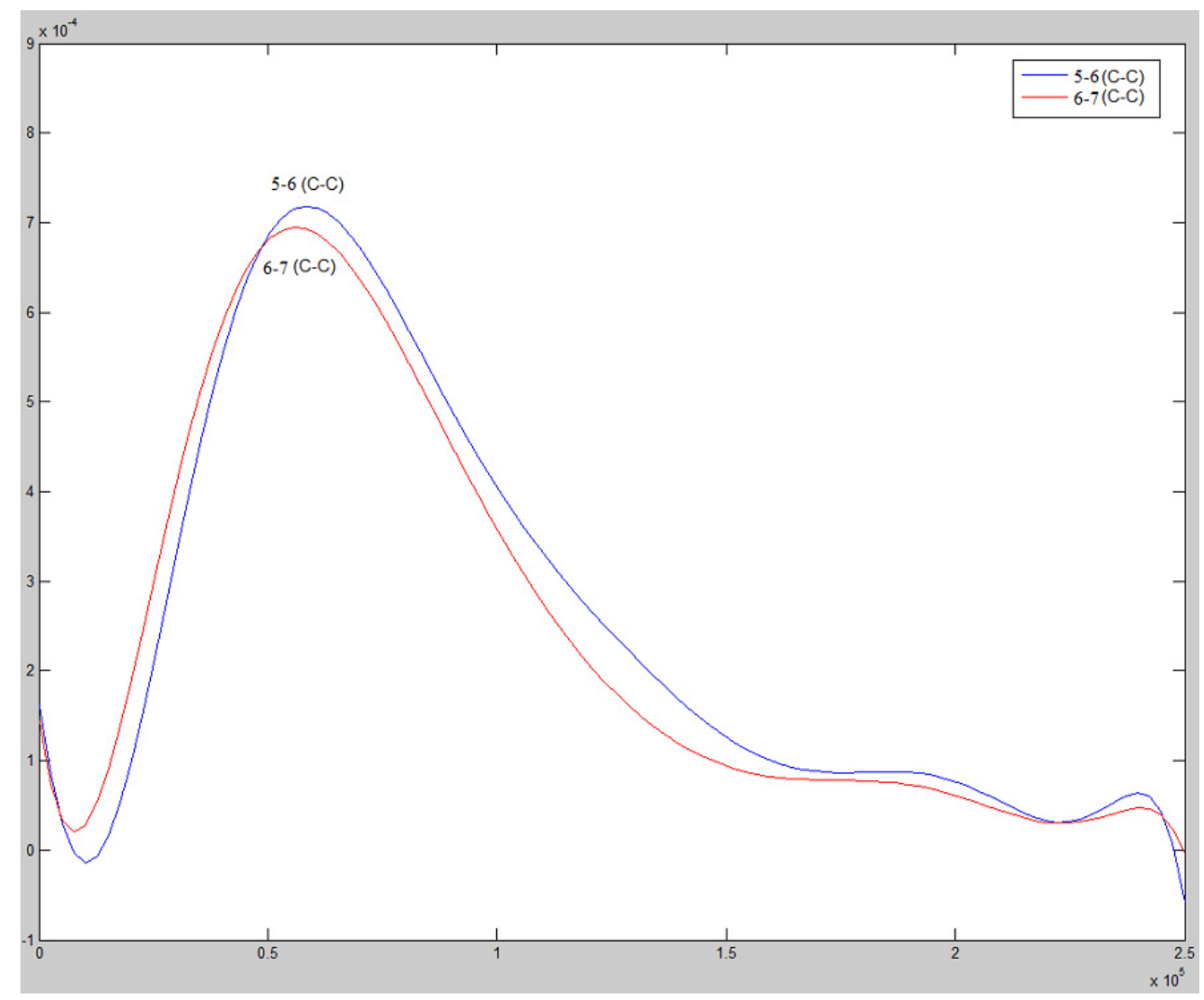

Figure 4.9: De-noised and Fitted Frequency Domain curve (5-6 and 6-7) 
Plotting the Time domain data does not permit one to detect the exact location of the defects. The time domain data was therefore converted to frequency domain data in order to obtain the frequency domain tomography. Fast Fourier Transform (FFT) was used in to perform this signal processing. Discrete Fourier Transform (DFT) is a specific kind of discrete transform, used in Fourier analysis. It transforms one function into another, which is called the frequency domain. DFT is widely used in signal processing to analyze the frequencies, because it takes a discrete signal in the time domain and transforms that signal into its discrete frequency domain representation. The DFT transforms time-based data into frequency-based data. The DFT of a vector $x$ of length $n$ is another vector $y$ of length $n$ :

$y_{p+1}=\sum_{j=0}^{n-1} \omega^{j p} x_{j+1}$

where $\omega$ is a complex $n^{\text {th }}$ root of unity and is defined by:

$\omega=e^{-2 \pi i / n}$

FFT is an efficient and faster algorithm to compute the DFT and its inverse with a significant speed increase. The functions $\mathrm{Y}=\mathrm{FFT}(\mathrm{x})$ implement the transform using following equation:

$$
X(k)=\sum_{j=1}^{n} x(j) \omega_{n}^{(j-1)(k-1)}
$$

where $\omega$ is an $n^{\text {th }}$ root of unity.

$\omega_{n}=e^{-2 \pi / n}$

It is difficult to identify the frequency components by looking at the original signal. Converting it to the frequency domain, the discrete Fourier transform of the noisy 
signal $y$ is found by taking the fast Fourier transform (FFT). The FFT utilizes some algorithms to do the same thing as the DTF, but in much less time.

The frequency domain curve after de-noising and fitting with a tenth degree polynomial is sufficient to obtain the maximum amplitude of the signal. The maximum amplitude of the signal was $7.2 \times 10^{-4}$ for C-C test and $2.8 \times 10^{-4}$ for C-S test with concrete thickness of 7 inches for two different CSL tests. Figure 4.9 compares the frequency domain for two C-C tests, and it can be seen that both tests have almost the same frequency domain data. Also, they have the same maximum amplitude of signal. Results from two C-S tests show that for one test with concrete thickness of 5 inches, the maximum amplitude of the signal is $8 \times 10^{-5}$, and for other test with concrete thickness of 4 inches, it is $6.5 \times 10^{-5}$. These results show that the concrete thickness can be directly correlated to the maximum amplitude of the signal. Hence, any change in the concrete thickness due to the presence of voids inside the cage will cause the frequency domain and maximum amplitude of the signal to change. All results show that the maximum amplitude of signal occurs at $500 \mathrm{kHz}$. This is because the data acquisition signal graph includes 250 data points, sampled at $500 \mathrm{KHz}$ in the CHA software results.

After performing the FFT of the signal, the frequency spectrum of the signal is plotted to observe the characteristics of the signal. To have a better illustration of the results, all the results are plotted in contour format. The frequency domain data is then de-noised with wavelets in order to obtain a best fit curve of the function. The de-noising method based on wavelet decomposition is one of the most significant applications of wavelets. Finally, the obtained signal in frequency domain is fitted into a curve in order to reduce the time consuming calculation performed on discrete data sets. 
Figure 4.10 shows the frequency domain graph for one CSL test between two inside tubes through the shaft length, which is obtained from time domain using FFT. This plot shows that for each depth, the frequency domain graph will change depending on the concrete thickness and presence of any kind of void between the tubes. Examining different parameters such as FAT, energy, velocity, strength of signal, and amplitude of signal shows that frequency imaging of the signal is capable of precisely showing the void location.

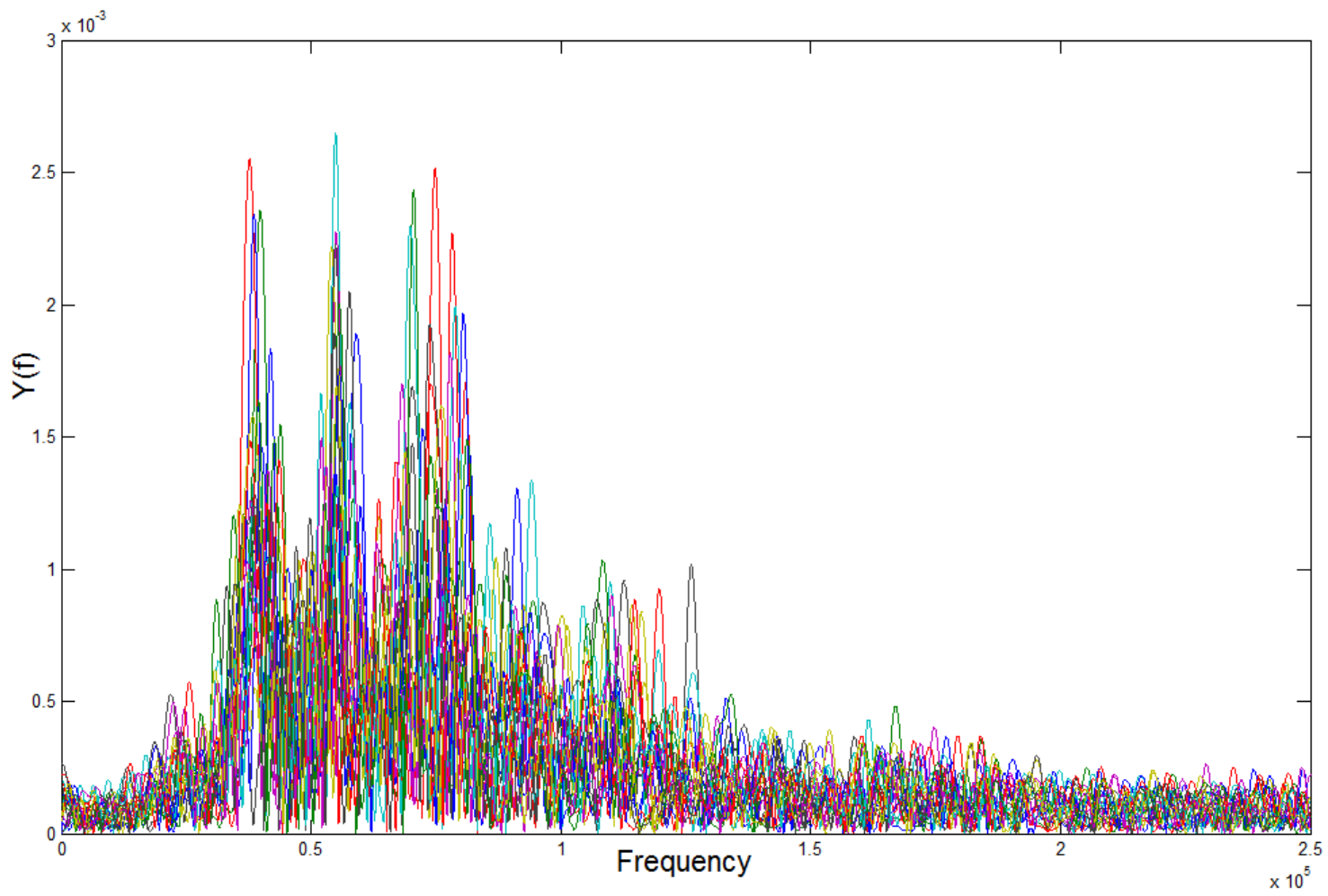

Figure 4.10: Frequency Domain Graph through the Shaft Length 


\section{Test Results}

A three dimensional (3D) tomographic image helps evaluate the extent of local defects. Tomography is a mathematical procedure that operates on the measured data where the shaft is modeled as a grid, with each node being assigned the properties of the wave. The exit CSL tomographic methods are based on wave speed, which is based on a change in first arrival time (FAT) given that the distance between the CSL tubes is known. FAT of all data points in all tube combinations with known probe locations is used to solve for the wave speed at each node point. This study presents a novel idea that replaces arrival time with information of frequency received by the receiver probe in the tomography method. FTA takes the FFT of the signal and works based on the change in the frequency domain data and maximum frequency amplitude of the signal. Each point in the drilled shaft grid is assigned a signal frequency amplitude in the FTA method to have a better observation of the defect location. Uniform signal frequency amplitude generally produces straight ray travel paths, but variable frequency amplitude causes curved ray paths.

The amplitude of the signal in both time and frequency domain are compared to determine which one can show a more accurate configuration of the void location. Figures 4.11 and 4.12 show the result of CSL test between the inside tubes (Tubes 5 and 7) in Specimen 1. Figure 4.11 is time domain tomography, which is based on time domain data. In Figure 4.11, the horizontal axis indicates the length of the shaft and vertical axis is data points. The third dimension, which is shown by color, is indicating the amplitude or voltage of the signal. This plot shows the amplitude of the signal at different points in time. Low wave speed or slow FAT indicates concrete with poor 
quality. In Figure 4.11, it can be seen that in the uniform concrete the strength of the signal is around 6 volt and in foam locations the strength decreased to -8 volts. The exact location of the void cannot be identified using this time domain approach.

Figure 4.12 is based on frequency domain data. In this figure, the horizontal axis indicates the frequency of the signal, the vertical axis is length of the shaft and the third dimension indicates the frequency amplitude of the signal. This graph shows the amplitude of the signal at different points. Low frequency amplitude indicates the location of the void. It can be seen that for zones with uniform concrete, the frequency amplitude is around $16 \times 10^{-4}$. This number decreases to $10^{-4}$ around the void. It can be seen from Figure 4.12 that the exact location of the voids can clearly be identified using frequency tomography. The major defects in the shaft were at the depth where the frequency amplitude of the signal decreased significantly. One void at the depth of 5 inches and other one at the depth of 36 inches was determined using this FTA method.

Figures 4.13 and 4.14 show the result of the CSL test between the inside tubes (Tubes 6 and 8) in Specimen 2. Figure 4.13 shows the time domain tomography for the CSL test for Specimen 2 between Tubes 6 and 8. Figure 4.14 shows the frequency tomography after the CSL test for Specimen 2. It can be seen that using frequency tomography, the exact location of the void can be clearly detected at about 24 inches depth below the surface. 


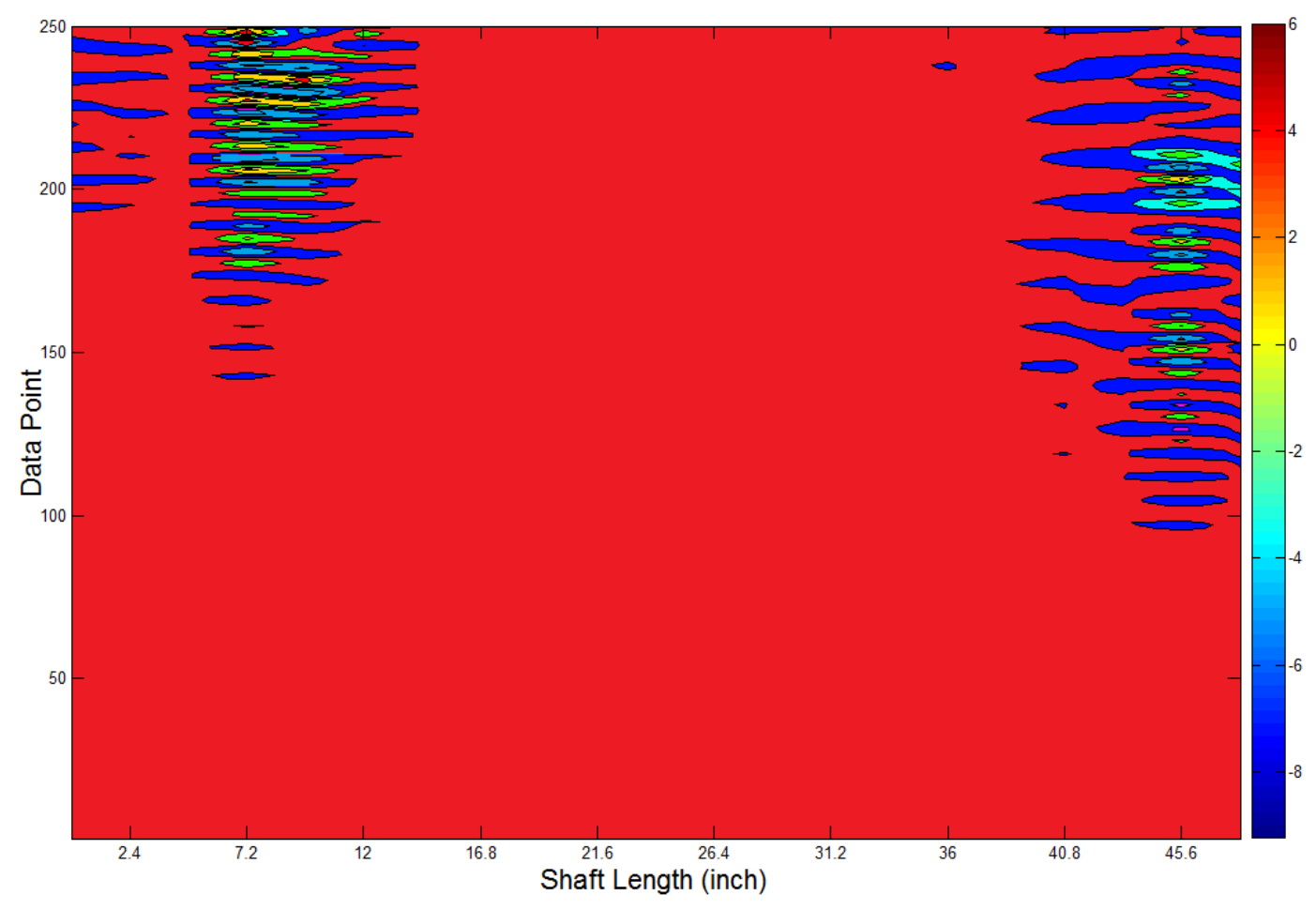

Figure 4.11. Time Domain Tomography (Specimen 1)

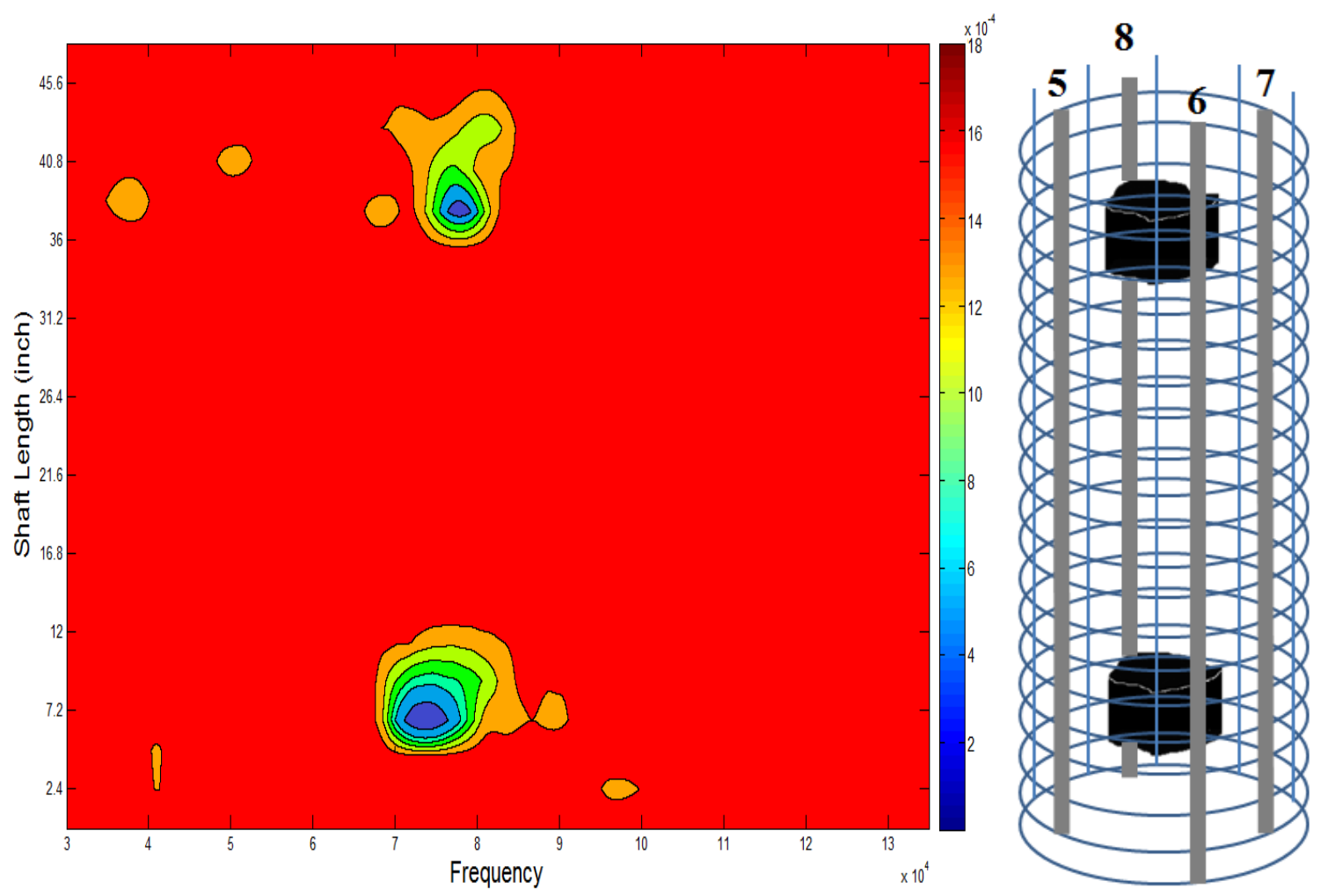

Figure 4.12. Frequency Domain Tomography (Specimen 1) 


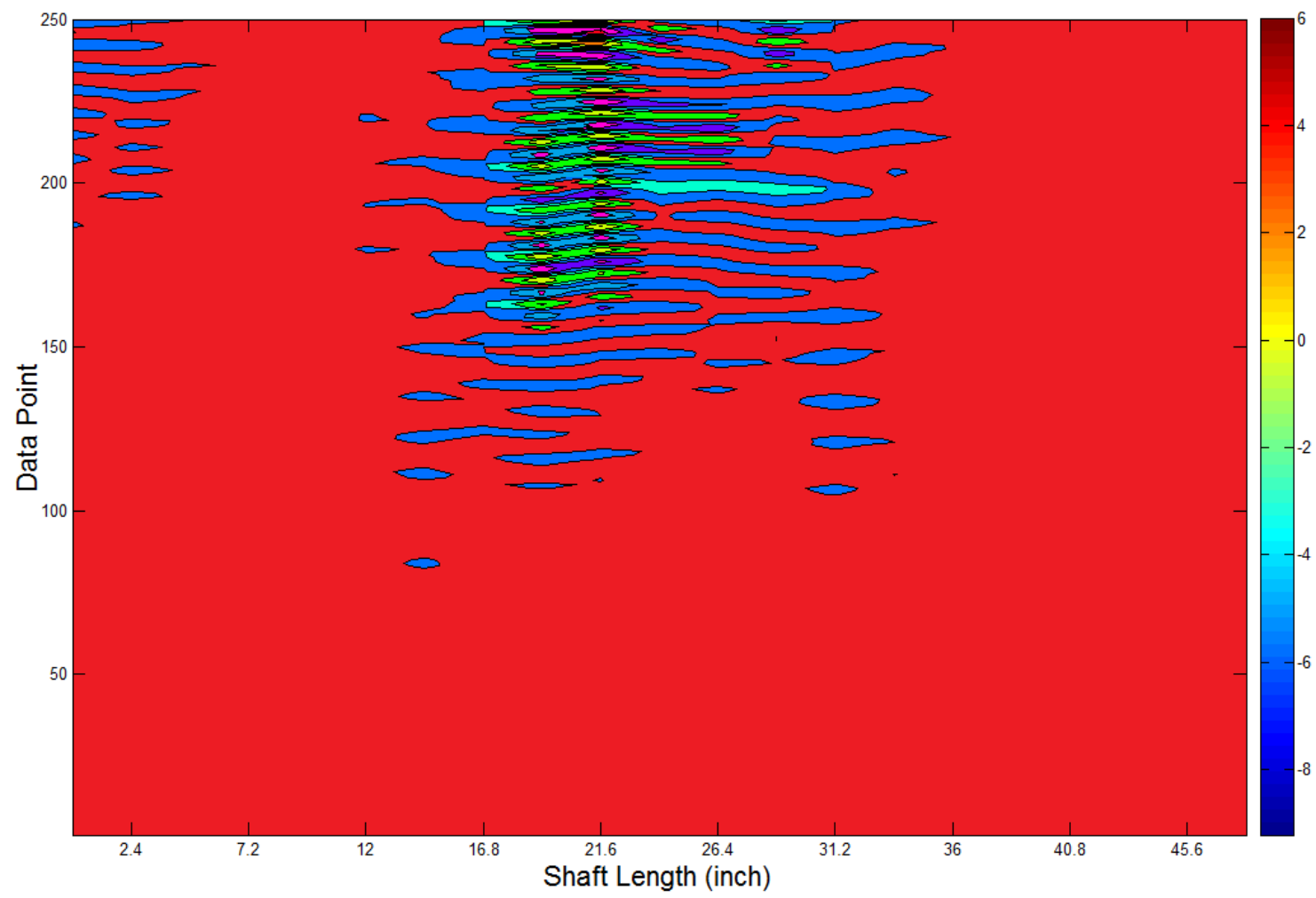

Figure 4.13. Time Domain Tomography (Specimen 2)

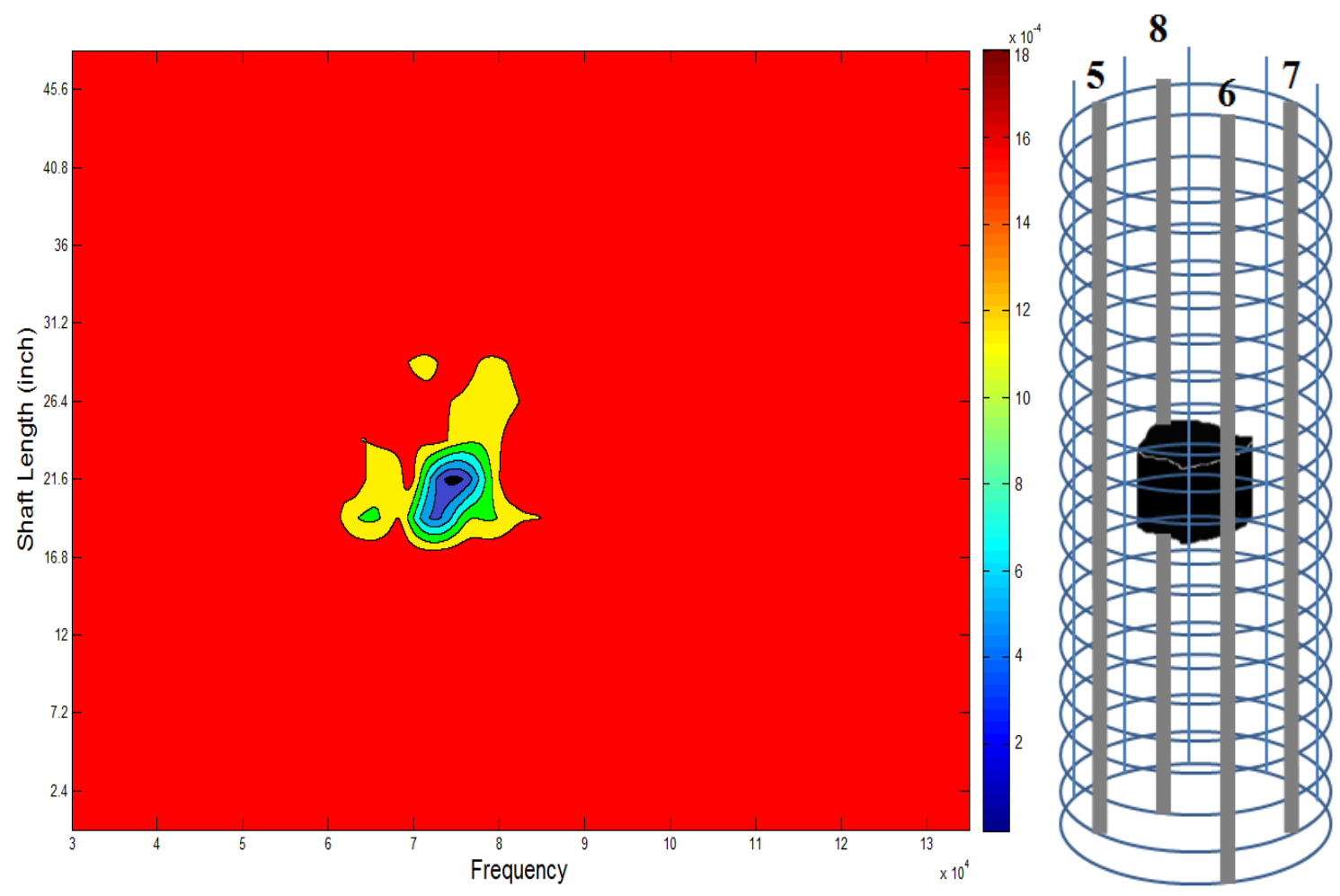

Figure 4.14. Frequency Domain Tomography (Specimen 2) 


\section{Conclusions and Summary}

A new method of accurately determining the location of voids in drilled shafts after using the application of signal processing on the CSL test results was presented. The new method overcomes the limitations and inaccuracies of currently used methods. Much previous research focuses on the arrival time and wave speed to detect the defects in drilled shaft foundation, such as cross-hole tomography. This new method is based on a color change in the frequency amplitude of the signal recorded by the receiver probe in the location of defects and it is called Frequency Tomography Analysis (FTA).

In order to obtain the exact location of the void, the data acquisition signal from CHA is plotted in time domain. FFT process was used to convert the time domain signal into the frequency domain. The frequency domain data was de-noised to obtain the best estimate of the function. This method is employed after CSL has determined the high probability of an anomaly in a given area and is applied to improve location accuracy and to further characterize the feature.

An improved standard method is proposed that considers not only the traditional arrival time changes but also the signal strength and frequency amplitude of the signal reduction to improve the location accuracy. The technique has a very good resolution and clarifies the exact depth location of any void or defect through the length of the drilled shaft for the voids inside the cage.

A sufficiently large frequency amplitude reduction from a large defect would define a defect even when the time domain information looks normal. In cases of local defects which include only part of the cross section, frequency tomography analysis is very helpful to visualize and quantify the extent and location of the defect. Such information is 
useful for the structural engineer who must assess the adequacy of the drilled shaft to support the applied loads. 


\title{
V. BEHAVIOR OF AXIALY LOADED SHAFT FOUNDATIONS WITH SYMMETRIC VOIDS OUTSIDE AND INSIDE THE CAGING
}

\author{
Masood Hajali and Caesar Abishdid
}

\begin{abstract}
Drilled shaft foundations are usually constructed with anomalies and defects because of their huge size and visually unexposed nature underground. During the construction process, different types of anomalies such as necking, soft-bottom gap at the base, voids and soil intrusions can occur. Anomalies throughout the length can significantly reduce the axial load capacity of the drilled shaft. This paper studies the effect of voids inside and outside the reinforcement cage on the strength and axial load capacity of drilled shafts. The objective of this research is to quantify the extent of loss in axial strength and stiffness of drilled shafts due to presence of three different types of symmetric voids throughout their lengths; also, to evaluate the potential for buckling of longitudinal bars within the various types of voids. To complete these objectives, fifteen large-scale drilled shaft samples were built and tested using a hydraulic actuator at the Florida International University's (FIU) Titan America Structures and Construction Testing (TASCT) laboratory. During the static load test, load-displacement curves were recorded by the data acquisition system (MegaDAC). Results show that the presence of symmetric voids outside the rebar cage (void Type C) that occupy $40 \%$ of the cross sectional area of the drilled shafts cause $27 \%$ reduction in the axial capacity, while the symmetric voids that penetrate inside the core (void Type B) cause $47 \%$ reduction in the axial capacity. The findings indicate that the voids Type B decrease the capacity and
\end{abstract}


stiffness of drilled shafts more than other types due to the resulting inadequate confinement of the concrete and reinforcement.

Keywords: Drilled Shaft Foundation, Axial Load Capacity, Strength, Void, Cage, Buckling, and Stiffness.

\section{Overview}

Drilled shaft foundations are the most commonly used type of foundation to support heavy structures, including high rise buildings and bridges. They are constructed by placing fluid concrete and steel cage in drilled holes in the ground. Advances in construction technology of drilled shaft foundations in the last ten years caused them to become an economic replacement to group piles and driven piles. A reason for this trend is the apability of using nondestructive testing (NDT) as an essential component of deep foundation construction for quality assurance. Several NDT techniques that can be used to detect anomalies are described in detail in Wightman (2004) and Haramy (2007). Cross-hole sonic logging (CSL) (Baker 1993 and O’Neill 1999), sonic mobility (Rix et al. 1993, Davis 1995, Olson 1998), cross-hole tomographic (Olson and Hollena 2002), Impulse echo testing, and gamma-gamma testing [1] are all NDT techniques that are used in the field. Iskander, et al. (2003) [2] concluded that down hole methods such as CSL and cross hole tomography are generally able to identify defects exceeding $10 \%$ of the cross sectional area in size. NDT methods mentioned above can detect different types of anomalies such as necking, bulbing, soft bottom, voids, lack of concrete cover over reinforcement or cavity created during concrete placement. Some previous works evaluated the effects of single voids in one side of the shaft on the shaft axial capacity. However, they neither consider the various percentages of voids as covered in this study, 
nor did they compare the results with intact specimen, both experimentally and analytically.

Iskander, et al. (2003) [2] studied drilled shafts constructed with built-in defects located in various areas within the shaft. The purpose of the study was to assess the effect of anomalies on the axial capacity in varved clay. Six drilled shafts were tested, the void size varying from 5 to $11 \%$ of the cross-sectional area, and soil inclusions varying from $5-17 \%$ of the cross-sectional area. A soft bottom resulted in a $33 \%$ reduction in end bearing relative to a sound bottom. The capacity of the drilled shaft with no planned structural anomalies but with soft bottom were $5 \%$ to $10 \%$ higher than the shaft with a sound bottom and some structural anomalies. The increase of strength was insignificant, so the difference between the two drilled shafts was not recorded during construction.

O'Neill, et al. (2003) [3, 4] studied the effect of two different asymmetric voids of $15 \%$ on the axial load capacity. Eleven scaled drilled shaft samples were tested in the lab to study the behavior of drilled shafts with minor flaws under flexural and axial loading. The study concluded that minor anomalies in the form of small voids decrease the strength of a shaft in axial compression by less than 10 percent. Jung G., et al. (2006) [5] evaluated the effect of artificial anomalies including soft bottom, concrete segregation and contractions of cross sections by $10-20 \%$ on drilled shaft capacity.

Haramy (2006) [6] presented a comprehensive study on performance monitoring of concrete mix during its hydration process, CSL detection of anomaly locations, tomographic imaging of the anomaly, and the effects of anomalies on drilled shaft capacity. Haramy, et al. (2007) [7], focused on the evaluation of load bearing capacity of drilled shafts with anomalies under various conditions using 3-D numerical analysis and 
modeling to evaluate the serviceability of a defected drilled shaft. The study results showed that friction angles of surrounding geo-materials, soil density, and percentage of consolidation influence the stress concentration around anomalies; and that such stress concentration can trigger crack propagation and worsen the corrosion process. When anomalies occur, the NDT methods can assist in detecting their locations and sizes. Anomalies near the top of a drilled shaft will significantly affect its structural capacity.

Anomalies throughout the length can significantly reduce the axial load capacity of a drilled shaft. The shape and size of such voids can influence drilled shaft axial load carrying capacity in different manners as shown in Figure 5.1. It is therefore important to evaluate the effect of various types of voids on the axial load capacity of the shaft as a function of different percentages of the cross-sectional area. Fifteen (15) scaled drilled shaft samples were tested in the lab to study their structural behavior with respect to symmetric voids under uniaxial compression loadings. Tests were performed to determine the effects of shape, size and length of voids on the shafts' axial load capacity; and to evaluate the crack pattern and stress concentration near the voids, or the fracture behavior (field observation) of the drilled shaft under axial loading.

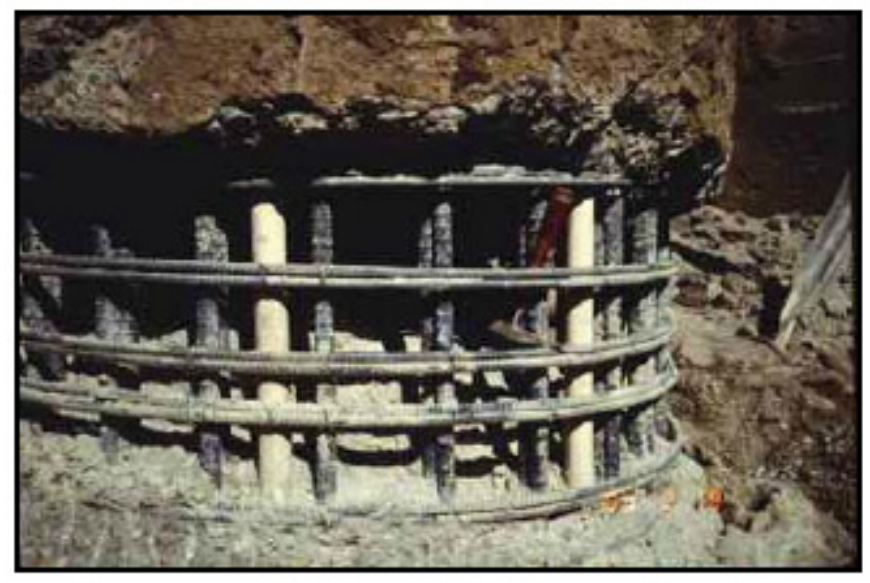

Figure 5.1: Typical Void Anomalies in a Drilled Shaft [8] 


\section{Testing Program}

Fifteen drilled shaft samples were tested at FIU's TASCT laboratory under axial compression using a hydraulic actuator with a maximum load capacity of 235 kips (1046 $\mathrm{KN}$ ). Axial load and vertical displacement at top of the shaft sample was recorded during the tests. The length and diameter of the shafts, stirrup spacing, length of anomaly, and steel reinforcement amount were kept constant in all samples.

\section{Void Shapes and Locations Considered}

Different anomaly types were considered in the form of symmetric voids with different cross sectional areas ranging from 10 percent to 40 percent of the gross cross sectional area of the shaft model based on the common void percentages in real-life drilled shafts. Also, the void sizes were determined based on the maximum size of the voids in drilled shaft foundations which can be detected by NDT methods. Three different symmetric voids shape were considered: (a) void Type A, (b) void Type B, and (c) void Type $\mathrm{C}$ as shown in Figure 5.2, with different arc length or arc angle, $\mathrm{X}^{\circ} . \mathrm{X}^{\circ}$ is the same for void Type A and void Type C. For void Types A and C, the arc lengths are $3.53,7.07,10.68$, and 14.14 inches $(9,18,27$, and $36 \mathrm{~cm})$ on each side thus occupying $10 \%$ to $40 \%$ of the cross sectional area of the drilled shafts. For void Type B, the arc lengths are $1.77,3.53,5.26$, and 7.07 inches $(4.5,9,13.4$, and $18 \mathrm{~cm})$ that occupy $10 \%$, $20 \%, 30 \%$, and $40 \%$ of the cross sectional area of the drilled shafts, respectively.

Void Type A penetrates through the concrete cover and the longitudinal bars. Void Type $\mathrm{B}$ penetrates inside the concrete core, and void Type $\mathrm{C}$ just penetrates the concrete 
cover. The concrete core inside the void Type B has a diameter of 4 inches $(10.16 \mathrm{~cm})$. The length of the voids, VL, is the same for all the samples which is 10 inches $(25.4 \mathrm{~cm})$ along the length of the shaft as shown in Figure 5.3. All voids in the scaled shafts were located at the middle of the sample while being tested in axial compression.

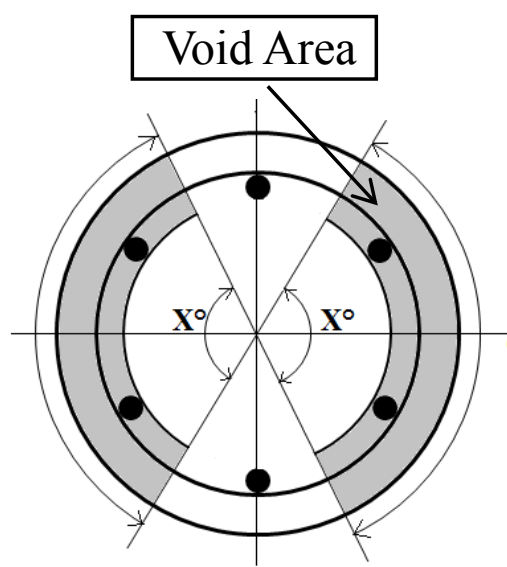

(a) Void Type A

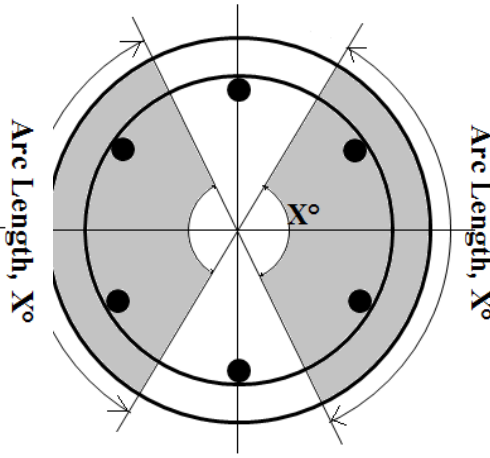

(b) Void Type B

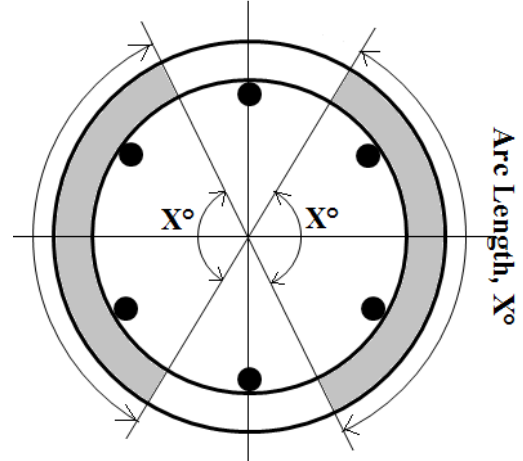

(c) Void Type C

Figure 5.2: Shape of the Voids Considered in the Experimental Program

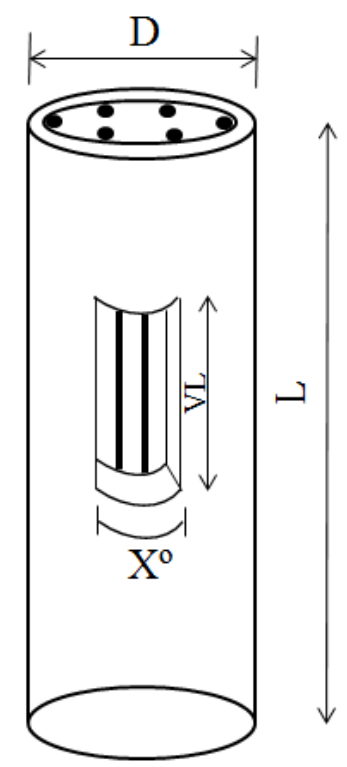

Figure 5.3: Drilled Shaft Profile with Void at the Middle 


\section{Test Specimens}

Table 5 summarizes the characteristics of the test specimens used in this study. All of the considered shaft specimens were one-fourth scale of a full-size drilled shaft in Florida with a diameter of 3 feet $(91.4 \mathrm{~cm})$ and length of 16 feet $(487.7 \mathrm{~cm})$. The samples were tested at the FIU's TASCT Laboratory. The diameter and length of the shaft samples were kept constant at 9 inches $(22.86 \mathrm{~cm})$ and 4 feet $(122 \mathrm{~cm})$, respectively. The shafts were longitudinally reinforced with 6 No. 4 steel bars that were equally spaced around the perimeter. This amount of steel corresponded to 2 percent of the gross cross-sectional area of the shaft. The longitudinal bars were Grade 80 with the nominal yield strength of $80 \mathrm{ksi}(551.6 \mathrm{MPa})$. The ties were No. 3 and were spaced along the axis of the shaft at 4 inches O.C.. The clear cover used on all steel reinforcement was 1 inch.

Specimens 1 to 4 had void Type A with void areas of 10, 20,30, and 40 percent of the gross cross-sectional area of the shaft model (void area as shown in Figure 5.2a). The arc lengths for specimens 1 to 4 were 5.53, 7.07, 10.68, and 14.14 inches $(14,18,27$, and 36 $\mathrm{cm})$ respectively. Specimens 5 to 8 had void Type B and specimens 9 to 12 had void Type $\mathrm{C}$ with the same percentages. The arc length for specimens 5 to 8 were $1.77,3.53$, 5.26, and 7.07 inches $(4.5,9,13.4$, and $18 \mathrm{~cm})$, respectively. Specimens 13,14 , and 15 were constructed without anomalies. Specimens 13 and 14 were the control specimens, and did not include any form of void with six equally spaced No. 4 longitudinal rebars around the perimeter. The last specimen, specimen 15, did not include any form of voids and was longitudinally reinforced with 6 No. 3 steel bars equally spaced around the perimeter. 
Table 5: Characteristics of Tested Drilled Shaft Specimens

\begin{tabular}{|ccccccc|}
\hline $\begin{array}{c}\text { Specimen } \\
\text { No. }\end{array}$ & Void Type & $\begin{array}{c}\text { Concrete } \\
\text { Strength } \\
(\mathrm{MPa})\end{array}$ & $\begin{array}{c}\text { Diameter } \\
(\mathrm{cm})\end{array}$ & $\begin{array}{c}\text { Longitudinal } \\
\text { Steel }\end{array}$ & $\begin{array}{c}\text { Void } \\
\text { Percentage } \\
(\%)\end{array}$ & $\begin{array}{c}\text { Arc Angle } \\
\mathrm{X}^{\circ}\end{array}$ \\
\hline 1 & & 20.8 & 22.86 & 6 No. 4 & 10 & 45 \\
2 & $\mathrm{~A}$ & 20.8 & 22.86 & 6 No. 4 & 20 & 90 \\
3 & & 20.8 & 22.86 & 6 No. 4 & 30 & 136 \\
4 & & 20.8 & 22.86 & 6 No. 4 & 40 & 180 \\
\hline 5 & & 20.8 & 22.86 & 6 No. 4 & 10 & 22.5 \\
6 & \multirow{2}{*}{$\mathrm{B}$} & 20.8 & 22.86 & 6 No. 4 & 20 & 45 \\
7 & & 20.8 & 22.86 & 6 No. 4 & 30 & 67 \\
8 & & 20.8 & 22.86 & 6 No. 4 & 40 & 90 \\
\hline 9 & & 48.3 & 22.86 & 6 No. 4 & 10 & 45 \\
10 & \multirow{2}{*}{$\mathrm{C}$} & 48.3 & 22.86 & 6 No. 4 & 20 & 90 \\
11 & & 48.3 & 22.86 & 6 No. 4 & 30 & 136 \\
12 & & 48.3 & 22.86 & 6 No. 4 & 40 & 180 \\
\hline 13 & No Void & 48.3 & 22.86 & 6 No. 4 & 0 & 0 \\
14 & No Void & 20.8 & 22.86 & 6 No. 4 & 0 & 0 \\
15 & No Void & 20.8 & 22.86 & 6 No. 3 & 0 & 0 \\
\hline
\end{tabular}

The casting form for the drilled shaft specimens consisted of a cardboard Sonatube with an inside diameter of 9 inches. Before the steel cage was positioned inside the Sonatube, eight plastic spacers with 1 inch length were installed throughout the length of the cage to keep the cage at the middle of form, and ensure the 1 inch concrete cover. Figure 5.4a shows the steel cage of a shaft and the plastic spacers on it before concrete placement. A wood formwork was built and placed at the bottom of the Sonatube to ensure that the steel cage was aligned properly, and to secure the fluid concrete during casting (Figure 5.4b). To make the voids, the Sonatube was cut at the middle with a length of 10 inches and a width equal to that of the arc lengths which depends on the arc angle and the void percentage, as shown in Figure 5.5. Plywood was used to fabricate the void shape between the Sonatube and the steel cage; it was secured at the center of the steel cage before casting. Silicone glue was used at the end to cover the holes between the 
plywood pieces and steel cage to avoid any concrete leakage (Figure 5.5). Concrete was pumped vertically inside the Sonatubes for all the specimens to ensure uniformity. Concrete was not vibrated after casting to simulate actual conditions where concrete in drilled shafts is not consolidated. All specimens were tested 30 days after casting.
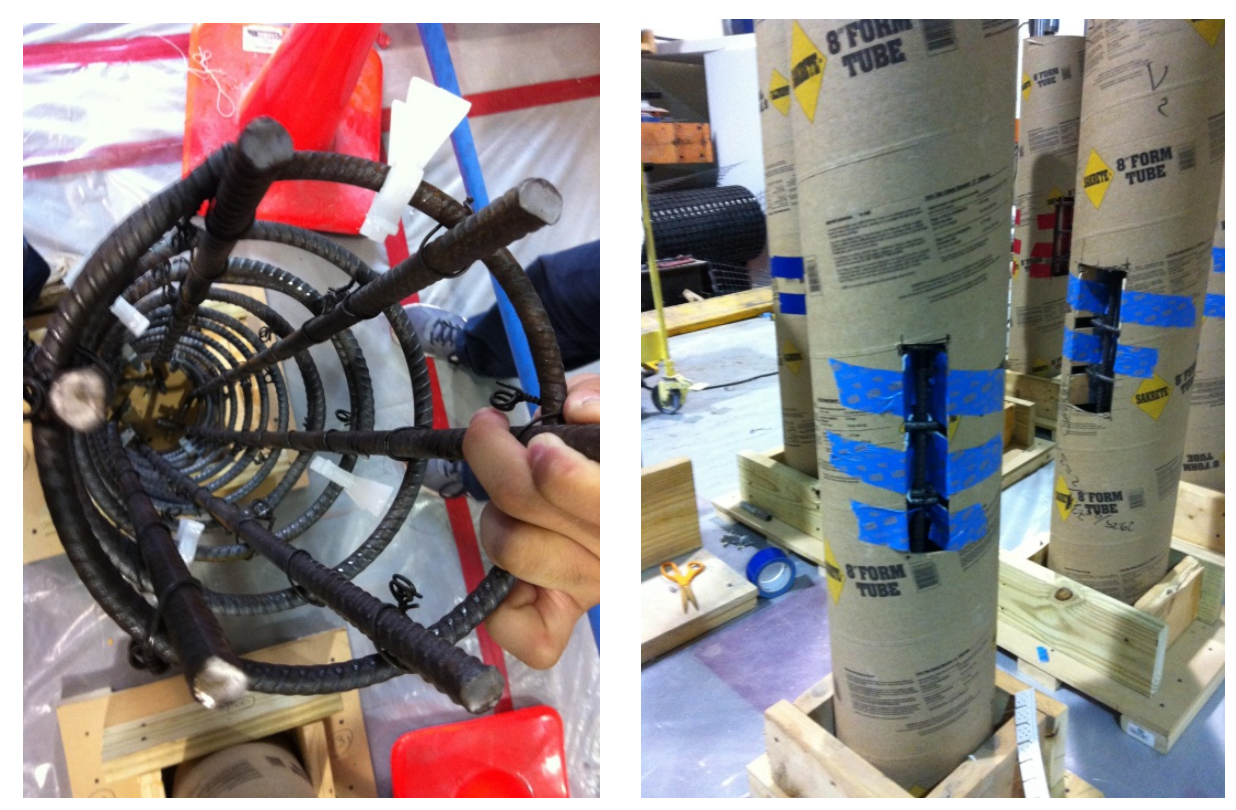

Figure 5.4: (a) Steel Cage of Specimen, (b) Sonatube with Void Tybe B, 10\%

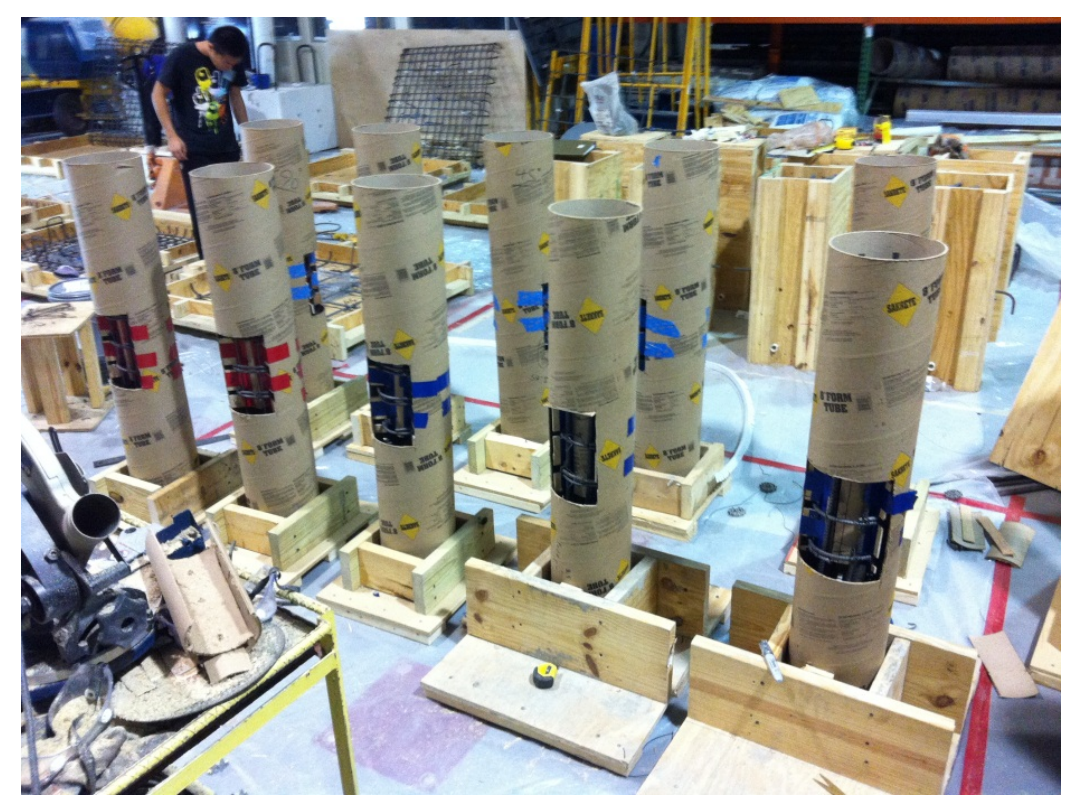

Figure 5.5: Specimens Formwork Before Concrete Placement 


\section{Material Properties}

The concrete used in this study was normal weight concrete $\left(150 \mathrm{lbs} / \mathrm{ft}^{3}\right)$. Standard concrete cylinder samples with 4-inch diameters and 8-inch lengths were tested using the Concrete Compression Machine in the laboratory at FIU. The average measured axial compressive strength for three standard cylinders was 37,900 lbs (168588 N) at 28 days. Therefore, the cured concrete cylinders had a compressive strength at 28 days equal to 3,015 psi (20.8 MPa). The concrete slump was measured to be 4 inches at the time of casting, and the maximum coarse aggregate size (rounded river gravel) was 0.5 inch (1.27 $\mathrm{cm})$. Fine aggregate was based on ASTM C33 natural sand with a fineness modulus of 3.0. The cement was type I Portland cement and comprised about 24 percent of the weight of the mix. The water to cement ratio varied between 0.4 and 0.42 , depending on the moisture content of the aggregate. Specimens 9 to 13 were constructed with concrete with compressive strength of 7,000 psi (48.3 MPa), with the same slump and same maximum coarse aggregate size. Sonatube with inside diameter of 9 inches $(22.86 \mathrm{~cm})$ was used as a formwork for the concrete. All shaft specimens were cast in a vertical position without vibration after concrete placement to simulate actual conditions.

A No. 3 bar was tested using a Universal Tensile Testing Machine in the laboratory at FIU. The tensile test loading ratio was $100 \mathrm{lbs} / \mathrm{sec}(445 \mathrm{~N} / \mathrm{sec})$. The longitudinal steel and ties in all the tested specimens were Grade 80 , with yield strength of $80 \mathrm{ksi}$. The actual yield strength was less than the nominal value $(75 \mathrm{ksi})$, and the modulus of elasticity was

$29 \times 10^{6} \mathrm{ksi}\left(2 \times 10^{8} \mathrm{MPa}\right)$. The stress-strain curve obtained for the No. 3 steel rebar is shown in Figure 5.6. 


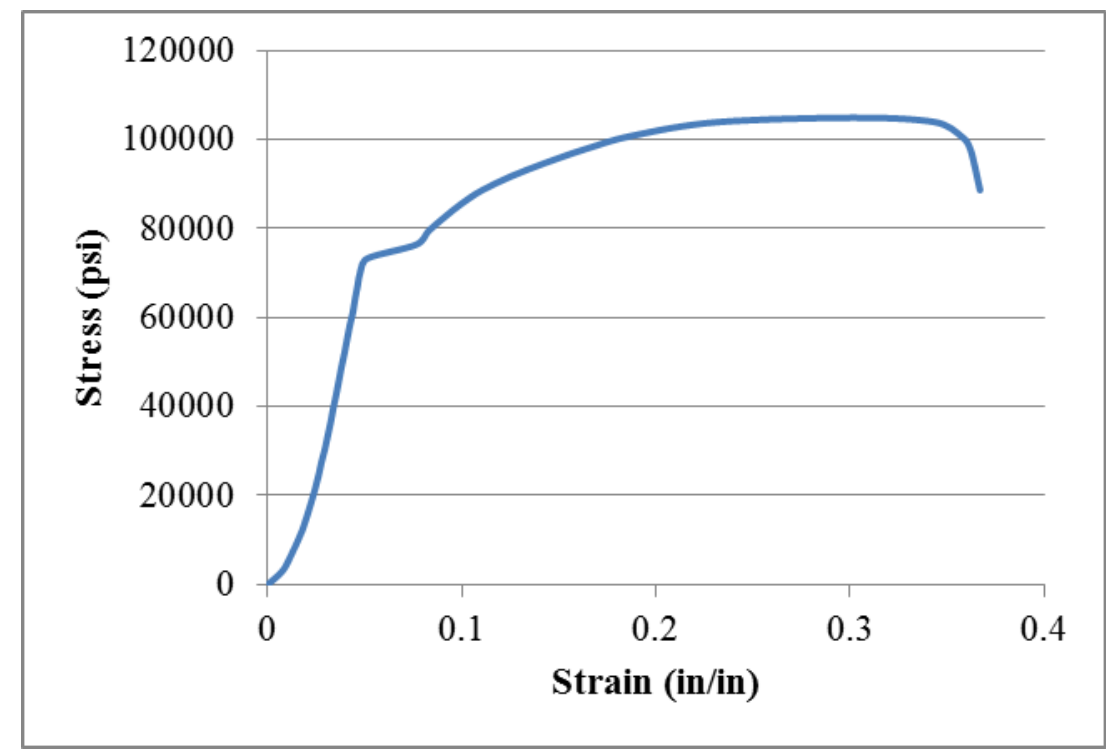

Figure 5.6: Stress-Strain Curves of Steel Rebar

\section{Testing Procedures}

Load tests were performed in general accordance with American Society for Testing and Materials (ASTM) D1143 test method for shafts under axial compressive load. All tests were performed in the same laboratory temperature to minimize thermal effects. All load tests were carried to structural failure. The test program was organized into two groups. Group I consisted of testing twelve specimens with voids (Specimens 1 to 12). First four specimens were cast with void Type A with void percentage from 10 to 40 percent; second four specimens with void Type B and third four specimens with void Type C, all with the same voids percentage. Group II consisted of testing control specimens without any voids (Specimens 13, 14, and 15). Specimen 13 was the control specimen for those shafts cast with concrete compressive strength of 7,000 psi (48.3 $\mathrm{MPa}$ ) and Specimens 14 and 15 were the control specimens for shafts cast with concrete compressive strength of 3,015 psi (20.8 MPa). All fifteen specimens were tested in pure 
axial compression in the TASCT laboratory at the FIU. The eccentricity of the applied load was approximated to be \pm 1.0 inch $( \pm 2.54 \mathrm{~cm})$.

The machine used for axial testing the drilled shaft specimens was a Shore Western hydraulic actuator with maximum capacity of 235 kips $(1,046 \mathrm{kN})$ as shown in Figure 5.7. The actuator moves from -10 inch to +10 inches $(25.4 \mathrm{~cm})$ which is total 20 inches $(50.8 \mathrm{~cm})$ of displacement from top to bottom. A displacement control procedure was adopted for all the tests at a rate of $0.012 \mathrm{in} . / \mathrm{min}(0.305 \mathrm{~mm} / \mathrm{min})$. The hydraulic actuator was equipped with a manually controlled electric pump, which allowed having a constant loading. All instruments were connected to a data acquisition system, which is a MegaDAC with a sampling frequency of $1 \mathrm{~Hz}$. The actuator deflection and shaft head displacement were recorded with the Linear Displacement Transducer (LDT) and the loading was recorded with the actuator's load cell.

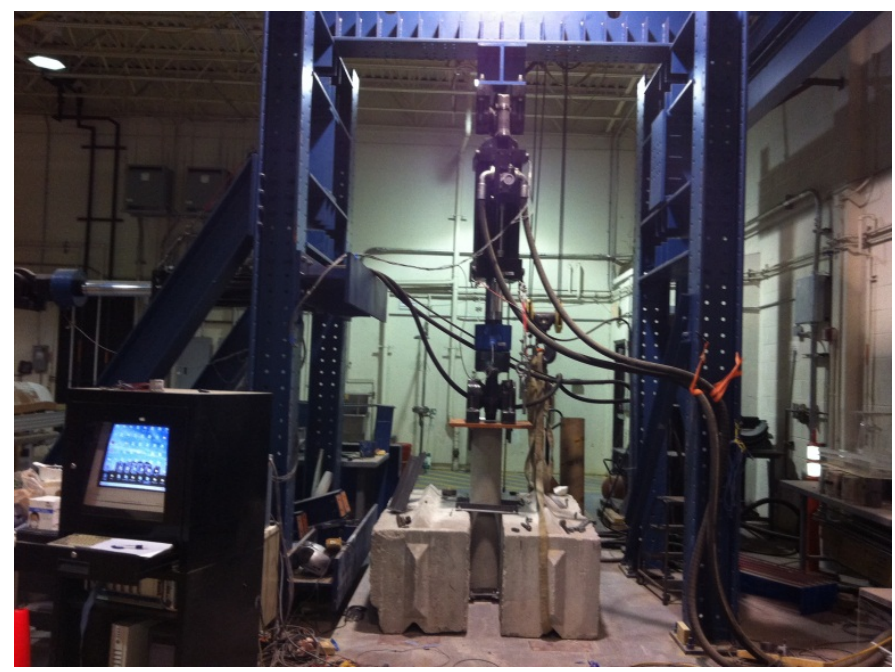

Figure 5.7: Hydraulic Actuator Machine Used for the Tests at FIU's TASCT Laboratory

A solid steel plate with thickness of $1 \mathrm{inch}$ was placed at the bottom of the specimens to provide a strong base. Two $2 \times 2 \times 6 \mathrm{ft}^{3}$ concrete blocks were constructed to 
use as lateral base support. These blocks were keeping the specimens immobile during the loading process. Angle bars of $1.5 \times 1.5 \times 0.25 \mathrm{in}^{3}\left(3.8 \times 3.8 \times 0.6 \mathrm{in}^{3}\right)$ were cut and used to make the support for the specimens. Two supports were considered at the bottom and middle of the specimen to prevent buckling of the samples in the first mode before failure, as shown in Figure 5.8. Figure 5.8 also shows the instrumentation scheme, geometry, and loading procedure for the specimen loaded axially.

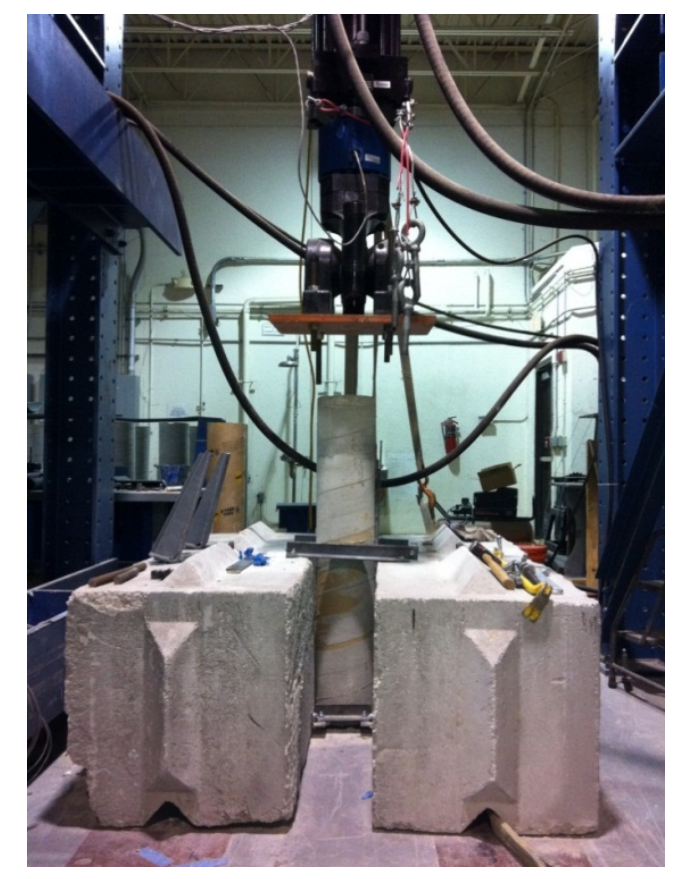

Figure 5.8: Test Setup

\section{Test Results and Discussion}

The behavior of the drilled shafts subject to axial load was investigated in this study. The axial load versus vertical displacement for Specimens 1 to 4 in test Group I is shown in Figure 5.9. The test results show that the presence of symmetric voids within the cross section affected both the strength and the stiffness of the shaft. The effect on the stiffness was much more pronounced, especially when the void penetrated inside the core of the 
shaft (void Type B). This result is due to having inadequate confinement of the concrete and reinforcement and local buckling of the longitudinal steel bars in the shaft.

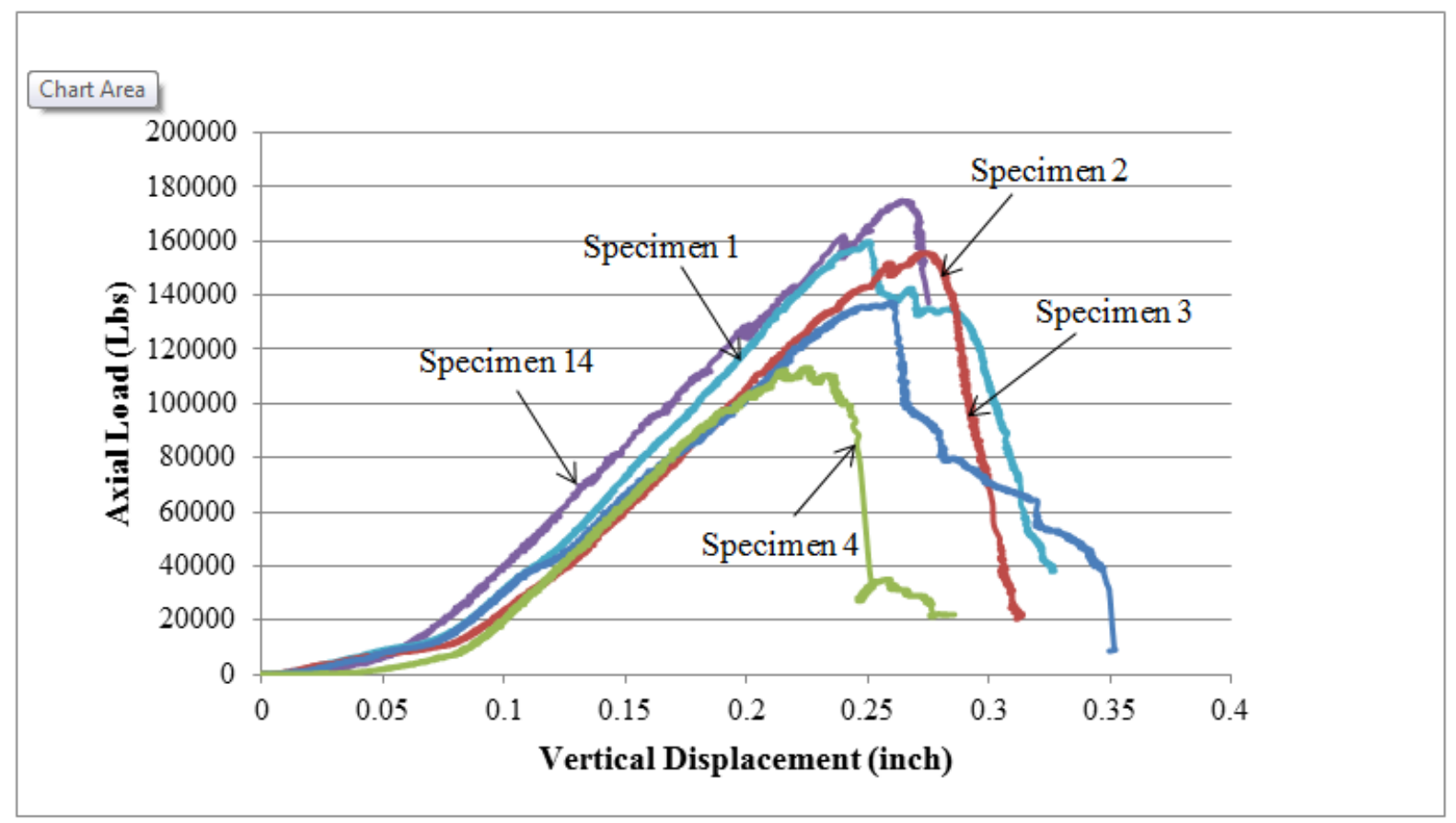

Figure 5.9: Axial Load versus Vertical Displacement for Specimens 1-4 (void Type A)

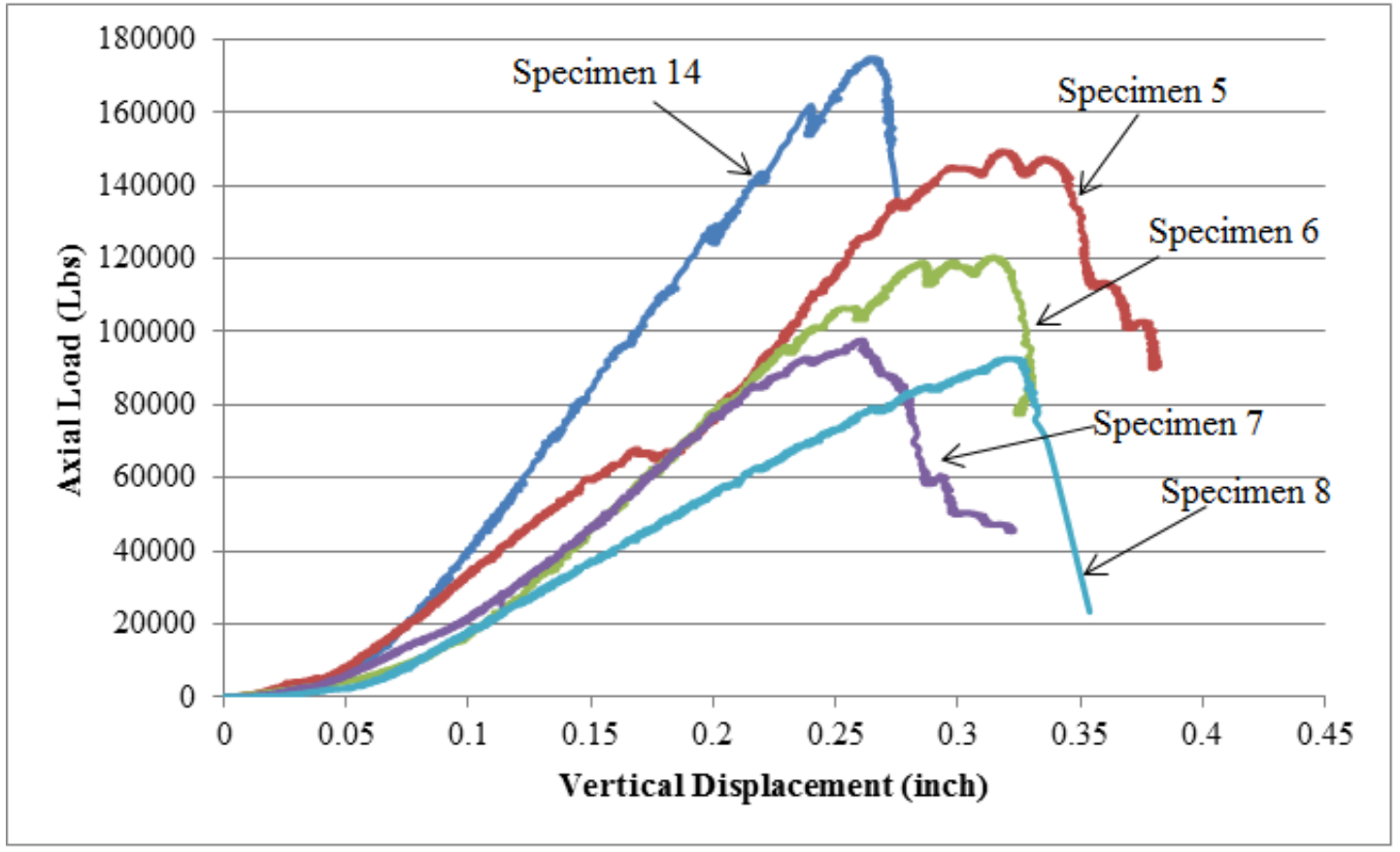

Figure 5.10: Axial Load versus Vertical Displacement for Specimens 5-8 (void Type B) 


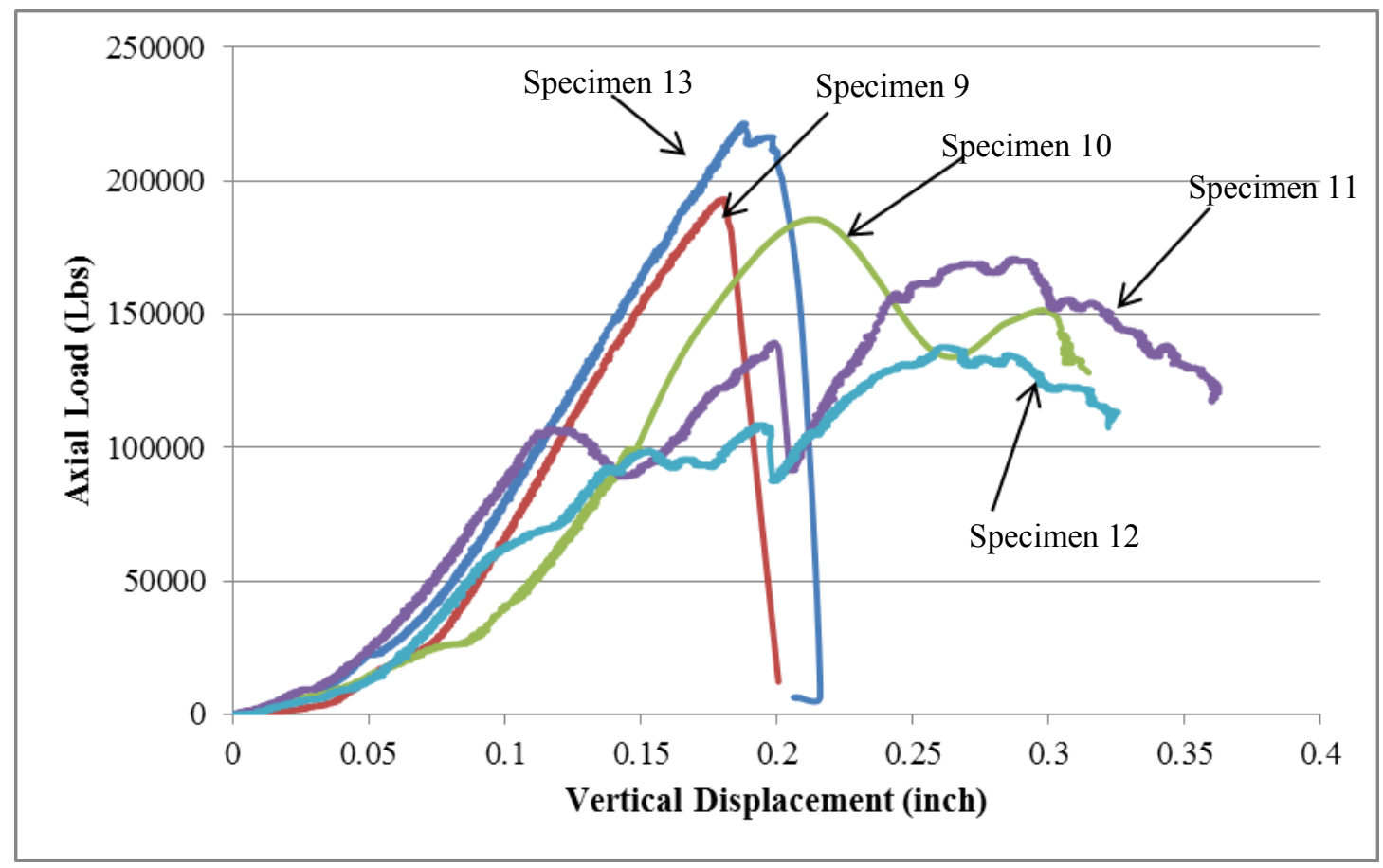

Figure 5.11: Axial Load versus Vertical Displacement for Specimens 9-12 (void Type C)

Table 5.6 shows that—compared to the intact specimen—the shafts with Type A void exhibited 10 to 37 percent lower axial compressive strength; shafts with Type B void exhibited 18 to 47 percent lower axial compressive strength, with concrete strength of 3,015 psi (20.8 MPa). The decrease in axial compressive strength for the shafts with Type $\mathrm{C}$ void was about 7 to 27 percent in comparison to the shaft without anomaly and with concrete strength of 7,000 psi (48.3 MPa). These results show that the presence of a void inside the cage (void Type B) will significantly decrease the axial strength of the shaft. 
Table 6: Maximum Axial Load Capacity for Shafts with Different Types of Voids

\begin{tabular}{|c|cc|cc|cc|}
\cline { 2 - 7 } \multicolumn{1}{c|}{} & \multicolumn{2}{c|}{ Void Type A } & \multicolumn{2}{c|}{ Void Type B } & \multicolumn{2}{c|}{ Void Type C } \\
\hline $\begin{array}{c}\text { Void } \\
\text { percentage }\end{array}$ & $\begin{array}{c}\text { Axial Load } \\
(\mathrm{KN})\end{array}$ & $\begin{array}{c}\% \\
\text { reduction }\end{array}$ & $\begin{array}{c}\text { Axial } \\
\text { Load } \\
(\mathrm{KN})\end{array}$ & $\begin{array}{c}\% \\
\text { reduction }\end{array}$ & $\begin{array}{c}\text { Axial } \\
\text { Load } \\
(\mathrm{KN})\end{array}$ & $\begin{array}{c}\% \\
\text { reduction }\end{array}$ \\
\hline $0 \%$ & 773.28 & & 773.28 & & 951.91 & \\
$10 \%$ & 693.54 & 10.31 & 632.18 & 18.25 & 878.33 & 7.73 \\
$20 \%$ & 658.35 & 14.86 & 521.19 & 32.60 & 843.34 & 11.41 \\
$30 \%$ & 604.87 & 21.78 & 420.72 & 45.59 & 789.38 & 17.07 \\
$40 \%$ & 483.575 & 37.46 & 406.46 & 47.44 & 686.52 & 27.88 \\
\hline
\end{tabular}

\section{Specimens Failure}

Figure 5.12 shows the fractured specimens after the conclusion of the testing. For all specimens, the shape of the void, size of the void, and length of the void greatly affected the axial compressive strength and stiffness of the shaft specimens. Generraly, it can be seen that cracks in specimensstarted around and in the vecinity of the voids, and weakened the specimens during loading. In specimens with Type B void, it can be seen that the fractures was clearly due to lack of confinement of the concrete and its reinforcement, because of its proximity to the void location. Specimens with void Type B had less critical buckling load or buckling capacity because the arc length was smaller. Buckling was a main reason of fracture for specimens with Type A void since the arc length of the void was much more than that in specimens with Type B void. Also, in specimens with Type A void, most of the longitudinal bars were placed in the void area. For example, specimen 4 had two symmetric voids with 180 degree arc angles each, which meant that it covered the entire perimeter of the specimen. Most of the growth cracks in the shaft specimens were in the longitudinal direction of the shaft, and they 
show a shear failure in the specimens under axial loading. All specimens behave similarly up to the shafts' failure point. At that point, the shaft specimens with void Type A and B fail by crushing and shearing of the concrete, and by the outward buckling of the steel bars. The specimens with void Type $\mathrm{C}$ are tougher than those with voids Types A and B because of the concrete cover around the longitudinal bars.

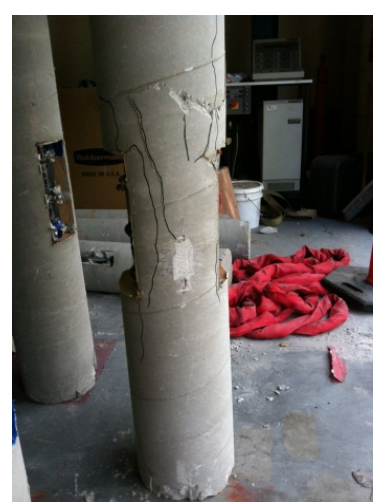

Specimen 1

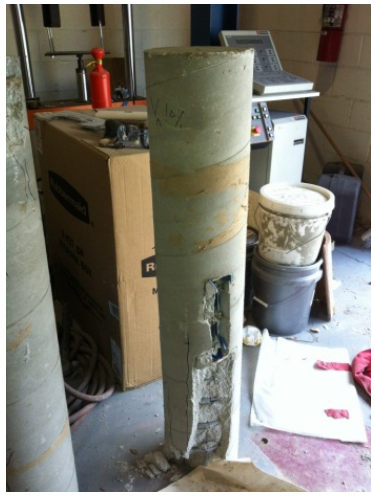

Specimen 5

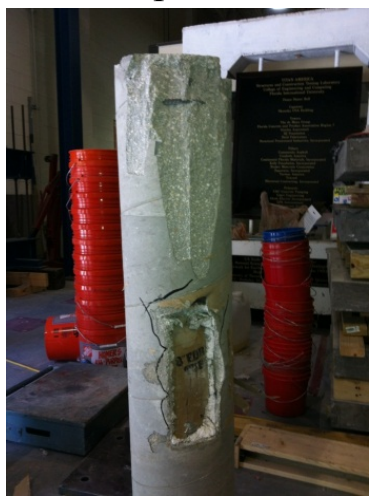

Specimen 9

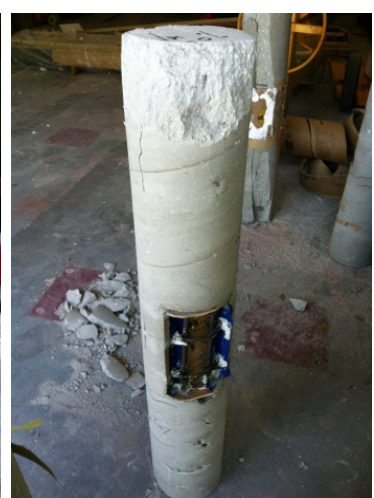

Specimen 2

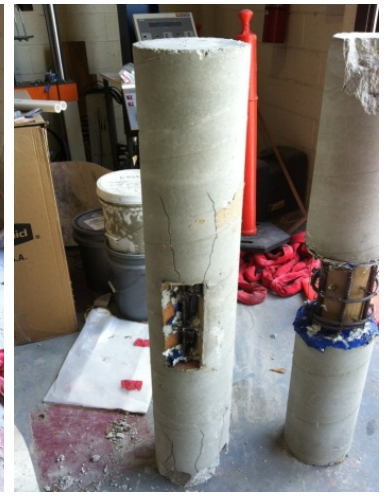

Specimen 6

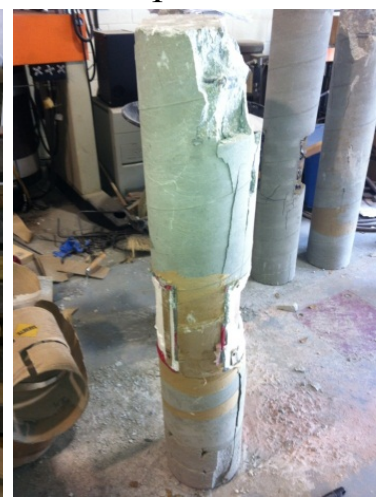

Specimen 10

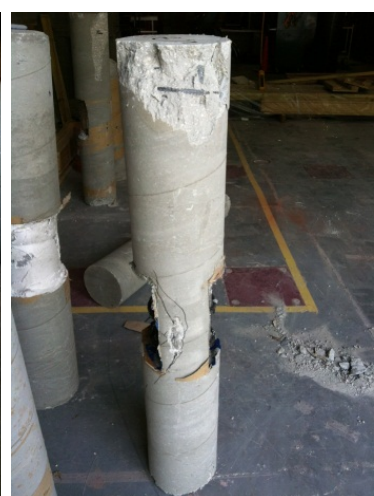

Specimen 3

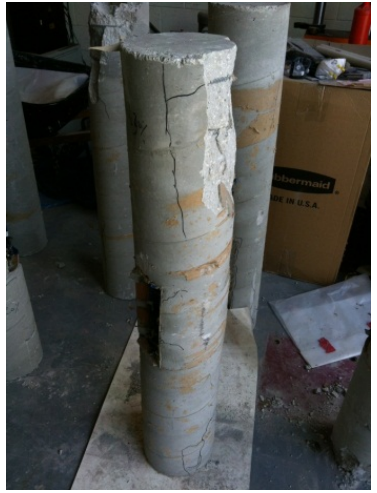

Specimen 7

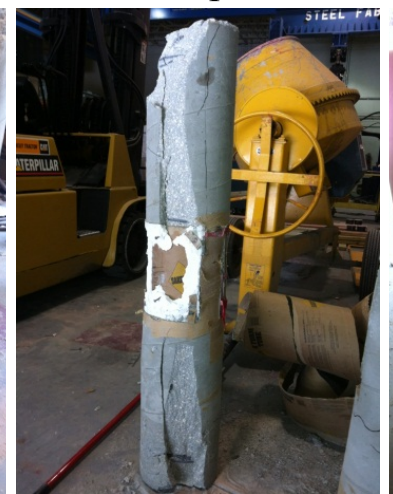

Specimen 11

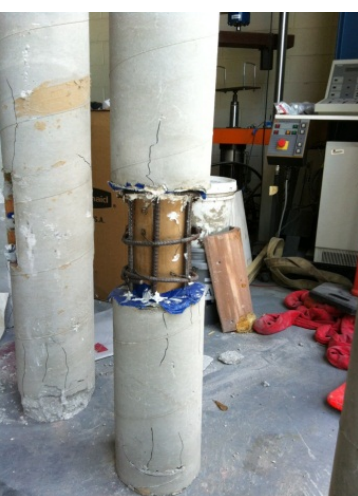

Specimen 4

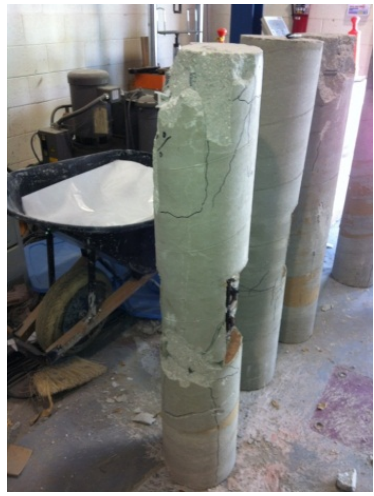

Specimen 8

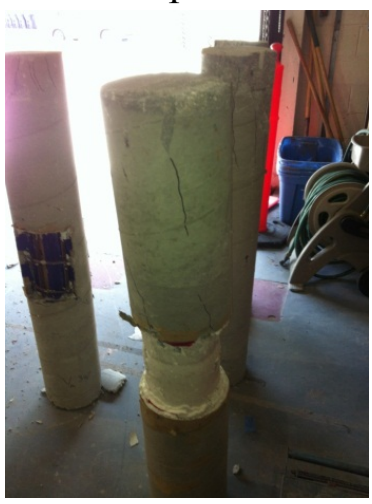

Specimen 12 


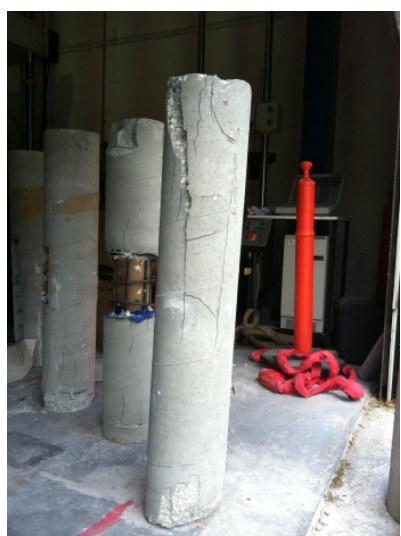

Specimen 13

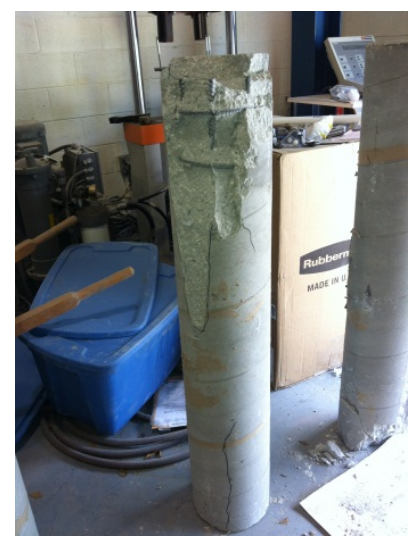

Specimen 14

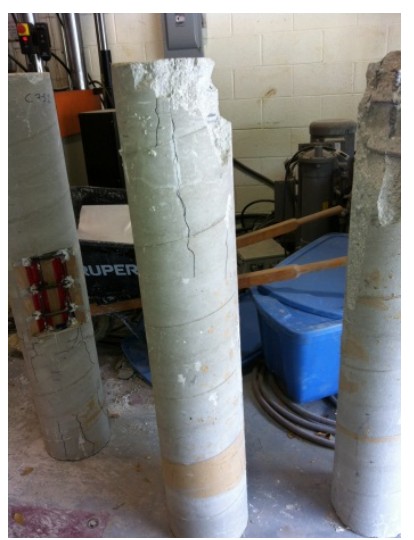

Specimen 15

Figure 5.12: Failure in Shaft Specimens after Testing

Failures in Specimens 13, 14, and 15, the intact specimens are shown in Figure 5.12. It can be seen that the failure cracks started from the top support location and grew in the longitudinal direction towards the top of the specimens. Also, the compressive axial load resulted in pure compression failure and material crushing in the region where the actuator was bearing on the specimens.

\section{Analytical Evaluation}

The results of the experimental test program were compared with the ACI 318 [9] and the AASHTO LRFD Bridge Design Specifications [10] formula for axially-loaded reinforced concrete members as shown in Eq. (19). The nominal theoretical axial load strength for the special case of zero eccentricity may be written as:

$\phi P_{n}(\max )=0.7\left[0.8\left\{0.85 f_{c}^{\prime}\left(A_{g}-A_{s}\right)+f_{y} A_{s}\right\}\right]$

where $f^{\prime}{ }_{c}$ is the nominal 28 day concrete compressive strength (psi), $f_{y}$ is nominal steel yield strength of the longitudinal bars (psi), $A_{g}$ is the gross area of the shaft section $\left(\mathrm{in}^{2}\right)$, and $A_{s}$ is total area of the longitudinal reinforcement $\left(i^{2}\right)$. Table 7 compares the experimental data with the analytical results for the compressive axial load capacity of 
the intact specimens. Table 7 shows that the analytical result of the axial load capacity based on Eq. (1) is almost $20 \%$ larger than the experimental results.

Table 7: Experimental vs. Analytical Axial Loads for the Drilled Shaft Specimens

\begin{tabular}{|c|c|c|c|}
\hline $\begin{array}{c}\text { Specimen } \\
\text { No. }\end{array}$ & $\begin{array}{c}P_{n}(\max ) \\
\text { Experimental }(\mathrm{KN})\end{array}$ & $\begin{array}{c}P_{n}(\max ) \\
\text { Analytical }(\mathrm{KN})\end{array}$ & $\begin{array}{c}\text { Difference } \\
(\%)\end{array}$ \\
\hline 13 & 951.91 & 1143.32 & 16.74 \\
14 & 773.28 & 880.96 & 12.22 \\
15 & 530.38 & 745.60 & 28.87 \\
\hline
\end{tabular}

Figure 5.13 shows a comparison of the axial load versus the vertical displacement for Specimens 14 and 15-the intact specimens without voids. Specimen 14 was longitudinally reinforced with 6 No. 4 steel stirrups that were equally spaced around the perimeter, and Specimen 15 with 6 No. 3 steel stirrups. It was determined that the strength of Specimen 14 at failure was 173.8 kips (773.1 KNs) and that of Specimen 15 was 119.2 kips (530.23 KNs), which is almost $15 \%$ larger.

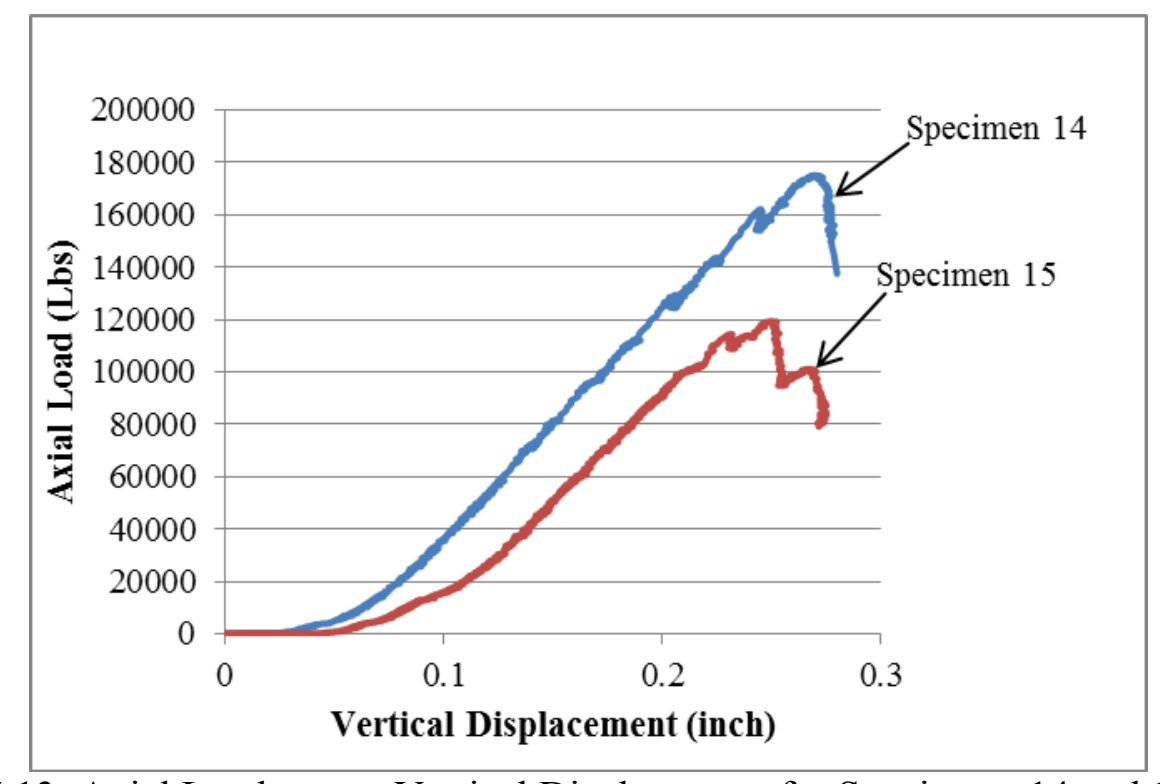

Figure 5.13: Axial Load versus Vertical Displacement for Specimens 14 and 15 (Intact Specimens) 


\section{Conclusions}

1. This paper presented the results on fifteen drilled shaft specimens under axial compressive load tested at the TASCT laboratory at FIU. The shaft specimens were constructed with three different types of built-in symmetric voids in an attempt to study the effect of voids outside and inside the caging on the axial load capacity of drilled shafts. Void Type A resulted in a $21 \%$ reduction in axial strength, void Type B resulted in a $36 \%$ reduction, and void Type $\mathrm{C}$ resulted in a $15 \%$ reduction in axial strength. The test results showed that the presence of symmetric voids within the cross section affected both the strength and the stiffness of the drilled shafts. The effect on the strength and the stiffness was much more noticeable especially when the void penetrated inside the caging of the shaft (void Type B). This was deduced to be due to the lack of concrete confinement for the longitudinal bars.

2. Stress concentrations near the void location were much larger than other locations, and they caused shear cracks to appear around the voids, and the consequent failure of the specimen. The presence of symmetric voids outside the rebar cage (void Type C), that take up $40 \%$ of the cross sectional area of the drilled shafts, reduced the axial resistance of the shaft by only $27 \%$; those that penetrated inside the core (void Type B) reduced the axial resistance of the shaft by up to $47 \%$. Drilled shafts with all types of voids behaved in a similar fashion up to the shafts' failure point. At that point, drilled shafts with void Types A and B failed by crushing and shearing of the concrete and by outward buckling of the steel bars. Drilled shafts with void Type $\mathrm{C}$ showed more strength than those with 
void Types A and B due to the concrete cover around the longitudinal bars that provided confinement effects.

3. Comparison between the experimental and the analytical results of the compressive axial load capacity of the intact specimens showed that the analytical results are near $20 \%$ larger than the experimental results.

4. The study showed that voids will affect the axial structural capacity of the drilled shafts. Drilled shaft capacity is affected by the size and location of the void. Location and size of the void will have a significant influence on the confinement of the longitudinal bars, causing structural capacity reduction. The study showed that voids extending into the concrete core were more critical to the structural performance of a shaft than those located within the concrete cover. Voids penetrating the reinforcement cage result in more drilled shaft capacity reduction. The presence of voids outside the rebar cage will cause less axial capacity reduction due to the better confinement. It is recommended that a reduction factor $R$ be used in the structural design codes and specifications for drilled shafts. A reduction factor $R=0.90$ is recommended for drilled shafts located in environments where corrosion is not expected. This reduction factor can be changed depending on the location of the voids after nondestructive testing on the shaft. 


\title{
VI. EVALUATION OF DRILLED SHAFT STRUCTURAL CAPACITY REDUCTION DUE TO CORROSION IN LONGITUDINAL BARS
}

\author{
Masood Hajali and Caesar Abishdid
}

\begin{abstract}
Construction procedures of drilled shaft foundations are critical to the quality of the finished drilled shaft, and very careful inspection is required throughout. Drilled shafts are usually constructed with various types of anomalies due to their very large size and to being inaccessible throughout their entire subterranean length. Necking is one of the most critical types of the anomalies that can take place throughout the length of the shaft, causing loss of concrete cover around the longitudinal bars. In such cases, the reinforcing steel rebars will become exposed to, and in contact with, the surrounding soil, thus leading to corrosion of the longitudinal bars and lateral ties in the vicinity of the necking. This paper presents the results of an experimental study that was carried out to evaluate the effect of rebar corrosion on the axial load carrying capacity of drilled shaft foundations with symmetric voids. The objective of this study is to quantify the extent of loss in axial strength of drilled shafts due to presence of different corrosion percentages in the longitudinal bars. To achieve this, seven (7) large-scale drilled shaft samples were built and tested using a hydraulic actuator at the Florida International University's (FIU) Titan America Structures and Construction Testing (TASCT) laboratory. During the static load test, load-displacement curves were recorded by the data acquisition system (MegaDAC). Results show that the presence of corrosion in the longitudinal bars affects both the strength and buckling capacity of a shaft. The results of the experimental
\end{abstract}


program were used to investigate the drilled shafts' capacity reduction rate over a period of 40 years in Miami soil conditions due to such corrosion in the longitudinal bars.

Keywords: Drilled Shaft Foundations, Axial Load Capacity, Corrosion, Longitudinal Bars, Corrosion Rate, Capacity Reduction Rate, and CSL Tube.

\section{Overview}

The construction of higher and heavier structures in urban areas where noise and vibration regulations make hammering of piles prohibitive, lead to the development of the drilled shaft foundation that can reach stronger soil strata where shallow foundations could not develop sufficient capacity. A drilled shaft is formed by boring an open cylindrical hole into the soil and subsequently filling the hole with concrete. Drilled shafts are applicable to a wide variety of subsurface conditions, and a single shaft can carry very large loads without the need for a cap at the top. These are some of the many reasons why the use of reinforced concrete drilled shafts as deep foundations for various subsurface media has grown significantly in the last decade. The proper performance of drilled shafts and their carrying capacity require expert knowledge and experience in the effects of construction defects on such performance. Corrosion of the steel reinforcement is one such construction defects that can occur due to the penetration of voids into the concrete core. The loss of the concrete cover to the cage due to soil intrusion is the main culprit behind the shaft's vulnerability to rebar corrosion. Corrosion will reduce the cross section of the longitudinal bars and lateral ties which are located in the vicinity of the voids or "necking", thus causing reduction to the axial load capacity of the shaft. Corrosion rate of the steel reinforcements depends on certain parameters such as moisture 
content, organic content, level of compaction and grain size, $\mathrm{pH}$, chloride concentration, and resistivity of the soil.

Corrosion is the sublation of metal or properties change by chemical reaction with the environment. Corrosion is fundamentally a return of metals to their native state as oxides and salts. The only metals which exit in their native state are noble metals and copper, other metals are refined by applying energy in the heat process. Most chemical elements are present in soils to initiate corrosion on the steel surface. In general, the most corrosive soils contain large concentrations of soluble salts, especially in the form of sulfates, chlorides, and bicarbonates and may be characterized as very acidic (low $\mathrm{pH}$ ) or highly alkaline (high $\mathrm{pH})$ [1].

Some studies have addressed the issue of corrosion of steel bars inside the concrete. Sarhan and O'Neill [2] studied the results of an experimental work designed to investigate the effect of two different media of substantially different $\mathrm{pH}$ values on the rate of corrosion of steel reinforcement in sand and clay soils, and with different anode to cathode area ratios. Lichtenstein [ $[\underline{3}]$ evaluated various reasons of corrosion of buried pipelines. Among the causes reported are presence of cinders or free carbon in the soil, dissimilar soils, and stray currents. Berke et al. [4] and Fischer, et al. [ $[\underline{5}$ ] reported different rates of corrosion based on the chloride concentration. Miller and Hartt [ $\underline{6}]$ discussed the effect of stray currents on the corrosion of reinforcing steel in concrete using a physical model simulating a bridge structure. Galvanic currents driven by couples between exposed and covered steel were dependent on the surface area ratios of exposed anodic steel and covered cathodic steel. 
Tabsh and O'Neill [7] studied the effects of some minor anomalies on the axial capacity of drilled shafts. They considered variables including the shape and length of the void, confinement spiral pitch, rebar corrosion, and steel cage offset. They concluded that the effect of a void anomaly on the strength and ductility of a shaft is more critical when the spiral pitch is large. Corrosion of longitudinal reinforcement through a void anomaly was also evaluated in their study. Their results show that corrosion of longitudinal reinforcement reduced the ductility ratio by about 66 percent.

Gladstone et al, [8] investigated the durability of galvanized soil reinforcement and evaluated various reasons of corrosion in galvanized pipes embedded in soil. Fishman et al [9] studied condition assessment and corrosion monitoring of three walls at a site with aggressive reinforced fill and site conditions. Exhumed reinforcements for visual examination and laboratory testing; performed electrochemical testing on service reinforcements and coupons. A total of 12 monitoring stations were dispersed throughout the site providing a very good sample distribution. Wheeler $[10,11]$ studied screened inventory and established priorities for condition assessment and corrosion monitoring based on suspect reinforced fills.

Corrosion in longitudinal bars throughout the length can significantly reduce the axial load capacity of a drilled shaft. It is therefore important to evaluate the effect of different corrosion percentages on the axial load capacity of the shaft. Seven (7) scaled drilled shaft samples were tested in the lab to study their structural behavior with respect to corrosion in longitudinal bars. Based on the Miami soil conditions, the corrosion rate in the reinforcing bars and the drilled shafts axial load capacity reduction rate will then be 
calculated for a 40-year life span. Tests were also performed to determine the crack pattern and failure behavior (field observation) of the drilled shafts under axial loading.

\section{Testing Program}

Seven (7) drilled shaft samples were tested at FIU's TASCT laboratory under axial compression using a hydraulic actuator with a maximum load capacity of 235 kips (1046 $\mathrm{KN}$ ). Axial load and vertical displacement at top of the shaft sample were recorded during the tests. The length and diameter of the shafts, lateral tie spacing, length of anomaly, void area percentage, and void shape were kept constant in all samples. The void shape, size and location considered to analyze the effect of corrosion in this study are shown in section 1.1 below.

\section{Void Shape and Location Considered}

Seven (7) specimens were built to evaluate the effect of corrosion on the axial load capacity of the shafts. The void shape considered in the samples is shown in Figure 6.1 with arc length or arc angle of $\mathrm{X}^{\circ}$. The void penetrated through the concrete cover and the longitudinal bars. The reinforcing steel rebars will therefore be in contact with the surrounding soil area and will be susceptible to corrosion. For this void type, the arc lengths is 3.53 inches $(9 \mathrm{~cm})$ and occupies $20 \%$ of the cross sectional area of the drilled shaft. The anomaly type was considered in the form of symmetric voids with cross sectional area amounting to 20 percent of the gross cross sectional area of the shaft model based on common void percentages found in real-life drilled shafts. Also, the void size was determined based on the regular size of the voids in drilled shaft foundations, which is detected by NDT methods. This void type penetrates inside the concrete core as shown 
with gray color in Figure 6.1. The length of the voids, VL, is the same for all the samples, which is 10 inches $(25.4 \mathrm{~cm})$ along the length of the shaft, as shown in Figure 6.2. All voids in the scaled shafts were located at the middle of the longitudinal dimension of the sample when being tested in axial compression.

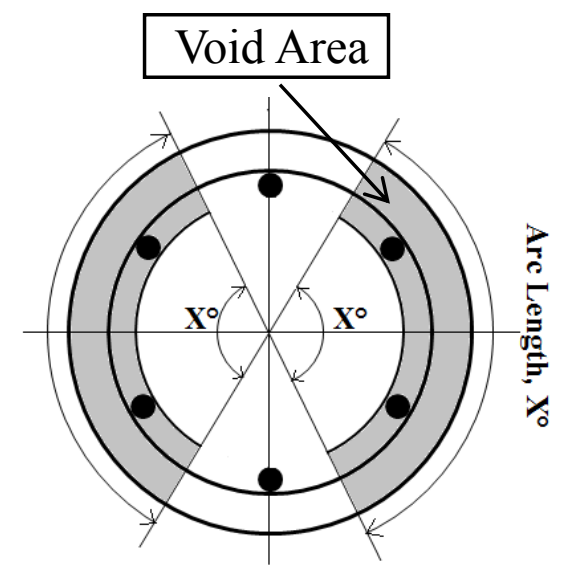

Figure 6.1: Shape of the Voids Considered in the Experimental Program

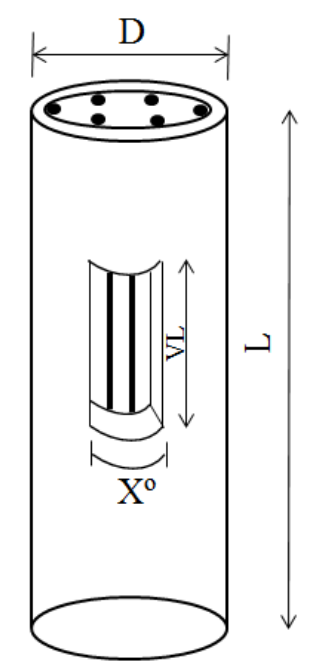

Figure 6.2: Drilled Shaft Profile with Void at the Middle

\section{Test Specimens}

Table 8 summarizes the characteristics of the test specimens used in this study. All of the considered shaft specimens were one-fourth scale of a typical full-scale drilled shaft 
in Florida which has a diameter of 3 feet $(91.4 \mathrm{~cm})$ and length of 16 feet $(487.7 \mathrm{~cm})$. The samples were tested at the FIU's TASCT Laboratory. The diameter and length of the shaft samples were kept constant at 9 inches $(22.86 \mathrm{~cm})$ and 4 feet $(122 \mathrm{~cm})$, respectively. The shaft samples without corrosion were longitudinally reinforced with 6 No. 4 steel bars, equally spaced around the perimeter. This area of steel corresponded to 2 percent of the gross cross-sectional area of the shaft. The longitudinal bars were Grade 80 with the nominal yield strength of $80 \mathrm{ksi}(551.6 \mathrm{MPa})$. The lateral ties used were No. 3 and were spaced along the axis of the shaft at 4 inches O.C.. The clear cover used on all steel reinforcement was 1 inch $(2.54 \mathrm{~cm})$.

Seven drilled shaft specimens were built for considering the effect of corrosion as summarized in Table 8. Specimen 1 did not have any steel corrosion; specimens 2, 3, 4, and 5 had $25 \%, 50 \%, 75 \%$, and $100 \%$ corrosion in the void part in longitudinal bars, respectively. To replicate the case of $25 \%$ corrosion for specimen 2 , the longitudinal bars were rubbed using rough carbon steel sheet. The diameter of the bars was reduced to $3.5 / 8$ inches. To replicate the case of 50\% corrosion for specimen 3, 6 No. 3 steel bars were used, and to replicate the case of $75 \%$ corrosion for specimen 4,6 No. 2 steel bars were used. To replicate the case of $100 \%$ corrosion for specimen 5, the longitudinal bars were completely severed in the void section. Specimen 6 did not have any void or corrosion and was reinforced with 6 No. 4 steel bars. Specimen 7 did not have any void and was reinforced with 6 No. 3 steel bars. Specimens 1 and 6 were control specimens to compare the structural capacity reduction of an intact specimen with a specimen with void and with specimens with void and corrosion. 
Table 8: Specifications of Tested Drilled Shaft Specimens for Corrosion

\begin{tabular}{|c|c|c|c|c|c|c|}
\hline \multirow{2}{*}{$\begin{array}{l}\text { Specimen } \\
\text { No. }\end{array}$} & \multicolumn{2}{|c|}{$\begin{array}{l}\text { Concrete } \\
\text { Strength }\end{array}$} & Diameter & \multirow{2}{*}{$\begin{array}{c}\text { Longitudinal } \\
\text { Steel }\end{array}$} & \multirow{2}{*}{$\begin{array}{c}\text { Void } \\
\text { Percentage } \\
(\%)\end{array}$} & \multirow{2}{*}{$\begin{array}{c}\text { Corrosion } \\
\text { Percentage } \\
(\%)\end{array}$} \\
\hline & psi & $\mathrm{MPa}$ & inch $\mathrm{cm}$ & & & \\
\hline 1 & 3015 & 20.8 & $\begin{array}{ll}9 & 22.9\end{array}$ & 6 No. 4 & 20 & 0 \\
\hline 2 & 3015 & 20.8 & 22.9 & 6 No. 3.5 & 20 & 25 \\
\hline 3 & 3015 & 20.8 & 22.9 & 6 No. 3 & 20 & 50 \\
\hline 4 & 3015 & 20.8 & 22.9 & 6 No. 2 & 20 & 75 \\
\hline 5 & 3015 & 20.8 & 22.9 & ------- & 20 & 100 \\
\hline 6 & 3015 & 20.8 & 22.9 & 6 No. 4 & 0 & 0 \\
\hline 7 & 3015 & 20.8 & 22.9 & 6 No. 3 & 0 & 50 \\
\hline
\end{tabular}

The casting forms for the drilled shaft specimens consisted of cardboard Sonatube with an inside diameter of 9 inches $(22.86 \mathrm{~cm})$. Before the steel cage was positioned inside the Sonatube, eight 1 inch $(2.54 \mathrm{~cm})$ plastic spacers were inserted throughout the length of the cage in order to keep the cage at the center of form, and to ensure the 1 inch $(2.54 \mathrm{~cm})$ concrete cover. It is important to place and center the reinforcing steel cage in the Sonatube prior to placing concrete. Figure 6.3a shows the steel cage of a shaft and the plastic spacers on it before concrete placement. A wooden formwork was built and placed at the bottom of the Sonatube to ensure that the steel cage was aligned properly, and to secure the fluid concrete during casting. To create the voids, the Sonatube was cut at the middle with a length of 10 inches $(25.4 \mathrm{~cm})$ and a width equal to that of the arc lengths, which depends on the arc angle and the void percentage, as shown in Figure 6.3b. Plywood was used to fabricate the void shape between the Sonatube and the steel cage; it was secured at the center of the steel cage before casting. Silicone glue was used at the end to cover the holes between the plywood and the steel cage in order to avoid any concrete leakage. 
Concrete was pumped vertically inside the Sonatubes for all the specimens to ensure uniformity. Concrete placement was continued in one operation to the top of the shaft. Concrete for drilled shafts was also designed and placed in such a manner that it could be pumped, or flow easily through the rebar cage by gravity to the bottom of the shaft without the nedd for any vibration. Concrete was not vibrated after casting to simulate actual conditions where concrete in drilled shafts is not consolidated. All specimens were tested 30 days after casting. Figure 6.4 shows all the specimens ready to be tested.
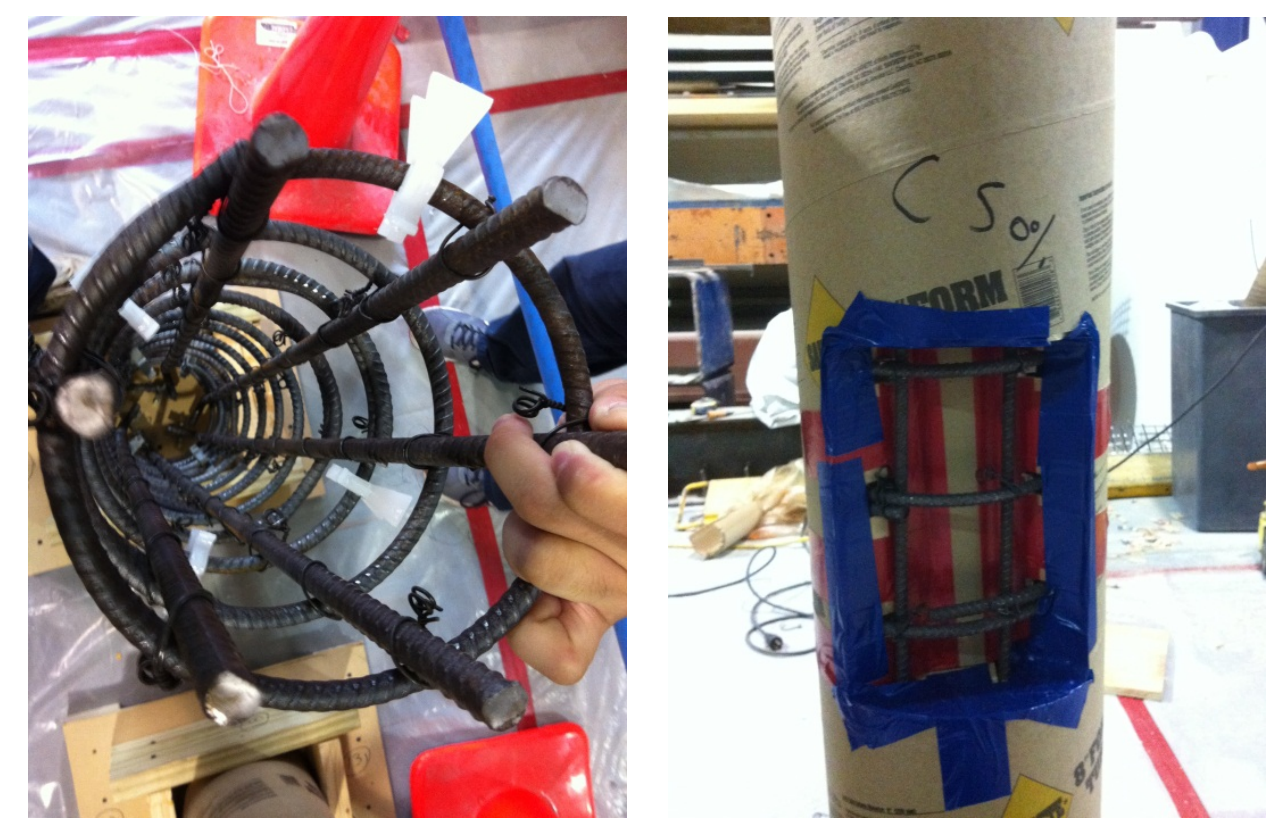

Figure 6.3: (a) Steel Cage of Specimen, (b) Sonatube Cut with 20\% Void Area 


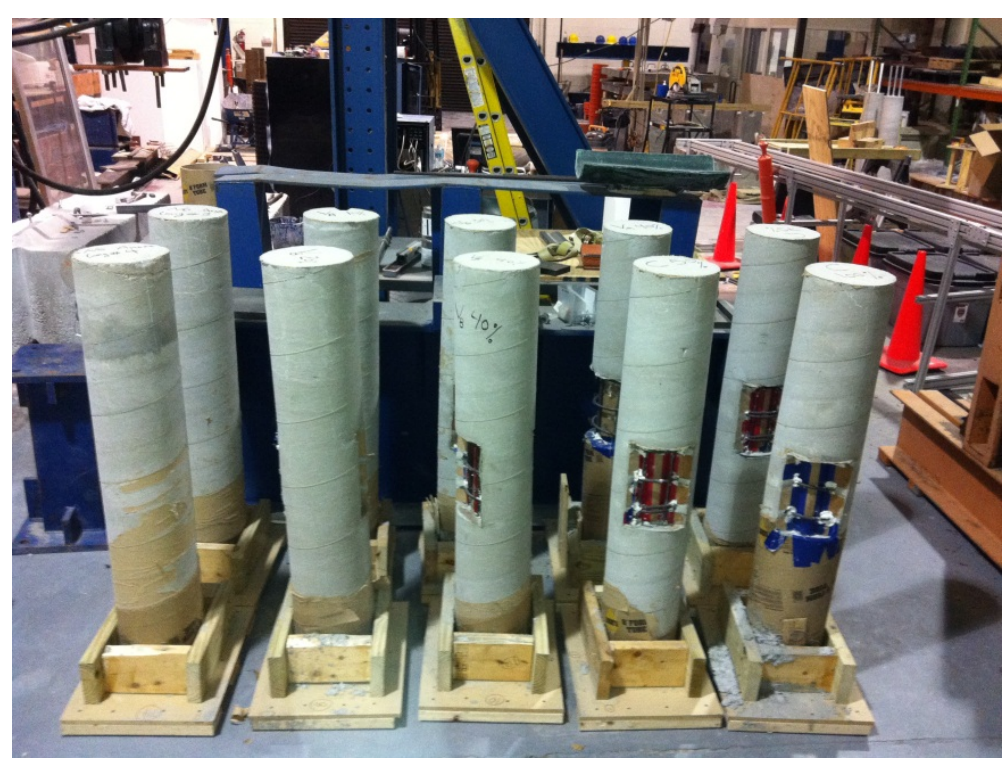

Figure 6.4: Specimens Ready for Testing

\section{Material Properties}

The concrete used in this study was normal weight concrete $\left(150 \mathrm{lbs} / \mathrm{ft}^{3}\right.$ or 23.565 $\mathrm{kN} / \mathrm{m}^{3}$ ). Standard concrete cylinder samples with 4-inch diameters and 8-inch lengths were tested using the Concrete Compression Machine in the laboratory at FIU. The average measured axial compressive strength for three standard cylinders was $37,900 \mathrm{lbs}$ $(168588 \mathrm{~N})$ at 28 days. Therefore, the cured concrete cylinders had a compressive strength at 28 days equal to 3,015 psi (20.8 MPa). The concrete slump was measured to be 4 inches at the time of casting, and the maximum coarse aggregate size (rounded river gravel) was 0.5 inch $(1.27 \mathrm{~cm})$. Fine aggregate was based on ASTM C33 natural sand with a fineness modulus of 3.0. The cement was type I Portland cement and comprised about 24 percent of the weight of the mix. The water to cement ratio varied between 0.4 and 0.42 , depending on the moisture content of the aggregate. Sonatube with inside diameter of 9 inches $(22.9 \mathrm{~cm})$ was used as a formwork for the concrete. All shaft 
specimens were cast in a vertical position without vibration after concrete placement to simulate actual conditions.

A No. 3 bar was tested using a Universal Tensile Testing Machine in the laboratory at FIU. The tensile test loading ratio used was $100 \mathrm{lbs} / \mathrm{sec}(445 \mathrm{~N} / \mathrm{sec})$. The longitudinal steel and lateral ties in all the tested specimens were Grade 80 , with yield strength of 80 ksi. The actual yield strength was less than the nominal value (75 ksi), and the modulus of elasticity was $29 \times 10^{6} \mathrm{ksi}\left(2 \times 10^{8} \mathrm{MPa}\right)$. The stress-strain curve obtained for the No. 3 steel rebar is shown in Figure 6.5.

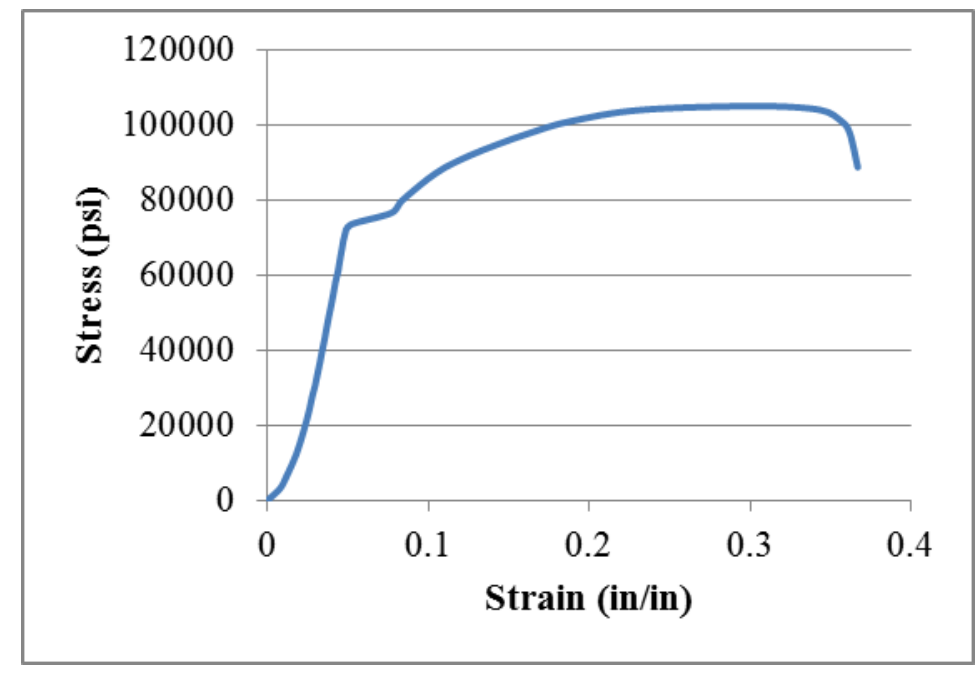

Figure 6.5: Stress-Strain Curves of Steel Rebar

\section{Testing Procedures}

Load tests were performed in general accordance with American Society for Testing and Materials (ASTM) D1143 test method for shafts under axial compressive load. All tests were performed in the same laboratory temperature to minimize variances due to thermal effects. All load tests were carried to structural failure. The test program was organized into two groups. Group I consisted of testing seven specimens (Specimens 1 to 
7), of which 5 specimens having corrosion in the longitudinal rebars (Specimens 2, 3, 4, 5, and 7), and the control specimens (Specimens 1 and 6). Control Specimen 1 has void, but has no corrosion. Control Specimen 6 has neither void nor corrosion. Specimen 7has no void, but has $50 \%$ corrosion. Specimens 2 to 5 were cast with $25 \%$ to $100 \%$ corrosion in the void section, having a void area of $20 \%$ of the cross-section of the drilled shaft area. Group II consisted of testing three specimens (Specimens 8, 9, and 10) with PVC, galvanized CSL tubes, and one control specimen. All ten specimens were tested in pure axial compression in the TASCT laboratory at the FIU. The eccentricity of the applied load was approximated \pm 1 inch $( \pm 2.54 \mathrm{~cm})$.

The machine used for axial testing of the drilled shaft specimens was a Shore Western hydraulic actuator with a maximum load capacity of $235 \mathrm{kips}(1,046 \mathrm{kN})$ as shown in Figure 6.6. The actuator moves from -10 inch to +10 inches $(25.4 \mathrm{~cm})$, which is total of 20 inches $(50.8 \mathrm{~cm})$ of displacement from top to bottom. A displacement control procedure was adopted for all the tests at a rate of $0.012 \mathrm{in} . / \mathrm{min}(0.305 \mathrm{~mm} / \mathrm{min})$. The hydraulic actuator was equipped with a manually controlled electric pump, which allowed having a constant loading. All instruments were connected to a data acquisition system, which is a MegaDAC with a sampling frequency of $1 \mathrm{~Hz}$. The actuator deflection and shaft head displacement were recorded with the Linear Displacement Transducer (LDT), and the loading was recorded with the actuator's load cell. 


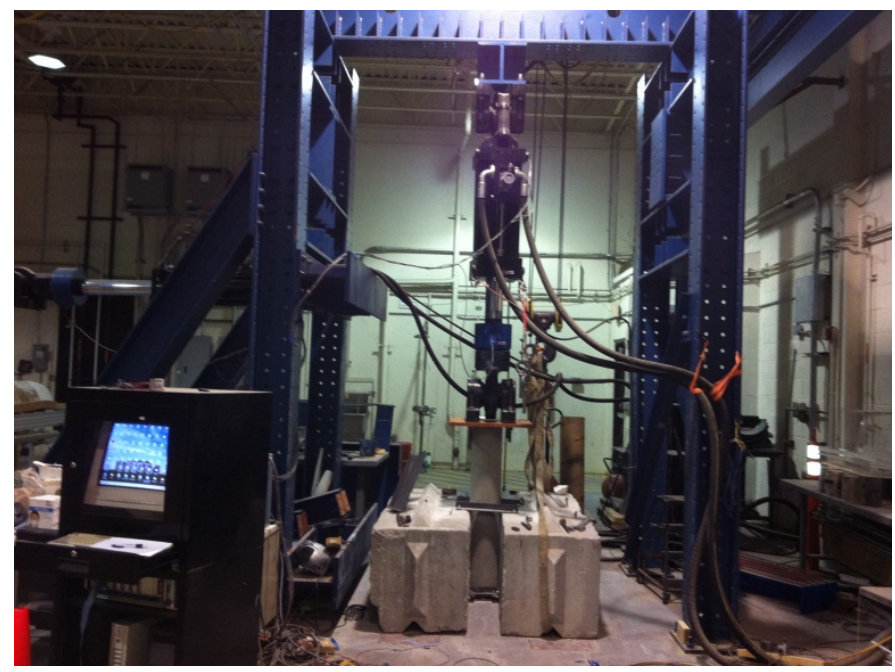

Figure 6.6: Hydraulic Actuator Machine Used for the Tests at FIU's TASCT Laboratory

A solid steel plate with a thickness of 1 inch $(2.54 \mathrm{~cm})$ was placed at the bottom of the specimens to provide a strong base. Two $2 \times 2 \times 6 \mathrm{ft}^{3}\left(61 \times 61 \times 183 \mathrm{~cm}^{3}\right)$ concrete blocks were constructed to use as lateral base support. These blocks kept the specimens immobile during the loading process. Angle bars of $1.5 \times 1.5 \times 0.25 \mathrm{in}^{3}\left(3.8 \times 3.8 \times 0.63 \mathrm{~cm}^{3}\right)$ were cut and used to support the specimens. Two supports were used: one at the bottom and another at the middle of the specimen in order to prevent buckling of the samples in the first mode before failure, as shown in Figure 6.6. Figure 6.6 also shows the instrumentation scheme, geometry, and loading procedure for the specimens loaded axially.

\section{Test Results and Discussion}

The behavior of the drilled shafts subject to axial load was investigated in this study. The axial load versus vertical displacement curves for Specimens 1 and 6 in test Group I are shown in Figure 6.7. Specimen 6 is an intact specimen, and Specimen 1 has 20\% void area $(20 \%$ of the cross-section area of the drilled shaft) penetrating inside the concrete 
cover, but without corrosion in longitudinal rebars. The test results show that the presence of symmetric voids of $20 \%$ of the cross-section of the drilled shaft area will cause a $14 \%$ reduction in axial load carrying capacity of the drilled shaft. The effect on the stiffness of the shaft was much more pronounced, especially when the void penetrated inside the core of the shaft. This result is due to having inadequate confinement of the concrete and reinforcement, and the local buckling of the longitudinal steel bars in the shaft.

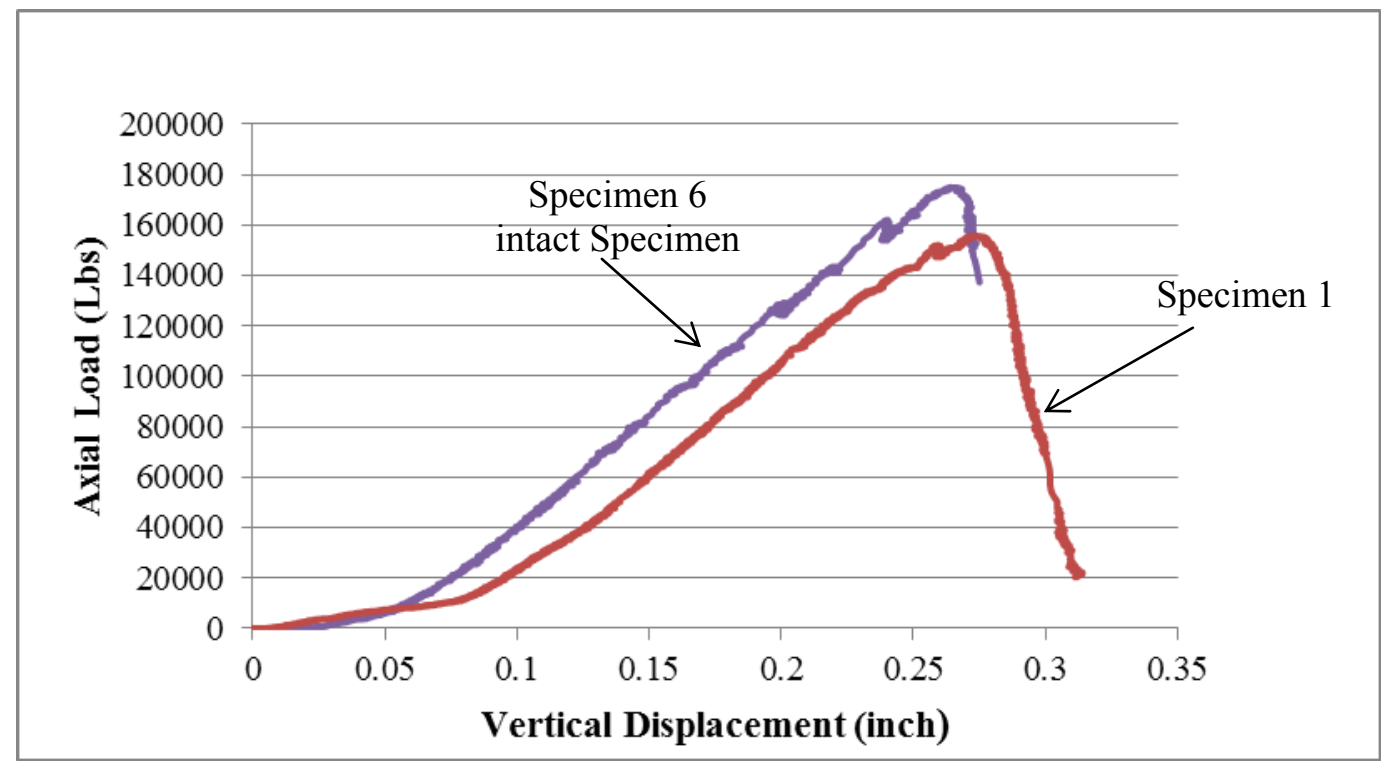

Figure 6.7: Axial Load versus Vertical Displacement for Specimens 1 and 6

The axial load versus vertical displacement curves for Specimens 1 to 5 in test Group I are shown in Figure 6.8. They have the same void area (20\%) penetrating inside the concrete cover. Specimens 2, 3, 4, and 5 have 25\%, 50\%, 75\%, and $100 \%$ corrosion in longitudinal rebars in the void section. Figure 6.8 shows that the presence of $25 \%$, $50 \%, 75 \%$, and $100 \%$ corrosion in the longitudinal rebars cause $12 \%, 21 \%, 31 \%$ and $58 \%$ reduction in the axial load capacity of the drilled shaft, respectively. 


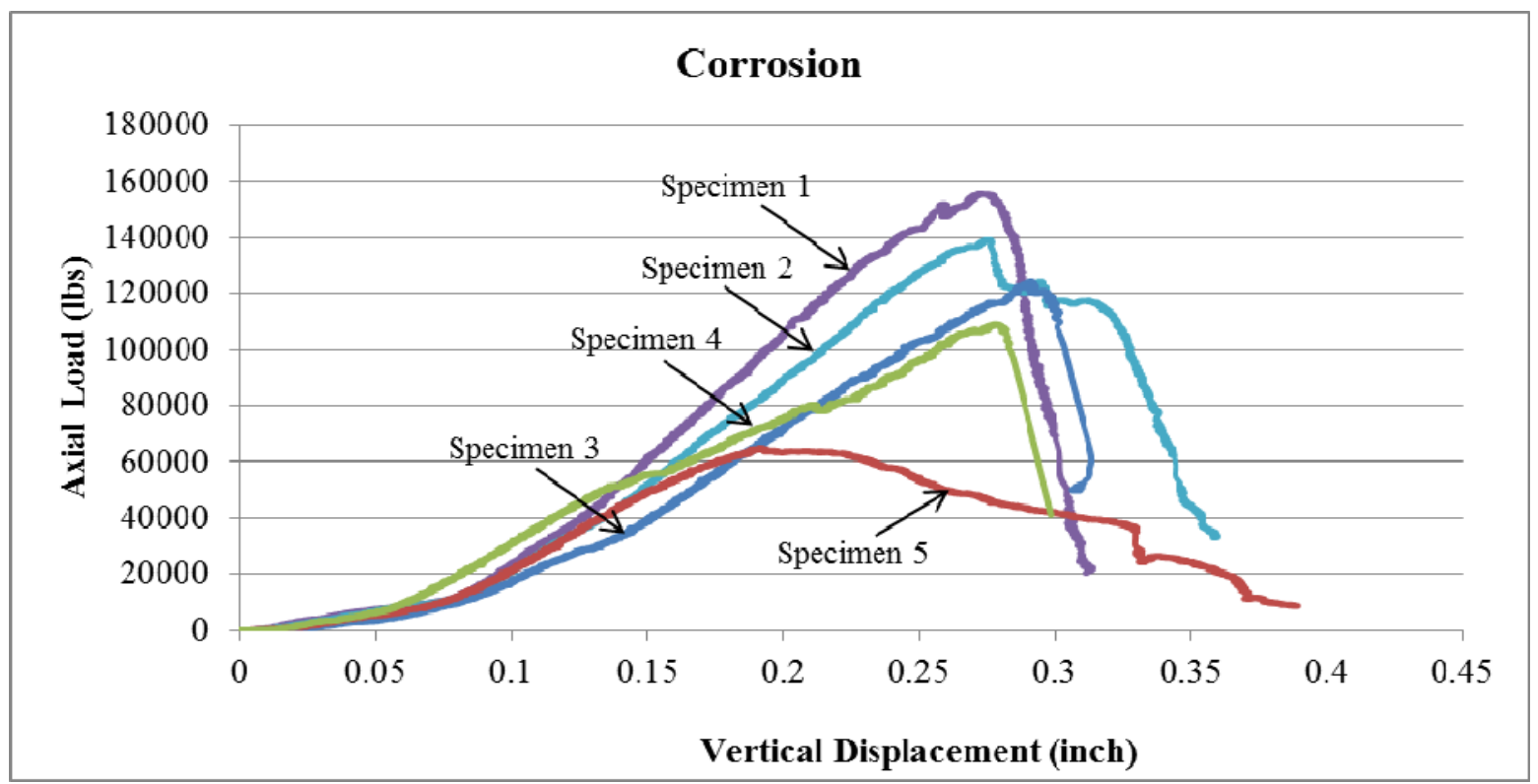

Figure 6.8: Axial Load versus Vertical Displacement for Specimens 1-5 (Corrosion)

These results show that, compared to the intact specimen, the shafts with $20 \%$ void exhibited 14 percent lower axial compressive strength; shafts with 100\% corrosion exhibited 64 percent lower axial compressive strength. These results show that the presence of a void inside the concrete cover along with 100\% corroded longitudinal rebars will significantly decrease the axial strength of the shaft. Therefore, changing the corrosion percentage from $0 \%$ to $100 \%$ in longitudinal rebars will reduce the axial load carrying capacity by upwards of $60 \%$. Figure 6.9 shows the change in axial capacity reduction rate with corrosion percentage. 


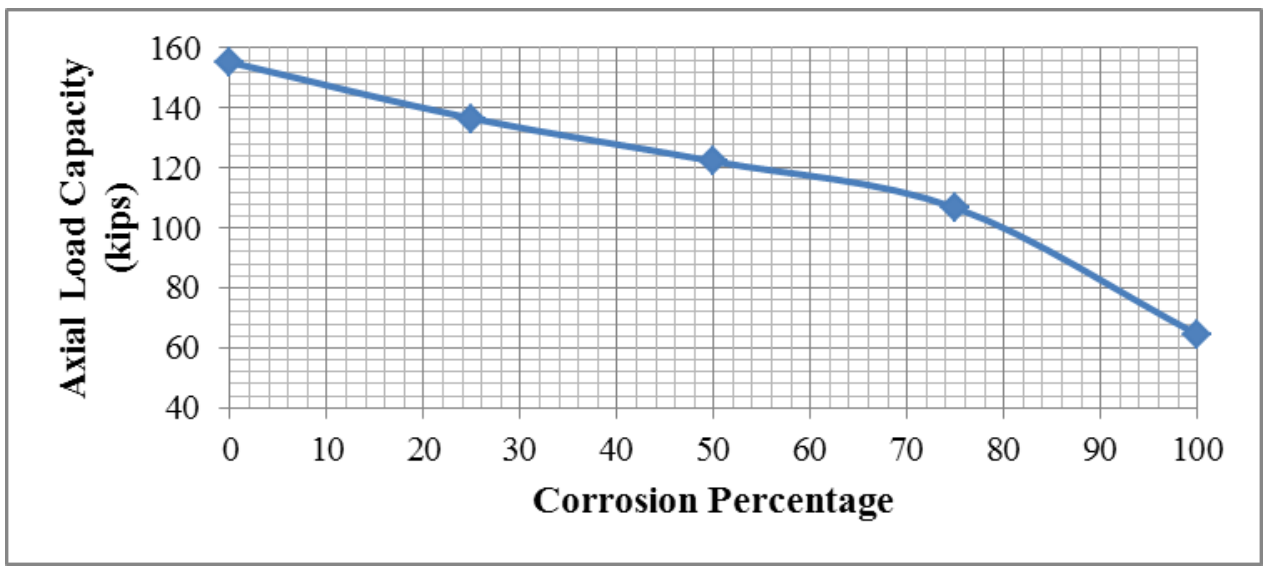

Figure 6.9: Axial Load Capacity vs. Corrosion Percentage in Longitudinal Rebars

Figure 6.10 shows a comparison of the axial load versus the vertical displacement for Specimens 6 and 7. Specimen 6 was longitudinally reinforced with 6 No. 4 steel bars that were equally spaced around the perimeter, and Specimen 7 with 6 No. 3 steel bars. It was determined that the strength of Specimen 6 at failure was 137.8 kips (613 kNs) and that of Specimen 7 was 119.2 kips $(530.23 \mathrm{kNs})$, which is almost $13 \%$ larger. It can therefore be said that $50 \%$ corrosion in longitudinal bars will cause a $13 \%$ axial load capacity reduction, even when no voids exist in the drilled shaft. The same corrosion percentage in the longitudinal bars with symmetric void in the concrete cover will cause $21 \%$ axial load capacity reduction. 


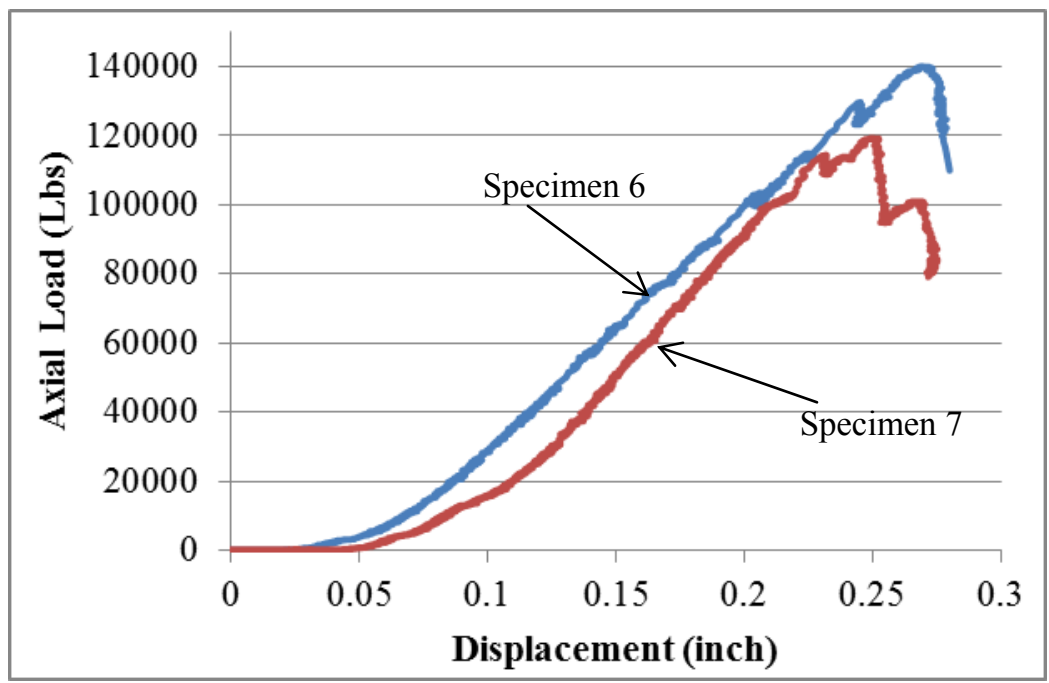

Figure 6.10: Axial Load versus Vertical Displacement for Specimens 6 and 7

\section{Specimens Failure}

Figure 6.11 shows the fractured specimens after the conclusion of the testing. For all specimens,the shape of the void, size of the void, and corrosion of the longitudinal bars in the void section greatly affected the axial compressive strength and stiffness of the shaft specimens. Generraly, it can be seen that cracks in specimens started around and in the vecinity of the voids, and weakened the specimens during loading. In Specimen 1 (no corrosion and with $20 \%$ void area penetrating the concrete cover), it can be seen that the fracture occurred due to the crushing of the concrete at the top of the specimen and large cracks around the void section. It can be said that the fractures were clearly due to the lack of confinement of the concrete and its reinforcement in the vicinity of the void.

In Specimen 2 (25\% corrosion in longitudinal bars), the fracture started in the vecinity of the void and the shaft failed by the crushing of the concrete piece between the two symmetrical void sections. Figure 6.11 shows that in Specimens 3, 4, and $5(50 \%$, $75 \%$, and $100 \%$ corrosion in longirudinal rebars, respectively), buckling was the main 
cause of failure. This can be deduced from the clear bending in the longitudinal bars after the loading process. Therefore, specimens with high level of corrosion had less critical buckling load or lower buckling capacity due to the weakness of longitudinal bars in the void section. Most of the growth cracks in Specimens 6 and 7 (without voids) were in the longitudinal direction of the shaft, and they show a shear failure in the shafts under axial loading (Figure 6.11). In these specimens, material crushing was in the region where the actuator was bearing on the specimens. Therefore, failure in specimens with corrosion in longitudinal bars was mostly due to buckling, whereas in specimens without voids it was due to shear failure.

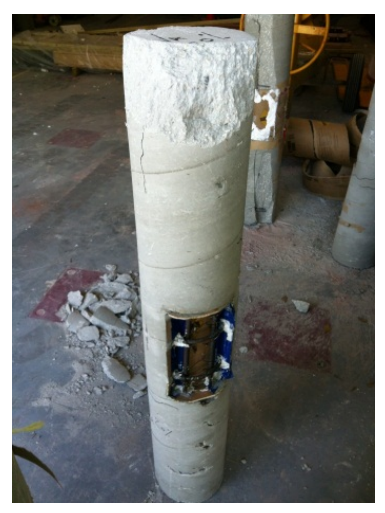

Specimen 1

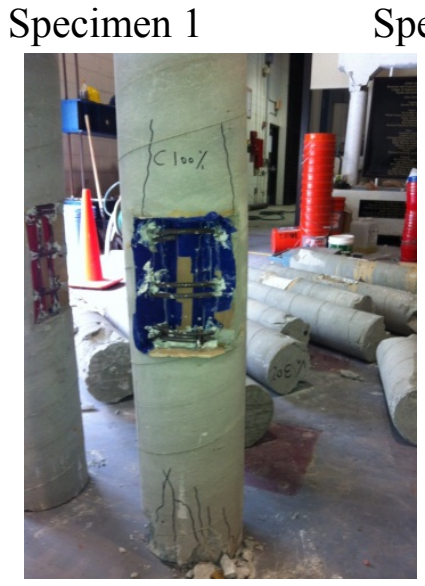

Specimen 5

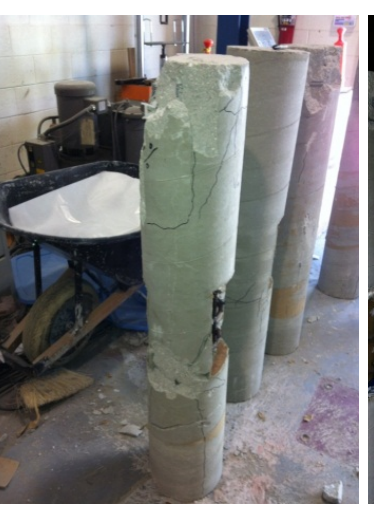

Specimen 2

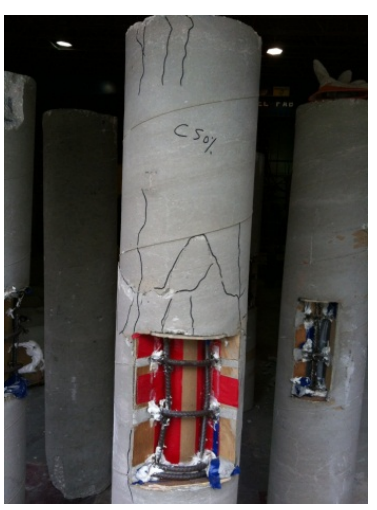

Specimen 3

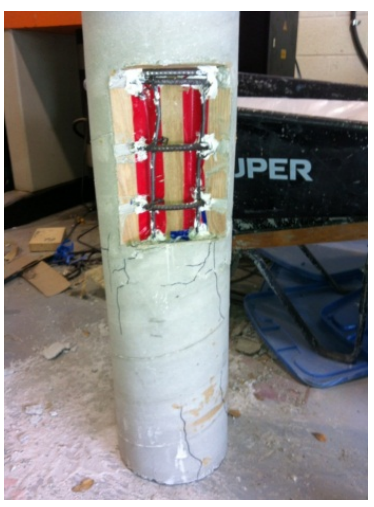

Specimen 4

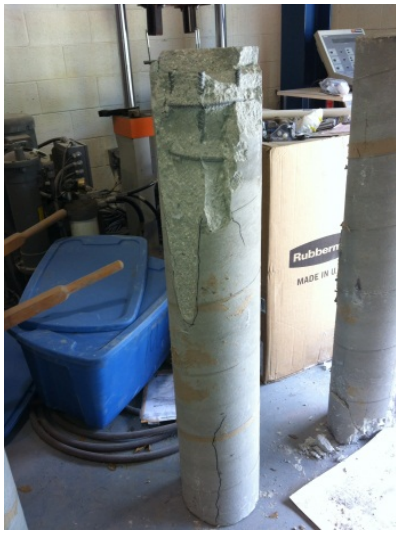

Specimen 6

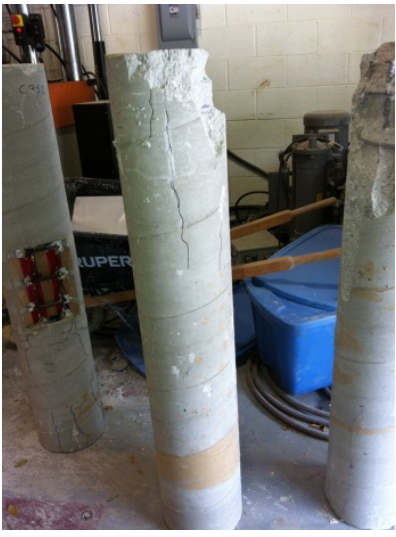

Specimen 7

Figure 6.11: Failure in Shaft Specimens after Testing 


\section{Axial Load Capacity Reduction over Time due to Corrosion}

Accelerated or unanticipated corrosion of the reinforcements may cause sudden failure of structures, generally along a nearly vertical plane of maximum tensile stresses in the reinforcements. This plane is located at a distance varying from 0 to $0.3 \mathrm{H}$ from the facing; where $\mathrm{H}$ is the height of the structure [1]. A few instances of advanced corrosion that have compromised the service life of structures have been documented in the United States, Europe and South Africa (Blight and Dane, 1989; Elias, 1990; Fishman et al., 1986; Frondistou-Yannis, 1985; Armour et al., 2004; Gladstone et al, 2006 [8]; McGee, 1985; Raeburn et al., 2008). The most comprehensive data available in the field of underground corrosion are the results of extensive field testing done by the U.S. National Bureau of Standards (NBS) in programs originating as early as 1910 (Romanoff, 1957). Based on these studies, Romanoff at NBS suggested the following exponential equation to predict the amount of general corrosion at some time $(\mathrm{t})$ after burial [1]:

$$
x=K t^{n}
$$

where $x$ is the loss of thickness in the reinforcement rebar at time $(t)$, and $K$ and $n$ are constants that are soil and site dependent ( $n$ is less than unity). For different steels in a number of soil conditions, NBS determined a " $n$ " constant varying from 0.5 to 0.8 , and a " $K$ " constant between 20 and $180 \mu \mathrm{m}[1]$.

Based on the report [12] prepared by GEOSOL INC. for the city of Miami, the soil in Miami consist of clean to silty fine to coarse sand with variable percentage of limerock and shell fragment. The field exploration program in this report consisted of the performance of eight (8) Standard Penetration Test (SPT) borings (B-1 through B-8) to 
depth of 35 feet. In this field exploration, a layer of organic silt was encountered in test borings ranging from 2 to 13 feet $(0.61 \mathrm{~m}$ to $4 \mathrm{~m})$ below existing grades, with an average thickness of about 5 feet $(1.5 \mathrm{~m})$. The organic silt material had organic content ranging from 8 to $17 \%$. The natural moisture content is $17 \%$. The $\mathrm{pH}$ (acidity) for the soil was determined 7.3, the resistivity of soil was $22 \mathrm{ohm}-\mathrm{cm}$, chloride of $22100 \mathrm{ppm}$, and sulfate of $2530 \mathrm{ppm}$.

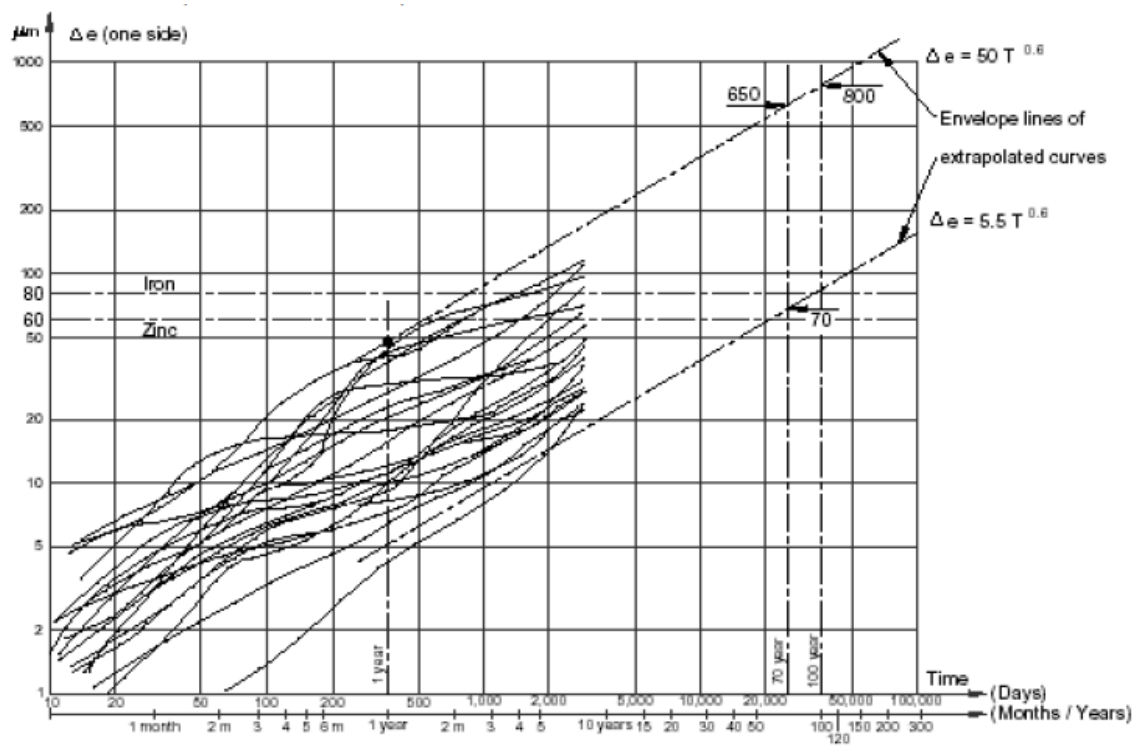

Figure 6.12. Summary of Electrochemical Test cell Data at 50\% and 100\% Saturation [1] Using the NBS model, the available data for a wide range of soils, and Figure 6.12 for the City of Miami, the soil condition using Equation (21) will be: $x=30 t^{0.6}$

Based on theoretical considerations, a factor closer to 3 , which is negatively correlated with the diameter, is more applicable to single reinforcing bars with a circular cross section. Additional corroboration with test data from reinforcement samples collected from the field is needed to verify the appropriate factor for geometries other 
than flat strips. Current design specifications presume that the factor of 2 , which was initially and specifically determined for flat thin galvanized steel strips, also applies to all other types of galvanized steel reinforcements, whatever their size and shape. Note that due to redundancy of bar mats, a factor of 2 is also considered reasonable for these reinforcements. With considering $\mathrm{x}$ as a thickness of the corroded part as shown in Figure 6.13, the corroded area will then be calculated from Equation (22), and the corrosion percentage will be calculated from Equation (23).

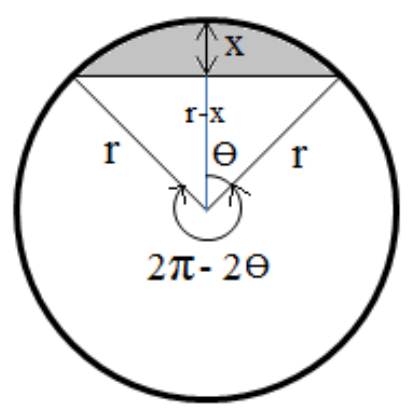

Figure 6.13. Longitudinal Bar Section with Corroded Thickness x

$$
A_{(\text {corroded })}=r^{2} \theta-\left\lfloor(r-x) \sqrt{\left(2 r x-x^{2}\right)}\right\rfloor
$$

Corrosion $\%=\left[\theta-\left(\frac{r-x}{\pi r^{2}}\right) \sqrt{\left(2 r x-x^{2}\right)}\right] \%$

where $x$ is corroded thickness, $r$ is radius of the reinforcing bar, and $2 \theta$ is the corroded angle in the reinforcing bar cross-section. Using Equation (21), the corroded thickness of single reinforcing bar with a circular cross section can be measured with time. Corrosion percentage in the longitudinal bars can then be calculated from Equation (23) as shown in Table 9 for the City of Miami soil conditions. 
It can be seen that around $50 \%$ corrosion in longitudinal bars will occur over a period of 20 years, and around $80 \%$ corrosion will occur over a time period of 40 years for the reinforcing steel rebars which are in contact with the surrounding Miami soil. The calculated corrosion percentage relates to a drilled shaft sample with $20 \%$ void area penetrating inside the concrete cover as considered in this study (Specimen 1). Figure 6.9 shows the axial load capacity reduction versus corrosion percentage in the longitudinal rebars. Using the trend line of Figure 6.9, the axial load capacity reduction with time can be measured based on the corrosion percentage as shown in Table 9. Table 9 shows that drilled shafts with $20 \%$ void area in contact with Miami soil will lose, due to the time effect of corrosion, over $21 \%$ of their axial load capacity over a time period of 20 years, and over $35 \%$ of their capacity over a time period of 40 years.

Table 9: Axial Load Capacity Reduction with Time in Drilled Shaft Foundations

\begin{tabular}{|c|c|c|c|c|c|c|}
\hline \multicolumn{2}{|c|}{ T (Time) } & \multicolumn{2}{l|}{ x (Corrosion Thickness) } & \multicolumn{1}{l|}{} \\
\cline { 1 - 2 } $\mathrm{t}($ year) & $\mathrm{t}($ day) & $\mathrm{cm}$ & inch & $\begin{array}{c}\text { Corroded Area } \\
\left(\mathrm{in}^{2}\right)\end{array}$ & $\begin{array}{c}\text { Corrosion } \\
(\%)\end{array}$ & $\begin{array}{c}\text { Axial Capacity } \\
\text { Reduction }(\%)\end{array}$ \\
\hline 5 & 1825 & 0.272 & 0.107 & 0.031 & 15.68 & 7.1 \\
\hline 10 & 3650 & 0.412 & 0.162 & 0.055 & 28.11 & 13.5 \\
\hline 15 & 5475 & 0.525 & 0.207 & 0.077 & 39.07 & 17.4 \\
\hline 20 & 7300 & 0.624 & 0.246 & 0.096 & 48.93 & 21.3 \\
\hline 25 & 9125 & 0.713 & 0.281 & 0.114 & 57.88 & 23.8 \\
\hline 30 & 10950 & 0.796 & 0.313 & 0.130 & 66.00 & 26.4 \\
\hline 35 & 12775 & 0.873 & 0.344 & 0.144 & 73.34 & 31.6 \\
\hline 40 & 14600 & 0.946 & 0.372 & 0.157 & 79.92 & 35.4 \\
\hline
\end{tabular}

\section{Conclusions and Recommendations}

This paper presented the results on seven (7) drilled shaft specimens tested at the TASCT laboratory at FIU under axial compressive load. The shaft specimens were 
constructed with one type of built-in symmetric voids in an attempt to study the effect of corrosion of the longitudinal rebars in the void section inside the caging on the axial load capacity of drilled shafts. The results show that the presence of symmetric voids with void area comprising $20 \%$ of the cross-section of the drilled shaft will cause $14 \%$ reduction in the axial load carrying capacity of the drilled shaft. Also, the presence of $25 \%, 50 \%, 75 \%$, and $100 \%$ corrosion in the longitudinal rebars in the mentioned void area cause $12 \%, 21 \%, 31 \%$ and $58 \%$ reduction in the axial load capacity of the drilled shaft, respectively. The test results showed that the presence of both corrosion and symmetric voids within the cross section significantly affected the strength of the drilled shafts. Drilled shaft sample with $100 \%$ corrosion longitudinal bar inside the $20 \%$ symmetric void exhibited $64 \%$ lower axial compressive strength compared to the intact sample.

In other comparisons, the results show that $50 \%$ corrosion in longitudinal bars without void will cause $13 \%$ axial load capacity reduction. The same corrosion percentage in longitudinal bars with symmetric void in the concrete cover will cause $21 \%$ axial load capacity reduction.

Observation of fractured specimens show that in specimens with $50 \%, 75 \%$, and $100 \%$ corrosion in longirudinal rebars, buckling was the main reason of failure. Therefore, specimens with high corrosion percentage had lower critical buckling load or buckling capacity because of the weakness of longitudinal bars in the void section. Most of the growth cracks in specimens without voids were in the longitudinal direction of the shaft, and they show a shear failure. 
More importantly, the study demonstrated that drilled shafts with $20 \%$ void area in contact with Miami soil will lose over 21\% of axial load capacity over a time period of 20 years and will over $35 \%$ over a time period of 40 years due to corrosion in their longitudinal bars. The study therefore recommends that corrosion series tests should be required on all new bridge foundations. These tests should be carried out on the soil and water at the location of the structure. These tests should be done on structural backfill materials and on subsurface materials along drainage alignments to determine the corrosion classification to be considered during design. The axial load capacity reduction due to corrosion can then be estimated over any period of time. 


\title{
VII. CONTRIBUTION OF THE SIDE RESISTANCE AND TIP RESISTANCE ON THE TOTAL AXIAL LOAD CAPACITY OF DRILLED SHAFT FOUNDATIONS
}

\author{
Masood Hajali and Caesar Abishdid
}

\begin{abstract}
The main loads applied on the drilled shafts are axial compressive loads. It is important to know how many percent of the maximum applied load will be shed in side friction and how much will be transferred to the base. Part of the axial load carrying capacity of the drilled shaft is resisted by the soil below the tip of the shaft which is tip resistance and the other part is resisted by the friction developed around the drilled shaft which is side resistance. The axial capacity of the drilled shaft foundation is influenced by the size of the drilled shaft, and soil characteristics. In this study, the effect of the size and soil characteristic will be investigated on the contribution of side resistance and end bearing capacity. Also, the study presents a three-dimensional finite element modeling of a drilled shaft subjected to axial load using ANSYS12. The top displacement and settlement of the drilled shaft are verified with analytical results. The soil profile is considered as Table 10 and for a drilled shaft with $7 \mathrm{ft}$ diameter and $95 \mathrm{ft}$ length the stresses in z-direction are calculated through the length of the shaft. There is a good agrrement between analythical and finite element results in contribution of side resistance and tip resistance for the drilled shaft.
\end{abstract}

Keywords: Drilled Shaft, Side Resistance, Tip Resistance, Axial Load Capacity, Finite Element Method 


\section{Overview}

Drilled shafts are the most popular of deep foundations, because they have the capability that one single shaft can easily carry the entire load of a large column from a bridge or tall building. Drilled shaft may be an economical alternative to pile foundations because a pile cap is not needed, which not only reduces that expense, but also provides a rough surface in the border of soil and concrete to carry more axial load. Due to the larger construction sizes of drilled shafts, they have excellent axial load carrying capacity.

The condition at the bottom of the excavation can affect the end bearing capacity of the drilled shaft. Also, type of the soil and size of the drilled shaft can affect the frictional resistance. The side resistance and end bearing capacity's equations of the drilled shaft foundation in cohesive and cohesion-less soils are shown here from AASHTO standard.

\section{Drilled Shaft Resistance}

Drilled shafts shall be designed to have adequate axial and structural resistance, tolerable settlements, and tolerable lateral displacement. Nominal axial compression resistance of a single drilled shaft is computed from Equation (24).

The factored resistance of drilled shafts, $R_{R}$, shall be taken as:

$$
R_{R}=\phi R_{n}=\phi_{q p} R_{p}+\phi_{q s} R_{s}
$$

in which:

$R_{R}=q_{p} A_{p}$

$R_{s}=\sum q_{s i} A_{s i}$

where $R_{p}$ is nominal shaft tip resistance (kips), $R_{s}$ is nominal shaft side resistance (kips), $\Phi_{q p}$ is resistance factor for tip resistance specified in table 10.5.5.2.4-1 in AASHTO, $\Phi_{q s}$ 
is resistance factor for side resistance specified in table 10.5.5.2.4-1 in AASHTO, $q_{p}$ is unit tip resistance (ksf), $q_{s}$ is unit side resistance (ksf), $A_{p}$ is area of shaft tip $\left(\mathrm{ft}^{2}\right)$, and $A_{s}$ is area of shaft side surface $\left(\mathrm{ft}^{2}\right)$.

\section{Estimation of Drilled Shaft Resistance in Cohesive Soils}

\section{Side Resistance}

The nominal unit side resistance, $q_{s}$ in ksf, for shafts in cohesive soil loaded under undrained loading conditions by the $\alpha$-Method shall be taken as:

$q_{s}=\alpha S_{u}$

$\alpha=0.55 \quad$ for $\quad \frac{S_{u}}{P_{a}} \leq 1.5$

$\alpha=0.55-0.1\left(\frac{S_{u}}{P_{a}}-1.5\right) \quad$ for $\quad 1.5 \leq \frac{S_{u}}{P_{a}} \leq 2.5$

where $S_{u}$ is un-drained shear strength, $\alpha$ is adhesion factor (dim), $P_{a}$ is atmospheric

pressure $(=2.12 \mathrm{ksf})$

\section{Tip Resistance}

For axially loaded shafts in cohesive soil, the nominal unit tip resistance, $\mathrm{q}_{\mathrm{p}}$, by the total stress method as provided in O'Neill and Reese (1999) [1] shall be taken as:

$q_{p}=N_{c} S_{u} \leq 80.0$

$N_{c}=6\left[1+0.2\left(\frac{Z}{D}\right)\right] \leq 9$

where $D$ is diameter of drilled shaft (ft), $Z$ is penetration of shaft (ft), $S_{u}$ is undrained shear strength (ksf). 


\section{Estimation of Drilled Shaft Resistance in Cohesion-less Soils}

\section{Side Resistance}

The nominal unit side resistance is calculated by:

$q_{s}=\beta \sigma_{v}^{\prime} \leq 4.0 \quad$ for $\quad 0.25 \leq \beta \leq 1.2$

in which for sandy soil:

$\beta=1.5-0.135 \sqrt{z} \quad$ for $\quad N_{60} \geq 15$

$\beta=\left(\frac{N_{60}}{15}\right)(1.5-0.135 \sqrt{z}) \quad$ for $\quad N_{60}<15$

where $\sigma_{v}{ }^{\prime}$ is vertical effective stress at soil layer mid-depth (ksf), $\beta$ is load transfer coefficient (dim), $z$ is depth below ground, at soil layer mid-depth (ft), and $N_{60}$ is average SPT blow count in the design zone under consideration.

For gravelly sands and gravels:

$\beta=2.0-0.06(z)^{0.75} \quad$ for $\quad N_{60} \geq 15$

$\beta=\left(\frac{N_{60}}{15}\right)(1.5-0.135 \sqrt{z}) \quad$ for $\quad N_{60}<15$

\section{Tip Resistance}

The nominal tip resistance, $\mathrm{q}_{\mathrm{p}}$ in $\mathrm{ksf}$, for drilled shafts in cohesion-less soils by the O’Neill and Reese (1999) [1] method shall be taken as:

$q_{p}=1.2 N_{60} \quad$ for $\quad N_{60} \leq 50$

where $\mathrm{N}_{60}$ is average SPT blow count in the design zone under consideration

$q_{p}=0.59\left[N_{60}\left(\frac{P_{a}}{\sigma_{v}^{\prime}}\right)\right]^{0.8} \sigma_{v}^{\prime} \quad$ for $\quad N_{60}>50$ 
$P_{a}$ is atmospheric pressure $(=2.12 \mathrm{ksf})$, and $\sigma_{v}{ }^{\prime}$ is vertical effective stress at the tip elevation of the shaft (ksf).

\section{Analytical Work}

A cohesionless (drained) soil profile is considered based on the Standard Penetration Test (SPT) was performed in Phoenix, Arizona soil [6] profile as shown in Table 10.

\begin{tabular}{|c|c|c|}
\hline $\begin{array}{c}\text { Depth } \\
\text { (ft) }\end{array}$ & Soil Type & $\begin{array}{c}\text { N60 } \\
\text { (blows/ft) }\end{array}$ \\
\hline $0-25$ & $\begin{array}{c}\text { Fine to coarse } \\
\text { sands }\end{array}$ & 25 \\
\hline $25-75$ & Gravelly sands & 42 \\
\hline $75-90$ & $\begin{array}{c}\text { Fine to coarse } \\
\text { sands }\end{array}$ & 18 \\
\hline $90-130$ & Gravels & 49 \\
\hline
\end{tabular}

Table 10. Soil Profile [6]

The total axial resistance versus depth is developed using Equations (24) to (36) for the drilled shafts with different diameters for both cohessive and cohesion-less soils. The soil profile is commonly divided into layers and the depth $\mathrm{z}$ is measured to the center of a layer. For each $5 \mathrm{ft}$ layer, vertical effective stress at soil layer mid-depth (ksf) is obtained from table 10. Load transfer coefficient and unit side resistance is calculated at depth $\mathrm{z}$ from Equations (30), (31), and (32) and the side resistance for that layer is obtained by multiplying the unit friction resistance with the perimeter area of the shaft. Figure 7.1 shows the side resistance versus depth for the drilled shafts with different diameters from 4 feet to 10 feet and length of up to 130 feet. 


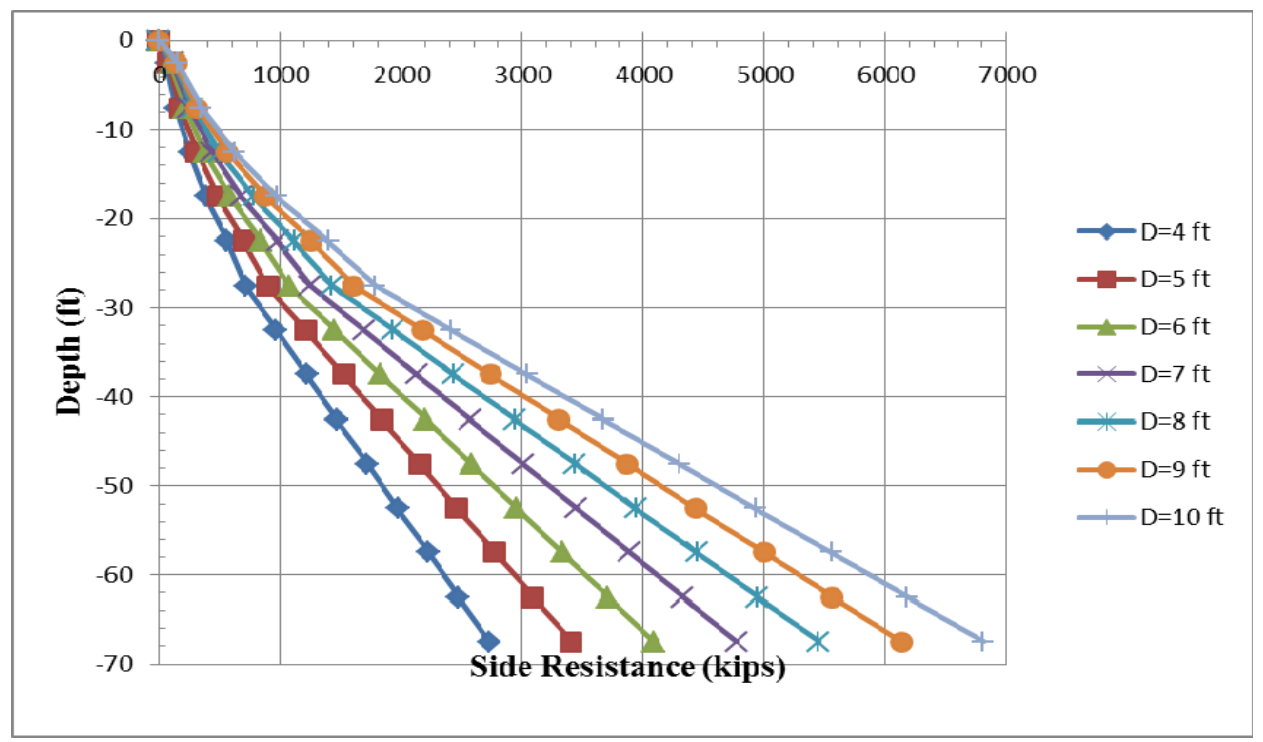

Figure 7.1. Side Resistance vs. Depth for Different Drilled Shaft Diameters

Also, vertical unit tip resistance is calculated from Equations (35) and the tip resistance for that layer is obtained by multiplying the unit tip resistance with the base area of the drilled shaft. The side diameter and the base diameter for each drilled shaft are considered the same. Figure 7.2 shows the tip resistance versus depth for the drilled shafts with different diameters.

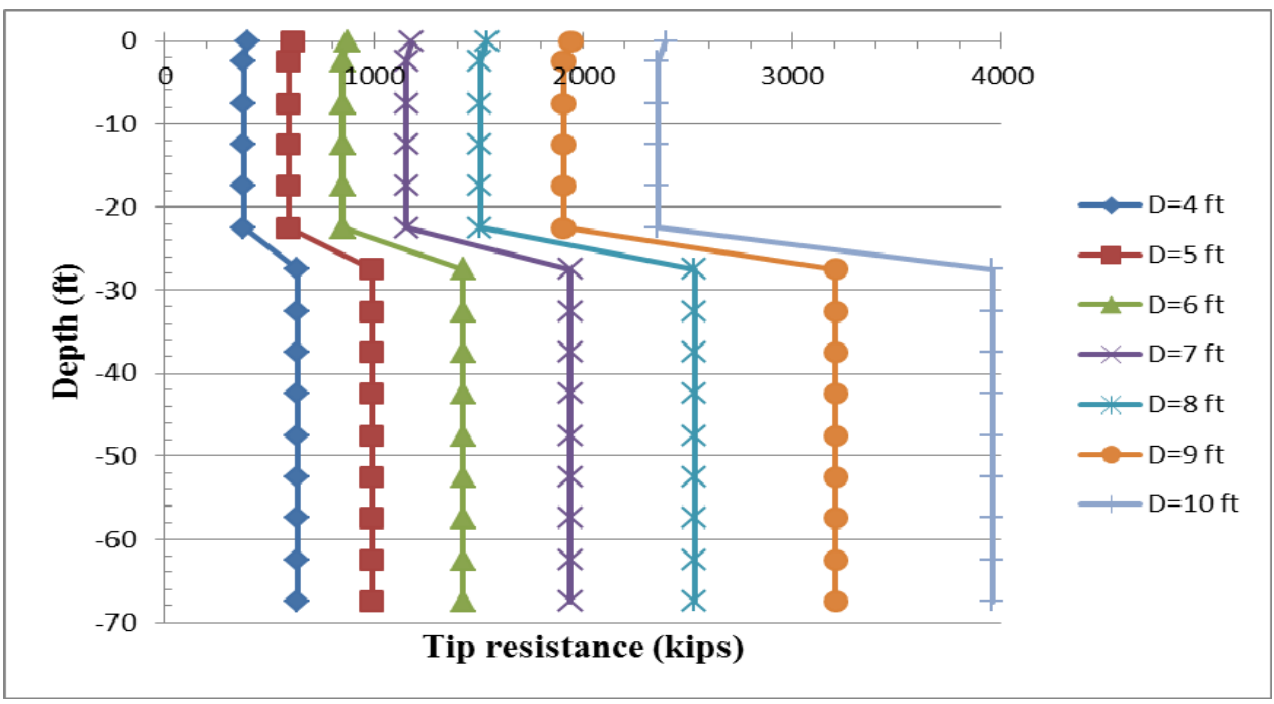

Figure 7.2. Tip Resistance vs. Depth for Different Drilled Shaft Diameters 
Therefore, the total axial resistance of drilled shafts is shaft tip resistance plus shaft side resistance. Figure 7.3 shows the total axial resistance versus depth for the drilled shafts from $4 \mathrm{ft}$ to $10 \mathrm{ft}$ diameteres.

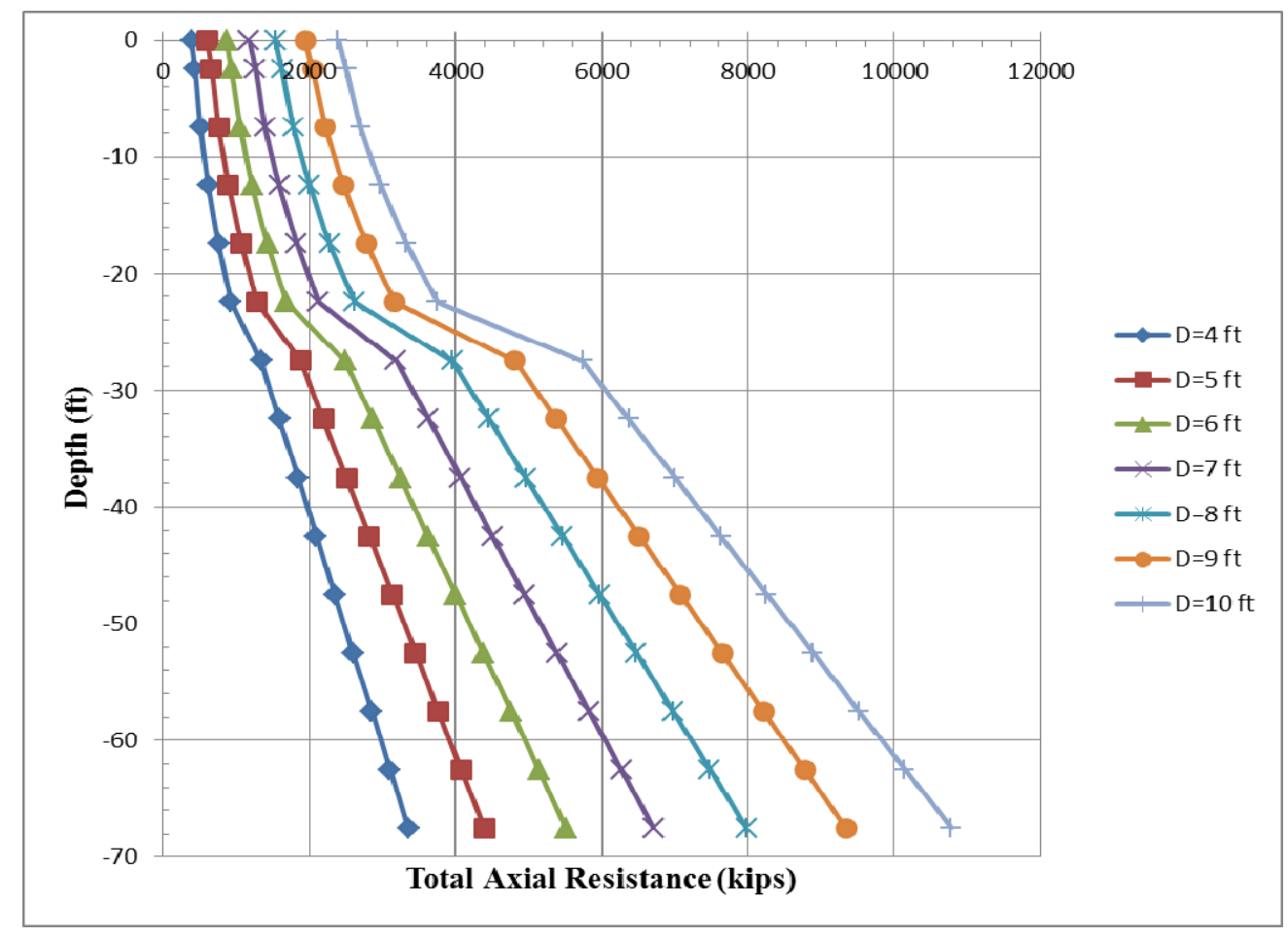

Figure 7.3. Total Axial Resistance vs. Depth for Different Drilled Shaft Diameters

Figure 7.4 shows the side resistance percentage of the drilled shafts for different diameters. It can be seen that with increasing in the depth of the drilled shaft side resistance percentage is increased on a second degree polynomial curve. 


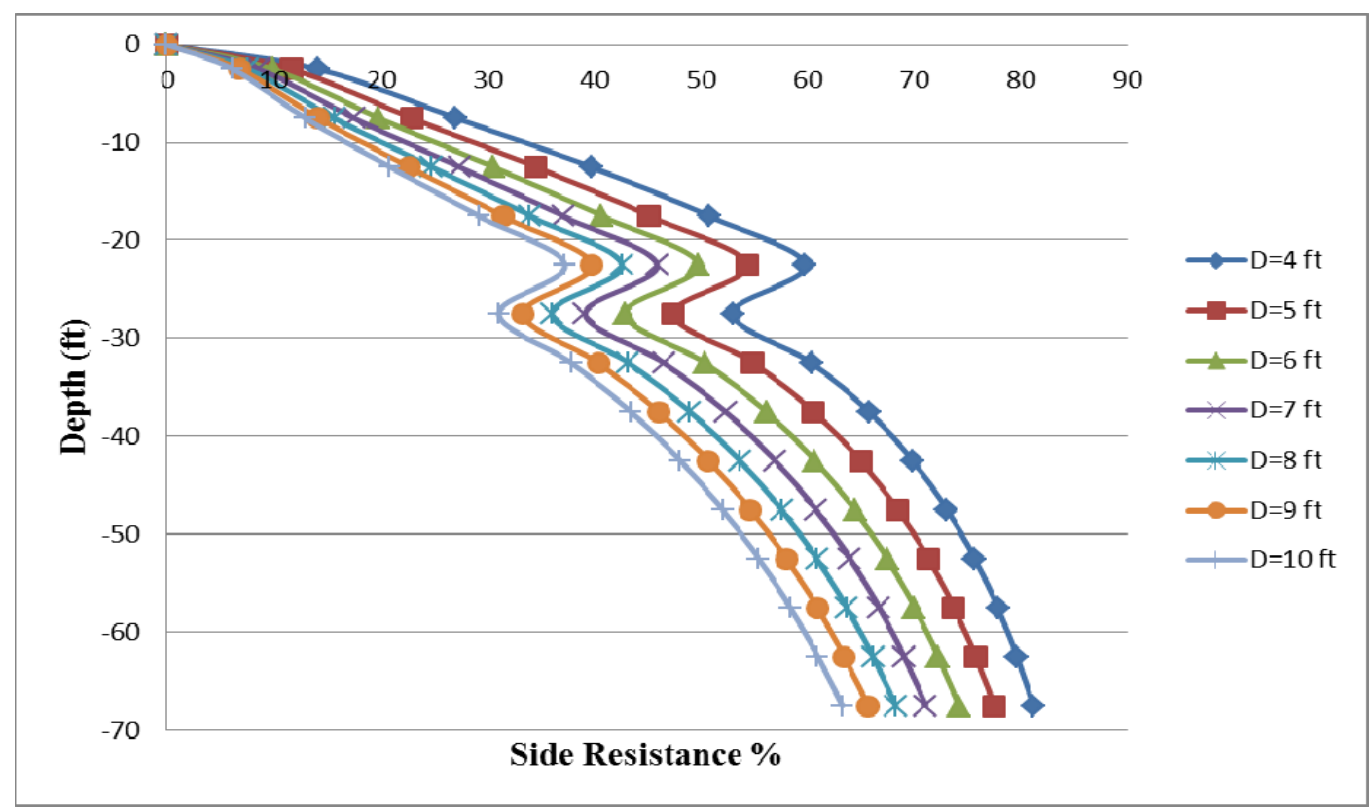

Figure 7.4. Side Resistance Percentage vs. Depth for Different Drilled Shaft Diameters

\section{Finite Element Model}

Full three-dimensional geometric model is used to represent the soil and drilled shaft as shown in Figure 7.5. Drilled shaft is analyzed in ANSYS software. The diameter of the drilled shaft is $D=7 \mathrm{ft}$ and the length of the drilled shaft is $L_{1}=95 \mathrm{ft}$. A cylindrical volum is considered as a media for the soil around the drilled shaft with the length and width of $2 \times \mathrm{L}_{1}$ and the diameter of $2 \times \mathrm{D}$. This size is selected for the soil volume around the drilled shaft because it has the closest result to the analytical results. The constructed model contains soil, concrete, and reinforcement bars. Four nodes tetrahedral structural solid with rotations is used for soil and eight nodes element is used for concrete as shown in Figure 7.6. The contact elements are used to connect the nodes between soil and concrete around the drilled shaft for contact and sliding between two surfaces. 


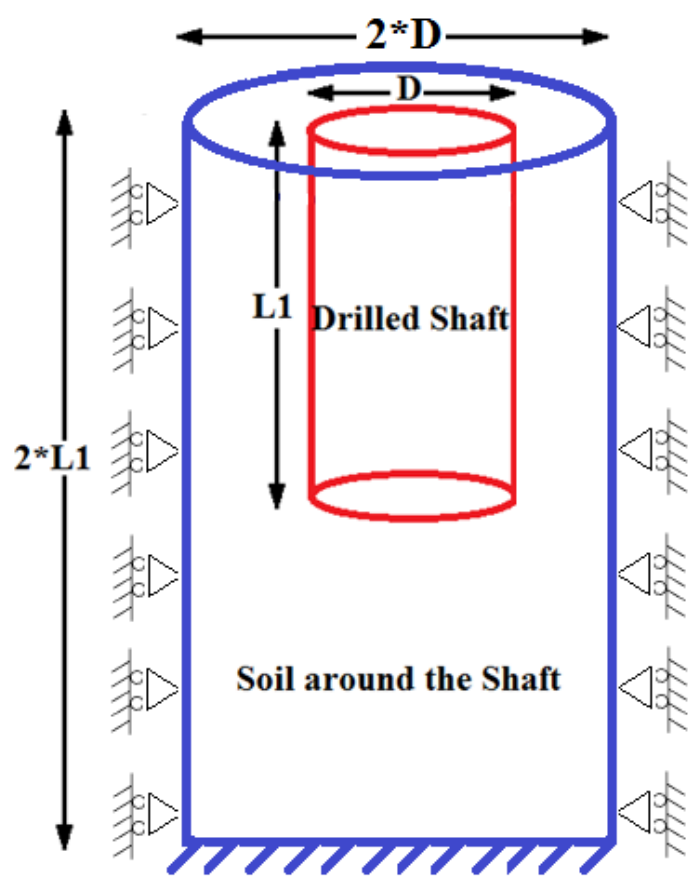

Figure 7.5. Drilled Shaft Geometry

The mesh size of the drilled shaft part is smaller than the soil region. Total of 13617 nodes and 14802 elements (including 1008 contact elements) have been used for modeling the drilled shaft in this study. Constraints include fixed supports for the bottom plane and roller supports for the plane in the $\mathrm{x}$ and $\mathrm{y}$ direction. A 7000 kips point load is applied at the top of the drilled shaft. In order to avoid high local compression of the drilled shaft due to point load, point load is distributed over the top surface of the drilled shaft. The Newton-Raphson method is an iterative process of solving the nonlinear equations which is used in this model 


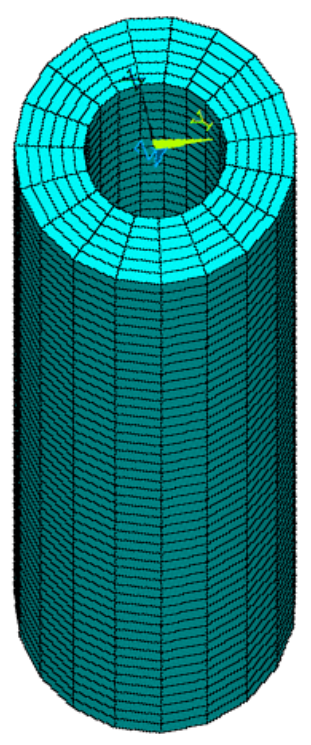

Figure 7.6. Meshing the Soil around the Shaft

\section{Material}

The constructed model contains soil, concrete, and reinforcement bars. Table11 shows the material properties of the model.

\begin{tabular}{|c|c|c|}
\hline Material & Concrete & $\begin{array}{c}\text { Steel } \\
\text { Reinforcement }\end{array}$ \\
\hline $\begin{array}{c}\text { Elastic Modulus } \\
\text { (ksi) }\end{array}$ & 3,605 & 29,000 \\
\hline Poisson's Ratio & 0.2 & 0.3 \\
\hline
\end{tabular}

Table 11. Material Properties

Drucker-Prager model is used with an approximation to the Mohr-Coulomb plasticity model but maintains the use of Cohesion and Dilatancy angle for the porous media. Von mises is used for the yield criterion and elastic-perfectly plastic for the material response of the Drucker-Prager model in ANSYS12. Table 12 shows the properties of the soil. 


\begin{tabular}{|c|c|c|c|c|c|c|}
\hline & $\begin{array}{c}\text { Modulus } \\
\text { of } \\
\text { Elasticity } \\
(\mathrm{ksi})\end{array}$ & Poisson's ratio & $\begin{array}{c}\text { Density } \\
(\mathrm{pcf})\end{array}$ & Cohesion & $\begin{array}{c}\text { Angle } \\
\text { of } \\
\text { friction }\end{array}$ & $\begin{array}{c}\text { Dilatancy } \\
\text { angle }\end{array}$ \\
\hline Soil & 13.88 & 0.45 & 120 & 0.06 & 35 & 30 \\
\hline
\end{tabular}

\section{Table 12. Soil Properties}

The shaft is longitudinally reinforced with twenty nine No. 12 steel bars that are equally spaced around the perimeter. This amount of steel corresponds to 2.12 percent of the gross cross-sectional area of the shaft. The spirals consist of No. 8 bars spaced along the axis of the shafts at $20 \mathrm{in}$. Bi-linear stress-strain relationship is used for the steel (O'Neill and Reese (1999)) as shown in Figure 7.7(b). For steel, the value of yield stress $\left(f_{y}\right)$ is the same in compression and in tension. Reinforcing steel used is Grade 60 with a yield stress of $60 \mathrm{ksi}$ and a modulus $(E)$ of 29,000 ksi.

Two different non-linear stress-strain relationships are also used for the concrete. The first one is unconfined stress-strain relationship and the second one is confined model. Concrete is used with 4000 psi ultimate compressive strength concrete. For concrete, the compressive strength depends on the mobilized compressive strain. Unconfined concrete model used in this study was O'Neill and Reese model (1999) [7]. In this model, the compressive strength increases up to the reduced ultimate compressive strength $\left(f_{c}^{\prime \prime}\right)$, which is taken as a percentage of the 28-day cylinder compressive strength. The strength in unconfined model is expressed as:

$$
\begin{aligned}
& f_{c}=f_{c}^{\prime \prime}\left[2\left(\frac{\varepsilon}{\varepsilon_{0}}\right)-\left(\frac{\varepsilon}{\varepsilon_{0}}\right)^{2}\right] \quad \text { for } \quad \varepsilon<\varepsilon_{0} \\
& f_{c}=0.85 f_{c}^{\prime \prime} \quad \text { for } \quad \varepsilon<0.038
\end{aligned}
$$


$f_{c}=$ linearly interpolated for $\mathcal{E}_{0} \leq \mathcal{E} \leq 0.038$

$f_{c}^{\prime \prime}=0.85 f_{c}^{\prime} \quad$ and $\quad \varepsilon_{0}=\frac{1.7 f_{c}^{\prime}}{E_{c}}$

where $f_{c}^{\prime}$ is the concrete compressive strength at 28 days, and $E_{c}$ is the initial tangent slope of the stress-strain area. The value $E_{c}$ can be estimated as:

$E_{c}=57000 \sqrt{f_{c}^{\prime}}$

In such a case, a multilinear stress-strain relationship can be included which follows the stress-strain curve of the material being used. This will allow ANSYS to more accurately model the plastic deformation of the material. Confined concrete model used in this study was Mander model (1988) [7]. Reinforced concrete members with axial compression forces may be confined by using transverse steel to enhance the member strength and ductility. The form of the stress-strain curve for confined concrete can be expressed in terms of a simple uniaxial relationship.

\section{Results}

The results of the ANSYS model are shown in Figures 7.7 and 7.8. Figure 7.7 shows the displacement in $\mathrm{Z}$ direction on the drilled shaft nodes. It can be seen that vertical displacement at top of the shaft is around 2.4 inches and at the bottom of the shaft is 0.22 inches. Figure 7.8 shows displacement in $\mathrm{Z}$ direction on the stirrups and longitudinal bars nodes inside the shaft. The side resistance for the drilled shaft can be obtained by 
multiplying the stress in z-direction with the perimeter area of the shaft through the length of the drilled shaft. The tip resistance is calculated by multiplying the stress at the tip of the shaft with the area of the drilled shaft section. Results show that for this ANSYS model, 25 percent of the axial load is carried by the tip and 75 percent is resisted by the friction between soil and shaft.

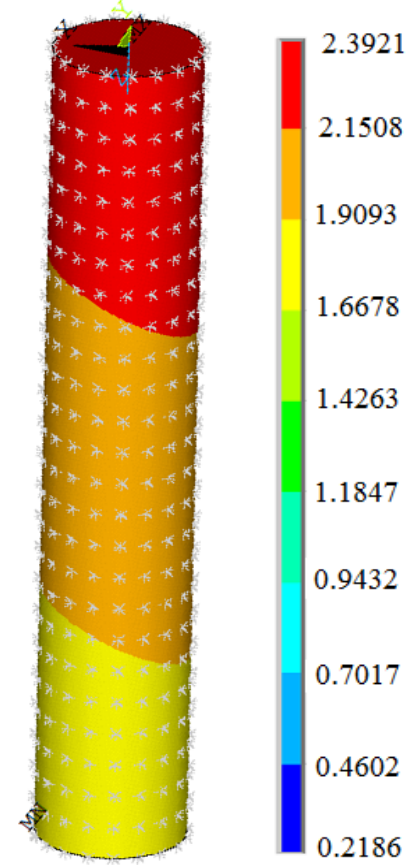

Figure 7.7. Z-component of Displacement in Drilled Shaft Nodes (Un-confined Model) 


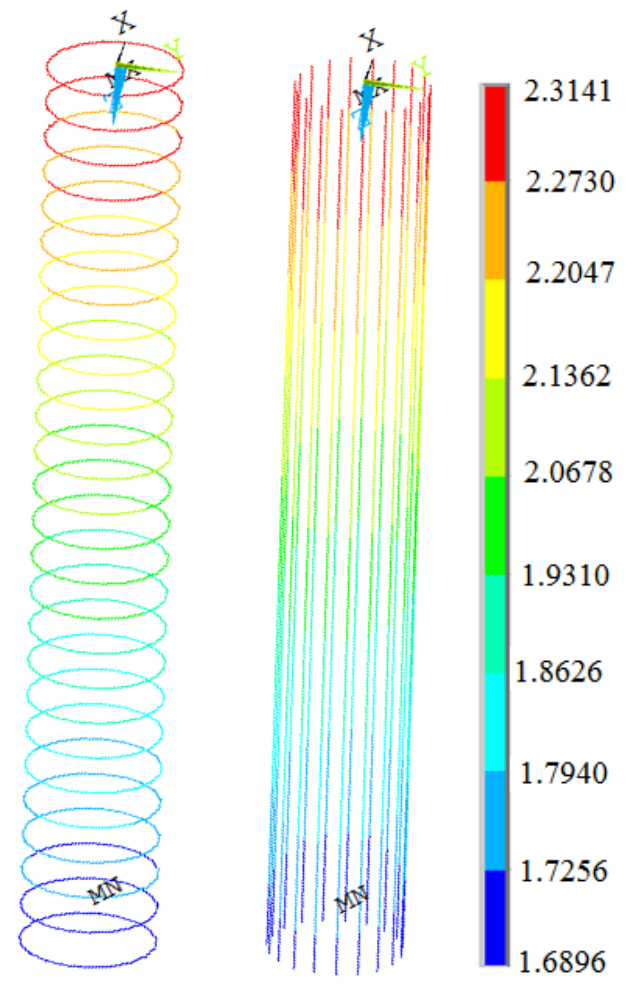

Figure 7.8. Z-component of Displacement in Longitudinal and Stirrups

Figure 7.9 shows that load versus vertical displacement for the Finite Element

model in the bottom, middle, and top node on the drilled shaft. It can be seen that they have almost the same behavior as stress strain relationship. Also, Load versus vertical displacement in the soil nodes is shown in Figure 7.10 for three different nodes at the bottom, middle and top of the drilled shaft. It can be seen that there is a critical point load on the curve that vertical displacement decrease after that point. With increasing the axial load after 5000 kips, the vertical displacement on the soil nodes will decrease. 


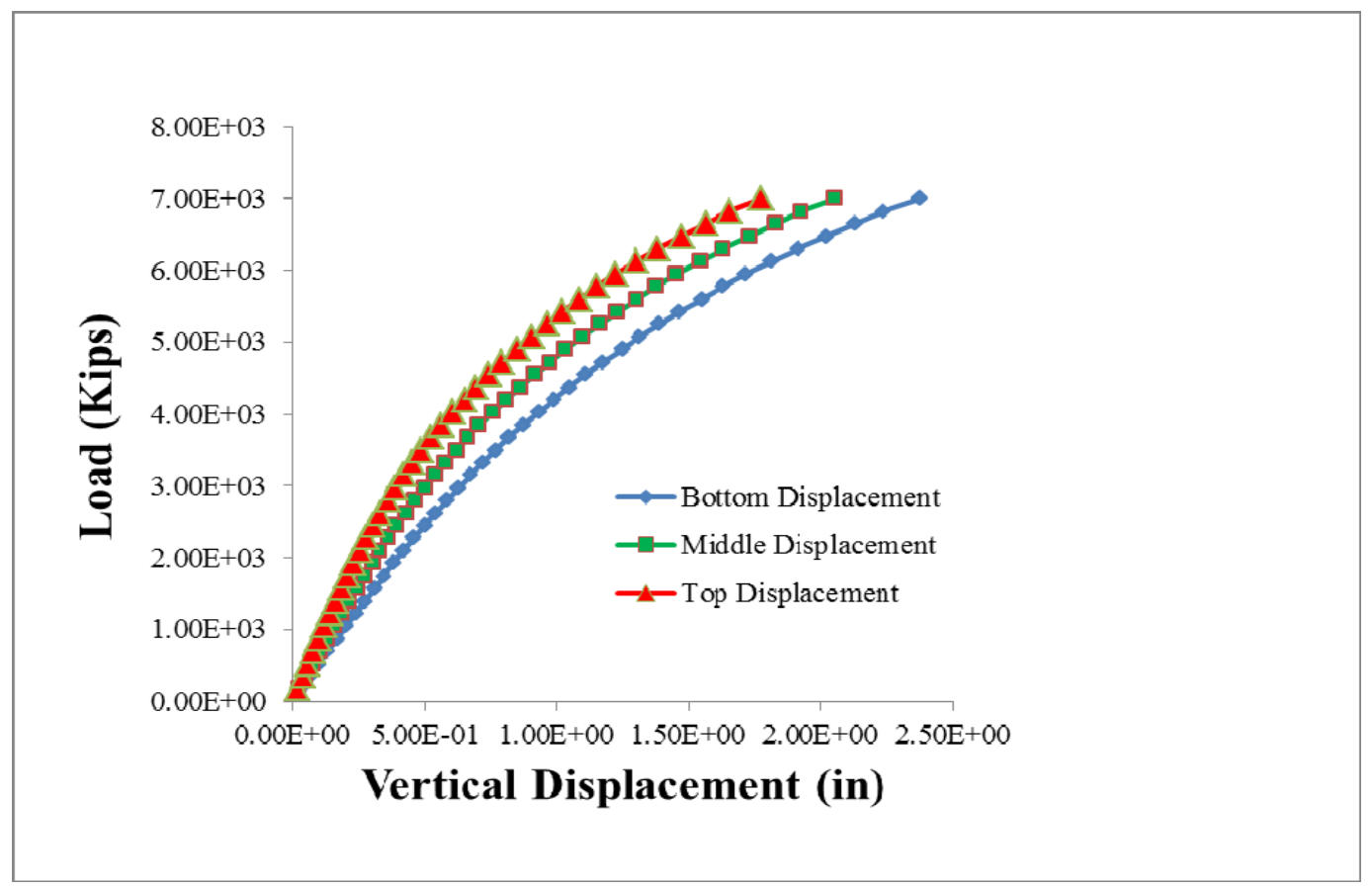

Figure 7.9: Load-displacement in drilled Shaft (Un-confined Model)

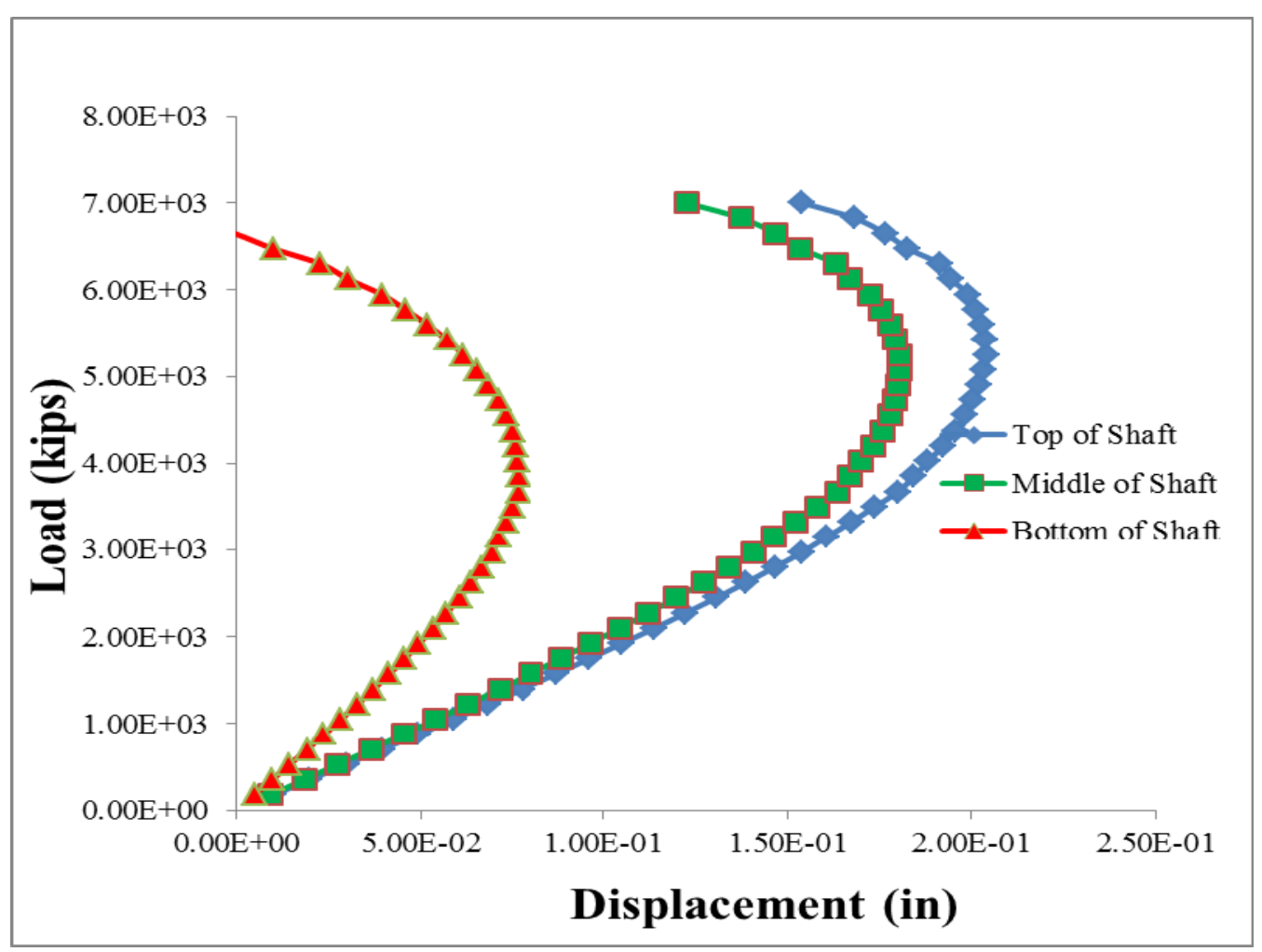

Figure 7.10: Load-displacement in Soil (Un-confined Model) 
Here, we compare the analytical results with ANSYS results for both confined and un-confined models. It shows that un-confined model is closer to the analytical results since we have stirrup and longitudinal bars in the concrete and is closer to realistic. In confined model for the concrete, since bars have been removed and confined concrete model has been used for the stress-strain relationship, the load-displacement curve is less than analytical and unconfined results.

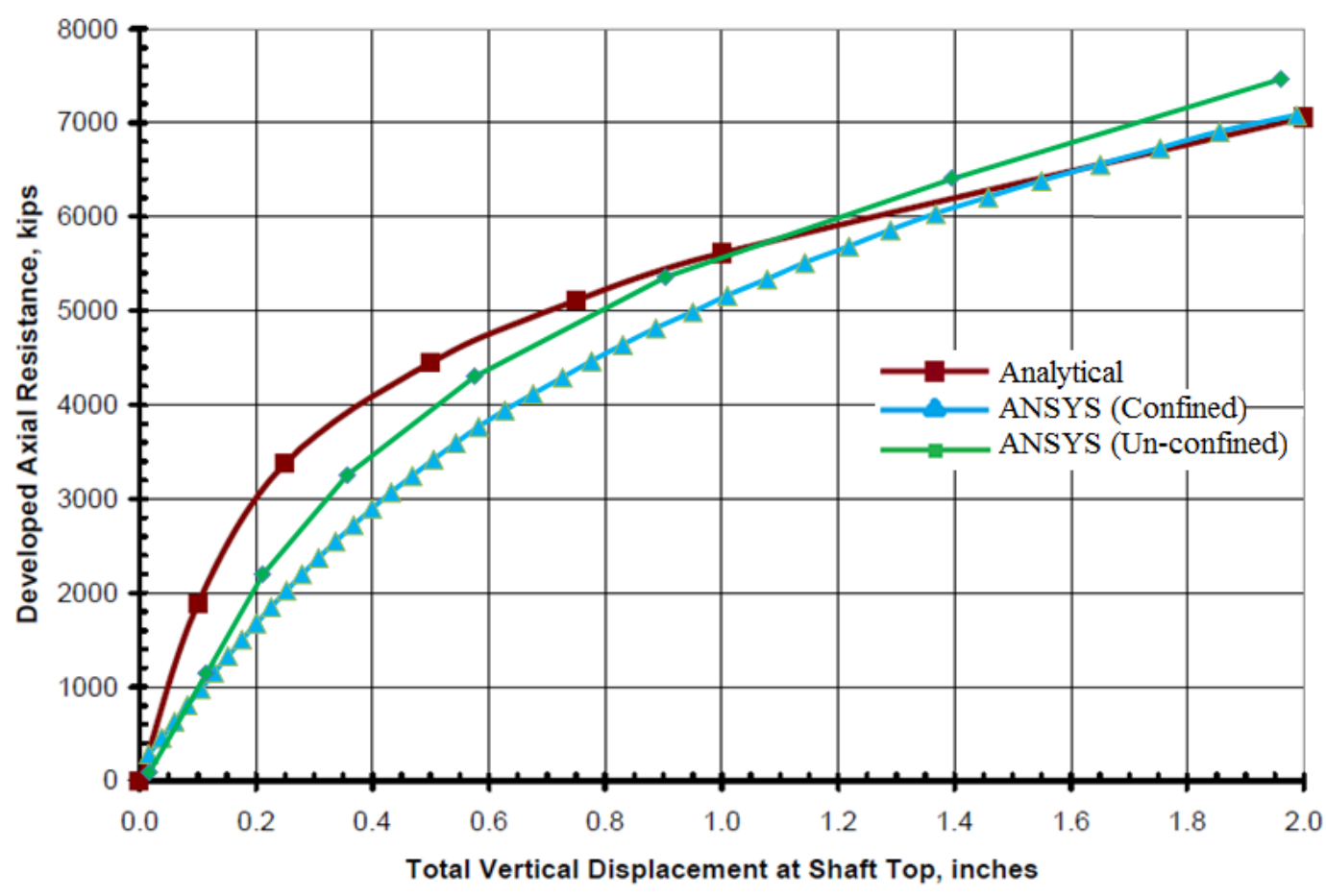

Figure 7.11: Load-displacement Analytical in Comparison to Finite Element

\section{Conclusion}

1) A comprehensive finite element model for drilled shaft foundations was provided. This model can consider soil with different layers around the drilled shaft. It also can 
be run for drilled shafts with different diameters and lengths. Also, different type of concrete, confined model and unconfined model, and different type of soil can be used in the provided model.

2) Based on the results presented, it is concluded that with increasing in the depth of the drilled shaft, side resistance percentage will be approximately increased on a second degree polynomial curve.

3) For drilled shafts with the diameters of $4 \mathrm{ft}$ to $10 \mathrm{ft}$, in the first depths the difference between the total axial load capacities of drilled shafts is less than the end of the shafts.

4) For a drilled shaft with $7 \mathrm{ft}$ diameter, $95 \mathrm{ft}$ length and soil profile shown in Table 10, both analytical and ANSYS model show that 75 percent of the total axial load is resisted by the soil around the shaft or side resistance and the rest of the axial load is resisted by the tip resistance.

5) This study was primarily concerned about modeling a simple stress-strain relation for both unconfined and confined concrete which can represent the behavior of normalstrength concrete in drilled shaft foundations. This study considered two different models for the concrete, confined and unconfined model. Results show that unconfined concrete model had closer results to the analytical results in comparison to confined concrete model. 


\section{SUMMARY AND CONCLUSIONS}

The two major objectives of this research were developing a new method of determining an accurate measurement of the diameters of drilled shafts and evaluating the effect of voids and corrosion on the strength and axial load capacity of drilled shafts. This method of determining an accurate measurement of the diameters of drilled shafts during construction overcomes the limitations and inaccuracies of currently used methods was developed using down-hole nondestructive testing. Another method was developed to visualize and quantify the extent and location of the defect in drilled shafts after performing CSL using application of signal processing on the CSL test results. This method is based on a color change in the frequency amplitude of the signal recorded by receiver probe in the location of defects and it is called Frequency Tomography Analysis (FTA).

Also, experimental work was used considering three different types of built-in symmetric voids in an attempt to study the effect of voids outside and inside the caging on the axial load capacity of drilled shafts. More shaft specimens were constructed with one type of built-in symmetric voids in an attempt to study the effect of corrosion of the 
longitudinal rebars in the void section inside the caging on the axial load capacity of drilled shafts.

A comprehensive finite element model for drilled shaft foundations was provided. This model can consider soil with different layers around the drilled shaft. It also can be run for drilled shafts with different diameters and lengths. Also, different type of concrete, confined model and unconfined model, and different type of soil can be used in the provided model.

\section{NDT Assessment to Obtain the Shape of the Drilled Shaft Foundations}

In order to obtain the exact diameter of the drilled shaft, the location of the border between the concrete and the soil had to be determined through the evaluation of the integrity of the concrete outside the cage. The methodology that was developed to obtain the diameter of the drilled shaft is economic, since it does not require the set-up and use of another NDT device, but rather builds upon the CSL tests used to check the integrity of the inside concrete.

A second-degree polynomial relationship between concrete thicknesses and the maximum amplitude of the signal was derived with an average percent error of 8.5. Also, variation of concrete thickness with the maximum amplitude of the signal curve showed that with increasing thickness of concrete the error increases. The maximum amplitude of the signal for various concrete thicknesses occurred at the same frequency of the data acquisition signal graph in CHA sampled at $500 \mathrm{KHz}$. 
While more preparation is required to install outside tubes for CSL testing offered in this study, it is reasonable to perform testing on all production shafts. CSL provides more ability to quantify a defect in the shaft and allows for accurate determination of shaft quality inside and outside the cage to have better estimation of its actual load carrying capacity.

\section{NDT Assessment to Detect the Defect Location of the Drilled Shaft Foundations}

A new method of determining an accurate location of the voids in drilled shafts after performing CSL test between inside tubes that overcomes the limitations and inaccuracies of currently used methods was developed using application of signal processing on the CSL test results. Many previous papers and proposals rely on the arrival time and wave speed to detect the defects of drilled shaft foundation such as crosshole tomography. This method is based on a color change in the frequency amplitude of the signal recorded by receiver probe in the location of defects and it is called Frequency Tomography Analysis (FTA).

An improved standard method is proposed that considers not only the traditional arrival time changes but also the signal strength and frequency amplitude of the signal reduction to improve the location accuracy. The technique has a very good resolution and clarifies the exact depth location of any void or defect through the length of the drilled shaft for the voids inside the cage.

A sufficiently large frequency amplitude reduction from a large defect would define a defect even if the time domain information were normal. In cases of local defects which include only part of the cross section, frequency tomography analysis is very 
helpful to visualize and quantify the extent and location of the defect. Such information is useful for the structural engineer who must assess the adequacy of the drilled shaft to resist the applied load.

\section{Structural Capacity Reduction Due to Anomalies in Shaft Foundations}

The test results showed that the presence of symmetric voids within the cross section affected both the strength and the stiffness of the drilled shafts. The effect on the strength and the stiffness was much more noticeable especially when the void penetrated inside the caging of the shaft. This was deduced to be due to the lack of concrete confinement for the longitudinal bars. The study showed that voids will affect the axial structural capacity of the drilled shafts. Drilled shaft capacity is affected by the size and location of the void. Location and size of the void will have a significant influence on the confinement of the longitudinal bars, causing structural capacity reduction. The study showed that voids extending into the concrete core were more critical to the structural performance of a shaft than those located within the concrete cover. Voids penetrating the reinforcement cage result in more drilled shaft capacity reduction. The presence of voids outside the rebar cage will cause less axial capacity reduction due to the better confinement. It is recommended that a reduction factor $R$ be used in the structural design codes and specifications for drilled shafts. A reduction factor $R=0.90$ is recommended for drilled shafts located in environments where corrosion is not expected. This reduction factor can be changed depending on the location of the voids after nondestructive testing on the shaft. 
Also, the presence of $25 \%, 50 \%, 75 \%$, and $100 \%$ corrosion in the longitudinal rebars in the mentioned void area cause $12 \%, 21 \%, 31 \%$ and $58 \%$ reduction in the axial load capacity of the drilled shaft, respectively. The test results showed that the presence of both corrosion and symmetric voids within the cross section significantly affected the strength of the drilled shafts. Drilled shaft sample with $100 \%$ corrosion longitudinal bar inside the $20 \%$ symmetric void exhibited $64 \%$ lower axial compressive strength compared to the intact sample.

In other comparisons, the results show that $50 \%$ corrosion in longitudinal bars without void will cause $13 \%$ axial load capacity reduction. The same corrosion percentage in longitudinal bars with symmetric void in the concrete cover will cause $21 \%$ axial load capacity reduction.

Observation of fractured specimens show that in specimens with $50 \%, 75 \%$, and $100 \%$ corrosion in longirudinal rebars, buckling was the main reason of failure. Therefore, specimens with high corrosion percentage had lower critical buckling load or buckling capacity because of the weakness of longitudinal bars in the void section. Most of the growth cracks in specimens without voids were in the longitudinal direction of the shaft, and they show a shear failure.

More importantly, the study demonstrated that drilled shafts with $20 \%$ void area in contact with Miami soil will lose over $21 \%$ of axial load capacity over a time period of 20 years and will over $35 \%$ over a time period of 40 years due to corrosion in their longitudinal bars. The study therefore recommends that corrosion series tests should be required on all new bridge foundations. These tests should be carried out on the soil and water at the location of the structure. These tests should be done on structural backfill 
materials and on subsurface materials along drainage alignments to determine the corrosion classification to be considered during design. The axial load capacity reduction due to corrosion can then be estimated over any period of time.

\section{REFERENCES}

1. Braja M. D., Principles of Foundation Engineering, seventh edition,

2. Koerner, R. M., Mccabe, W. M., and Lord, A. E., "Acoustic emission behavior and monitoring of soils," Acoustic Emissions in Geotechnical Engineering Practice, ASTM STP 750, American Society for Testing and Materials, pp. 93-141 (1981).

3. Samtani, N.C. and Liu, J. J., Use of In Situ Tests to Design Drilled Shafts in Dense and Cemented Soils, GEOFRONTIERS 2005, Geotechnical Special Publication 132.

4. Reese, L. C., O’Neill, M. W. (1999). "Drilled Shafts: Construction Procedures and Design Methods," Publication No. FHWA-IF-99-025, Federal Highway Administration.

5. Pizzi, J.F. (2007). "Case History: Capacity of a Drilled Shaft in the Atlantic Coastal Plain." Journal of Geotechnical and Geoenvironmental Engineering, Vol 133, No. 5, 522- 530 .

6. ASTM (1995). "Annual Book of ASRM Standards, Soil and Rock, American Society for Testing and Materials, Vol. 4.08, Philadelphia, Pennsylvania.

7. Osterberg, J. O., and Pepper, S. F. (1984). "A new simplified method for load testing drilled shafts."' Foundation drilling, Association of Drilled Shaft Contractors, Dallas, 9-11. 
8. Amir, J.M. (2005). "Discussion on "Low Strain Integrity Testing of Piles: Three Dimensional Effects" by Y.K. Chow, K.K. Phoon, W.F. Chow and K.Y. Wong, J. Geotechnical and Geoenvironmental Engrg. 131 (2): 342-343.

9. ASTM (2008). "Standard test Method for integrity testing of concrete deep foundations by ultrasonic crosshole testing, Designation D 6760-08," West Conshohocken PA: 3.

10. Amir, J.M. \& Amir, E.I (2009): Capabilities and Limitations of Cross Hole Ultrasonic Testing of Piles, Proc IFCEE, Orlando.

11. Amir, J.M. (2002): Single-Tube Ultrasonic Testing of Pile Integrity, ASCE Deep Foundation Congress, Vol 1 pp. 836-850, Orlando.

12. Brettman, T. and Frank, M. (1996). "Comparison of cross-hole and single tube sonic integrity logging methods", Proc 5th Intl Conf on Application of stress-wave theory to piles, Orlando, 698-707.

13. Van Koten, H. and Middendrp, P. (1980). "Equipment for integrity testing and bearing capacity of piles", Proc Intl Seminar on Application of stress-wave theory to piles, Stockholm, 1980.69_76.

14. Rausche, F., (2004) "Non-Destructive evaluation of deep foundations," Proceedings: Fifth International Conference on Case Histories in Geotechnical Engineering University of Missouri, Rolla, MO, Paper No. OSP-5.

15. Pu, S.H., Cegla, F., Drozdz, M., Lowe, M.J.S., Cawley, P., and Buenfeld, N.R., (2004). "Monitoring the setting and early hardening of concrete using an ultrasonic waveguide," Insight: Non-Destructive Testing and Condition Monitoring, Vol. 46, No. 6, June, pp. 350-354.

16. Gyungja Jung, Sung-Min Cho, and Myoung Mo Kim, (2007). Defects of Drilled Shaft and Effects of Surrounding Geo-materials Predicted by Sonic-echo Tests, Vol. 30 , July 1-6.

17. American Concrete Institute (1998). Nondestructive Test Methods for Evaluation of Concrete in Structures, ACI Report 228.2R-98, ACI, Farmington Hills, MI, USA.

18. Amir J. (2001). 'Reflections on Pile Integrity Testing', in Deep Foundations Institute Specialty Seminar on Nondestructive Testing for Drilled Shafts, St Louis, MO, USA, October 3, DFI, Hawthorne, NJ, USA.

19. ADSC-IAFD/DFI International (2003). Drilled Shaft Inspector's Manual, 2nd edition, joint publication by ADSC-IAFD, Dallas, TX, USA and DFI International, Hawthorne, NJ, USA. 
20. Reese, L. C., O’Neill, M. W. (1999). "Drilled Shafts: Construction Procedures and Design Methods," Publication No. FHWA-IF-99-025, Federal Highway Administration.

21. ASTM D6760, (2008), “Standard Test Method for Integrity Testing of Concrete Deep Foundations by Ultrasonic Crosshole Testing".

22. Baker, C.N., Drumright, E.E., Briaud, J-L., and Mensah, F., (1993). "Drilled Shafts for Bridge Foundations." FHWA Publication FHWA-RD-92-004, Federal Highway Administration Office of Engineering and Highway Operations, McLean VA.

23. O’Neill, M. W., Tabsh, S. W., and Sarhan, H. A. (2003). "Response of drilled shafts with minor flaws to axial and lateral loads." Engineering Structures, 25(1), 47-56.

24. Camp, W. M., Holley, D.W., Canivan, G.J. (2007). "Crosshole Sonic Logging of South Carolina Drilled Shafts: A Five Year Summary." Deep Foundations, American Society of Civil Engineers, pp. 1-11

25. Jalinoos, F., Mekic, N., Hanna, K. (2005) "Defects in Drilled Shaft Foundations: Identification, Imaging, and Characterization." Publication No. FHWA-CFL/TD-05003, Federal Highway Administration.

26. Olson, D. L., Hollema, D. A., (2002). "Crosshole Sonic Logging and Tomographic Velocity Imaging of a New Drilled Shaft Bridge Foundation.” Structural Materials Technology Topical Conference, Cincinnati, Ohio.

27. Fullagar, P.K., Livelybrooks, D.W., Zhang, P., Calvert, A.J., Wu, Y. (2000) "Radio tomography and borehole radar delineation of the McConnel nickel sulfide deposit, Sudbury, Ontario, Canada Geophysics.” 65, pp. 920-1930.

28. Haramy K. Y. (2006), Structural Capacity Evaluation of Drilled Shaft Foundations with Defects, MS thesis, University of Colorado Denver.

29. Chang N., Nghiem H., (2008), "Drilled Shaft Axial Capacity Due to Anomalies." Report No. FHWA-CFL/TD-08-008. Federal Highway Administration Colorado.

30. Lew, M., Zadoorian, C.J., Carpenter, L.D. (2002) "Integrity Testing of Drilled Piles for Tall Buildings, Structure.” A joint publication of: National Council of Structural Engineers Associations: Council of American Structural Engineers, October, pp. 1417.

31. Iskander, M., Roy, D., Kelley, S., and Ea, C., (2003), "Drilled Shaft Defects: Detection, and Effects on Capacity in Varved Clay, 10.1061/ASCE,1090-0241, 129:12,1128. 
32. Nejadpak, A.; Mohammed, O. A., (2013) "Physics-Based Modeling of Power Converters From Finite Element Electromagnetic Field Computations," Magnetics, IEEE Transactions on, vol.49, no.1, pp.567-576.

33. Hertlein, B., Davis, A., 2006, "Nondestructive Testing of Deep Foundation." John Wiley \& Sons Ltd, TA775. H395.

34. Iskander, M., Roy, D., Kelley, S., and Ea, C., 2003, "Drilled Shaft Defects: Detection, and Effects on Capacity in Varved Clay", 10.1061/ASCE,1090-0241, 129:12,1128.

35. Sami W Tabsh and Michael W. O’Neill, 2003, "Effects of Minor Anomalies on Axial Capacity of Drilled Shafts." Transportation Research Record, Paper No. 01-0176, pp 65-72.

36. O’Neill M., Tabsh S.W., Sarhan, H., 2003, "Response of drilled shafts with minor flaws to axial and lateral loads." Engineering Structures, Vol 25, Issue 1, pp 47-56.

37. Jung G., Kwon, Jung S.J., and Kim, 2006, Evaluation of Full-Sized Cast-in-Place Pile Capacity with Artificial Defects. Journal of the Transportation Research Board, No. 1975, TRB, Washington D.C.

38. Haramy K. Y., 2006, Structural Capacity Evaluation of Drilled Shaft Foundations with Defects, MS thesis, University of Colorado Denver.

39. Haramy K. Y., Rock A., Chang N. Y., 2007, Numerical Analysis of Load Bearing Capacity of Drilled Shafts with Defects, Proceedings, 32nd Annual Conference on Deep Foundations, Colorado Springs, CO.

40. Chang N., Nghiem H., 2008, "Drilled Shaft Axial Capacity Due to Anomalies." Report No. FHWA-CFL/TD-08-008. Federal Highway Administration Colorado.

41. AASHTO, LRFD Bridge Design Specifications, Customary U.S. Units, 5th Edition, American Association of State Highway and Transportation Officials, 2010.

42. Barker, R. M., et al., 1991. "Manual for the Design of Bridge Foundations," National cooperative Highway Research Program Report 343, Transportation Research Board, 2101 Constitution Avenue, Washington, DC.

43. Iskander, M., Kelley, S., Ealy, C., and Roy, D., 2001. "Load tests on drilled shafts with planned defects in varved clay." Proc., Transportation Research Board Meeting, (CD-ROM), National Academy Press.

44. Iskander, M., Roy, D., Ealy, C., and Kelley, S., 2001. "Class-A prediction of construction defects in drilled shafts." Transportation Research Record 1772, Transportation Research Board, Washington, D.C., 73-83. 
45. O’Neill, M., and Reese, L., 1999. “Drilled shafts: construction procedures and design methods.' Rep. No. FHWA-IF-99-025, Washington, D.C.

46. Elias, V., Fishman, K., Christopher, B., Berg, R., 2009, "Corrosion of Soil Reinforcements for Mechanically Stabilized Earth Walls and Reinforced Soil Slopes." Technical Report, Department of Transportation Washington, D.C.

47. Sarahan, H., O’Neill, W., Simon, D., 2002, “Corrosion of Reinforcing Steel in Drilled Shafts with Construction Flaws." Transportation Research Board, Washington, D.C.

48. Lichtenstein, J. (1978). "Fundamentals of Corrosion Causes and Mitigation," Materials Performance, Vol. 17, No. 3, pp. 29-32.

49. Berke, N. S., Dallaire, M. P., Hicks, M. C., and Hoopes, R. J. (1993). "Corrosion of Steel in Cracked Concrete," Corrosion, Vol. 49, No.11, pp. 934-943.

50. Fischer, K. P., Bryhn, O., and Aagaard, P. (1984). "Corrosion of Steel in Concrete: Some Fundamental Aspects of Concrete with Added Silica," Corrosion, Vol. 40, No. 7, pp. 358-365.

51. Miller, R. L., and Hartt, W. H. (1976). "Stray Current and Galvanic Corrosion of Reinforcing Steel in Concrete," Materials Performance, Vol. 15, No. 5, pp. 20-26.

52. Tabsh, W., O’Neill, M. W., 2002, “Effects of Minor Anomalies on Axial Capacity of Drilled Shafts.” Transportation Research Board, Paper No. 01-0176. Pp. 65-72.

53. Gladstone, R.A., Anderson, P.L., Fishman, K.L., and Withiam, J.L. (2006). "Durability of Galvanized Soil reinforcement: 30 Years + of Experience with MSE," Journal of the Transportation Research Board, No. 1975, Transportation Research Board, National Research Council, Washington, D.C., pp. 49-59.

54. Withiam, J.L., Fishman, K.L. and Gaus, M.P. (2002). "Recommended Practice for Evaluation of Metal-Tensioned Systems in Geotechnical Applications" NCHRP Report 477, National Academy Press, Washington, D.C., 93p.

55. Wheeler, J.J., 2002. "New York's Mechanically Stabilized Earth Corrosion Evaluation Program," TRB 81st Annual Meeting CD-ROM, Transportation Research Board, Washington, D.C.

56. Wheeler, J.J. (1999). "NYSDOT, MSES Corrosion Evaluation Program," End of the Year Report for 1998, NYSDOT Geotechnical Engineering Bureau, Albany, NY.

57. Riccobono, O., 2009, "Report of Subsurface Exploration and Geotechnical Engineering Evaluations." Prepared by GEOSOL INC. for BBC ENGINEERING, INC. 
58. Amiri, S. N., (2011) "A Comprehensive study on Soil Consolidation", Verlag Dr. Mueller Publisher, Germany, ISBN 978-3639355819.

59. ASTM D6760, Standard Test Method for Integrity Testing of Concrete Deep Foundations by Ultrasonic Crosshole Testing.

60. Iskander, M., Roy, D., Kelley, S., and Ea, C., 2003, "Drilled Shaft Defects: Detection, and Effects on Capacity in Varved Clay", 10.1061/ASCE,1090-0241, 129:12,1128.

61. O'Neill M., Tabsh S.W., Sarhan, H., 2003, "Response of drilled shafts with minor flaws to axial and lateral loads." Engineering Structures, Vol 25, Issue 1, pp 47-56.

62. Haramy K. Y., 2006, Structural Capacity Evaluation of Drilled Shaft Foundations with Defects, MS thesis, University of Colorado Denver.

63. Amiri, S., N., 2011 "A Comprehensive study on Soil Consolidation", Verlag Dr. Mueller Publisher, Germany, ISBN 978-3639355819.

64. Reese, L. C., O’Neill, M. W. (1999). "Drilled Shafts: Construction Procedures and Design Methods," Publication No. FHWA-IF-99-025, Federal Highway Administration.

65. AASHTO. 2002. Standard Specifications for Highway Bridges, $17^{\text {th }}$ Edition, HB-17. American Association of State Highway and Transportation Officials, Washington, DC.

66. Rollins, K. M., Clayton, R. J., Mikesell, R. C., Blaise, B. C. (2005). "Drilled Shaft Side Friction in Gravelly Soil." Journal of Geotechnical and Geoenvironmetral Engineering, Volume 131, Issue 8, 987-1003.

67. Bal Krishna Maheshwari, Kevin Z. Truman, M. Hesham El Naggar, and Phillip L. Gould, (2004). "Three dimensional finite element nonlinear dynamic analysis of pile groups for lateral transient and seismic excitations", NRC Research Press, Can. Geotech. J. 41: 118-133.

68. Bathe, K.J. 1982. Finite element procedures in engineering analysis. Prentice-Hall, Inc., Englewood Cliffs, N.J.

69. Geotechnical Design Policy DS-1, Intermodal Transportation Division, 206 South Seventeenth Avenue Phoenix, Arizona 85007-3213, Arizona Department of Transportation, December 2010, page14.

70. Reddier M. K. M., (2009). "Stress-Strain Model of Unconfined and Confined Concrete and Stress-Block Parameters." Master Thesis, Texas A\&M University. 
71. Sahadat Hossain, Victor Omelchenko, Mohammed Adil Haque, Jubair Hossain, Capacity of a Drilled Shaft in Mid-Atlantic Region, EJGE, Vol. 13, Bund. E.

72. Yang, M. Z., Islam, M. Z., Drumm, E. C., Zuo, G. (2004). "Side Resistance of Drilled Shaft Socketed into Wissahickon Mica Schist.” Geotechnical Special Publication, No. 124, GeoSupport - Drilled Shafts, Micropiling, Deep Mixing, Remedial Methods, and Specialty Foundation Systems, Proceedings of Sessions of the GeoSupport Conference: Innovation and Cooperation in Geo, 765-777.

VITA

MASOOD HAJALI

February 01, 1985

2003-2007

2007-2009

$2009-2010$

2010-2013
Born, Tehran, Iran

B.Sc. Civil Engineering

K.N.Toosi University of Technology

Tehran, Iran

M.Sc. Civil Engineering

Sharif University of Technology

Tehran, Iran

Graduate Study, Structural Engineering

Pennsylvania State University

State Collage, Pennsylvania, US

Ph.D. Candidate, Civil Engineering

Florida International University

Miami, Florida, US 
